


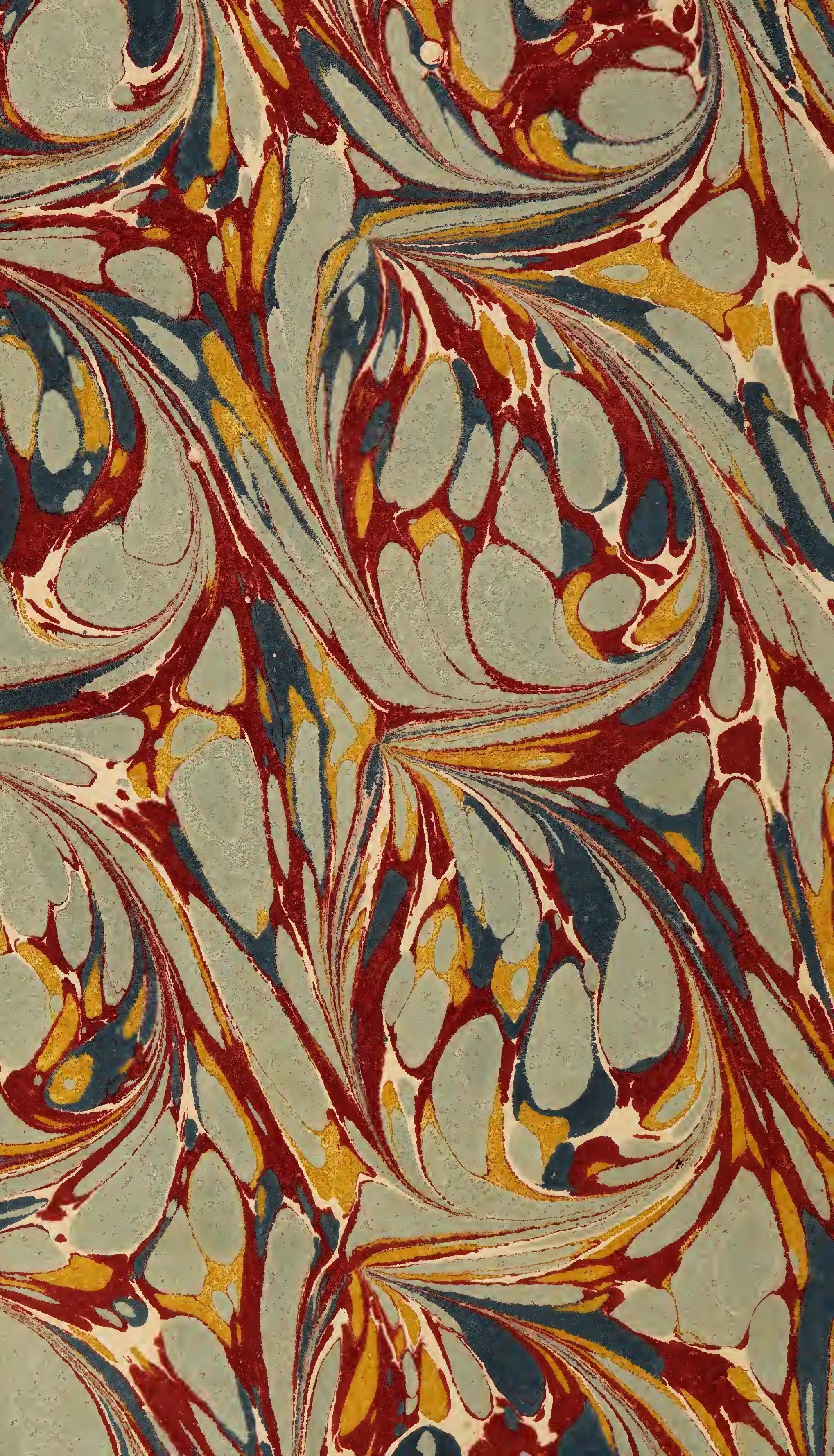




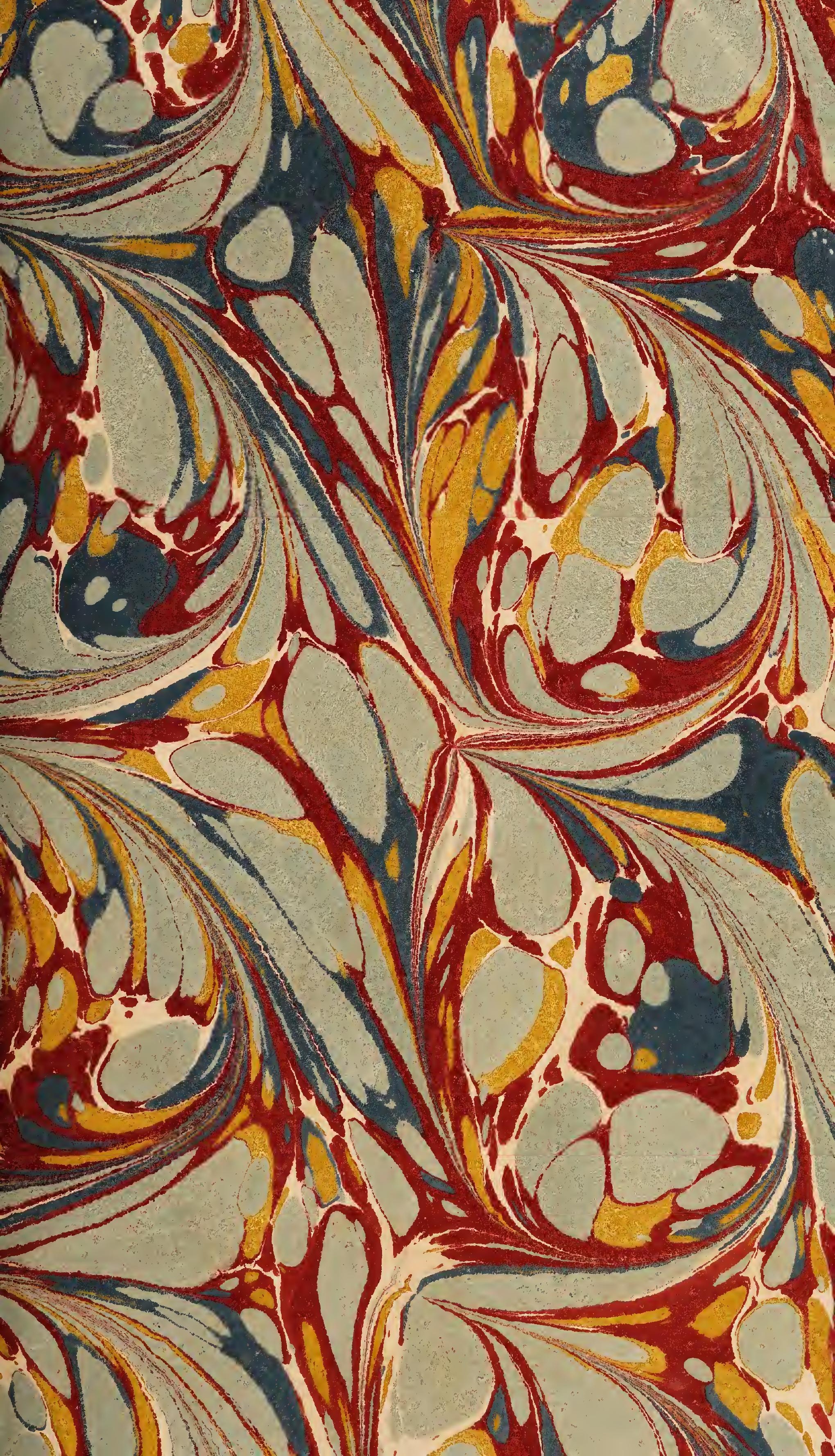


Digitized by the Internet Archive in 2018 with funding from Wellcome Library

https://archive.org/details/b29341322_0001 

$1 / 7$ 



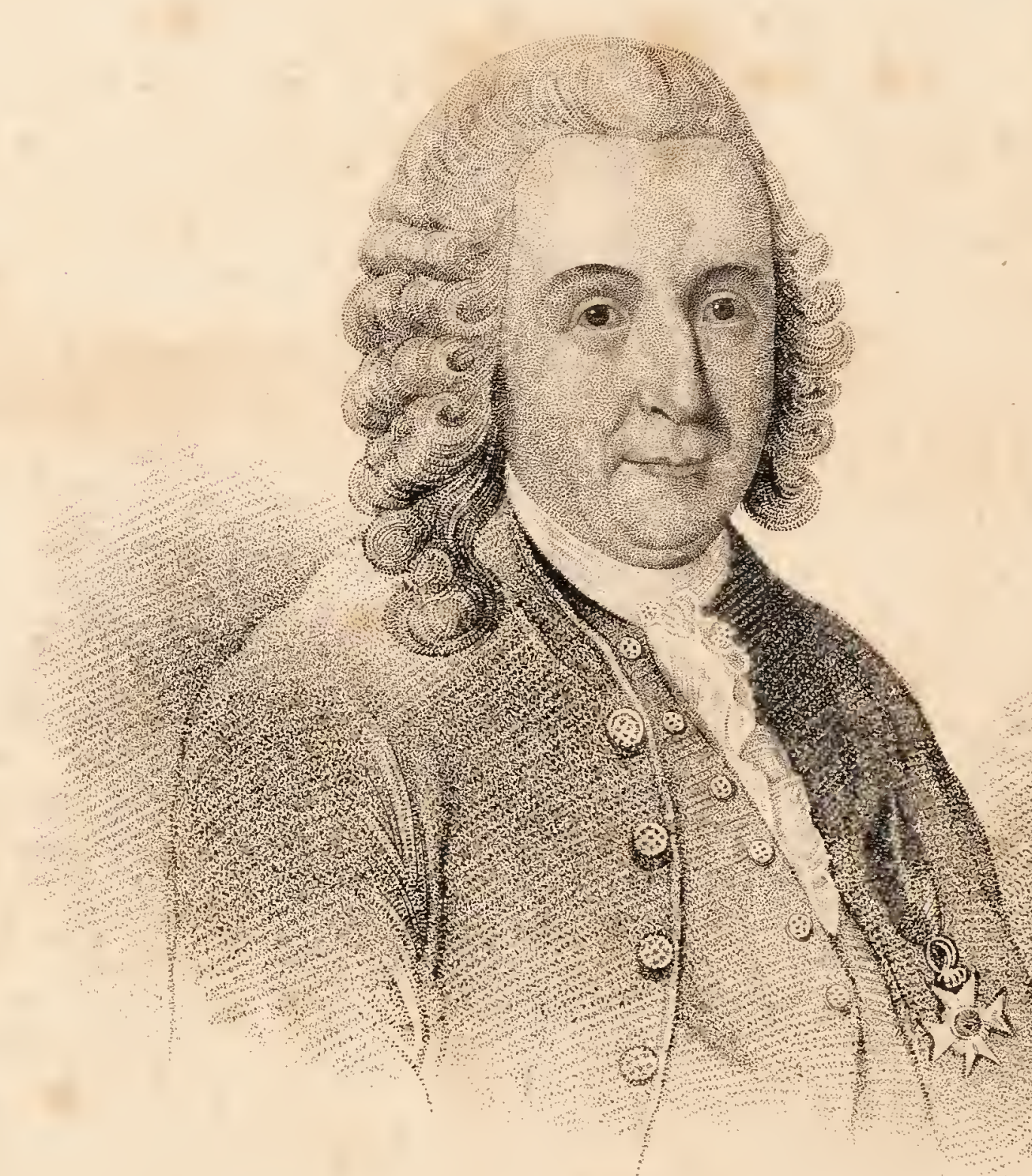

Penny iculp,

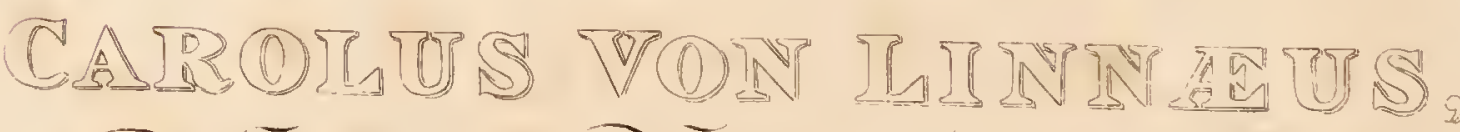

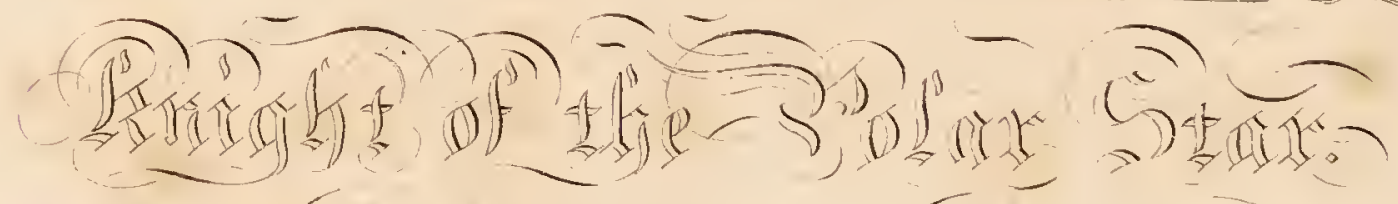

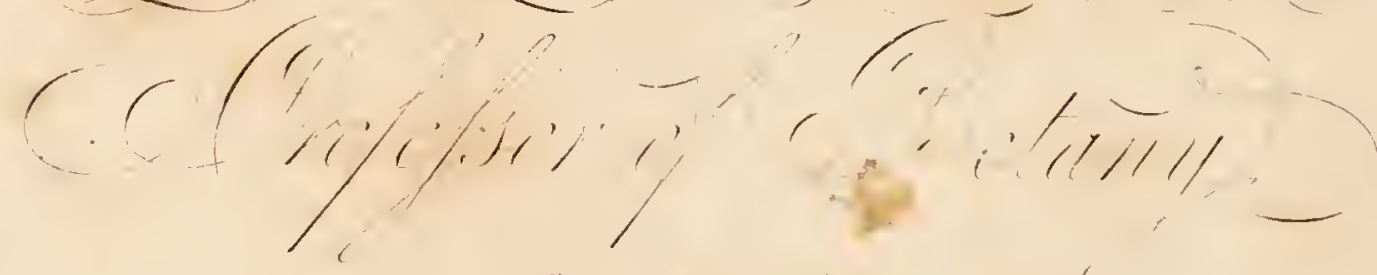

$$
\begin{aligned}
& \text { (r) } 3 x^{\prime \prime}
\end{aligned}
$$




\title{
MEDICAL BOTANY:
}

-

\author{
HISTORY OF PLANTS
}

IN THE

\section{MATERIA MEDICA}

OF THE

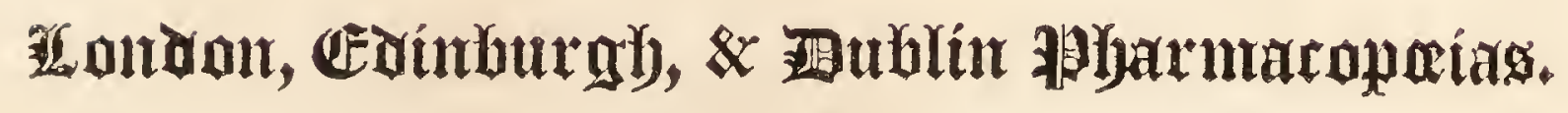

ARRANGED ACCORDING TO

THE LINN EAN SYSTEM。

VOL. I.

ILLUSTRATED BY SEVENTY-TWO COLOURED PLATES AND

A PORTRAIT OF LINNÆUS.

\section{LONDON :}

PRINTED FOR E. COX AND SON,

ST. THOMAS'S-STREET, SOUTHWARK:

SOLD ALSO BY

刃. CALLOW, PRINCES STREET, SOHO; HARDING, ST. JAMES'S STREET ; T. AND G. UNDERWOOD, FIEET STREET; HIGHLEY, FIEET STREET ; SHERWOOD, NEELY, AND JONES, PATERNOSTER ROW; SIMPKIN AND MARSHALL, STATIONERS' COURT ; ANDERSON, SMITHFIELD ; BURGESS ANDHILL, WINDMILL STREET; J. COX, NO. 11, BERNERS STREET, OXFORD STREET; P. BROWN, EDINBUIGH ; HODGES AND M'ARTHUR, DUBLIN. 



\title{
THIS VOLUME
}

IS RESPECTHULLY DEDICATED

TO

\section{WILLIAM BABINGTON, M.D.}

\&c. \&c. \&c.

AS A

TRIBUTE TO SUPERIOR PROFESSIONAL MERIT,

AND AS A

\section{Cestimony of esteem and (5ratitude,}

\author{
FOR \\ FAVORS CONFERRED \\ UPON HIS
}

MUCH OBLIGED AND MOST OBEDIENT SERVANT,

THE AUTHOIR.

LONDON, 1821 。 



\title{
TABLE OF CONTENTS
}

TO

\author{
VOLUME I.
}

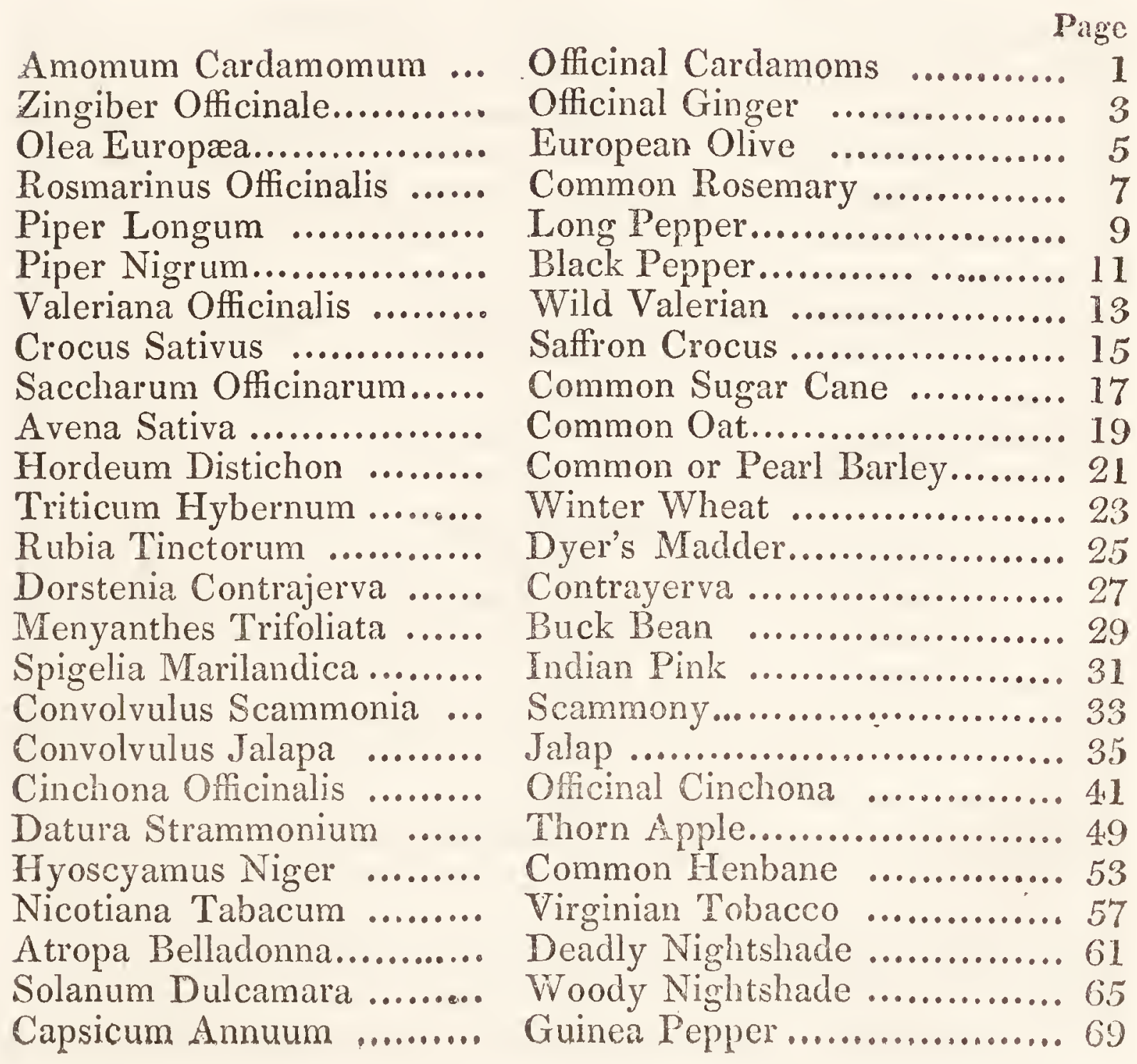


Strychnos Nux Vomica..... Chironia Centaurium......... Rhamnus Catharticus ....... Vitis Vinifera Cephalis Ipecacuanha ...... Bonplandia Trifoliata ....... Ulmus Campestris............ Gentiana Lutea ................. Daucus Carota ................ Conium Maculatum ......... Ferula Assafœtida ............ Bubon Galbanum ............. Cuminu Cyminum ............ Coriandrum Sativum......... Pastinaca Opoponax ......... Anethum Foniculum......... Anethum Graveolens......... Carum Carui ................... Pimpinella Anisum .......... Sambucus Nigra............... Linum Usitatissimum ...... Linum Catharticum .......... Allium Sativum ............... Scilla Maritima ............... Aloe Perfoliata ................ Acorus Calamus................ Rumex Acetosa............... Colchicum Autumnale ...... Esculus Hippocastanum ... Daphne Mezereon............ Amyris Elemifera ............ Polygonum Bistorta .........

Laurus Cinnamomum ......

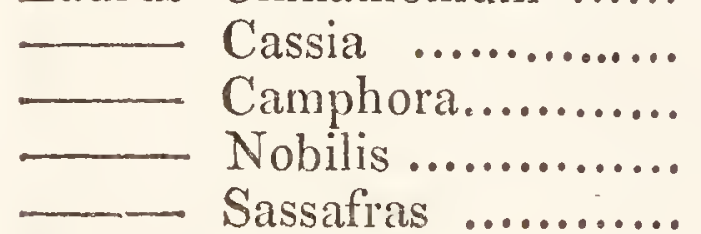

Rheum Palmatum ............

Cassia Fistula.................. Senna ..................

Guaiacum Officinale ..........

Ruta Graveolens............... Toluifera Balsamum ......... Myroxlyon Peruiferum ...... Hamatoxly on Campechianum Quassia Simaruba ............ Excelsa...............
Poison Nut

Page

Common Centaury............... 77

Purging Buckthorn ............ 79

Common Vine...................... 81

Ipecacuanha ..................... 85

Angustura Bark .................. 89

Common Elm ...................... 93

Gentian ........................... 95

Common Carrot ................... 99

Common Hemlock ............... 103

Devil's Dung ..................... 109

Galbanum ........................ 113

Cummin .......................... 117

Common Coriander............... 119

Rough Parsnep .................. 121

Common Fennel.................. 123

Common Dill .................... 127

Common Carraway.............. 129

Anise ............................ 131

Common Black Elder............ 133

Common Flax.................... 135

Purging Flax .................... 139

Common Garlick.................. 141

Officinal Squill ................ 145

Socotrine or Spiked Aloes...... 151

Sweet-scented Flag ........... 157

Common Sorrel ................. 161

Meadow Saffion ................. 163

Horse Chesnut ................. 167

Mezereon........................... 169

Elemi ............................ 173

Great Bristort................... 175

Cinnamon Tree ................ 177

Cassia Tree...................... 181

Camphor Tree.................... 183

Common Bay Tree............. 189

Sassafras Tree.................. 193

Officinal Rhubarb ............. 197

Purging Cassia ................ 203

Senna ........................... 205

Officinal Guaiacum.............. 209

Common Rue................... 213

Balsam of Tolu ................. 217

Sweet-smelling Balsam Tree... 221

Campechy Wood .............. 225

Mountain or Bitter Damson ... 229

Quassia Tree .................... 233 


\section{PREFA CE.}

IN the whole circle of the Sciences, from the centre to its circumference, perhaps there is no one study which is more pleasing and gratifying to the mind than that of Botany : it must be peculiarly interesting to the individual, who, not satisfied with observing the external differences which exist between one plant and another, is desirous, by a careful and minute examination of each in its internal varieties, to become acquainted with its particular structure, and of ascertaining (in many instances at least) its general use. A child may walk into the field, and amuse himself with the group of 
flowers which there present themselves to his notice. He may be able to distinguish between the TuliP and the Snowdrop, the Rose and the Lilly, and be delighted with their external beauties and rich varieties; but it is the BOTANIST alone, who, by an accurate knowledge of the various parts of the plant, can expatiate on its wonderful formation, whilst, astonished at the exact adaptation of the parts, he is imperceptibly and almost involuntarily led from "Nature up to Nature's God."

If then a knowledge of Botany is so necessary to the Man of Science and general Literature, it must be obvious that those plants in the vegetable kingdom which possess medicinal properties ought peculiarly to attract the attention of Medical Practitioners.

There being but one work extant, expressly on the subject of Medical Botany, and this too expensive and voluminous for general use, the Author was, by 
repeated 'solicitations, induced to undertake the following publication. The favourable reception which it has hitherto met with entitles him to conclude that his labours have not been altogether unprofitable. "With regard to the execution of the Plates, he begs to state that every attention has been paid to the Drawing, Engraving, and Colouring. The Prints of Plants of foreign production have been obtained from the most authentic sources.

Some persons have raised objections to the work, on the ground of its conciseness: in answer to such, the Author begs to observe, that he has been careful to make those observations only which appeared to him to be essentially necessary; introducing as little extraneous matter as possible.

To refer again to the necessity of a close attention to the study of Medical Botany for the professional character, would probably be tedious and superfluous; considering, however, that this branch of science has 


\section{xii}

of late years been very much neglected, it may be proper to urge the Student in Medicine in particular to a more diligent attention to it, as being not merely an ornamental part of Medical Education, but as really necessary to the complete formation of the professional character.

By a recent arrangement at Apothecaries' Hall, no gentleman is admitted as a Member of that highly respectable body, without having previously undergone an examination as to his attainments in the study of Botany. This circumstance of itself should act as a stimulus to the junior part of the profession to prosecute their inquiries in this department of science.

London, 1821. 



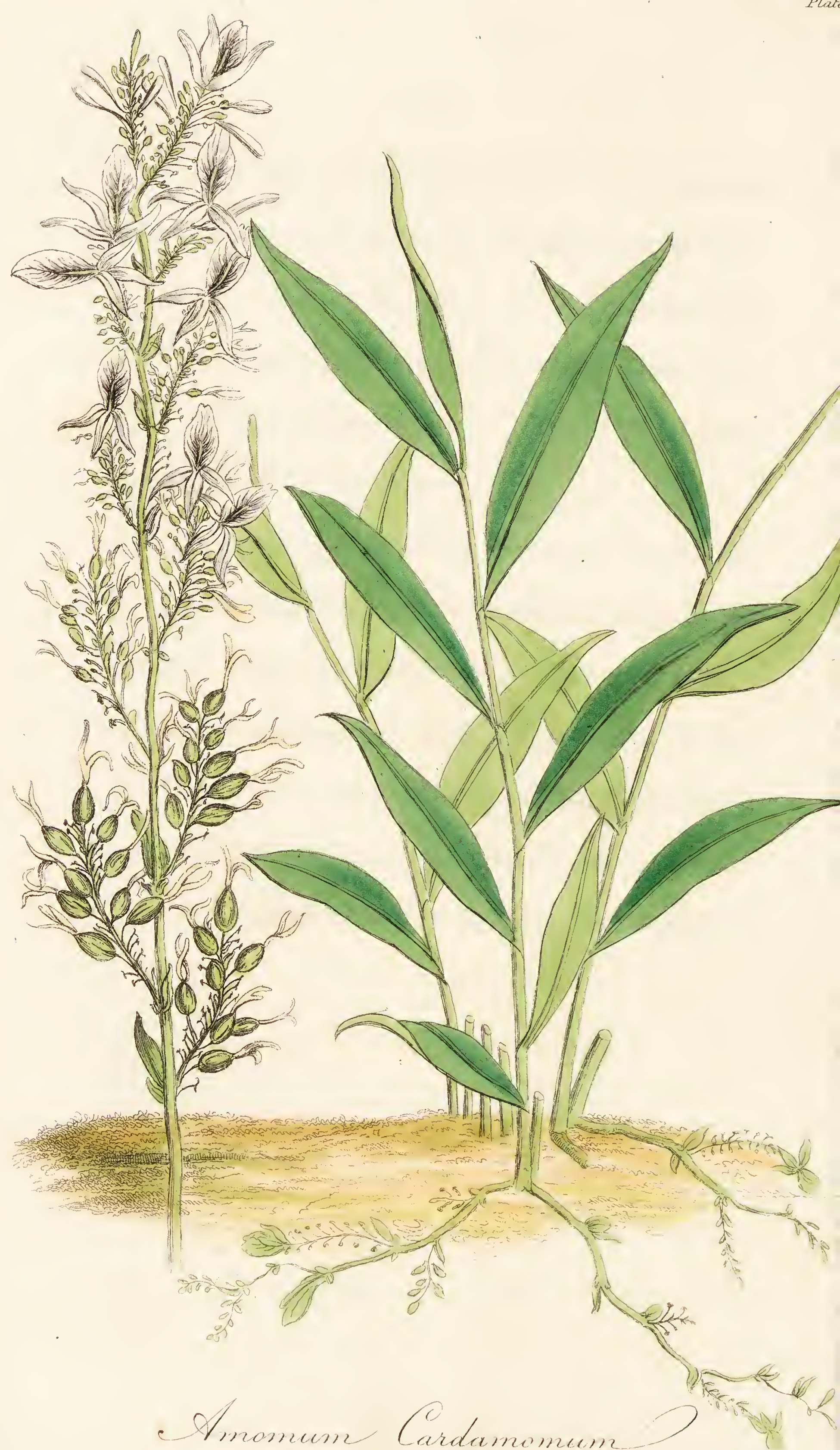




\section{enedical botam.}

\section{AMOMUM CARDAMOMUM-AMOMUM REPENS-ELETTARIA CARDAMOMUM.}

\section{The Officinal or Lesser Cardamom.}

Semina.

\section{Class I. Monandria.-Order I. Monogynia.} Natural Order. Scitamines.

Specific Character. Scape perfectly simple and very short, with alternate bracteæ.

THis plant grows on the coast of Malabar, in the East Indies, thriving in moist situations.

The root is perennial, of an oblong and tortuous figure, and of a whitish colour, and fibrous : the stems rise to a considerable height, and are smooth, simple, and round, about the thickness of the finger. The leaves are lanceshaped and entire, placed alternately on the stalk; the stems, from which the flowers proceed, are sent off from the root, and trail along the ground, and the flowers are furnished with leaflets of an oblong shape. The calyx is small and monophyllous, and divided into three teeth at the margin; the corolla is monopetalous, divided into four unequal segments; of these the three outermost are slender and uniform; 
the centre one is broad and large, of an irregular shape and concave. The filament is broad and grooved, and terminating in the anther; the germen is roundish; the capsule oblong, trivalved, striated, and divided into three cells, which contain several angular brownish seed.

The seed is the part of this plant which is used: these are imported into this country in their capsules, in which they should be preserved till used; for when deprived of them, some of their aroma is lost. When bruised, they yield a sweet aromatic smell, and are of a pungent taste. Their virtues are extracted both by spirit and water, but more completely by the former; a pungent essential oil, of a yellowish colour, is afforded by distillation. The seeds are stimulant and aromatic, and form a useful aromatic tonic in dyspepsia, flatulent colic, \&c. The Indians are accustomed to eat them to promote digestion. Their dose is from grs. v. to $9 \mathrm{j}$. The preparations into which they enter are, Tinctur. Cardam. comp. Gent. comp. Rhei et Sennæ. Extract. Colocynthidis compositum. Confect. Aromatic. Pulvis Cinnamomi compositus; and Spir. Etheris Aromaticus. 



$$
\text { 被 }
$$


2. AMOMUM ZINGIBER.ZINGIBER OPFICINALE.

Officinal, or narrow-leaved Ginger. Radix.

Class I. Monandria.-Order I. Monogrina.

Natural Order. - Scitimines.

Specific Character. The flower-stem naked, with oval spikes.

$\mathrm{T}_{\mathrm{HIS}}$ is a perennial plant, native of the East Indies, and it grows also spontaneously in Guinea and other western parts of Africa. It is now cultivated in the West Indies to a considerable extent. It flowers in September, and fades in December, and its roots are dug up in January following.

The root is tuberous, of a some what compressed roundish form, marked with rings; when young, it is externally of a white colour, internally soft and of greenish colour; when it gets older, it becomes greyish, and of fibrous texture. Its stalks are two or three feet high, which are simple, cylindrical, and sterile. The leaves are smooth, lanceolate, alternate, about six inches in length, and one and a half in breadth. The flower-stalk rises to about a foot in height immediately from the root, erect, round, and leafless, each terminating in an oval imbricated spike. Corolla monopetalous divided into four unequal parts. The fruit is an oval capsule, divided internally into three cells, which contain several blackish seeds, of an agreeable odour and bitter taste. 
The root is the only part of this plant which is used medicinally. When dug up, they are divided, and the fibres and dirt are removed from them; they are then exposed to the sun till dry; and, lastly, are covered with clay or chalk to preserve them from insects. The ginger that is procured for preserves, is dug up when it is about four months old, at which time the root is tender and succulent.

The best ginger is the white, and should be of firm texture, free from worm holes, and heavy : that which is light and very friable, is bad. The black is less aromatic, for its properties are impaired by its being infused in boiling water.

This root has an aromatic pungent smell, and also a hot sharpe taste; it is of a stomachic and stimulant nature. It affords a small quantity of essential oil by distillation, on which its odour seems alone to depend, for it has no pungent taste. Its pungency and odour are extracted by water and spirit. It is useful in dyspeptic habits, flatulencies, \&c.; and, as an adjuvant, to prevent the griping effects of other medicines. It is seldom employed alone. Dose from $\mathrm{gr}$. $\mathrm{x}$. $\operatorname{ad} 3 \mathrm{ss}$. The preparations into which it enters are, Syrupus et Tinctura Zingiberis. Conf. Opii. Conf Scammoni. Infusum Sennæ. Pulu. Cinnamomi comp. Pulv Sennæ comp. Pilul. Scillæ comp. Tinct. Cinnam. comp. 


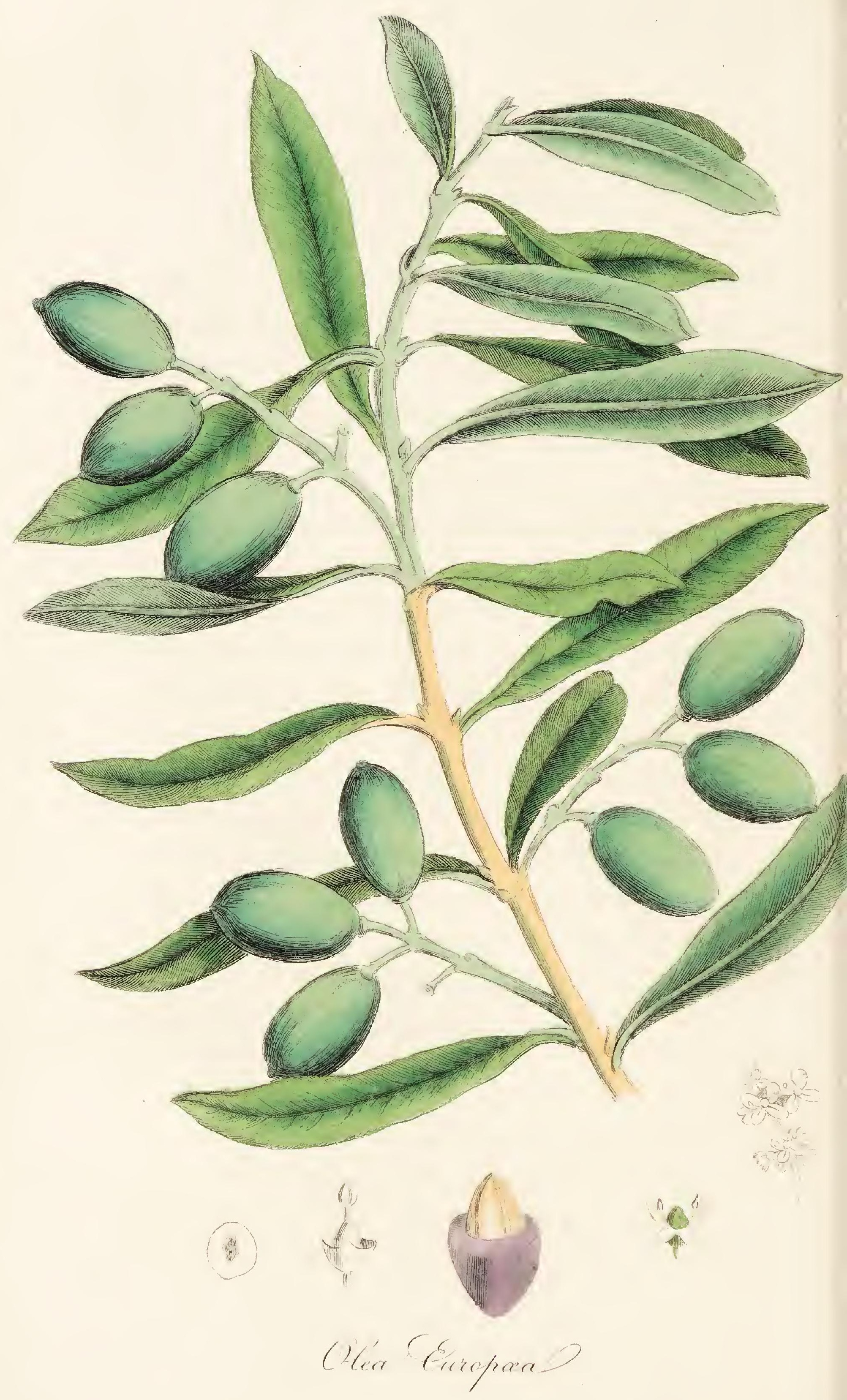


3. OLEA EUROP EA

European Olive Tree.

Drupæ oleum expressum.

\section{$\longrightarrow$ \\ Class 1I. Diandria, Order I. Monogynia.}

Natural Order. SEPIARie.

Specific Character. Leaves Lanceolate, quite entire.

$T_{H I s}$ tree is a native of the south of Europe, and also of the north of Africa; it is cultivated in France, Spain, Italy, \&c. This plant has been cultivated in all ages, as well on account of the beauty and perpetual greenness of its leaves, as for the utility of its fruit: it was held in great veneration by the ancients. It flowers from June to August.

The olive is a tree of moderate size, the wood of which is hard and veined; it has numerous branches of a greyish colour. The leaves are opposite, hard, entire, lance-shaped, and evergreen, having short foot-stalks : the calyx is tubular and divided into four segments : the corolla has four divisions. The flower is white : the filaments are two, tapering and crowned, with erect anthers : germen round, supporting a short simple style furnished with a stigma, which is cleft in two. The fruit is a drupe of an oval shape, of a deep violet colour when ripe; of a bitter taste: but the form, size, and colour, vary much : it contains a hard thick nut.

There is a great variety of this tree, distinguished both by the size of the fruit and shape of the leaves: the best 
grows in stony and dry places. To obtain the best oil, the olives are taken when perfectly ripe, and immediately pressed; but inferior sorts are afterwards obtained by boiling the seeds and again pressing them: if the olives are gathered before they are ripe, the oil expressed from them has a better taste.

Good oil is of a whitish yellow colour, transparent, very fluid, without smell, and of a sweet taste, not too unctuous : it congeals at $38^{\circ}$. of Fahrenheit.

It is an emollient, demulcent, and laxative : combined with an alkali and water forms an emulsion useful in cough, \&c.; it has been applied externally in burns, combined with lime-water; but it seems inferior to milk, as it is very apt to become rancid. This oil enters into the composition of ointments, and the best soap is made from it. The inferior kinds are useful for a variety of purposes, viz. for burning, \&c. Dose, $3^{\text {ss. }}$ ¡jss.

Preparations into which it enters, are, plaisters, linaments, ointments, cerates, \&c. 



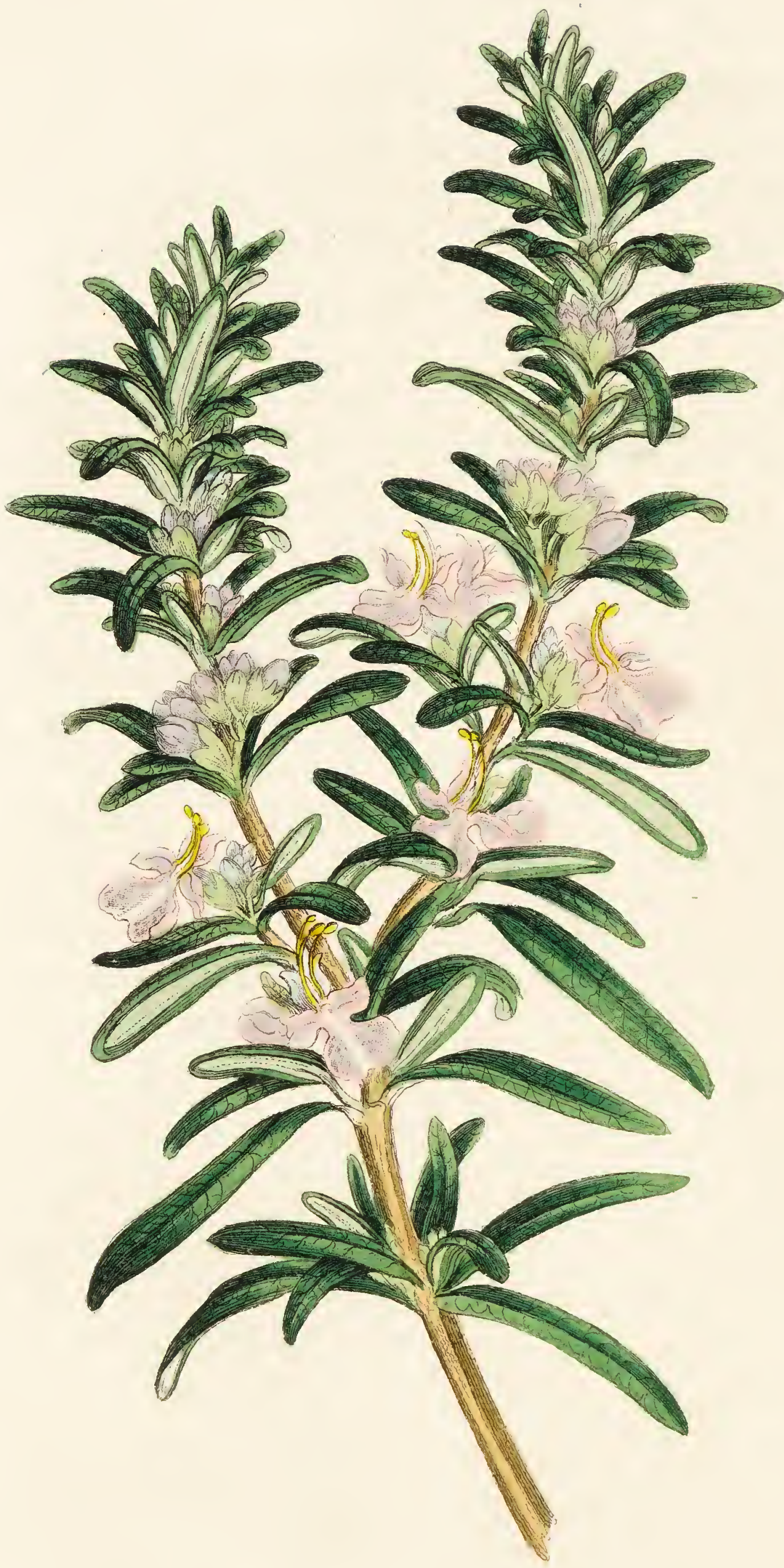

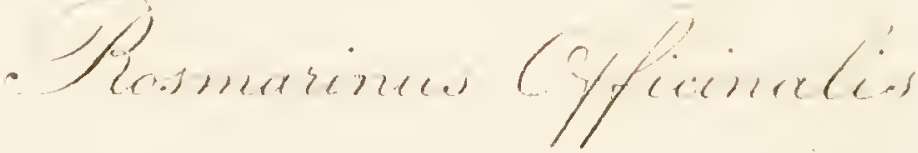




\section{ROSMARINUS OFFICINALIS.}

\section{Common Rosemary.}

\section{Cacumina.}

\section{Class II. Diandria.-Order I. Monogynia.}

\section{Natural Order. Verticillate.}

Specific Character. Corolla unequal, the upper lip two-parted. Filaments long, curved, and simple, with a tooth.

'THIs plant is a native of the south of Europe, viz. Spain, Italy, \&c. flowering in April and May; it is likewise much cultivated in our gardens, but the former is generally preferred.

It is a perennial shrub, growing to the height of five or six feet, with numerous branches, covered with a greyish bark, and thickly beset with leaves. The leaves are without footstalks, opposite, long, narrow, entire, obtusely pointed, with the margin turned back; of a dark green colour on the upper side, and veined and of a silvery colour underneath. The flowers are of a pale blue colour, arising from the axillæ of the leaves; the calyx is bell-shaped, and divided into two lips, of which the outermost is entire, the under cloven into two pointed segments. The corolla is monopetalous; its tube longer than the calyx, divided into two lips, the upper erect and fibid, the lower divided into three segments, the middle the largest of the three; the stamens are long, curved, and furnished with a tooth, supporting oblong anthers; the style is the height of the stamens, very slender, and supporting a 
simple sharp stigma; the germen is divided into four parts, containing four oblong seeds.

This herb possesses a grateful and strong arumatic odour; its taste is warm and pungent, resembling camphor : these properties chiefly reside in the extreme branches, i. e. in the leaves and calices, the corolla having scarcely taste or smell. It affords a considerable quantity of essential oil by distillation, upon which its properties appear to depend. Water extracts from it a bitter principle only; whilst alcohol extracts the whole of its virtues. Its medical properties are stimulant and antispasmodic; hence useful in nervous affections, as head-ache, vertigo, palsy, and flatulencies; it has been said by some to possess the properties of an emmenagogue. The preparations of it are an essential oil and the spirit, which is called Hungary water. A conserve made of it would be a good mode of administering it. Its dose is from grs. x. to $z$ ss. 



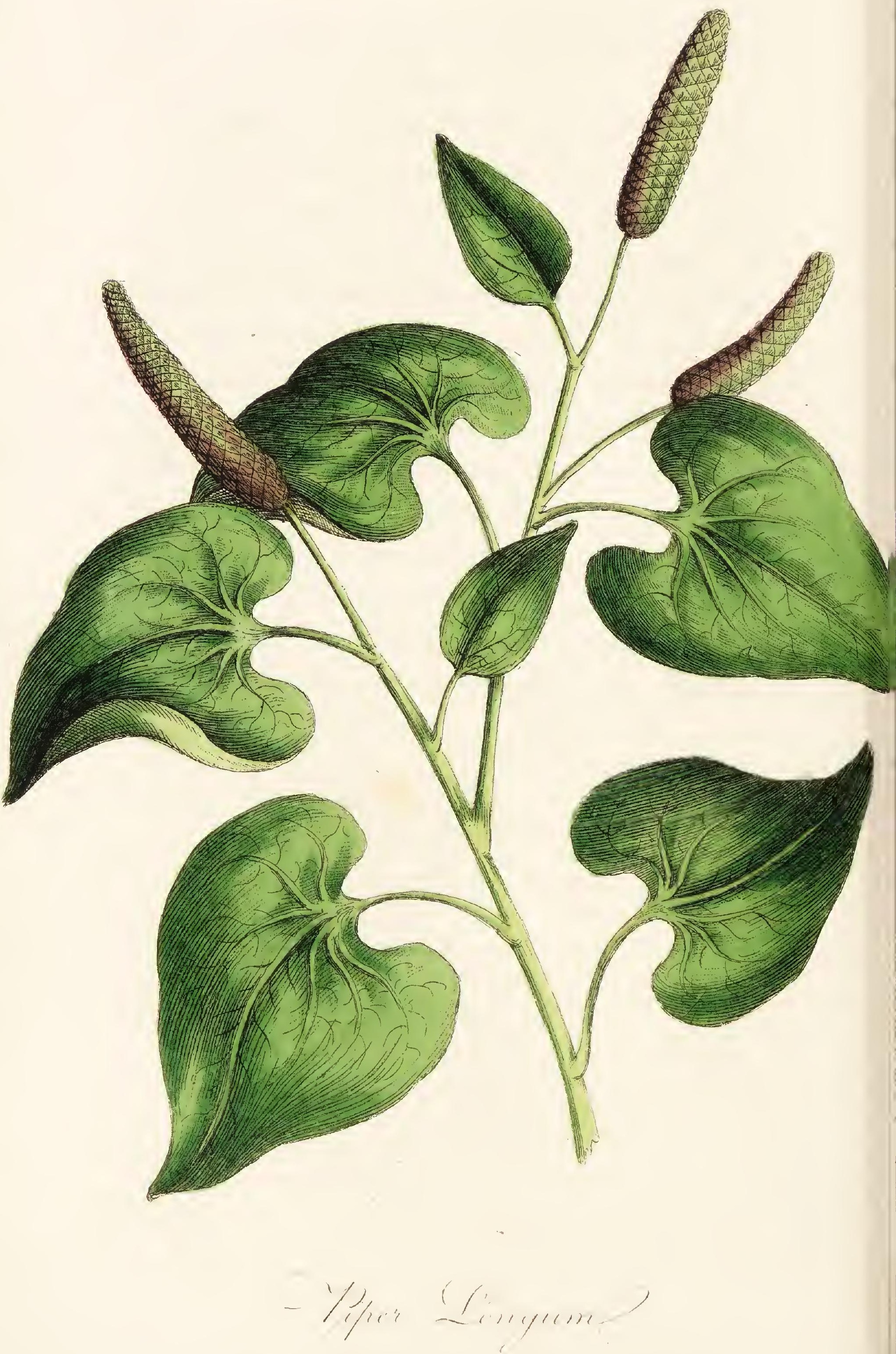




\section{P I P E R L N $\mathrm{N} U \mathrm{M}$. Long Pepper.}

Fructus immaturus siccatus.

\section{Class II. Diandria.-Order III. Trigynia.}

Natural Order. Piperita.

Specific Character. Leaves cordate, petiolate, and sessile.

$\mathrm{T}_{\text {Hrs plant is a native of the East Indies, but is particularly }}$ cultivated in Java and Malabar.

The stems are smooth, round, slender, branched, and climbing. The leaves commonly cordate, pointed, entire, and of a deep green colour, and are alternate. The flowers are of small size, in short, dense, terminal spikes.

The fruit consists of very small berries lodged in a pulpy substance. 'The fruit is most pungent when in the unripe condition; hence it is gathered before ripe, and exposed to the heat of the sun to be dried. We do not have the grains alone, but it is imported into this country connected with the pulp, forming bodies which are rather more than one inch in length, tuberculated, of greyish colour, compact texture, and subcylindrical form. Its taste is very pungent and warm; its aromatic odour is but light. Its pungency and warmth appears to depend on the resinous part of the fruit, whilst its odour resides in an essential oil, which rises in distillation: the whole of its virtues are extracted by spirit of 
wine, but only partially by water. This is the strongest of all the peppers, but possesses the same properties as the other species. It is a powerful stimulant and tonic; uscful in flatulencies and weakness of the stomach, with other dyspeptic symptoms; will sometimes allay sickness, and also useful as a gargle in the atonic inflammation of the tonsils. Dose from grs. v. to $9 \mathrm{i}$. The preparations which it enters into are, the Confect. Opii. Pulv. Cinnam. comp. Pulv. Cretæ comp. et. Tinct. Cinnam. comp. 


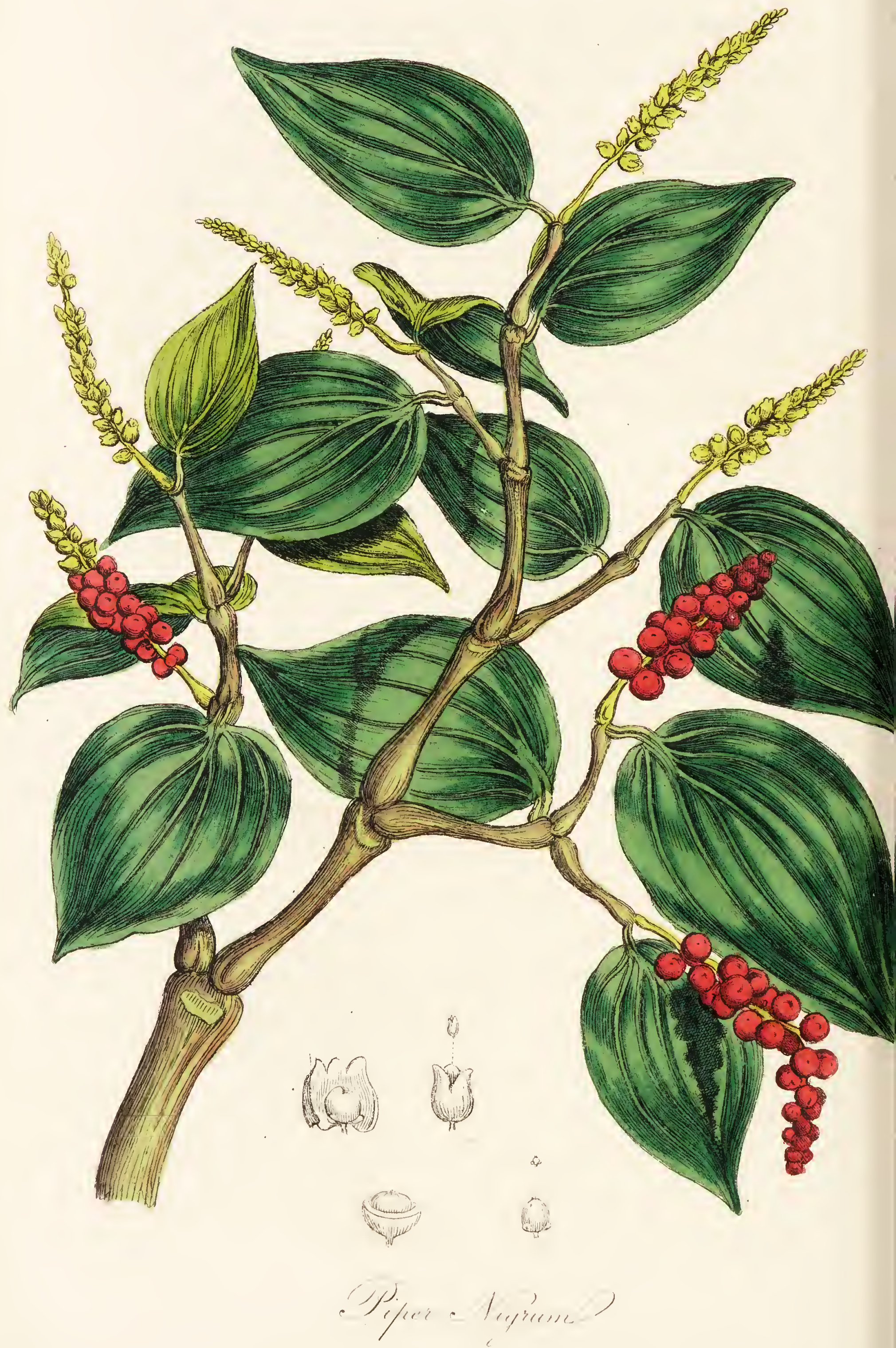




\section{PI P E R N I G R U M.}

\section{Black Pepper.}

Braccæ.

\section{Class 1I. Diandria.-Order III. Trig ynia.}

\section{Natural Order. Piperita.}

Specific Character. Leaves ovate, seven nerved underneath, smooth ; petioles perfectly simple.

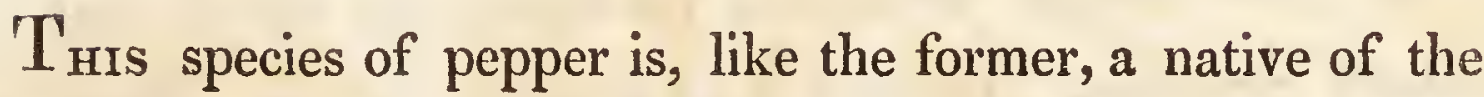
East Indies; but it is cultivated with such success in Malacca, Java, and especially in Sumatra, as to enable them to supply the whole world with its fruit. It thrives best in moist soils.

It is a shrubby, creeping perennial plant. The stems are smooth, round, and jointed, swelling as they approach the joint, woody, slender, branched, and eight or ten feet in length. The leaves are ovate, entire, smooth, and seven nerved, and of a dark green colour. The flowers are small, white, sessile, and placed in terminal spikes; calyx and corolla irregular; filaments wanting; the germen is ovate, supporting three rough stigmas: the fruit is a round berry of reddish colour, containing one seed.

These plants require support till they are three years old, at which time they acquire considerable height, and are looped off to within a few feet of the ground, which strengthens them, and the next year they bear fruit. When they come 
to perfection, they afford two crops annually, and will bear fruit for six or seven years.

As the fruit does not all ripen at the same time, it is gathered as it ripens, and then dried upon mats in ovens : these berries are at first green, and afterwards of a bright red colour, and by drying, they are changed to a black. The white pepper is the fruit of the same plant, gathered when ripe, and deprived of its external coat by steeping it in water.

The properties and medicinal uses of the black pepper are similar to those of the long, except that it is somewhat milder: it is seldom used as a medicine, but chiefly for culinary purposes. Its dose is from grs. $x$. to $3^{\text {ss. }}$. There are no officinal preparations. 



\section{VALERIANA OFFICINALIS.}

\section{Officiñal, or Wild Valerian.}

Radix.

\section{Class III. Triandria.-Order I. Monogynia.}

Natural Order. Aggregate.

Generic Character. Calyx o. Corolla monopetalous, gibbous on one side of the base, superior. Seed one.

Specific Character. Flowers triandrous, all the leaves pinnate.

$\mathrm{T}_{\mathrm{HIS}}$ species of Valerian is a perennial plant growing wild in this country, commonly occupying moist situations; but sometimes it is found on more elevated and drier pastures; the roots of the latter possess more fragrance, and hence are preferred for medicinal purposes. It flowers in June and July.

The root is somewhat stumped, fibrous, sending out long, creeping fibres from its crown: the stalk is three or four feet in height, upright, smooth, round and grooved, terminating in flowering branches disposed crosswise : leaves are opposite, connate, bearded at the base on the underside, pinnated: the leaflets are either opposite or alternate, slightly decurrent, lanceolate, oblong, unevenly toothed, veined and smooth; the floral leaves are trifid, and sometimes entire. Flowers are small, growing in sort of corymbs, terminal, and of a pale flesh colour, and of a peculiar smell; calyx none, but there is a slight margin on the 
top of the germen; corolla tubular, divided into five obtuse segments: filaments longer than the corolla, terminating in roundish anthers of the colour of the flowers: style slender and shorter than the filaments, furnished with an obtuse trifid stigma; germen conical, containing one seed.

The root, which is the only part of the plant used, should be dug up early in spring, or late in autumn, the latter is preferred; when it is found to possess a strong unpleasant smell ; an ungrateful, bitter, and sub-acrid taste. It is externally of a brown colour, and internally whitish : after being dried it should be kept in a dry place. Its smell and taste are extracted both by water and spirit. When distilled with water it affords no essential oil, but imparts to it the odour of the root.

It is a stimulant and antispasmodic, and seems beneficial in some nervous disorders. In epilepsy it has been administered with decided benefit; though it does not always prove equally so; likewise in hysteria and chorea sancti viti. I have seen it diminish the frequency of epileptic fits, given in doses of a drachm, which was repeated as often as the patient could take it: there is no danger of its producing any bad effects; therefore, when it is employed, as much should be given as the patient can bear on his stomach. It is recommended in other complaints, as catalepsy, hemicrania, worms, \&c.; but its virtues in these diseases have not been sufficiently determined to decide upon the subject.

The best form of administering it is in powder, mixed with mace; its dose is from 3 ss. to $\xi s s$, even $\xi j$. has been occasionally given. The officinal preparations are Tinct. Valerianæ。 Tinct. Valer. Ammon. Extract et Infus. Valerianæ. 



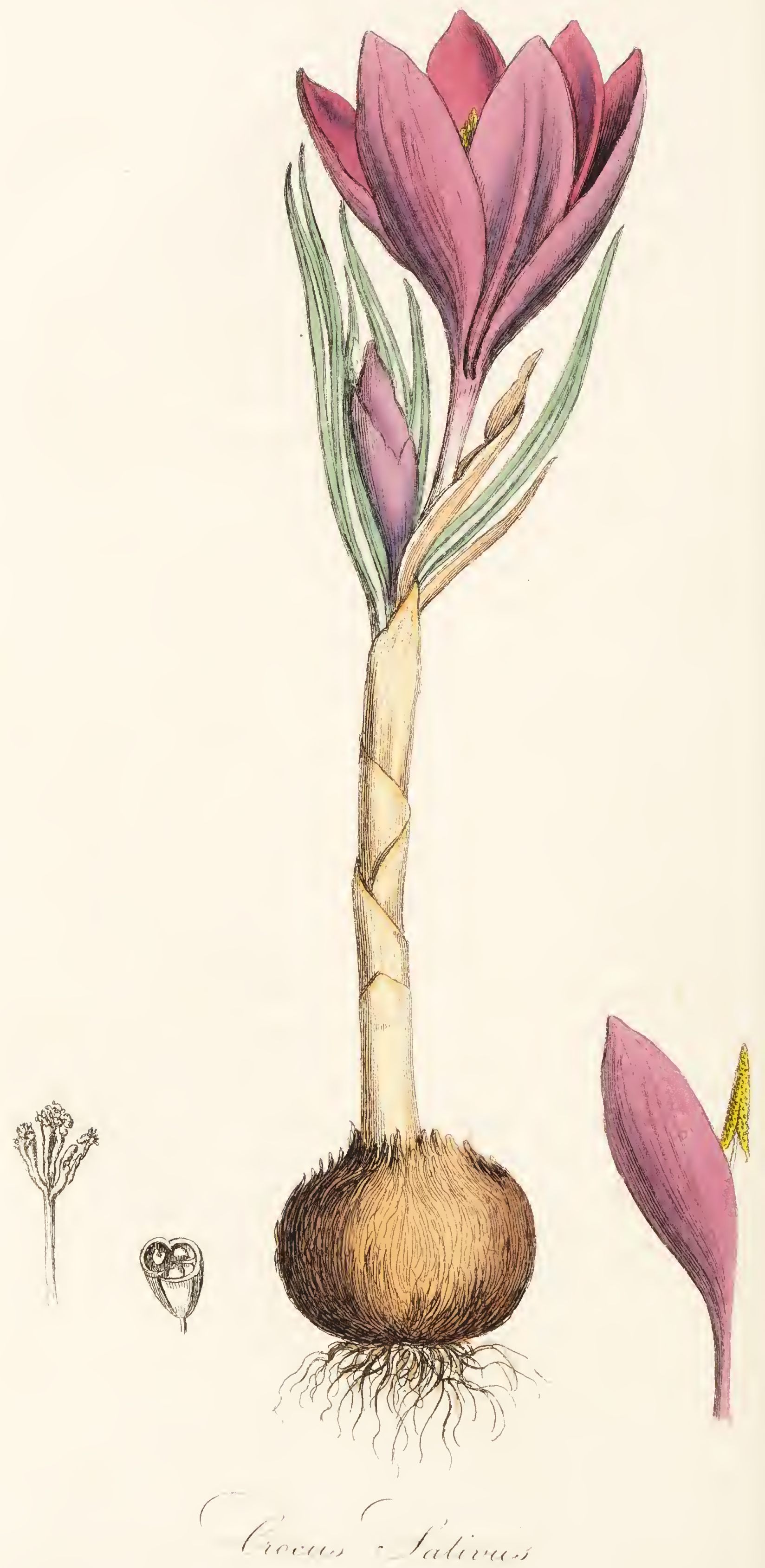




\section{CROCUS SATIVUS.}

\section{Saffron Crocus.}

Stigmata.

\section{Class III. Triandria.-Order I. Monogynia.}

\section{Natural Order. Liliacer.}

Generic Character. Corolla six-parted, equal.

Stigma convoluted.

Specific Character. Stigma trifid, length of the corolla; leaves narrow and rolled in at the margins.

$\mathrm{T}_{\mathrm{HE}}$ crocus is a bulbous rooted plant, growing in many parts of England and other temperate European countries, though it appears probable it was originally a native of the East.-It is both cultivated as an ornament to our gardens, and by some for the sake of the saffron. It requires a dry and elevated situation; flowering in September and October.

The flower appears before the leaves, is large and of a lilac colour, rising a little above the ground, upon a slender tube. The leaves are linear, turned in at the edges, having a white line in the centre, radical, of a rich green colour, and surrounded by a membranous sheath in common with the tube supporting the flower. The corolla is separated into six nearly elliptical petals, which are equal; the stamens are short and tapering, supporting yellow anthers; the style is the length of the corolla, supporting a stigma, which is deeply divided into three, which are of a dark orange red colour, varying to a white at the base; the capsule is three-celled, and contains several round seeds. 
The stigmas, or summits of the pistils, (the only parts of the flower which are used,) being selected from the flowers, which are gathered every morning before they open, are dried by the heat of a stove with great care, and it becomes by this process formed into cakes which are fit for use. It is said to be adulterated with the Carthamus Tinctorius and with smoked beef. The imposition may be detected by the want of white ends, and by its possessing less colouring property, and by the unpleasant smell which the bad would occasion, when thrown into the fire. It is sometimes mixed with treacle and oil, to increase its weight. It should be chosen fresh, tough, moderately dry, and with difficulty pulverised; of an orange red colour, and a strong diffusive aromatic smell. Its taste is warm, bitter, and pungent. In order to preserve the aromatic properties of the saffron, it is necessary to keep it in bladder and tin. Its properties are extracted by water and spirit. It yields a golden coloured oil by distillation, having the smell of saffrou. It is very doubtful whether this article possesses decidedly medicinal properties. It is said to be a stimulant and cordial, and recommended as beneficial in hysterical and other nervous affections. At present it is chiefly used as a colouring matter or adjuvant to other remedies.-Dose gr.x. to Эii. The officinal preparations are Syrupus et Tinctura Croci, and it is contained in the Conf. Aromat. Tinc. Rhei. Rhei Comp. Aloes Comp. Cinchon. Comp. et Pil. Aloes c. Myrrha. 



\section{SACCHARUM OFFICINARUM. Common Sugar Cane.}

Saccharum. Saccharum purificatum.

\section{Class III. Triandria.-Order II. Digynia.}

\section{Natural Order. Gramina.}

Generic Character. Calyx two-valved, involucred, with a long lanugo. Corolla two-valved.

Specific Character. Flowers pannicled, leaves flat.

THE sugar-cane grows wild both in the East and West Indies, and is much cultivated in the latter, where it arrives at great perfection.

The root is jointed, perennial, and fibrous, sending off stems which rise to the height of ten or twelve feet and more, and are simple, smooth, and jointed, about two inches in diameter. The leaves are long and narrow, resembling a blade of grass, one arising from each joint, the base of it embracing the stem. The flowers are in terminal pannicles, and of small size: the calyx is a glume of two valves: the corolla is composed of two valves shorter than the calyx : the filaments are the length of the corolla, and support oblong anthers: the germen is oblong, and contains an oblong seed.

The canes are fit to be collected in a year, after being planted, when they are cut off a little above the ground; the same plant produces fruit for twenty years or more. When gathered they are separated from their leaves and pannicles, and bound into bundles, and conveyed to a mill, commonly a wind-mill, where they are ground between two iron rollers, and the juice is expressed into large receivers; from thence it is conveyed into the boilers, where it is mixed with a quantity of quick-lime or potass, and then boiled down to a due consistence; the use of the lime or potass is to combine with or saturate any acid that may be present, as the malic, \&c.; when a thick scum is observed on its surface the clear liquor is drawn off into another boiler, and into four successive ones, and undergoes a boiling in each, but with more care. It may be necessary to explain that the boilers diminish gradually in size, and each situated 
below the one preceding it, so as conveniently to allow of the syrup being let out of one into another. When it is sufficiently boiled, which may be known by a glutinous feel which it has, it is drawn off into large wooden vessels, and allowed to crystallize, and the fluid part, or molasses, separates from it: it is removed from these vessels into large casks, which have holes in them, and the molasses being allowed to drain off, the sugar is fit for exportation. It is in this state that we receive it. The best is in large clear whitish grains, free from syrup, and destitute of any empyreumatic smell. In the process of purification it is mixed with lime-water, and then boiled in bullocks' blood, or white of egg: during the boiling, its impurities, which rise to the surface, must be skimmed off, and when it is boiled down to a proper consistence, it is poured into conical moulds of unglazed earthenware, which have apertures at the apex, to allow the escape of the uncrystallized fluid: the broad end of the cone is covered with moist clay, the water of which percolates the mass, and carries with it any syrup which might otherwise colour it. It is then carefully dried, and constitutes what is called loaf-sugar. This, for particular purposes, is exposed to the same process again, and forms the double refined sugar. The raw sugar is of a yellowish colour, without smell, and of a sweet taste, and perfectly dry: the purified or loaf is of a white colour and of a close compact texture, extremely brittle, and unalterable in the air.

It is composed of carbon, oxygen, and hydrogen.

Sugar is chiefly employed as a condiment, or to cover the unpleasant taste of some medicines.* It is sometimes given in cases of scurvy, and applied to scorbutic ulcers with advantage, and is the most certain antidote in cases of poisoning by Verdigris. When taken in large quantities it proves nutritive and laxative.

Sugar is a substance which is contained in many vegetable substances, as parsnips, beet-root, carrots, starch, and a variety of others; and in animals, viz. in milk, it exists in considerable quantities, and in the disease called Diabetes Mellitus it is found considerably to increase the specific gravity of the urine, which affords by evaporation a quantity of sugar. It may be taken ad libitum.

The officinal preparations are Syrupi, Confectiones, et Trochisci omnes.

* It is used in considerable quantities in the preparation of oxalic acid, that very corrosive poison which has lately proved so fatal to several individuals. 


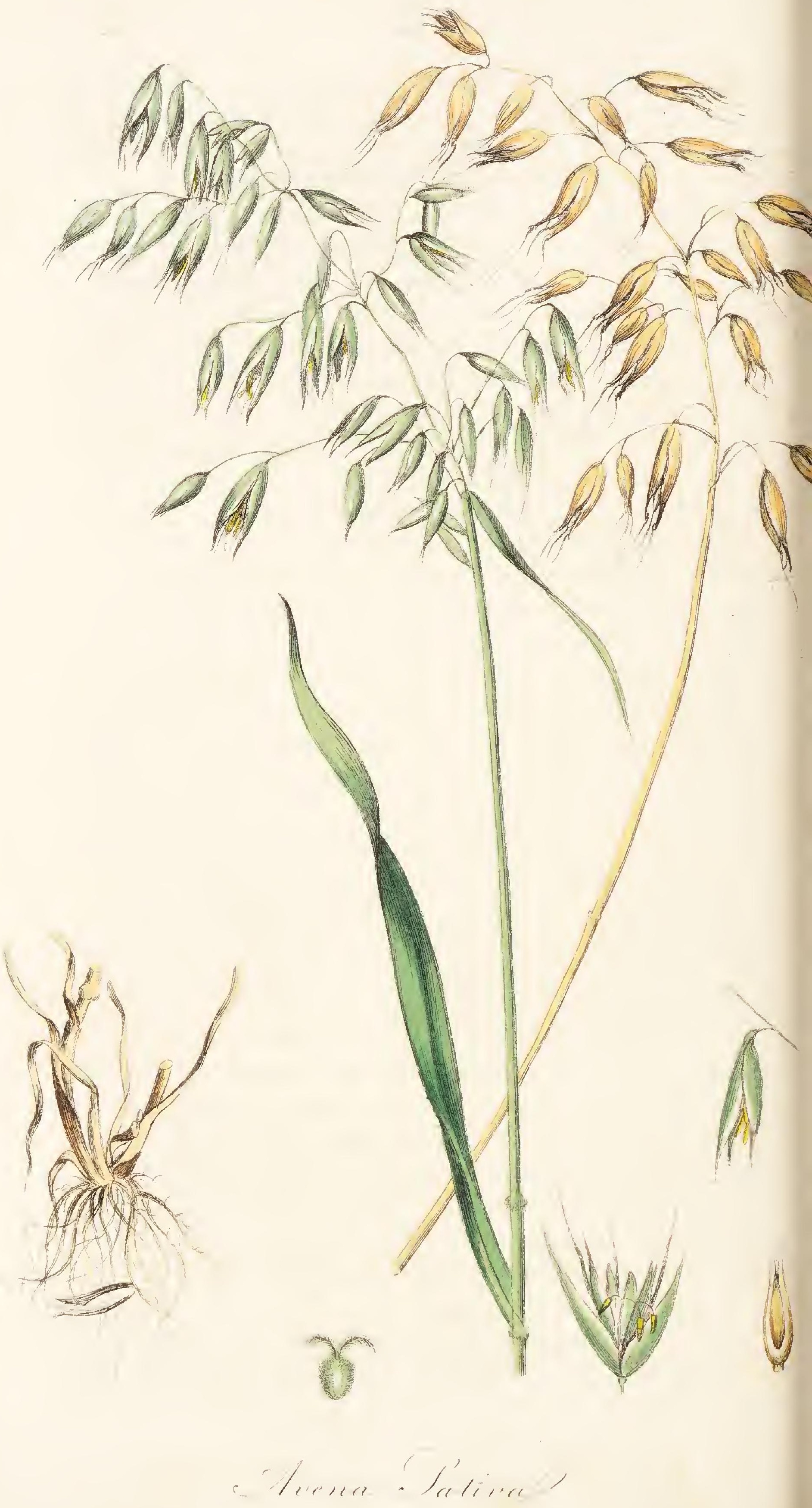




\title{
10. AVENA SATIVA. \\ Common Oat.
}

Semina nudata tunicis.

\section{Class III. Triandria.-Order II. Digunia.}

\author{
Natural Order. Gramina.
}

Generic Character. Calyx two-valved, many flowered. Awn twisted on the back.

Specific Character. Pannicled, calices two seeded, seeds smooth, one awned.

THIS useful grass, which originated in Asia, is cultivated in this as well as in many other countries, on account of its great utility as food, \&c. It will grow in most situations.

The root is annual, composed of numerous fibrillæ. The culm proceeding from it is straight, hollow, and jointed, rising to the height of about three feet. The leaves resemble those of most grasses, being of considerable length, and rough to the feel. The flowers grow in loose pannicles six or seven inches in length: the glumes of the calyx are two, linear, green, striated and very pointed, and longer than the flowers they envelope; the flowers of each calyx are commonly two: the filaments support oblong anthers, the germs support the styles, having plumous stigmas.

There are several varieties of this plant, as to the appearance of the flowers, and colour of the seeds, which are brown, black, or white.

Oats possess scarcely any sensible properties. When deprived of their husks they are called groats, which are employed in making gruel. The whole of their nutritive qualities are ex- 
tracted by decoction in water, which consist chiefly of mucilage and starch. These decoctions are employed as nutritients, in inflammatory affections, \&c. and as diluents, when any acrid matter is present in the stomach or intestines, such as would occur in cholera, or where any poisonous substance had been taken. In these cases it may also be administered in the form of an enema. By some of the poor of Sweden, oats are made into bread, where there is a deficiency of other grain; and also in Norway, and some other countries, they are used for a similar purpose. The bread made from them is of a dark colour and bitter taste. The decoction, which is the only form in which these seeds are administered, may be taken ad libitum. It enters. into no officinal preparation. 


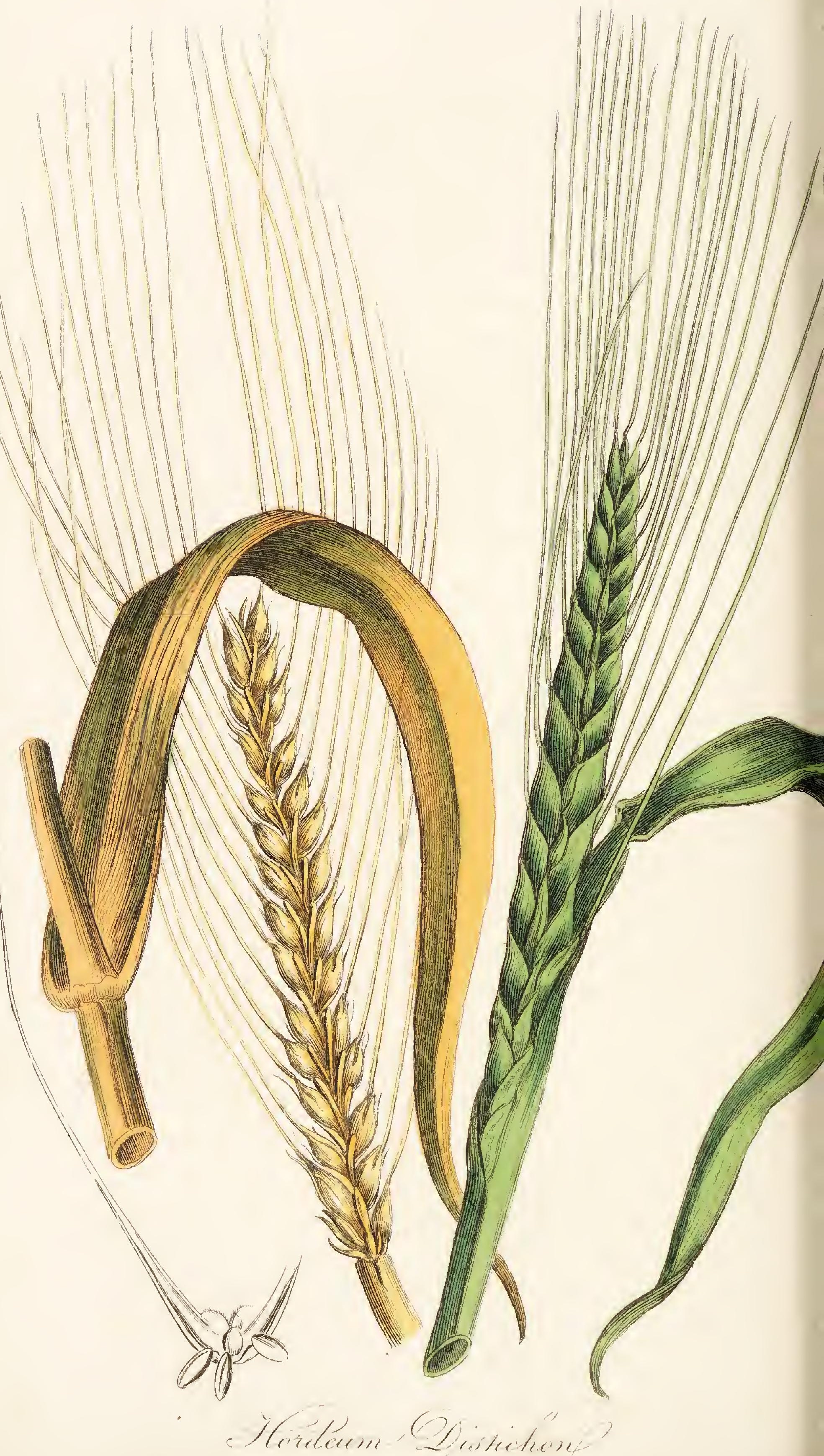




\section{HORDEUM DISTICHON.}

Common, or Pearl Barley.

Semina tunicis nudata.

\section{Class III. Triandria.-Order II. Digynia.}

Natural Order. Gramina.

Generic Character. Calyx lateral, two-valved, one flowered, three-fold.

Specific Character. Florets lateral, male beardless, with imbricated angular seeds.

$\mathrm{T}_{\text {H1S }}$ is an annual plant, the seeds of which are sown in spring, and come to perfection the following summer. It is said by some to be a native of Tartary, whilst others consider that it originated in Italy; but it is now cultivated in most European countries.

As it grows in this country, the seeds are supported upon a straight, smooth, articulated stem, which commonly grows to the height of two or three feet. It has a long flat spike, with two lateral rows of small male florets, and a middle row fertile. The valves of the calyx are linear, and one half shorter than the corolla, terminating in a long serrated beard or awn. The leaves are long, sharp, and of a bright green colour. The husk, when ripe, is angular, and applied close upon the grain, which, when deprived of it, is oblong, angular, sulcated, and of a straw colour.

The grain, as it is procured from the barn, is called crude barley; but when deprived of the husks, it is, by means of a mill, reduced to a roundish form of a pearly whiteness, and hence its name. 
Barley possesses scarcely any smell or taste. It is used both medicinally and as an article of food; and in Spain and other hot countries for horses, instead of oats. The plant is chiefly cultivated for the purpose of making malt and spiritous liquors.

The decoction, commonly called barley-water, is a very useful beverage in fevers and inflammatory diseases, particularly when acidulated by some of the vegetable acids. It possesses properties very similar to the oat, and is, like that, composed of starch, mucilage, and saccharine matter, hence it is a very good article of diet as well as medicine. The officinal preparations are, Decoct. Hordei; Decoct. Hordei comp.; which may be taken ad libitum. 



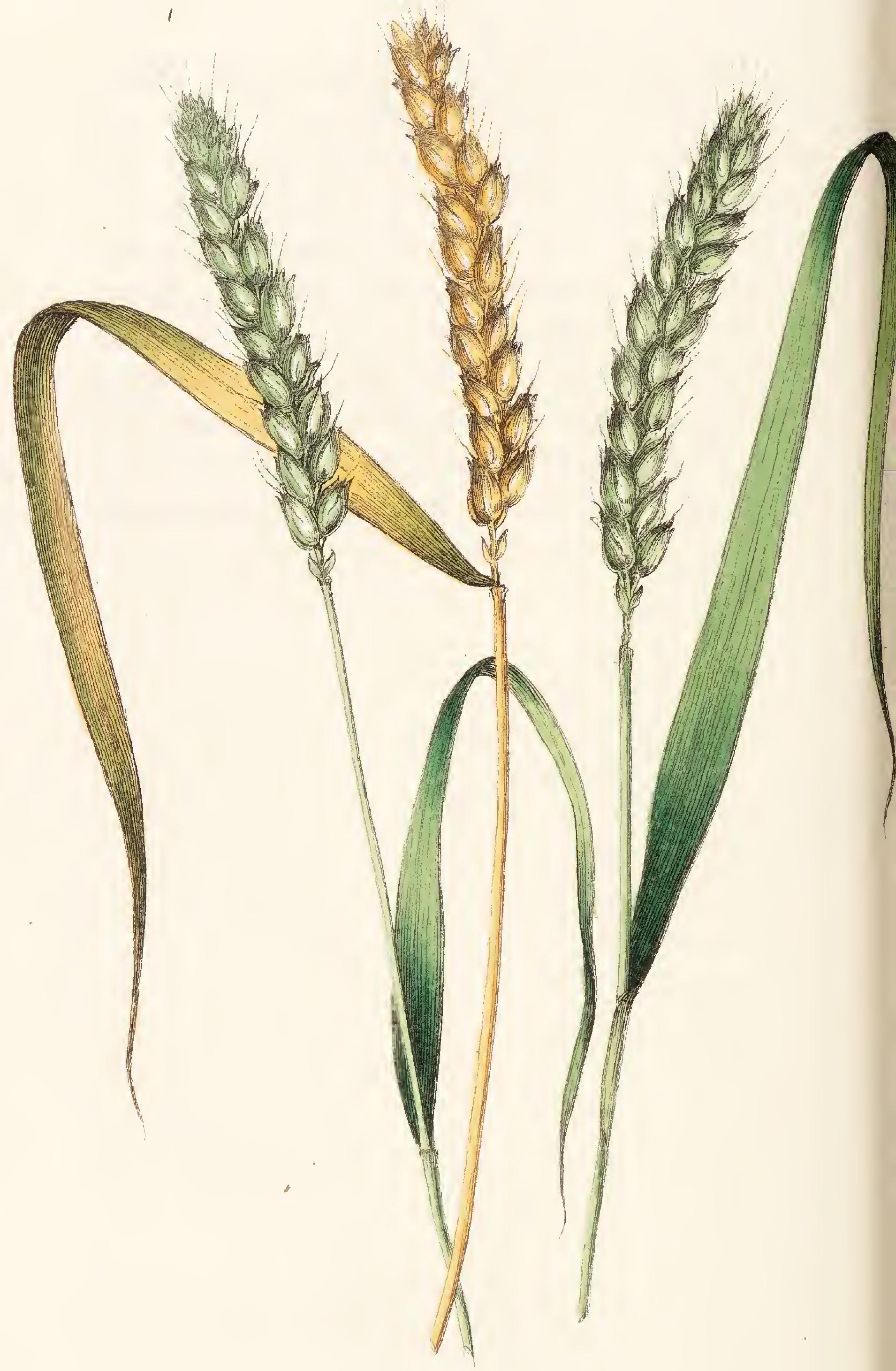

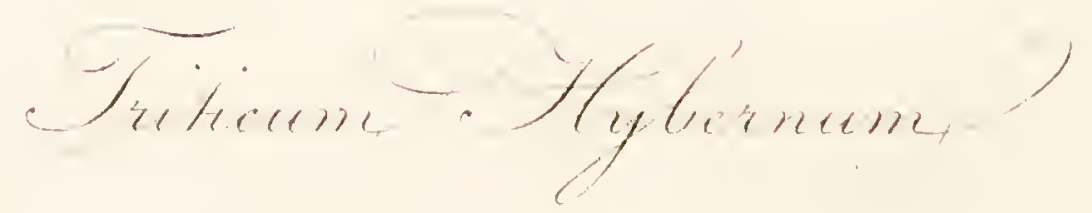




\section{TRITICUM HYBERNUM.}

\section{Winter Wheat.}

Amylum et Farina.

\section{Class III. Triandria.-Order II. Digynia.}

Natural Order. Gramina.

Generic Character. Calyx two-valved, solitary, subtriflorous. Flower somewhat obtuse.

Specific Character. Calyces four flowered, ventricose, smooth, imbricated, and nearly beardless.

THERE have been many disputes respecting the origin of this valuable plant; but it is most probable that it was first transferred from Italy into other countries. It is now cultivated in every part of Europe, both in hot and cold climates, as Spain, Sweden, Russia, England, \&cc. The softer grains grow in the cold regions, whilst, on the contrary, the hard seeds are common to warm climates.

The spikes of this annual plant are long, with the seeds lodged in four rows, and imbricate; the chaff is smooth, bellied, and terminated by very short awns. The seeds are oblong, sulcated lengthwise, externally yellow, but internally quite white.

This grain is ground and passed through sieves of different degrees of fineness, after which it is in a fit state for making bread: the coarse part which remains is called bran.

Starch is obtained by steeping the bruised or whole seeds in water, till they swell, and afford a milky juice upon being pressed; they are then exposed to pressure in bags placed in water, till 
the whole of their juice is extracted. The liquor is then set by, to allow of the freculi subsiding; a short time after which it is put into vessels which admit of the separation of the dirty particles: it is then repeatedly washed, and dried by a gentle heat. The substance remaining in the bag, after pressing out the milky fuice, is gluten, which is very analogous to animal fibrine; it putrefies in a similar manner, and affords a considerable quantity of Ammonia. The saccharine matter is dissolved in the water in which the wheat is washed, and it may be obtained by evaporation and crystallization.

It is unnecessary to mention flour or bread as articles of diet. The bread made from wheat flour is more nutritive and palatable, than that of any other species of grain. It is useful as an external application, in the form of Poultice, to erysipelatous and other unhealthy sores, and also in promoting suppuration. It is the best vehicle for giving some of the more active remedies in the form of Pills, such as the Nitrate of Silver, and some of the preparations of Copper and Mercury.

Starch should be of a white colour free from taste or smell: insoluble in cold water and alcohol, but it is converted by boiling water into a semitransparent jelly. This substance is used more for domestic than medicinal purposes. It is, however, very useful in some cases of Diarrhæa and Dysentery, in the form of enema; either alone or combined with opium. It is employed as an article of food in some disorders, and in the formation of lozenges. The officinal preparations:-Mucilago Amyli; Pulv.; Tragacanth. comp.; Trochisci Gummosi. 



\section{RUBIA TINCTORUM.}

\section{Dyer's Madder.}

Radix.

\section{Class IV. Tetrandria.-Order I. Monogynia.}

Natural Order. Stellate.

Generic Character. Corolla one petalled, bellshaped. Berries two, one-seeded.

Specific Character. Leaves annual, stem prickly.

$\mathrm{T}_{\mathrm{HE}}$ madder is a perennial plant, native of Germany, Italy, and some parts of France; it flowers in June.

The root is creeping, its fibres are about the thickness of a goose-quill, and of a deep red colour, proceeding from a knotted head. The stems are quadrangular, jointed, ribbed, procumbent; and beset with rough, short points, which allow of its being supported by the neighbouring plants; they are generally three or four feet in length. The leaves are elliptical, rough, pointed, ciliated, and placed in whorls of four or five together. The branches bearing the flowers, proceed in pairs from the joints of the stem. The flowers are small, terminal, and of a yellow colour: the calyx is divided into four teeth; the corolla is bell-shaped, cut into four oval segments; the filaments are short, supporting simple erect anthers; the germen is inferior, and double; the style is slender, and supporting two globular stigmas; the fruit consists of two round berries, each containing an oval seed. 
The madder root has a bitter and somewhat austere taste; it has a weak smell. When the root is dug up, it is dried, deprived of its exterior covering, and bruised; it is then packed up in barrels for sale. Its colour is extracted both by water, spirit, and essential oils. It is a substance much used by dyers, and possesses the curious property of tinging some of the secretions of a red colour, in those animals who are fed upon it; the urine, milk, and bones, are the parts chiefly coloured; but it also tinges the serum of the blood, some say the perspiration is affected in a similar manner. In consequence of the power which this root has of penetrating both the solids and fluids of the body, it has been employed in several diseases, as Scrophula, Rickets, Amenorrhrea, and many others, but without any particular advantage. Its dose is from $\mathrm{gr} . \mathrm{xv}$. to $3 \mathrm{j}$. It enters into no officinal preparation, and indeed might very well be dispensed with altogether as a medicine. 


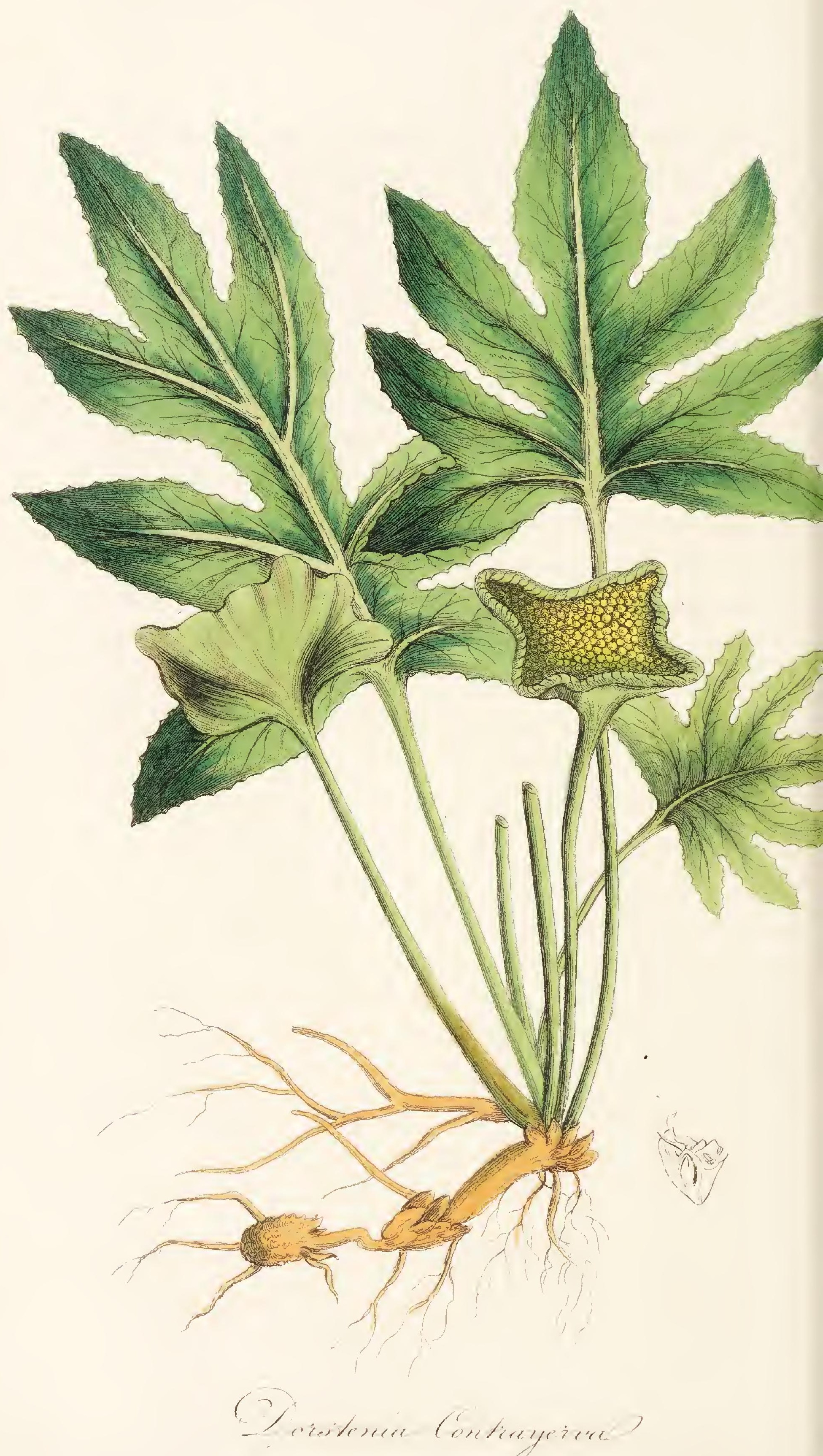




\section{DORSTENIA CONTRAJERVA.}

\section{Contrayerva.}

Radix.

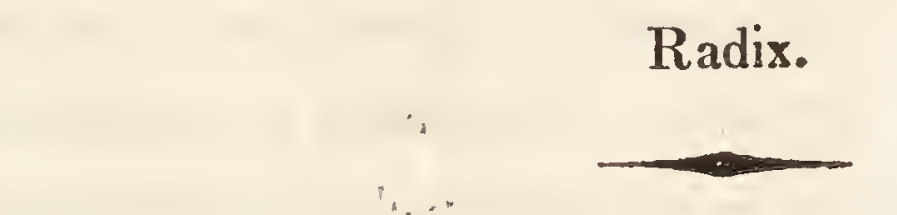

Class II. Triandria.-Order I. Monogynia.

Natural Order. Sca BRID质.

Generic Character. Receptacle common one-leaved, fleshy, in which solitary seeds are placed (without attachment).

Specific Character. Scapes rooted, leaves pinnatifid hand-shaped, receptacles quadrangular.

THIs perennial plant is a native of Peru and some of the West India islands, growing in rocky situations. It is at this time cultivated in some of the gardens of Paris in considerable quantities.

The root is knotty; tuberculated, and of a firm texture, externally of a reddish brown, and internally of a white colour; it sends off numerous long and slender fibres. The leaves, which proceed from the root by long footstalks, somewhat vary in their form; they are several inches in length, lobed, pointed, and unequally dentated. The flowers proceed immediately from the root, supported by simple peduncles shorter than the leaves, which terminate in quadrangular receptacles, about an inch in length, and angular at their edges, containing a great number of small sessile flowers. The capsule possesses such elastic power when ripe, as to throw out the seeds with considerable force.

The root possesses a peculiar aromatic smell, and a warm bitter taste; and if chewed for any length of time, leaves behind 
it a burning sensation.* There are two other species of the Dorstenia, the Drakena and Alexitaria; the roots of the three species are often gathered indiscriminately. The virtues of the root are extracted by water and spirit. It contains a considerable quantity of mucilage, so that its decoction wal not pass through the filter.

The Spaniards have attributed much success to the use of this article in cases of poison; but the accounts appear unfounded. It is a sudorific and tonic, but possesses neither of these properties in any remarkable degree. It is recommended in Typhus and Nervous Fevers, and in some species of Variola. The form of administering it, is either in powder or infusion, its virtues being somewhat impaired by boiling; but it is seldom given alone. Its dose is from grs. 10 to $3 \mathrm{ss.}$. Officinal preparations : Pulv. Contrajervæ comp.

* The fibres are much inferior in smell and taste to the thicker part of the root. 



\section{MENYANTHES TRIFOLIATA-TRI- FOLIUM PALUDOSUM.}

\section{Buck Bean.}

Folia.

\section{Class. V. Pentandria.-Order I. Monog ynia.}

Natural Order. Rotaces.

Generic Character. Corolla hirsute. Stigma bifid. Capsule one-celled. Specific Character. Leaves ternate.

THis plant is very common in marshy situations, through all parts of England; it is perennial, and flowers in June and July.

The root is long, creeping, fibrous, and jointed. The stems are about ten inches in height, spreading, and support ternate leaves. The flower-stalk, which springs from within the sheath of a leaf, is round, smooth, and taller than the leaves. The calyx is five-toothed, the corolla funnel-shaped, cleft into five segments, which are sometimes entirely white; yet they are generally of a rose colour on the outerside, and fringed within, so as to give it a fibrous appearance.

The leaves of the Buck-bean have an intensely bitter taste, which may be extracted by water or spirit; it is nearly inodorous. The whole of the plant is very bitter, and is said to be employed, sometimes, as a substitute for hops. Sulphas Ferri throws down 
from an infusion of it, a precipitate, which shows that it possesses astringency: it likewise proves emetic, purgative, and diuretic. It has been used with apparent advantage in several diseases, viz. Rheumatism, Gout, Intermittents, Cachexia, Jaundice, \&c.

We might expect some good effect from a plant possessing such strong sensible properties, particularly in some of these diseases; as in Jaundice, where there is a deficiency of bile, it may prove an useful substitute; and it may likewise tend to check the paroxysms of an intermittent, if combined with other medicines.

Its dose is from $\ni \mathbf{j}$. to $3 \mathbf{j}$. 



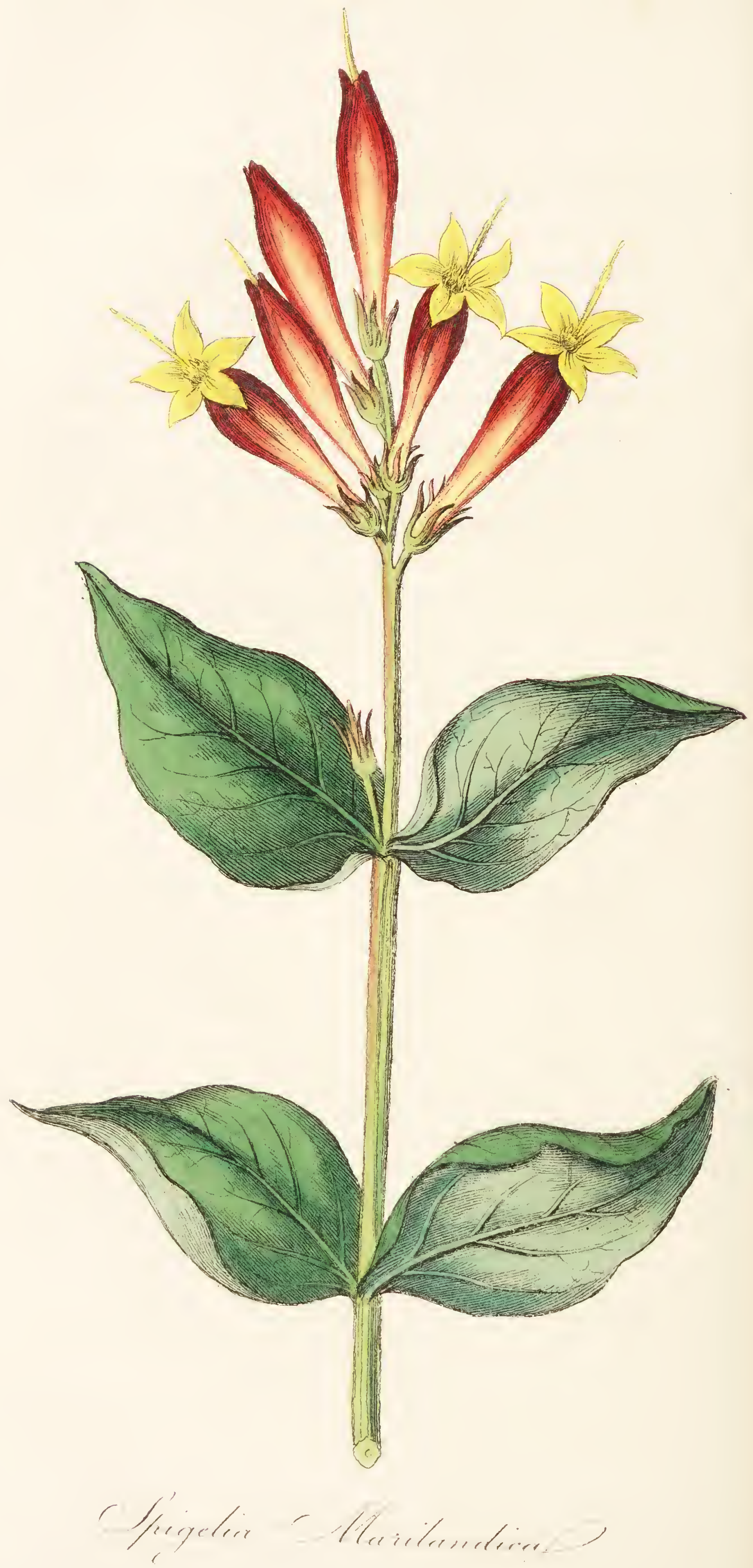




\title{
16. SPIGELIA MARILANDICA. \\ Perennial Worm Grass, or Indian Pink. Radix.
}

\section{Class V. Pentandria.-Order I. Monogynia.}

\author{
Natural Order. Stellate.
}

Generic Character. Corolla funnel-shaped. Capsules twin, two-celled, many seeded.

Specific Character. Stem four-sided, all the leaves opposite.

$\mathrm{T}_{\mathrm{H} 1 \mathrm{~S}}$ is a perennial plant, and a native of South Carolina and other parts of America; it requires a fertile soil, and flowers in July and August.

The root is horizontal, simple, unequal, with numerous long fibrillæ. The stalk is simple, erect, smooth, and obscurely quadrangular, of a purplish colour, and usually about eight or nine inches in height. The leaves are ovate-lanceolate, sessile, entire, somewhat undulated, and placed in pairs. The flowers are funnel-shaped, and terminate the stem in a spike: the calyx consists of five awl-shaped segments: the corolla is monopetalous, consisting of a tube swelling towards the middle, of a bright red colour externally and yellow within: the border five parted: the filaments are nearly the length of the corolla, supporting sagittate anthers: the germen is ovate, superior, and furnished with a round style, which is longer than the corolla, and jointed below: the seeds are many, small, and angular.

The whole of this plant has a bitter taste, and is anthelmentic; 
but the root is the most active part of it. It is advisable to give an emetic previous to administering this medicine, which may be given either in infusion or powder; the latter is the best form for adults : children will take it with safety and benefit; but for them the infusion mixed with sugared milk is the best form. Where the intestines are torpid, it may be combined with some purgative, as calomel or rhubarb. Its use must be persevered in for a week or ten days to obtain its full effects. It has been observed to produce vertiginous affections and dimness of sight, and in very large doses it has proved fatal; these symptoms are relieved by stimulants, as wine, aromatics, ammonia, and essential oils; they arise chiefly from the exhibition of the fresh root, for they seldom occur when the plant is dried. It has been recommended in remittent fevers of children, as well as in worms. Its dose is from gr.x. to $3 j$. Officinal preparations none. 



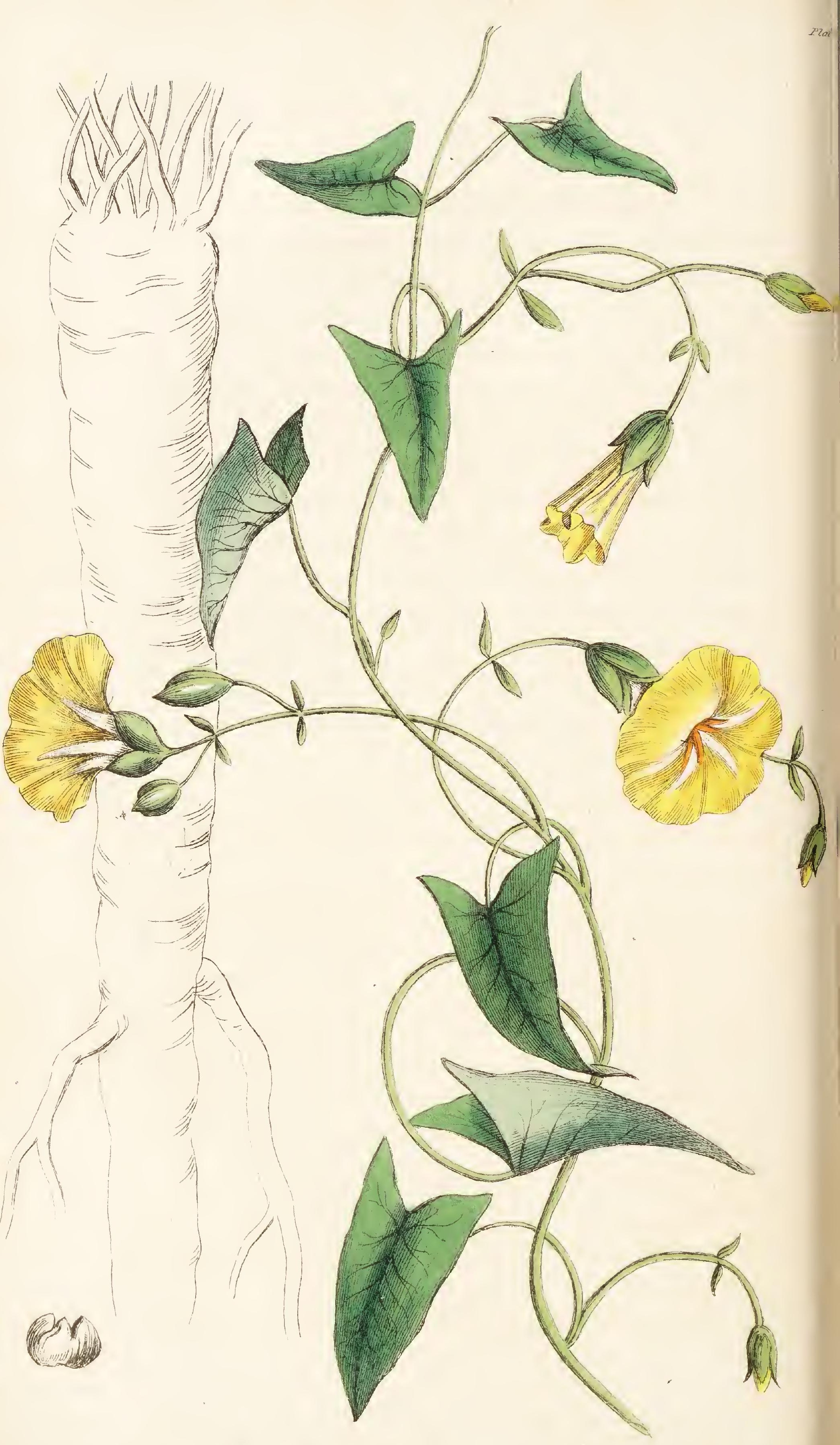

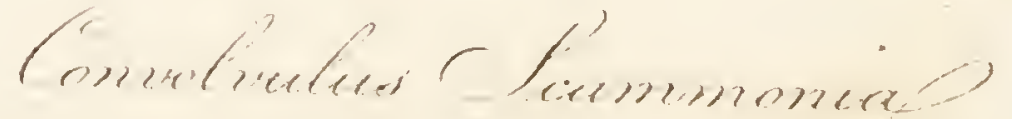




\section{CONVOLVULUS SCAMMONIA,}

Scammony, or Yellow Bindweed.

Gummi Resina.

Class V. Pentandria.-Order I. Monogynia.

Natural Order. CampanaceE.

Generic Character. Corolla bell-shaped, plaitêd.

Stigmas two. Capsule two celled, each cell containing two seeds.

Specific Character. Leaves sagittate, truncated on the back part, peduncles columnar with about three flowers.

THIs perennial plant grows plentifully on the chain of mountains extending from Antioch to Mount Lebanon, and is also a native of Syria.

The root is tapering, and branched towards its lower part, three or four feet in length, and from three to four inches in diameter, covered with bark of a light grey colour, and containing a considerable quantity of milky juice. Numerous slender, twining stalks, proceed from the root, 15 to 20 feet in length. The leaves are arrow-shaped, smooth, of a bright green colour, and placed upon long footstalks. The flowers, which stand in pairs on the pedicles, are funnel-shaped, plaited, and of a pale yellow colour: the calyx is double, consisting of four emarginated leaflets in each row; the capsule is three or four seeded, containing pyramidal seeds.

The root affords the Scammony of the shops. In the begin- 
sing of June, the earth is removed from the upper part of the roots, and an oblique incision is made into each, at the distance of about two inches from whence the stalks spring; a milky juice then flows, which is collected in convenient vessels placed at the most depending part. The quantity of juice obtained from each root is a few drams, which trickles away in about 12 hours; the whole that is collected from the different roots, is transferred to one common receptacle, where, by exposure to the air and sun, it hardens. It should be of a bright green colour, light, friable, with a fracture having a shining irregular appearance; it has an acrid taste, and its smell is somewhat peculiar and rather unpleasant. We meet with it in the shops, of various colours, from a light brown to nearly a black. In its recent and soft state, before it is imported, it is often adulterated with starch, ashes, juices of other plants, \&c. which of course renders the article less active. We can best ascertain its value by mixing it with water, when the pure Scammony will be dissolved or suspended, and the impurities will subside, and may be examined. The best kind comes from Aleppo, which is light and friable; an inferior sort is imporied from Smyrna, which is heavy, compact, of a dark colour, with scarcely any smell, and is found to contain more impurities than the former. It contains rather more than fifty per cent. of resin, the rest being extractive matter and gum. Proof spinit would be its best menstruum: but it is only given in the form of powder. It is rather surprising that some authors should have doubted the purgative quality of this article, which must be obvious to every one who gives it but a few trials; it is indeed one of our most useful purgatives. 'The ancients employed it as an external application, in the form of poultices, in cases of Sciatica, and for the rea moval of indurated tumours, scabies, Stc.: but this practice is 
now wisely laid aside, to make way for more effectual modes of treatment. It is now only employed as an internal remedy, and as it is an article possessing powerful purgative qualities, and one which can be relied on, it may be employed in any cases requiring such remedies, viz. in people of indolent habits, who generally have constipated bowels; and in children, to remove any foeculent accumulations; or when combined with Calomel it relieves that inactivity in the function of the liver, which is often connected with worms, and which insects it very effectually removes; this combination proves equally serviceable in dropsical patients, being a powerful hydragogue. It is necessary to combine it with some article to prevent its griping, as aromatics, or sugar, particularly when it is administered to children. The dose is from gr. iij. to Эj. The preparations into which it enters are Confect. Scammoniæ; Pulv. Scamm. Comp.; Ext. Colocynth. Comp ; Pulv, Sennæ Comp。 




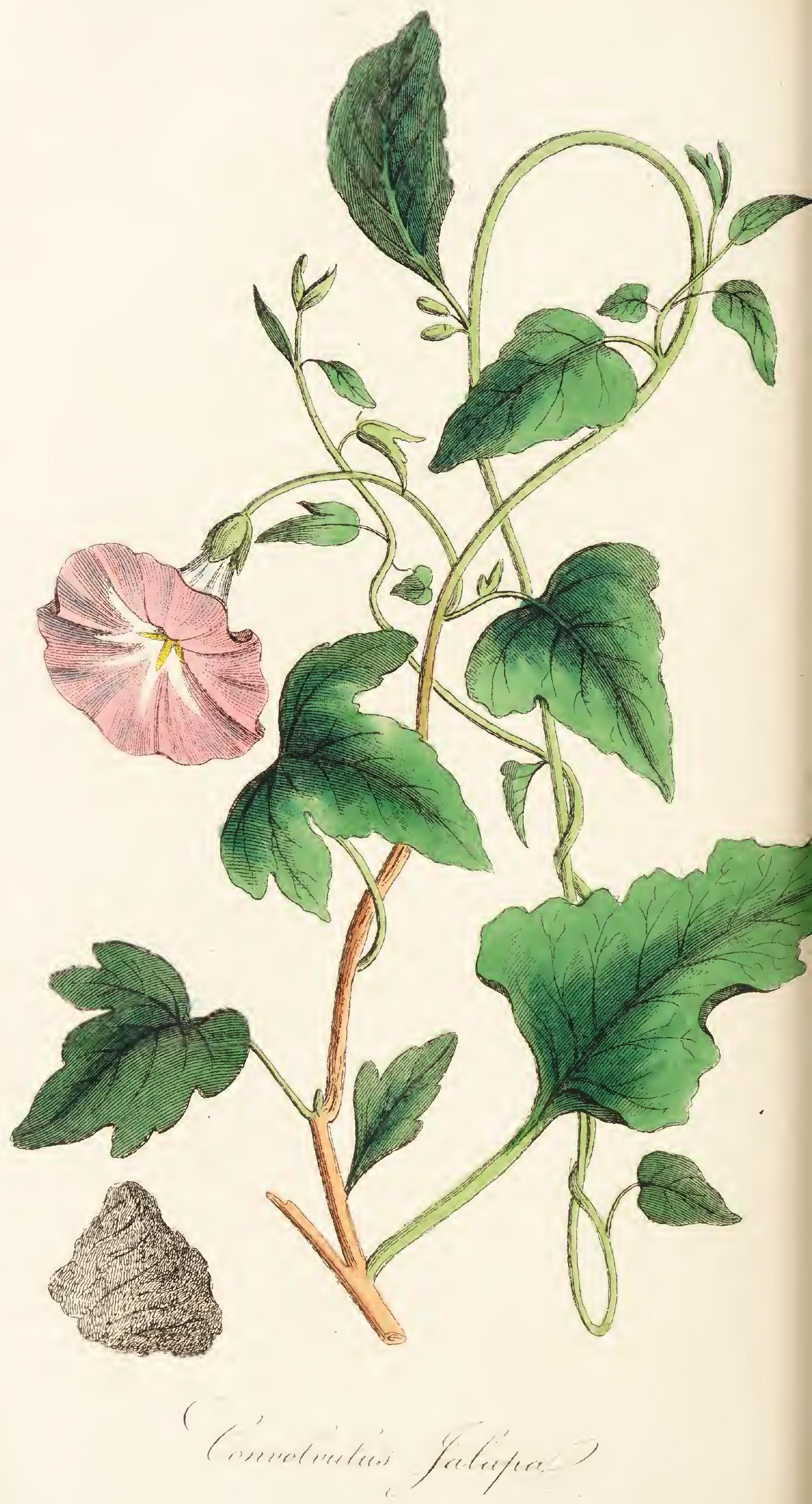




\title{
18. CONVOLVULUS JALAPA.
}

\author{
Jalap, Bind-weed.
}

Radix.

\section{Class V. Pentandria.-Order I. Monogynia.}

Natural Order. Campanaceer.

Generic Character. Corolla bell-shaped, plaited. Stigmas two. Capsule two-celled, each cell containing two seeds.

Specific Character. Stem twining, leaves ovate, somewhat heart-shaped, obtuse, obscurely repand, downy on the back part, peduncles supporting one flower.

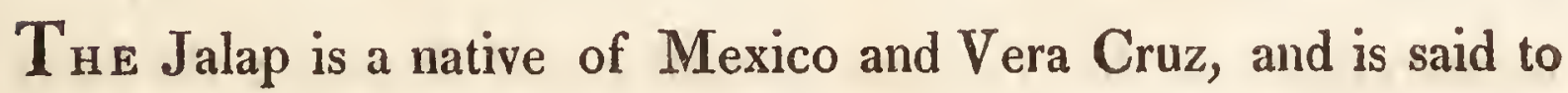
have derived its name from a city of Mexico, called Xalapa. It is found in dry soils, and flowers in August and September.

The root is perennial, ponderous, large, of an irregular oval shape and blackish colour, containing when fresh, a quantity of milky juice. It sends off several twining, striated, twisted stems, ten feet, or more in length. The leaves vary in their shape; they are generally somewhat cordate, but sometimes angular, or oblong and pointed, of a bright green colour, smooth and petiolated. The flowers are produced from short branches, which send off two peduncles, each bearing a large, bell-shaped, entire plaited flower, externally of a reddish colour, of a dark purple within: the calyx consists of five oval, concave leaves, of a pale green colour, 
indented at their points; the anthers are large and yellow, placed on short slender filaments: the style is shorter than the filaments, with a round stigma and oval germen.

The root, which is the only part of the plant medicinally used, is solid and of a compact texture, externally of a blackish colour, internally grey, intermixed with black stripes, of a resinous nature, and in proportion to the number of these striæ is the article preferred; that which is friable and worm-eaten should be rejected. We meet with it in the shops in two states; viz. the entire roots of an irregular shape, or cut into slices; the latter is likely to be adulterated with other roots, as Bryony; but this fraud may generally be detected by the light colour and spongy texture of the latter. It has a sweetish nauseous smell, and a slightly pungent taste. It is composed chiefly of resin, extractive matter, and starch; its purgative qualities reside in the former, for the watery extract may be taken in considerable quantities without producing any such effect. The whole of its virtues may be extracted by a mixture of rectified spirit and water. The medicinal effects of this root are purgative and diuretic; the latter quality is said to reside in the gum, but in some instances its diuretic effect is very doubtful, and is even denied by some. The powder is very useful in all species of dropsies, especially when combined with cream of tartar or calomel. It has been given with decided advantage in tænia, after other remedies have failed. As its purgative effect depends on the quantity of resin it contains, its activity must vary considerably. It may be given with safety both to children and adults; but as it is very likely to produce griping, it is necessary to combine it with some article that will prevent such unpleasant results, as cinnamon, mace, or sugar. It possesses considerable heating properties, and therefore should be avoided by persons of irritable constitutions, and where there 
is any iuflammatory tendency. It seems best adapted to those of indolent habit and cold temperament. Dose from gr. viij. to $9 \mathrm{ij}$. in powder, and it is advisable to administer it in this state, having then the whole virtues of the drug. It is said to be used in considerable quantities by distillers and porter brewers, and probably it is on this account that porter disorders the bowels in debilitated subjects. The officinal preparations are Tinct. Jalapæ; Pulv. Jalapæ Comp.; Extr. Jalapæ. 




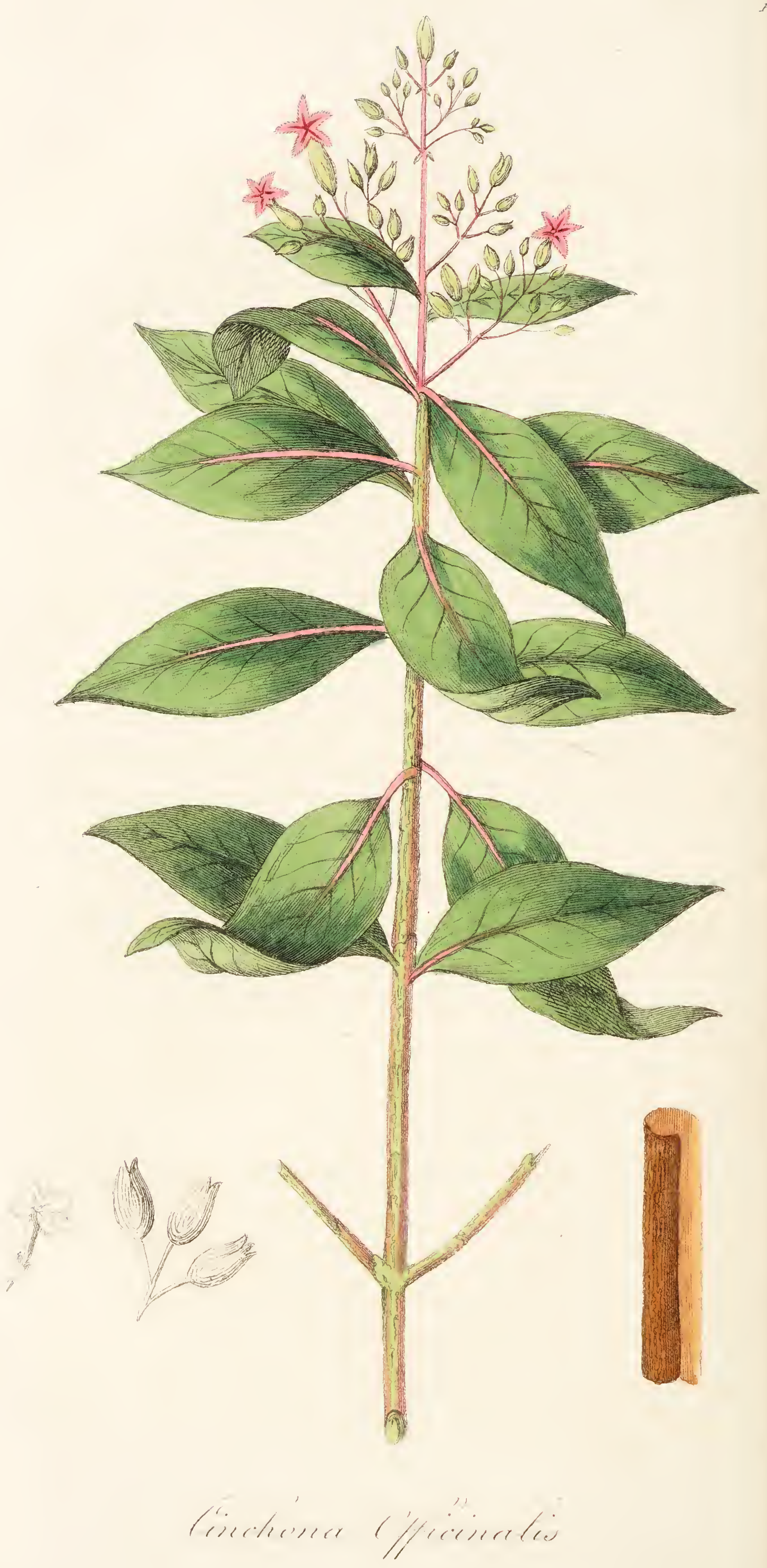




\section{CINCHONA OFFICINALIS-CORTEX PERUVIANUS,}

Officinal Cinchona, Peruvian Bark.

Cortex.

Class V. Pentandria.-Order I. Monoginia.

Natural Order. Contorte.

Generic Character. Corolla funnel-shaped. Capsule inferior, two-celled bipartite, with a parallel partition.

Specific Character. Leaves elliptical, pubescent underneath like the corolla, which has a woolly margin.

THE tree affording this useful bark, grows in the kingdom of Peru, more particularly in the neighbourhood of Loxa, thriving best in clayey and rocky soils, and in such parts of the mountains which are sheltered from the inclemencies of the weather. They do not generally grow in clusters, but are intermixed with the other trees in the woods.

The Cinchona tree is tall, and of different degrees of thickness, varying from a few inches to many feet in circumference. The branches are generally of a dark colour, commonly covered with some moss. The leaves are of an elliptical form, entire, nerved, smooth on their upper surface, and downy beneath, standing in pairs upon footstalks. The flowers are produced in pannicles, and stand upon slender pedicles; the calyx is small, 
bell-shaped, divided at the margin into five segments; the corolla funnel-shaped, consisting of a long cylindrical tube, divided into five oblong segments, red on their upper surface, woolly beneath, and fringed at their margins; the filaments are bristly, furnished with oblong anthers; the style is filiform, rather longer than the stamina, and supporting a round stigma: the germen ovate; the capsule two-parted, the cells of which are separated by a parallel partition; seeds small and numerous.

We are chiefly indebted to Condamine for the knowledge we possess of this plant, who availed himself of the opportunities which he had of examining it in its native soil. He informs us the best Quinquina grows on the mountain of Cajanuma, situated about two leagues and a half to the south of Loxa. The inhabitants of these parts distinguish three kinds, viz. the white, yellow, and red; but they make no distinction between the trees furnishing them; and Condamine was told from very good authority, that there was no difference in the flower, leaf, fruit, or external appearance of the trees affording the yellow and red barks. These two sorts grow together, and are gathered indiscriminately; this author is of opinion, that the pale bark is only a variety of the same species, somewhat altered in its character by its place of growth, which is usually in the lighest part of the mountains. In those situations, where the tree was undisturbed, it had acquired the size of a man's body, but it is now seldom met with larger than the thigh or arm, nor higher than twelve or fifteen feet, as the older trees are killed by their being stripped of the whole of the bark, which invariably destroys them, and even injures the young ones; some of the gatherers will even cut down the trees, that they may the more easily obtain the bark. It is peeled off in the months of September and November in the dry weather, and then spread out in 
the open air to dry, during which time it is frequently turned, and care taken to avoid wet; for if any moisture be allowed to get to it, it is very apt to turn black or rot. The Cinchona was first brought into use about the year 1630 by the Spaniards.

We have here given a figure of the Cinchona Officinalis of Linnæus; for although Spanish botanists have within these few years described three medicinal species of the genus Cinchona, besides several others which have not been introduced into the Pharmacopocias, yet as there are no drawings given of them which we could rely on as being correct, we have, rather than give any inaccurate plates, entirely omitted them; they are called Cordifolia, Oblongifolia, and Lancifolia, by Mutis and others.

\section{Cinchona Cordifolia. Yellow Bark.}

THIS is brought over to this country in chests, containing about $200 \mathrm{lbs}$; it consists of pieces from three to ten inches in length, of an irregular flattened shape, consisting of several layers, the external of which is brown, and the internal of a reddish yellow colour; its fracture is fibrous, and is easily broken down between the fingers; it has an intensely bitter taste, with some degree of astringency, and scarcely any smell. The odour of barks, which has been given as one characteristic mark of their goodness, seems to reside in a species of lichen which attaches itself to the bark; for the odour is found more considerable in proportion to the quantity of this extraneous substance. Its decoction strikes a deeper colour with the sulphate of iron than the other species. The quantity of resin which it contains is in less proportion than will be found in the Oblongifolia. Its virtues are extracted both by water and spirit. The decoction, when hot, is of a reddish colour, and upon cooling becomes yellow; and if good, possesses 
but little smell. The infusion in hot water has properties similar to a weak decoction: the cold infusion possesses considerable bitterness, with but little astringency. The bitterness is so fixed, that it is impossible to deprive the bark entirely of this property by simple infusion; for if repeated quantities of water be poured upon the powder, the bitterness will still remain, and cannot be entirely extracted without the assistance of heat. Proof spirit is its best menstruum; for the rectified only extracts the resinous parts, whilst the whole active ingredients of the bark are extracted by the former. To chemical analysis it affords mucilage, extractive matter, resin, and some alkaline and earthy salts.

The efficacy of the Cinchona as a remedy was but little known till it was administered to the Countess of Cinchon, whom it cured of an obstinate intermittent, and from that period it has been gradually acquiring its present superiority over the other articles of the Materia Medica, in the cure of this, and many other disorders.

This article has been used with such success in Intermittents, that it is now almost the only remedy employed in that disease, for there is scarcely a case, where the constitution will allow of its being administered, that does not yield to its influence. It is necessary to evacuate the bowels and stomach previous to administering it; and if there be any visceral congestion, or inflammation, we must precede its exhibition by local or general bloodletting; after this, we may commence with it immediately; as there is no occasion for any delay, although the necessity of it is strongly urged by some authors. The time for administering it is between the paroxysms, or we may begin towards the termination of the sweating stage. The best form of giving it in these fevers, is the powder, about a drachm for the dose or more, repeating it as often as the patient can take it without inconvenience. 
It is useful towards the termination of common Continued Fevers, when the heat of skin and febrile symptoms have disappeared: it must, however, be given in small quantities and with caution, or it will be likely to occasion a relapse: but if it should produce purging, it must either be entirely laid aside, or combined with some astringent, as Tinct. Opii vel Conf. Aromat.

This article seems especially required in those cases which show a disposition to putrescency; for if we may draw conclusions from experiments made out of the body, it certainly appears to possess antiseptic properties; hence its use in Confluent Smallpox, Scarlatina Maligna, and such diseases as are of a similar character. In some cases of Erysipelas, the Cinchona is one of our most useful remedies, especially when there is incipient gangrene, or other marks of debility in the patient.

In Chronic Rheumatism it may be advantageously given, particularly when the disease assumes a periodical form, or when the patient is worn out by constant sufferings.' It has also been strongly recommended in the acute form of the disease, but success does not usually follow its exhibition, unless it be pre'ceded by purgatives and diaphoretics.

In chronic diseases connected with debility, as Leucorrhæa, Gleet, \&c. and in Chorea, Hysteria, Tic Doloreux, and Scurvy, it is given with advantage. It used to be formerly employed as an external application to some kinds of sores, viz. such as were attended with very offensive discharges, and especially where they were disposed to gangrene, and is at the present day employed in such cases by some practitioners.

The forms of exhibiting the Bark are various, the most effectual, when it can be retained in the stomach, is the powder or decoction; but where one preparation will not agree we shall 
seldom fail of finding another that will suit our patient; in weakly and irritable stomachs, the watery extract is the best preparation, which may be given either in pills or mixture. The dose of the powder is from grs. v. to $3 \mathrm{ij}$.

Officinal Preparations :-Tinct. Cinchon.; Cinchon. Comp.; Extract. Cinchonæ; Cinchen. Resin.; Decoct. et Infus. Cinchon.

\section{The Cinchona Oblongifolia, or Red Bark.}

THIs is generally in larger pieces than either the yellow or pale, and is thicker and firmer; but like the former, occasionally assumes the quilled form; it breaks with a short smooth fracture, having a shining appearance; it appears as if composed of three distinct layers, the internal of which is the darkest; is of a deeper colour, and contains more resin than the other species; its taste is more harsh and unpleasant, and will not generally be found to agree with patients so well as the yellow, and is therefore less used; but its medicinal properties are similar.

\section{The Lancifolia, Pale or 2uilled Bark.}

THIs species is generally of a quilled form, hence its name; covered with a greyish epidermis, and internally of a pale cinnamon colour; its fracture is close and shining. The astringency and bitterness of this species are less than are observed in the yellow or red, hence it may perhaps agree with some weak stomachs better even than the yellow; but neither this nor the red Bark are equal to the yellow in point of medicinal qualities; but it is observed by people living in the neighbourhood where these trees grow, that they are all of equal power when fresh, and much more active, than when dried and kept any length of time.

The Cinchona is a drug very subject to adulteration, with barks 
of a totally different nature, and only resembling the true article in their external character; and the druggist will sometimes extract the virtues of the bark by boiling, and then expose it for sale, mixed with a few good pieces. We must, therefore, look well to its external character and chemical nature, before we buy it. A decoction of good Bark should be of a reddish brown colour when hot, and upon cooling become pale. The powder is the most frequently adulterated and if the genuine drug be wished for, we would recommend that this article be never bought in this state, as we are subject to the greatest impositions; for druggists often sell the powder which has been previously used for making decoctions, and mix it with the sawdust of wood similar in colour to the Cinchona, and it is with great difficulty we can ascertain the nature of the impurities. 




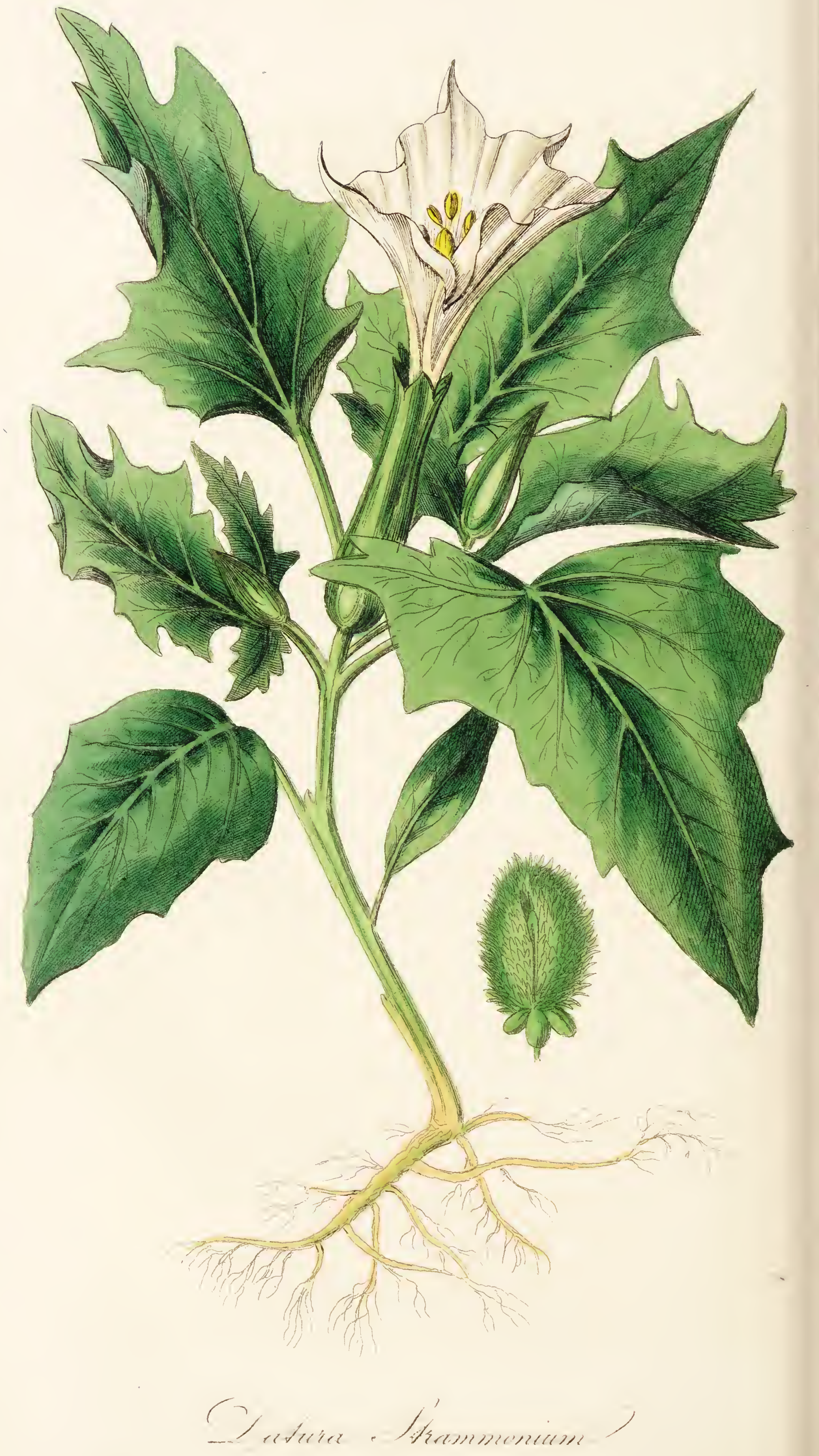




\section{DATURA STRAMMONIUM.}

\section{Thorn Apple, James-town Weed.}

Herba.

\section{Class V. Pentandria.-Order I. Monogynia.}

\section{Natural Order. LuRIDE.}

Generic Character. Corolla funnel-shaped, plaited. Calyx tubular, angular, deciduous. Capsule fourvalved.

Specific Character. Pericarps spinous, erect, oval; leaves ovate, glabrous.

$\mathrm{T}_{\mathrm{HE}}$ Thorn Apple is an annual plant, and a native of America, but is now found growing in many places in the vicinity of London, and elsewhere, upon dunghills, and amongst the rubbish thrown from gardens, which generally contains some of its seeds; for it is frequently cultivated, and when it once takes possession of a soil, it is with difficulty extirpated: it flowers in July.

The stalk is thick, round, smooth, spreading, dichotomous above, and rising from two to three feet in height. The leaves are of a dark green colour, large, irregularly ovate, pointed at the extremity, angular, deeply indented and supported by round footstalks. The flowers are large, white, axillary, solitary, placed on short, erect peduncles : the calyx is one leafed, tubular, pentangular, and four-toothed: the corolla is funnel-shaped, plaited, furnished with a long cylindrical tube, longer than the calyx. The filaments are slender, adhering to the tube, and support oblong 
flat anthers; the style is filiform, terminating in a short clubshaped stigma; the germen is oblong, and placed above the insertion of the corolla: the fruit is large, fleshy, ovate, beset with sharp spines, four-celled below, and two-celled above, containing numerous kidney-shaped seeds.

The whole of this plant possesses sedative properties, and has a disagreeable narcotic smell, with a nauseous bitter taste. It is said to have produced vertigo and stupor, when applied to the nostrils for any length of time. The seeds are the most active part of the plant, but the effects produced by other parts are similar, and only differ in being less violent. When taken internally in over doses, they act as a poison, producing symptoms which indicate derangement of the nervous system, viz. vertigo, intoxication, delirium, stupor, a degree of frenzy or madness, sometimes a total loss of memory, excessive thirst, convulsions, paralysis, quick small pulse, cold sweats, and death. It is said, by Dr. Barton, to have occasioned tetanus in a soldier, who ate it in mistake for the Chenopodium Album. Spraat mentions that it was a custom among the Chinese to infuse the seeds in their beer, which not only produces intoxication, but a degree of fury; and it is still used in Russia for a similar purpose: and from these intoxicating qualities they have been applied to most disgraceful and abominable purposes; an instance of which is mentioned in Murray's App. Medic. A mulierculis infidis Turcis, gynæceis inclusis, ad consopiendos et dementandos maritos, quo aliorum, magis desideratorum, amplexibus satientur, usurpari; et Hamburgi a vetula sic honestam freminam quo, se inscia mœchum admitteret, intoxicatam fuisse, narratur. When persons are labouring under the ill effects of this substance, the first object is to unload the stomach of its poisonous contents, which must be effected by some active emetic, as the sulphate of zinc; at the same time giving mucilaginous drinks, or milk. After 
the operation of the emetic, some vegetable acid should be administered freely; and if this practice be followed soon after the poison is taken, the patient will generally be recovered. Where from neglect or accident the patient has escaped observation, and has fallen a victim to the effects of this poison, the morbid appearances have not commonly been sufficient to account for death, which is an additional proof that it acts on the nervous system. Haller mentions one case where he found effusions of blood in the cortical substance of the brain.

This medicine was first introduced into practice by Baron Stoerck, who speaks favorably of its effects in mania, epilepsy, \&c.; and other foreign physicians notice it as a medicine of considerable power in those diseases; but experiments have been made by Greeding and others, which seem to contradict the statement of these authors. The forms in which the plant has been given are various, as the Powder, Extract, and Infusion of the leaves, but of all these, none is so powerful as the extract obtained from the seeds.

The Extr. Strammon. Sem. which is almost the only preparation used at the present day, proves very beneficial in those forms of chronic rheumatism which are attended with distressing pains, and indeed may be employed in the acute stage of the disease, combined with diaphoretics, and where opium is sometimes inadmissible. It has cured Tic Doloreux after other medicines have completely failed; it is not, however, recommended as a specific, for it sometimes proves ineffectual: but as this is a disease which frequently resists the effects of all medicines, the Strammonium may be advantageously added to the list, as it will often be found to relieve the paroxysms, and sometimes to effect a cure. In spasmodic and convulsive diseases it is an article of considerable power. But it is unnecessary to give a detail of all 
the diseases in which it would be useful : it will be sufficient to state, that in those cases where sedatives are required, and where from peculiarity in the constitution of the patient, or some other accidental cause, Opium proves hurtful, the Strammonium may be employed. It possesses advantages over Opium in some respects, such as not constipating the bowels, nor producing febrile symptoms; hence it may be employed in inflammatory affections, and some fevers. We should commence with small doses, as gr. $\frac{1}{4}$, and gradually increase it to gr. iij.t. d. The dose of the common Extract. Strammon. is from gr. jss. ad gr. x. The powder may be given in still larger doses.

Cataplasms of the bruised fresh leaves are used to dissipate indurated milk in the breasts of nurses, and allay the pain of irritable sores, and an Infusion, is an useful application in hæmorrhoids.

The smoke of Strammonium has of late been employed in spasmodic asthma; the mode of using is similar to that of tobacco; it produces an increased secretion of saliva, which is to be swallowed; it occasions a sensation of heat in the chest, and increased expectoration, and commonly a drowsiness follows the smoking. It is, however, more a palliative remedy, than one which can be depended upon as a radical cure. Officinal Pre parations, Extract. Strammon. 



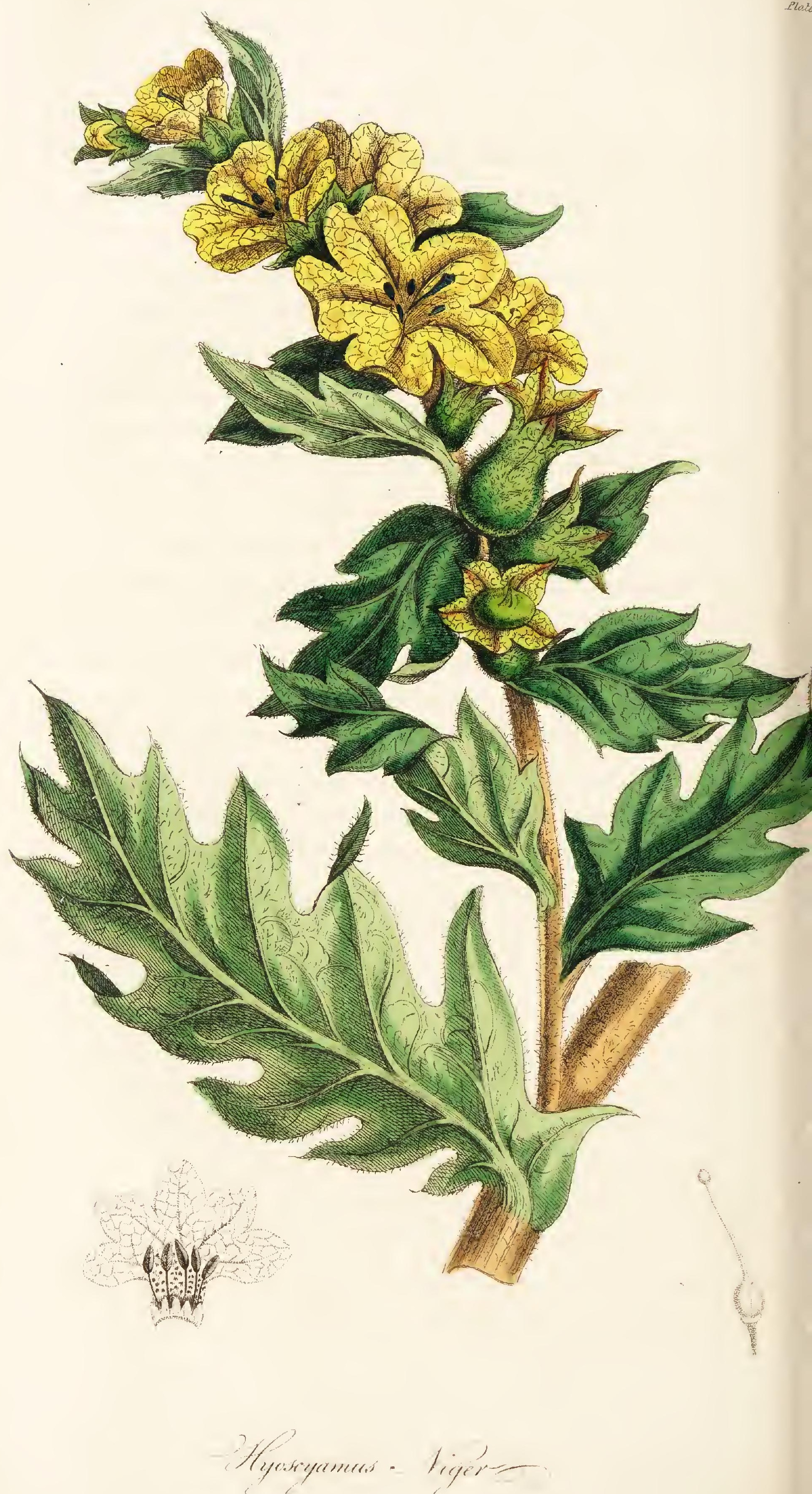




\section{HYOSCYAMUS NIGER,}

\section{Common Henbane.}

Herba et Semina.

\section{Class V. Pentandria.-Order I. Monogynia.}

\section{Natural Order. LuRIDE.}

Generic Character. Corolla funnel-shaped, obtuse. Stamina inclined. Capsule covered with a lid, two celled.

Specific Character. Leaves embracing the stem, sinuate; flowers sessile.

This annual plant is a native of England, and grows by the road-sides and in waste uncultivated places, thriving best in rich soils. It flowers in June and July.

The root is long, compact, tapering, and fibrous. The stalk is about two feet in height, erect, cylindrical, woody and branched, beset with white hairs. The leaves are large, alternate, embracing the stem, downy, deeply sinuated, undulated, and of a sea-green colour. The flowers are simple, placed on terminal leafy. spikes; they consist of a short tube with an expanded limb, which is divided into five obtuse segments of a straw colour, and reticulated with purple veins: the calyx is tubular, permanent $t_{2}$, and divided into five segments; the filaments are tapering and downy at the base, supporting purple anthers, and are inserted into the tube of the corolla: the style is longer than the corolla, and ends in a blunt stigma: the capsule is globular, invested with the body of the calyx, and contains numerous, irregular brown seeds. 
The general appearance of this plant would almost lead us to suspect its deadly nature, and this is confirmed by its strong, disagreeable, and narcotic odour; but it has scarcely any taste, and possesses but a slight degree of acrimony. Its best menstruum is proof spirit, which extracts the whole virtues of the plant.

The Henbane is a porrerful narcotic poison to the human subject, when taken in over doses; whilst some animals, as horses, cows, and goats, will feed upon it with impunity. It is said by Renard, that horse-dealers mix the seeds with oats, to fatten their horses. It proves destructive to dogs, birds, and fishes. Every part of the plant possesses poisonous qualities, and will destroy life if taken in sufficient quantity. The symptoms which it occasions are varying in proportion to the quantity taken; thus it will sometimes only produce temporary intoxication, with partial paralysis of the tongue: but generally, when any considerable quantity is swallowed, patients are affected with violent convulsions and distortions of the mouth and limbs, the risus sardonicus, a dimness or total loss of sight, considerable thirst, difficulty of breathing, with a quick irregular pulse. The symptoms, however, put on rather different forms according to the constitution or health of the patient; the above symptoms being sometimes accompanied with furious delirium, whilst at other times the patient remains in a state of stupor, very much resembling apoplexy. In cases of this description, our first object is to remove the offending matter from the stomach, and this should be effected as soon as possible; for it is observed, that when the narcotic poisons remain any length of time in the stomach, they render it so torpid that it is with the greatest difficulty we excite vomiting; an emetic should be speedily administered, as the Zinci Sulphas vel Cupri Sulphas, and at the same time we must give diluents freely. In plethoric 
habits, and particularly where the disease partakes of the nature of apoplexy, venesection will be necessary in addition to the emetic. When we suppose the contents of the stomach have been evacuated, vegetable acids should be given, as lemonade, which may be taken ad libitum. Orfila mentions a case of a lady, who had a decoction exhibited in the form of enema, for an ulcerated womb; and the consequence was, a stiffness of the tongue, temporary paralysis of one side, difficulty of breathing, and a state of stupor. Booerhave had tremblings and signs of intoxication brought on, from making a plaster of Henbane.

This anodyne, like the Strammonium, is often used as a substitute for Opium; but it is much inferior to it, and is indeed a remedy not always to be depended on, for some people will take it rather freely without experiencing any relief. The seeds were once much used in Hæmoptoæ, and are particularly recommended by Boyle in all Hæmorrhages: it cannot be denied that they may be useful in some diseases of this class, but it is a remedy, like opium, only applicable to such cases as depend on vascular irritability; for if given in active Hæmorrhages, as occurring in the ro. bust and plethoric patient, it would probably increase the disease. The seeds are now seldom used, but the preparation generally em. ployed is an extract obtained from the leaves, which contains the whole virtues of the plant. The use of this medicine was very much laid aside till the time of Baron Stoerck, who was induced, from some experiments which he made on dogs, to exhibit it to the human subject in diseases of a convulsive and spasmodic nature, and in Palpitatio Cordis, Mania, Melancholia, and many other diseases; and from the trials which he gave it, was led to recommend it in those diseases. Collin also speaks of its utility in nervous and spasmodic disorders; but the result of Greeding's experiments appears quite different: and Dr. Cullen says, "that 
he has seen no better effects result from the use of this article than from Opium, though it often proves an agreeable anodyne and soporiferous medicine." In Phthisis Pulmonalis it may be advantageously given to allay the cough and general irritability of the system. In Hæmorhoids it is more useful than Opium, as it tends to keep the bowels in a loose state, and in Colica Pictonum, combined with purgatives, it proves of great use; also, in Pyrosis, or Water-brash; and Grall-stones, where they occasion spasm of the ducts, from the irritation which they keep up. The same general observations will apply here as to Strammonium, with respect to its being occasionally a good substitute for Opium. The dose of the Extract is from gr. ij. ad gr. xv. plusve; we may increase the dose to a very considerable extent, (if it be done gradually,) without distressing the patient.

It is an useful sedative application in the form of Cataplasm or Ointment, to Scirrhous Breasts, Hæmorrhoids, and other painful affections. The fumes arising from the leaves of the Hyoscyamus, whilst drying, have been recommended for the toothache, but it is a very uncertain and rather dangerous remedy. The Officinal Preparations are Extract. et Tinct. Hyoscyami. 



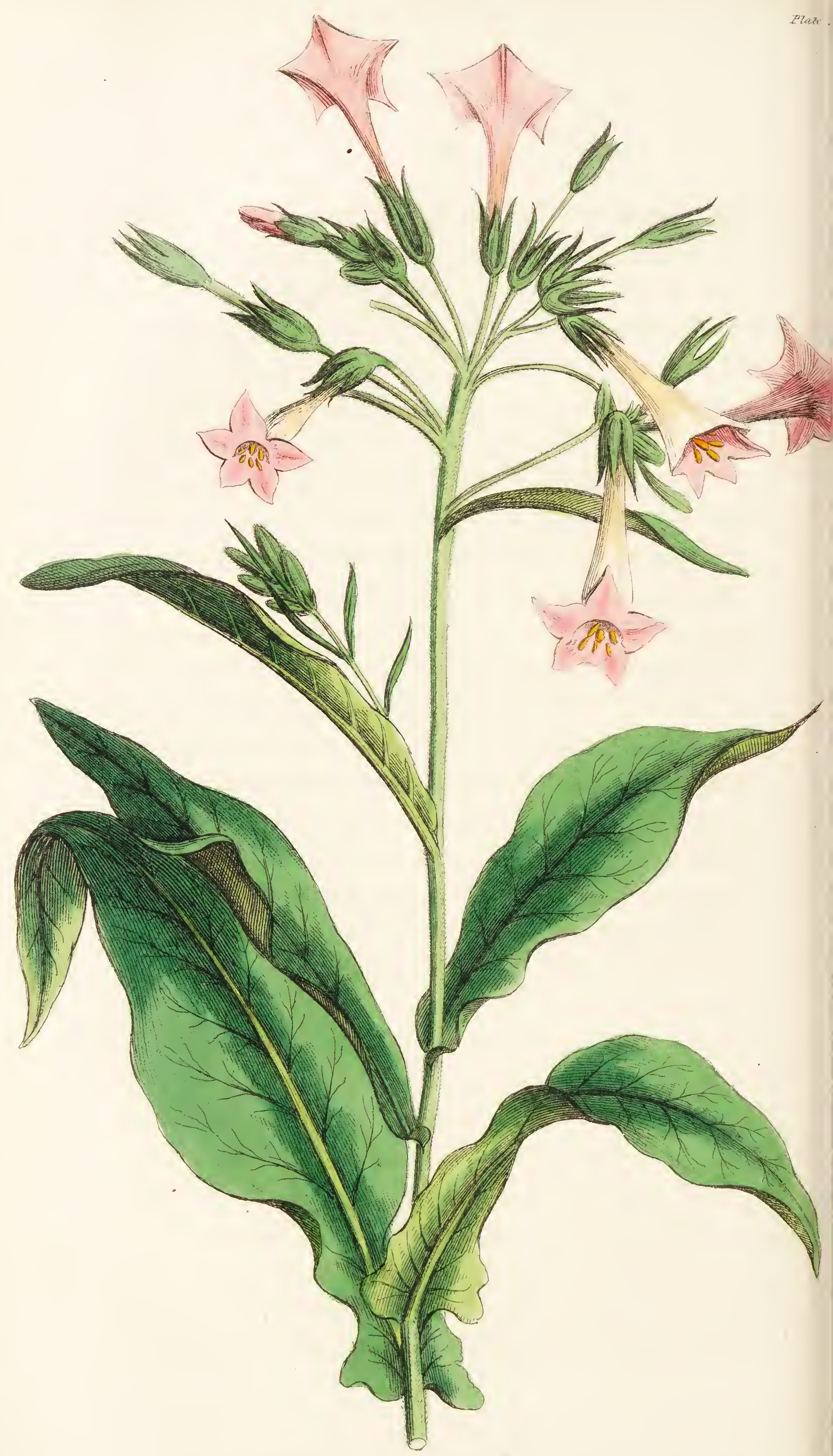

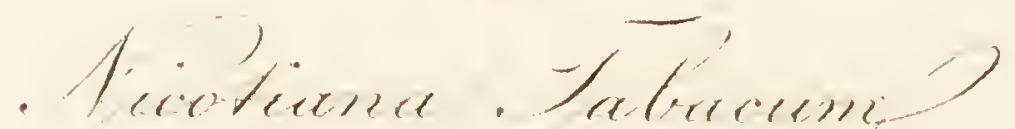




\section{NICOTIANA TABACUM.}

Virginian Tobacco.

Folia.

\section{Class V. Pentandria.-Order I. Monogynia.}

\section{Natural Order. LURIDE.}

Generic Character. Corolla funnel-shaped, with a plaited border. Stamina, inclined. Capsule, twovalved, two-celled.

Specific Character. Leaves ovate lanceolate, sessile, decurrent; flowers acute.

THE Tobacco is an annual plant, and native of South America : it is cultivated also in other parts of America, and in its neighbouring islands; also in Asia, and many parts of Europe.

The root is large and fibrous, sending up an erect branching stalk, four or five feet in lheight, round and hairy. The leaves are numerous, large, alternate, oblong pointed, entire, sessile, slightly decurrent, of a pale green colour, with a strong midrib; the bracteæ are strong, linear, and pointed. The flowers are in large terminal pannicles; the calyx is hairy, and divided into five acute segments; corolla monopetalous, funnel-shaped, of a purplish rose colour, with a tube twice the length of the calyx, opening like a cup, and divided into five short pointed segments; the filaments are the length of the tube of the corolla, and support oblong anthers; the germen is oval, and supports a long slender style, which terminates in a round cleft stigma; the capsule is divided into two cells, which contain many small roundish seeds. 
Tobacco, which is a plant of considerable use, is of different degrees of strength, according to the care taken in its cultivation. The plants are not allowed to attain their full growth, but when they have sent off about eight or nine leaves, the tops are nipped off, that the leaves may become larger : the time for cutting these plants is when the leaves are brittle; they are afterwards exposed to the air, that they may be rendered perfectly dry; then the leaves are stripped from the stalks, bound up in bundles; and packed in casks for exportation.

The leaves have a nauseous acrid taste, and when chewed, occasion a copious flow of saliva; their smell is narcotic, peculiar, and unpleasant. Its active principles are extracted both by spirit and water: by distillation it affords a very pungent essential oil, which is a very active preparation, and if applied to the tongue of a dog in a very small quantity, will speedily destroy life; the modus operandi of it is very obscure, but it appears to act in some indirect way upon the nervous system. The chief activity of Tobacco most probably depends on this essential oil, for by long boiling the decoction it is rendered almost inert.

The medicinal properties of Tobacco are narcotic, emetic, purgative, and errhine. When the leaves are swallowed, they occasion nausea, violent vomiting, vertigo, and relaxation of the bowels; similar effects have followed the snuffing of small quantities up the nose. Dr. Cullen mentions a case of a lady who had been in the habit of taking snuff for more than 20 years, but was at length obliged to omit it in the fore part of the day, in consequence of its always taking away her appetite; but this is a circumstance of rare occurrence, for where people have habituated themselves to the practice, it seldom produces such unpleasant symptoms. But where snuff is applied to the nose of a person who has not accustomed himself to the use of it, the first effect 
of it is to produce sneezing, and sometimes vertigo; and if it be repeated, it is not an uncommon thing for nausea, and loss of appetite to ensue. 'Dr. Cullen has observed it to affect the nervous system in a similar way to opium, wine, and other narcotics, by producing loss of memory and fatuity, which they will do if continued in for a length of time. In consequence of the increased secretion of mucus which snuffing occasions, it will sometimes relieve obstimate head-aches, and some affections of the eyes. It is very apt, however, to escape into the fauces, and by that means finds its way into the stomach, and occasions dyspeptic symptoms. Smoking is a custom which has prevailed for several centuries, and although a practice which may be generally indulged in with impunity, it is attended with some disadvantages; for in consequence of the smoke being applied to the salivary glands, it stimulates them, and occasions an increased secretion of that fluid, which is so essential to the function of digestion, and therefore it often lays the foundation of Dyspepsia. In people unaccustomed to it, similar effects are produced as are observed from taking snuff; such as vertigo, headache, anxiety, and sometimes vomiting and purging. Smoking has, however, proved useful in some cases of Spasmodic Asthma, and in certain cases of Dyspnoea, accompanied with difficult expectoration; the direct application of the smoke to a decayed tooth, and to the ear, will relieve the tooth-ache and ear-ache very effectually. It is men. tioned by some authors of note as an antidote to contagion, but such an opinion would be ridiculed, if advanced at the present day; the only way in which it can act, is by torpifying the nervous system, and thus rendering the body less susceptible to the impressions of contagion.

Tobacco is a medicine which produces such unpleasant symptoms when taken into the stomach, that it is now almost entirely 
discarded from practice as an internal remedy; for even when it is given, the practitioner is often disappointed in the result. The Infusion is employed in the form of enema, with advantage, in some cases of obstinate Constipation; but, generally speaking, it is a dangerous remedy. As to the propriety and safety of employing it in Strangulated Hernia, there is a considerable difference of opinion; by some it is considered as most unsafe, whilst others speak of it as highly beneficial, and it is no easy matter to decide as to the most advisable mode of practice; we may however safely say neither of these opinions should be strictly adhered to, for in the first instance, this disease is sometimes connected with such prostration of strength, that a Tobacco Enema would in all probability destroy the patient in a very short time; but on the contrary, when a person is in a vigorous state of health, pulse strong, and whose strength requires to be diminished, the Tobacco might be advantageously employed. We should use it with the greatest caution in every case, for there are several instances on record where it has proved destructive in this and other diseases: an infusion of half a drachm is quite sufficient for one clyster. As an external application it may be dispensed with, for when applied in that way, it is apt to occasion unpleasant symptoms. Thus Murray mentions a case where it was applied to cure the Itch, and it produced vomiting of blood, and couvulsions; and there are other cases upon record of the injurious effects of it as an external application. The Officinad Preparations are Infusum et Vinum Tąbaci. 


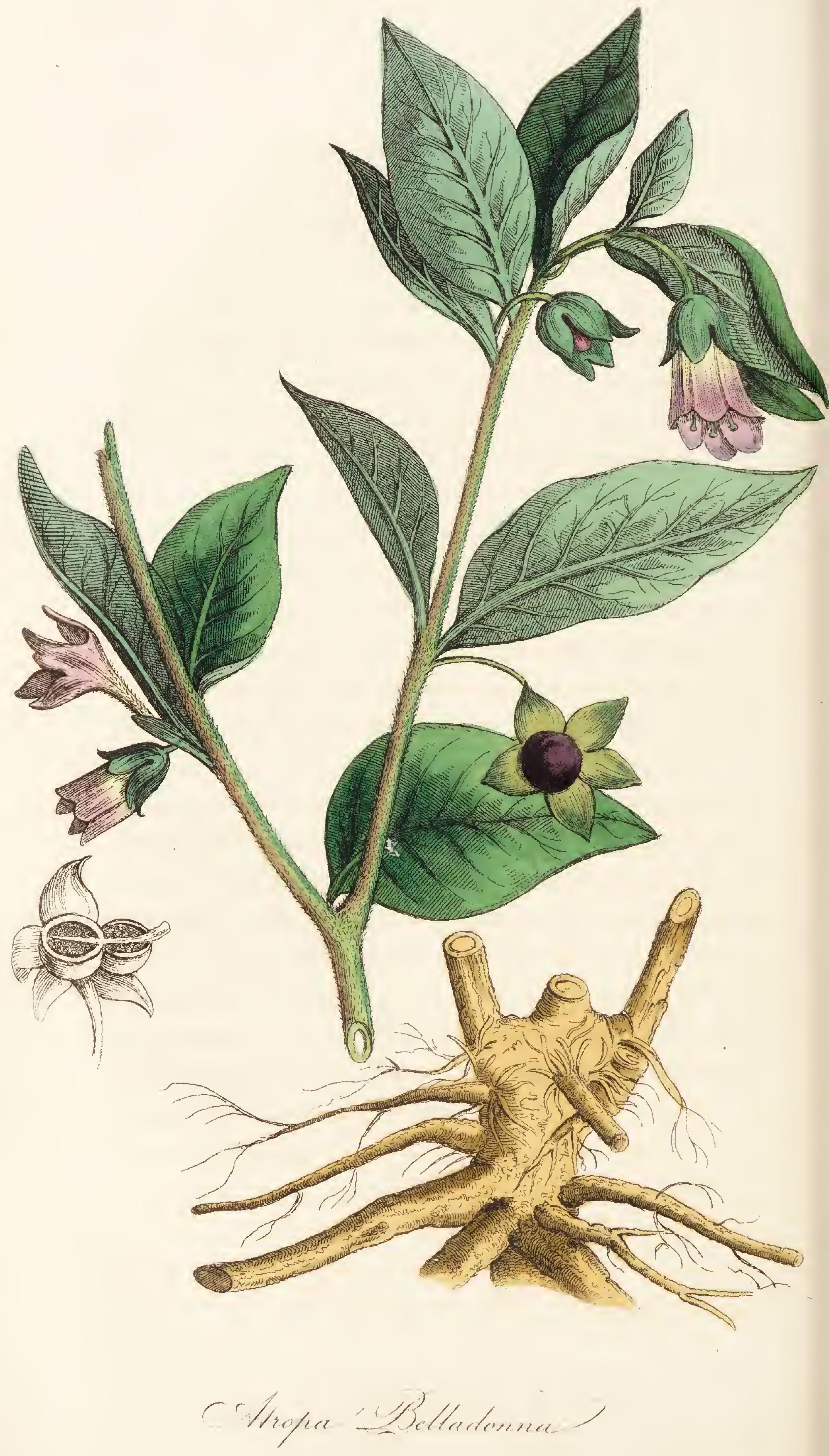


23. ATROPA BELLADONNA.

Deadly Nightshade.

Folia.

\section{Class V. Pentandria.-Order I. Monogynia.}

Natural Order. LURIDE.

Generic Character. Corolla bell-shaped, Stamina distant, Berry globular, two celled.

Specific Character. Stalk herbaceous, leaves oval and entire.

This perennial plant is common in hot and temperate climates, especially in stony and shady situations. It grows in many parts of England, but is seldom to be met with in the neighbourhood of London. . It flowers towards the latter end of June, its fruit ripens in September, and is frequently cultivated in our gardens.

The root of the Belladonna is thick, long, and branched; from which proceed several herbaceous, cylindrical, branched stalks, from three to five feet in height, of a purplish colour. The leaves are in pairs, oval, entire, soft, and pointed, of different sizes. The flowers are pendant, supported on solitary and axillary peduncles: the calys is monophyllous, deeply divided into five segments:' corolla monopetalous, bell-shaped, partially divided into five lobes; it is of a dusky purplish colour, and contains five stamens, whose filaments are inserted into the base of the corolla, supporting roundish anthers; a spheroidal germen supporting a style, with a divided stigma. The fruit is a roundish berry, contained within the calyx, of a blackish colour and pulpy, having several kidney-shaped seeds. 
The whole of this plant possesses poisonous qualities, on which account it is necessary to be well acquainted with it. The berries have a sweetish taste, rather sickly, leaving a sense of acrimony on the tongue; their appearance, is very alluring, and children are thereby induced to gather and eat them. After they have been swallowed a short time, the child is seized with symptoms of intoxication, delirium, excessive thirst, nausea, retchings, grinding of the teeth, and convulsions; the pupil becomes dilated and immoveable, an almost insensibility of the eye to external objects; the face becomes red and swelled; spasmodic contractions of the jaw : to these symptoms succeed subsultus tendinum, paleness of the face, coldness of the extremities, with a small, quick, and hard pulse; and the child will sometimes fall a victim. The symptoms are less urgent when taken in small quantities, and sometimes the only one present is temporary intoxication. In cases of this nature, the first object is to excite vomiting by Sulph. Zinci, or Pulv. Ipecac.; the stomach is generally very torpid, requiring powerful emetics: when the stomach is cleared, give saline purgatives, and after this, vegetable acids. Where death has been produced by these berries, the stomach, intestines, and liver have been found inflamed; the stomach is occasionally eroded. No mention is made of the appearances of the brain; but when the nature of the existing symptoms is considered, it is probable that some morbid appearance would be found there. Although this plant is so pernicious to man, it is eaten with impunity by some other animals.

The only parts used medicinally are the leaves, which possess properties similar to the berries, but are more active, and hence are equally injurious when injudiciously taken. Its medical effects are chiefly narcotic; but it likewise possesses some diaphoretic and diuretic properties. Cullen speaks of its being 
very useful in cancer, and even asserts that this destructive disease has been cured by it : subsequent trials of it, however, have not been attended with equal success. It, no doubt, would allay the irritability which is so very distressing in cancerous sores, and thus give a temporary alleviation to the patient's sufferings; but, unfortunately, no reliance can be placed on it as a remedy capable of producing a radical cure. Applied to the eyelids in the form of extract, it produces great dilatation of the pupil, "and on this account it has been used to render the operation for cataract less difficult."

It has been used with occasional advantage in several diseases; but as its effects appear rather undecisive, it will be unnecessary to enumerate them. It is requisite when administering this poisonous remedy, to be very cautious, always commencing with small doses, as gr. $\frac{1}{2}$, and gradually increasing it to gr. ij. vel gr. iij. But it is necessary here, as well as in using other active herbs, to recommence with the small dose, when employing a fresh bundle of the plant, as it is almost certain of varying in its effects.-Preparation, Extract. Belladonnæ. 



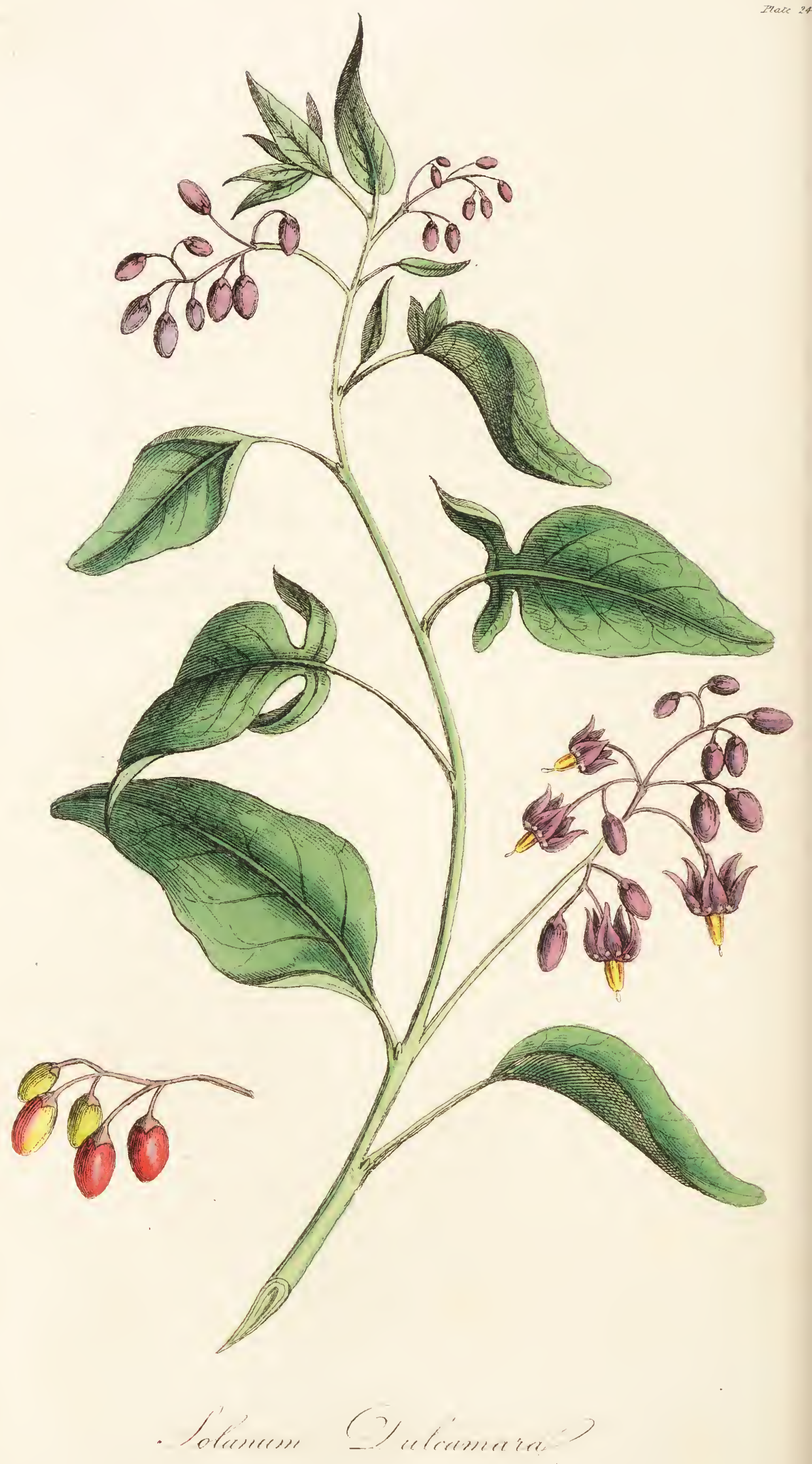




\section{SOLANUM DULCAMARA.}

Woody Nightshade, or Bitter Sweet.

Caules.

\section{Class V. Pentandria.-Order I. Monogynia.}

\section{Natural Order. LuRIDE.}

Generic Character. Corolla, wheel-shaped. Anthers, slightly coalescing, opening by two pores at the apex. Berry, two-seeded.

Specific Character. Stalk unarmed, branched, climbing, upper leaves halberd-shaped, racemes cymous.

$\mathrm{T}_{\mathrm{HE}}$ Dulcamara, which is an indigenous shrub, grows plentifully in those hedges which are in moist situations; it attaches itself to the bushes in its neighbourhood, flowering in June and July.

The root is ligneous and fibrous, from which springs a roundish, branched, brittle stem, which commonly climbs to the height of six or seven feet. The leaves are alternate, oval, entire, somewhat pubescent, of a dull green colour, the superior being halberd-shaped, whilst the inferior ones are undivided. The flowers are disposed in drooping clusters, opposite the leaves; the calyx is divided into five obtuse segments, of a purplish colour : the corolla is monopetalous and equally divided into five pointed, reflected segments of a bright violet colour, with two green dots at the base of each; the filaments are short, and inserted into the tube of the corolla; the anthers are large and 
erect, of a lemon yellow colour; the style is rather longer than the stamina, and supports an obtuse stigma; the berries are oval, scarlet, bilocular, and contain several yellowish seeds; they ripen in September.

The chief virtues of this plant appear to reside in the twigs, which, upon being chewed, first give a sensation of bitterness, but this is soon followed by a degree of sweetness, hence the name of Bitter-sweet; when fresh they have a nauseous heavy smell, which is entirely dissipated by drying, whilst their bitterness is increased. The roots possess similar properties. The stalks, which are the only parts employed, should be gathered early in spring, or towards the latter end of autumn, when they are destitute of leaves, for they are found to be most powerful at this period. Water extracts both the saccharine and bitter principle of the Dulcamara, whilst Spirit scarcely extracts any thing but the latter, for the spiritous extract is found to possess but little sweetness.

The Woody Nightshade appears to have properties similar to the other species of the Solanum in a slight degree; but we are not inclined to look upon it as poisonous, though that is the opinion of some authors. Murray says that if it be given freely before the stomach becomes accustomed to it, vomiting and purging is produced, and sometimes tremblings of the limbs and convulsions. We find, however, it may generally be taken without producing any such symptoms; and M. Duval has made some experiments with the berries, and from the result of them we may conclude, that they are not of a poisonous nature, for he has given to dogs from 50 to 100 for a dose, without observing any deleterious consequences. It is said to have the power of increasing all the secretions; but its chief operations are diuretic and sedative. Linnæus recommends it in Chronic Rheumatism; 
but Dr. Cullen has often seen it fail in this disease, although it has been useful in some cases. There are many other diseases in which it is recommended by different authors, Phthisis Pulmonalis, Asthma, Peripneumonia, Fluor Albus, Amenorrhœea, Vermes, \&c. : but at the present day, it is seldom employed in these diseases, its use being chiefly confined to cutaneous diseases, for which it is employed both internally and externally in decoction; and it may be also applied to scrophulous sores. The best form of administering this article is in decoction three or four times a day, it may also be given in powder and pills, and sometimes a watery extract is made from it; but they are all inferior to the decoction. 'The dose of the Powder' is from gr.x. to 3 j. In Decoction 3 ss. to 3 iij. Officinal Preparation, Decoct. Dulcamaræ.

The Solanum Nigrum was at one time considered as an article of some power in scrophula, cutaneous affections, \&c.; and from the report given of it by some authors, it would appear that it possessed considerable activity; but at the present day it is entirely laid aside; on this account, we trust our readers will be satisfied with the mere mention of it. 



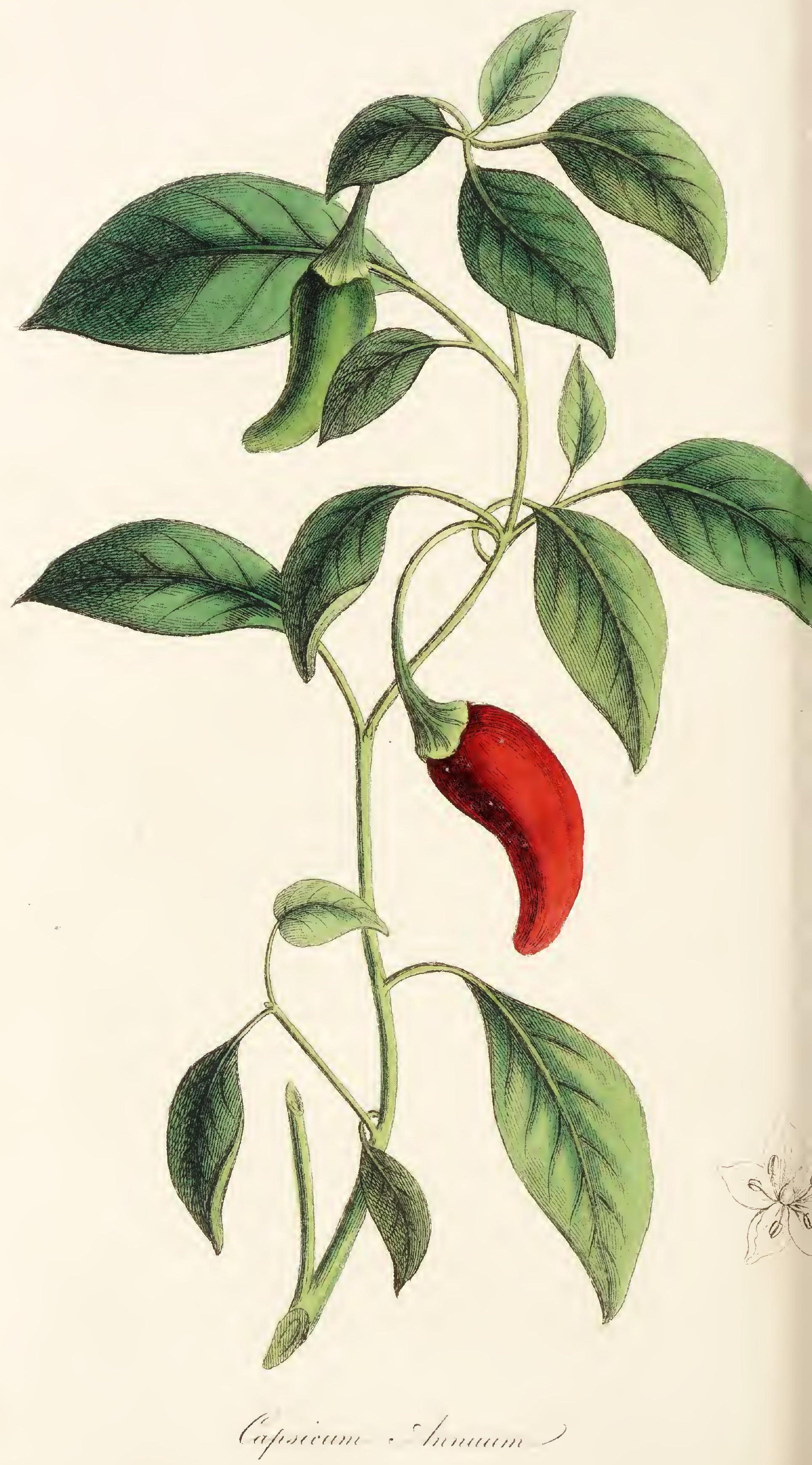


25. CAPSICUM ANNUUM-ANNUAL CAPSICUM.-GUINEA, OR COCKSPUR PEPPER.

Baccæ.

\section{Class V. Pentandria.-Order I. Monogynia.}

Natural Order. LURIDE.

Generic Character. Corolla wheel-shaped. Berry, without juice.

Specific Character. Stem herbaceous, peduncles solitary.

$T_{\text {HE }}$ Capsicum is au annual plant, a native both of the East and West Indies, but is frequently cultivated in our Gardens, chiefly on account of its beauty; it flowers in June and July.

The stem is roundish, smooth, crooked, branched, and rises three or four feet in height. The leaves are eliptical, smooth, entire, and placed irregularly on long footstalks. The flowers are solitary, axillary, and stand on long peduncles, and of a white colour; the calyx is persistent, tubular, and divided at its extremity into five short segments; the corolla is wheel-shaped, divided into five segments, which are spreading, pointed, and plaited; the filaments are short, tapering, and support oblong anthers; the germen is egg-shaped, supporting a slender style, which is longer than the filaments, and terminated by a blunt stigma ; the capsule is a long, conical, pendulous pod, or berry, of a shining orange or red colour, divided into two cells, and containing several Aat, kidney-shaped seeds. 
There are several varieties of the Capsicum; but the one commonly preferred is of a conical form and rather acute, being at first green, and afterwards becoming of a bright red. Its taste is similar to the peppers, but is much more pungent, setting the mouth as it were on fire, and this sensation continues for a long time; it has a slight aromatic smell. The whole virtues of the pod are extracted by water and spirit, but more completely by the latter; for the spiritous extract is found to be so extremely pungent, that it can scarcely be borne on the tongue.

This article often goes by the name of Cayenne pepper; but that substance is generally made up of a mixture of different species of Capsicum, the strongest of which is the Bird Pepper. As we receive the Cayenne from the Indies, it is generally mixed with muriate of soda, and sometimes with red lead; the latter may be detected by exposing some of the powder (previously mixed with flux) to the heat of a blow-pipe, which will reduce the metal.

The berries of Capsicum are chiefly used as a condiment, especially by the Indians, who take it very freely, there being scarcely an article of food into which it does not enter; they employ it also to promote digestion, and to create an appetite. It is said to have a very beneficial effect in preventing flatulence, which is apt to occur from the constant use of vegetable food; but, like all tonics and stimulants, if taken in excess, it produces dyspeptic symptoms; for such substances appear to supply the place of the bile, and thereby disturb one of the most important functions of the body, laying the foundation of obstructions in the liver. It is one of our most useful and simple stimulants, and is very applicable in those cases that require such remedies; as in some cases of Dyspepsia it has been given with advantage in small doses. In cases of Retrocedent Gout it is a very desirable stimulant, con- 
joined with Ammonia and other powerful remedies. Intermittent Fevers, which have proved very obstinate to the common modes of treatment, have been subdued by giving full doses of Capsicum in powder. But the disease in which this medicine appears to have been most serviceable, is the Cynanche Maligna, a disease which has proved very destructive to the negroes; but by taking grs. $x$ vel grs. xij of the powder ter vel quater in die, and at the same time using it as a gargle, the disease is generally subdued. In this country it is often employed successfully as a gargle in the same disease, and in other cases of sore throat, which assume a sloughy appearance, such as are often brought on from the injudicious use of Mercury. A cataplasm of Capsicum applied to the soles of the feet has evidently relieved the coma and delirium which commonly attend tropical fevers: they act as powerful rubefacients, without producing vesication.

Dose grs.v. ad 3 j.-Officinal preparations, Tinct. Capsici. 



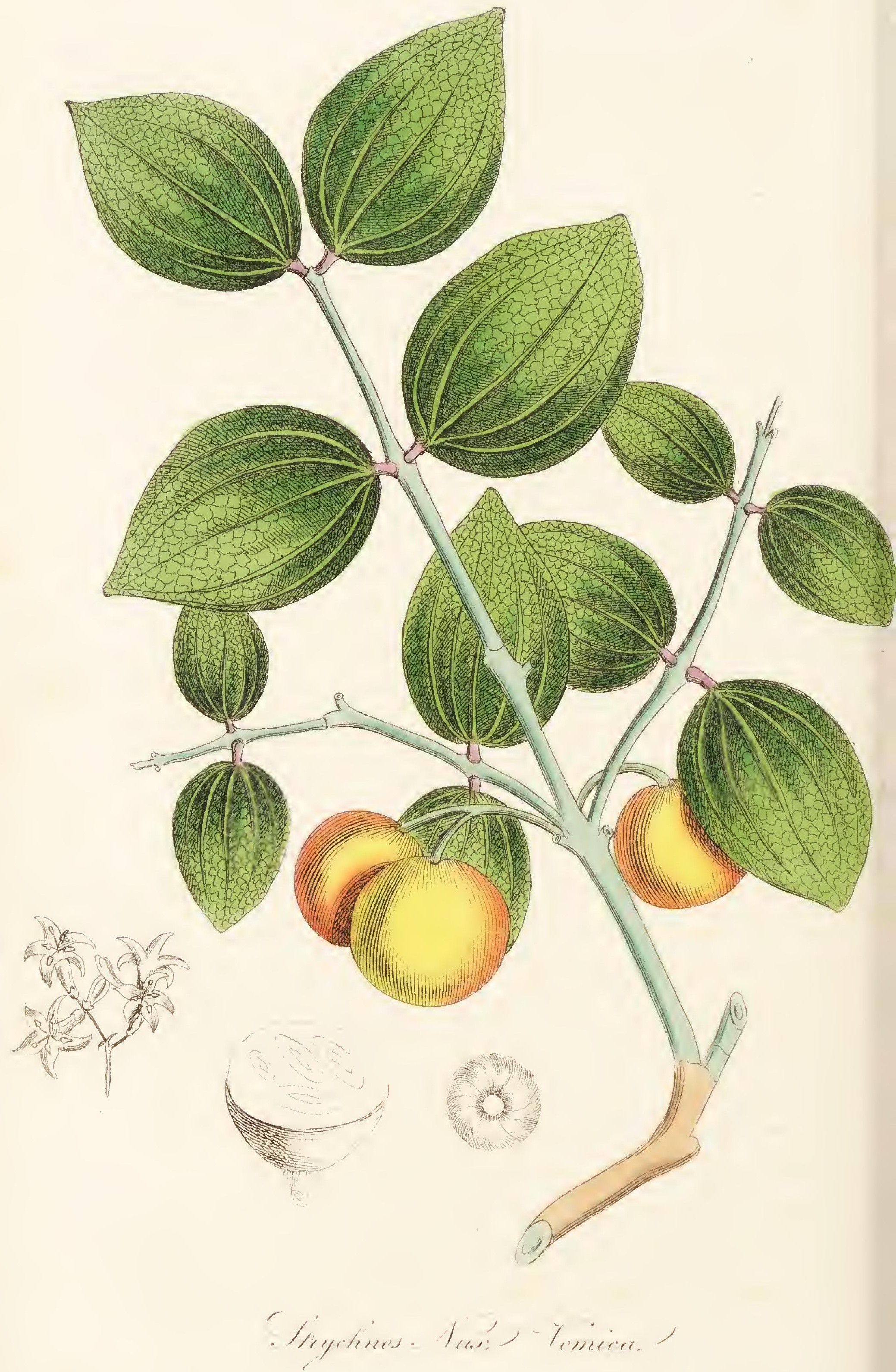




\title{
26. STRYCHNOS NUX VOMICA.
}

\author{
Vomic, or Poison Nut.
}

Semina.

Class V. Pentandria.-Order I. Monogynia.

Natural Order. LURIDE.

Generic Character. Corolla five-cleft. Berry onecelled, with a woody rind.

Specific Character. Leaves ovate, stalk naked.

The tree affording these seeds is a native of the East Indies, growing chiefly in Ceylon and Malabar, occupying sandy situations.

The Nux Vomica tree is of considerable size, sending off numerous strong branches. The young ones are glabrous, cylindrical, having swelled articulations, and covered with a green bark. The leaves are opposite, broad, ovate, entire, and pointed, proceeding from the joints upon short footstalks, of a deeper green on the inferior, than on the superior surface. The flowers are placed towards the extremities of the branches, in small corymbs; they exhale a disagreeable smell: calyx small, tubular, and divided into five pointed segments; corolla monopetalous, tubular, of a whitish colour, and divided into five segments; filaments short and fixed to the mouth of the tube, supporting oblong anthers: the style is longer than the stamens. The berry is round, at first 
of a green colour, afterwards of a golden yellow, containing several seeds, covered with hair. The seeds are flat, of a roundish shape, about an inch broad, and nearly a quarter of an inch thick, of a grey colour, and somewhat woolly, internally hard and tough like horn. The best kind are of a yellowish grey colour; those which are nearly black should be rejected. They are inodorous, but have a very bitter, acrid, and disagreeable taste. They are composed chiefly of gummy matter, a bitter principle, fixed oil, and some alkaline salts.

The Nux Vomica was first noticed by the Arabians as a substance of considerable activity, and from the numerous observations and experiments, made upon man and other animals, since that period, its deleterious and active properties have been, fully established. Various interesting experiments have been made by Orfila, upon dogs and other animals, which go to prove that every part of the seed is poisonous; hence it is very frequently employed to destroy rats. He has given to dogs the bruised:seeds, watery and resinous extracts, decoctions, the bitter principle, and oil; the most active of them is the spirituous extract; the watery extract is also very powerful, and the powder appears to be less active than any preparation obtained from it. This poison acts with more rapidity when introduced into wounds, than when taken into the stomach, and still more rapidly when injected into the veins. A very small quantity of the resinous extract introduced into the thighs of several dogs, destroyed them in a few minutes. Hoffinam mentions a case of a young girl, aged ten years, who took fifteen graius of the powder in two doses, for the cure of an obstinate Quartan Intermittent: the consequence was, that she died in a short time, after having experienced extreme anxieties, and made several efforts to vomit. A man; for the sake of experiment, took a scruple of it, in whom it produced 
intoxication, with a rigidity and tension of the muscles of the limb, but the effects of it gradually wore off. Its action is chiefly exerted on the nervous system, which is proved by the nature of the symptoms, and the rapidity with which they occur: this is fully confirmed by our finding no morbid appearances on dissection, where it has proved fatal either to the human subject or to dogs; and we are inclined to attribute the appearances mentioned by Wepfer to some other causes, and not to the action of the Nux Vomica. The symptoms produced by it are difficult and hurried respiration, convulsions, motions, first of the limbs and then of the whole body, with tetanic rigidity of the muscles of the extremities and trunk, and death commonly follows. Where the opportunity offers that we can render any assistance to persons who have taken this poison, our object is to unload the stomach of its contents as quickly as possible, and treat the case in the same manner as we have described, when speaking of poisons of a similar nature: electricity has likewise been proposed here.

Although this is a very active remedy, and its exhibition requires considerable care and attention, it may prove useful in some diseases ; we must not, however, give credit to all the statements of older writers, as regards its efficacy in many diseases, the very nature of which would often forbid its employment: thus it has been recommended as an antidote to Fever, Plague, Mania, Hydrobia, \&c. Murray mentions it as possessing considerable power over Intermittents, and he is supported in this opinion by several other writers; and it no doubt has cured this disease : but we think it should not be had recourse to till other remedies of equal virtue, and less dangerons, have failed. In some nervous diseases, as Epilepsy and Hysteria, the Nux Vomica may be had recourse to occasionally with advantage: we cannot, 
however, speak confidently of it in these diseases; for in fact it is a medicine which is but little employed at the present day.

The dose of the Powder is from gr. j. to grs.vj. The Extract should be commenced with in doses of gr. ${ }_{4}^{2}$, and this is the preparation we would recommend, made into Pills, for the Powder is so bulky, that it is very apt to disagree with the stomach. It enters into no Officinal Preparation. 



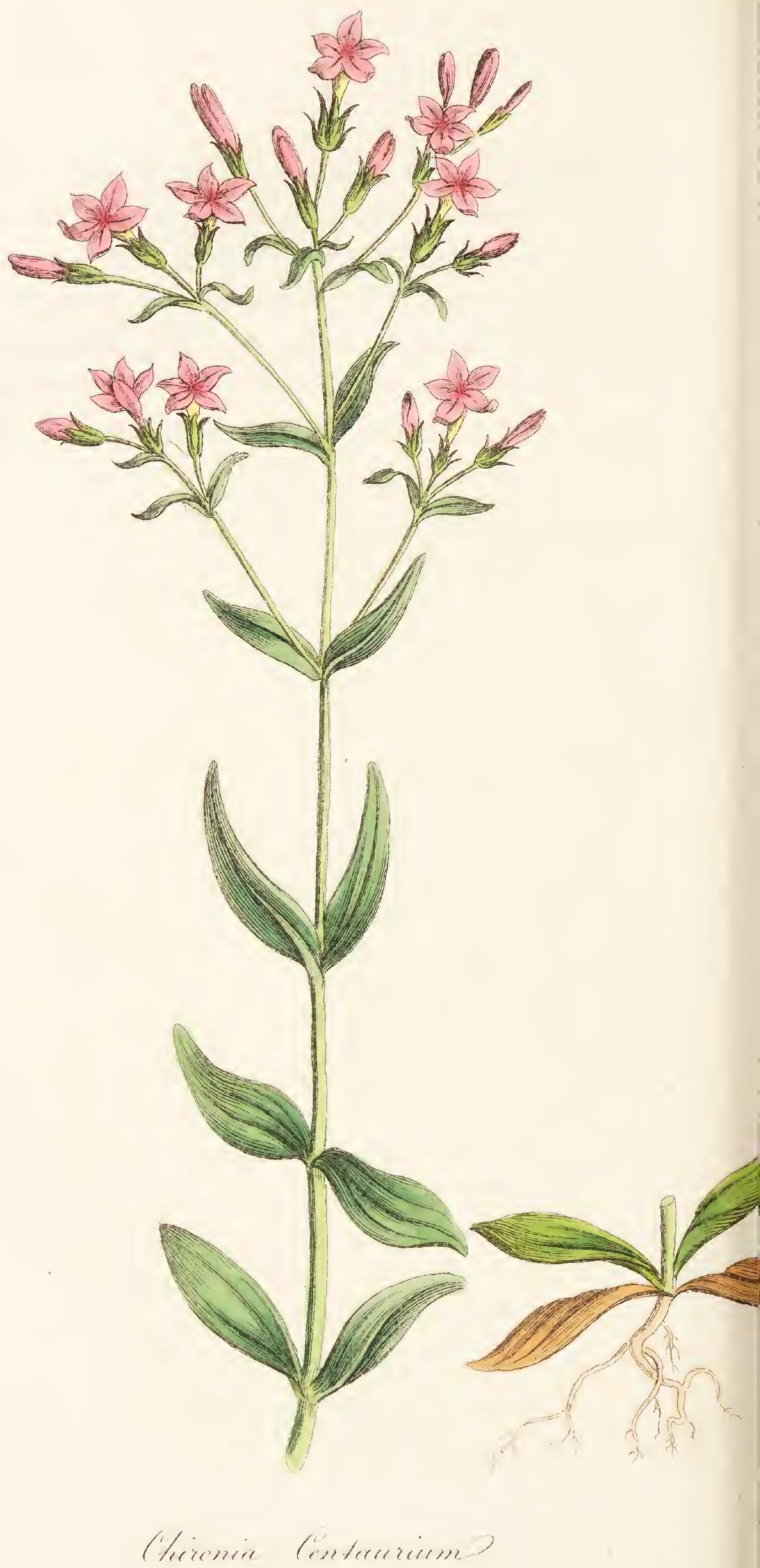




\section{CHIRONIA CENTAURIUM, CENTAU. RIUM MINUS.}

\section{Common or Lesser Centaury.}

Cacumina Florentia.

\section{Class V. Pentandria.-Order I. Monogynia.}

Natural Order. Rotaces.

Generic Character. Corolla wheel-shaped. Pistillum declined. Stamina fixed on the tube of the corolla. Anthers spiral at the end. Pericarp two-celled.

Specific Character. Corolla five-parted, funnelshaped, stalk dichotomous, pistillum simple.

THis annual plant grows wild in many parts of England, and is found in dry and barren pastures; it flowers in July and August. The root is woody, branched, and of a yellowish colour. The stalk, which rises from six inches to a foot in height, is erect, smooth, and angular. The leaves, which arise in pairs, are sessile, elliptical, smooth, three-nerved, and obtusely pointed. The flowers are terminal, in corymbs or bunches, sessile, and of a pink or rose colour: the calyx, which is half the length of the tube of the corolla, is divided into five erect segments; the corolla, is equally divided into five oval, spreading segments; the filaments are slender, shorter than the corolla, and furnished with oblong, yellow, twisted anthers: the germen is oblong, supporting a simple style with a clubbed stigma; 
The leaves and the tops of the Centaury, possess a considerable degree of bitterness, whilst the petals are stated by Lewis to be comparatively tasteless; it has no smell. Its active ingredients are extracted both by water and spirit; but the water, in addition to the bitter active principle, extracts a considerable quantity of mucilage; therefore, the spirituous is proportionally stronger than the watery extract.

This plant is not much used by practitioners at the present day, but certainly deserves more attention than is commonly given to it, for it possesses properties equal to many other bitters in common, use, which are much more expensive; and will prove a very good substitute for many exotics, of similar virtue. It is useful in weakness of the stomach and indigestion, and an infusion of it will often be a more serviceable tonic when a patient is recovering from the effects of a Fever, than the Cinchona; for it has no astringency, which the latter bark is so remarkable for. A very grateful and elegant preparation may be made by infusing it in water with cloves. In weakly constitutions, where there is a corresponding debility in the primæ viæ, it may be advantageously employed for the cure of Intermittents, half a drachm to one drachm of the powder, may be taken three or four times a day. It entered into the composition of the famous Portland Powder, that specific for the Gout. It is said, when applied externally, to correct the foetid discharges from unhealthy ulcers. No Officinal Preparation contains it. 



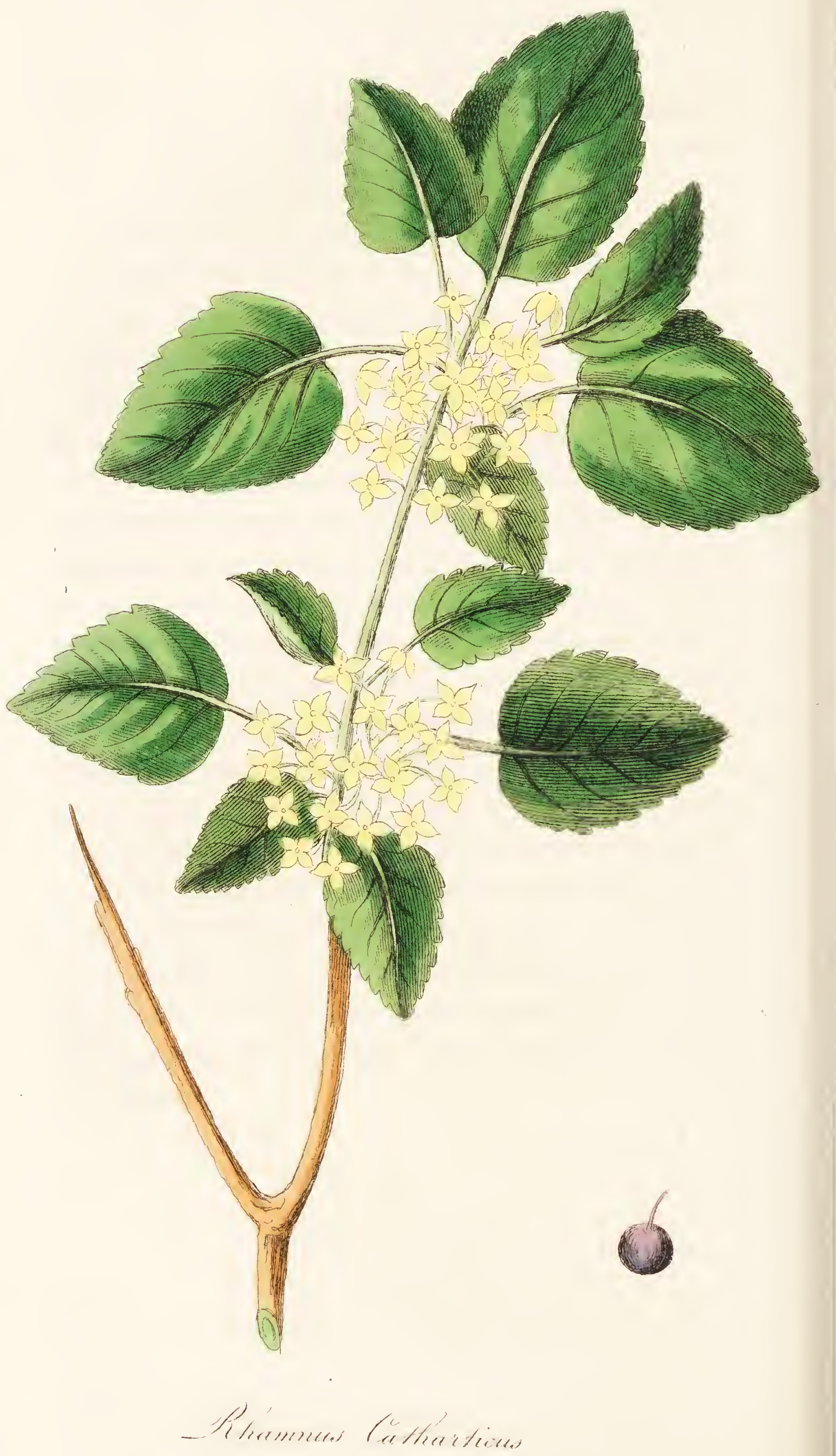


28. RHAMNUS CATHARTICUS, SPINA CERVINA.

Purging Buckthom.

Baccæ.

Class V. Pentandria.-Order $\mathbb{I}$. Monogynia. - Nalural Order. Dumosts.

Generic Character. Calyx tubular. Corolla, scales defending the stamens inserted into the calyx. Berry.

Specific Character. Spines terminal, flowers quadrifid, diœcious; leaves ovate, stalk erect.

THE Buckthorn is a low tree, growing in hedges and woods near brooks, in many parts of Britain ; flowering in June, and ripening its berries in September and October.

It rises with a strong woody stem, covered with a dark coloured bark, sending off several branches, which end in spines. The leaves, which stand on short footstalks in bundles, are ovate; veined, and serrated. The flowers proceed from the same buds as the leaves, small, peduncled, of a greenish yellow colour, and divided into four segments; they are frequently male and female upon different plants: the filaments are short, and arise from the base of a small convex scale, supporting round anthers: the germen is ovate, with a slender style and trifid stigma: the fruit is a round black berry, containing four seeds, which are pressed on one side.

The berry, which is the only part of this shrub which is used, is of a shining black colour, about the size of a pea, of a pulpy 
nature, and containing a deep green juice, having rather an unpleasant smell, with a bitter, subacrid, nauseous taste. These berries are often mixed with the fruit of the black berry bearing alder and the dog-berry tree; but this deception may be easily detected, by the berry of the buckthorn containing four seeds, whilst the berries of the alder contain only two, and those of the dog-berry only one; and the juice of the Buckthorn stains paper of a green colour, whilst the other juices do not. The colour of the juice varies according to the time at which the berries are gathered; if it be before they are ripe it is yellow, and if late in autumn of a purple colour. It is the expressed juice of the ripe berries, hardened by evaporation, that constitutes sapgreen, a pigment for painting, \&c.

The Buckthorn was much used by the ancients as a hydragogue cathartic in dropsies, also in rheumatism: but it is not superior to other remedies of a purgative nature, and is now almost entirely laid aside as an internal remedy, on account of the violence with which it acts, and it seldom fails to produce severe gripings, excessive thirst, and dryness of the mouth and fauces; these symptoms are, however, generally relieved by drinking copiously of diluents, as Dec. Hordei. When it is employed, the best preparation is the Syrupus Rhamni; but it must always be looked upon as a stimulating and drastic purgative. In the form of Enema, however, the syrup is a most useful and speedy cathartic, either alone, or combined with some other as Infus. Sennæ, vel Colocynthidis. The berries may be taken in doses of from $3 \mathrm{j}$ to $3 \mathrm{ij}$. Officinal Preparation, Syrupus Rhamni. 


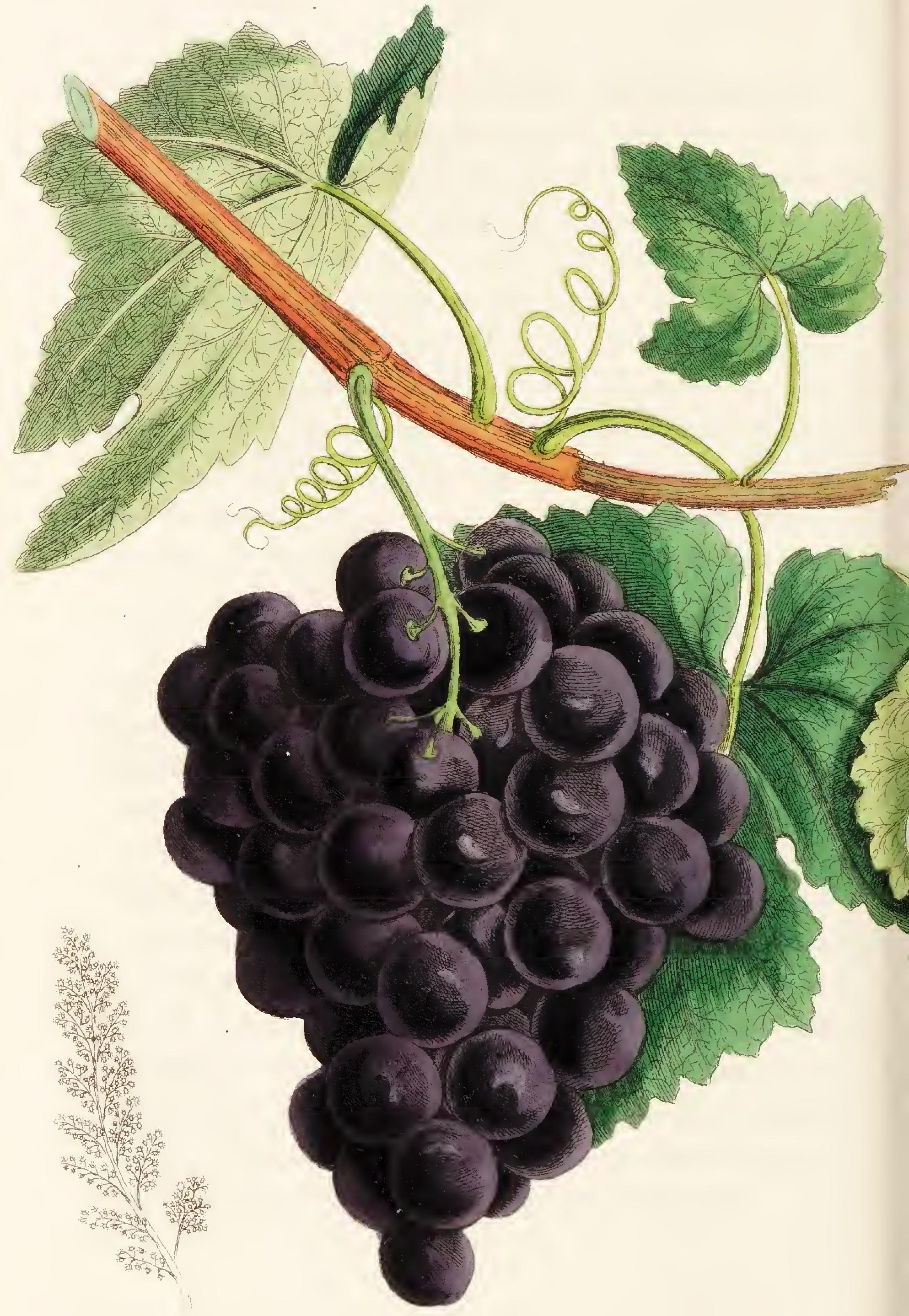

Yition Ulinifene, 


\section{VITIS VINIFERA. \\ Common Vine.}

Fructus maturus, recens, et siccatus.

\section{Class V. Pentandria.-Order I. Monogynia.}

\section{Natural Order. Hederacee.}

Generic Character. Petals cohering at the apex, shrivelling. Berry five-seeded, superior.

Specific Character. Leaves lobate, waved, and naked.

ThE Grape grows wild in temperate situations in most parts of the earth, and is cultivated in many climates where the heat is sufficient to bring the plant to perfection: it flowers in July.

The Vine has slender, twisted, climbing stems, covered with a rough, dark, fibrous bark. The leaves are lobed, deeply serrated, and placed alternately on long footstalks. The flowers are small, occurring in clusters, attended by tendrils : the calyx is very small, and divided into five small segments: the petals are whitish, small, oblong, adhering at their apices, and soon fall off : the filaments are tapering, and support simple anthers : the germen is egg-shaped and styleless, stigma cylindrical: the fruit is a large, succulent, globular berry, one-celled, and contains five hard seeds of an irregular form.

The Grape is subject to considerable variety as regards its shape, size, colour, and the nature of its juice, from the mode of cultivation and difference of soils. The juice is sometimes acidulous, and at other times sweet; the skin is at one time thick, and in another tree thin. The size of the branches, and the time at which they ripen, depends much on the care taken in dressing the vines. It is not cultivated in this country for the purpose either of making wine or raisins, but only as a pleasant article of diet. Grapes are sometimes gathered in their unripe state, for the purpose of obtaining verjuice from them, which has a harsh 
austere taste; but by mixing it with water, and rendering it palatable with sugar, it forms an useful beverage to allay thirst and correct any putrid tendency in the primæ viæ. The fruit in this unripe state contains a considerable quantity of malic and other vegetable acids, which diminish in quantity as the grapes ripen, and the saccharine matter then predominates. Ripe grapes contain mucilage, sugar, supertartrate of potash, and vegetable acids; they have a most grateful taste, and when taken freely, act as a mild cathartic and diuretic. They are very useful as articles of diet in fevers, dysentery, and inflammatory diseases. In people of weak digestion, they are apt to run into the acescent fermentation, and thus disagree with the patient; and the rinds, from the difficulty with which they are digested, will produce dyspeptic symptoms. They are recommended by Murray as an article of food in Phthisis, and are very useful, except in the latter stage, when the bowels are in such an irritable state, that they would probably bring on diarrhœa.

Raisins are prepared in two ways: either by dipping the grapes into an alkaline solution, and then hanging them up in the sun to dry, or by partially cutting the stalks of the branches, when the grapes are nearly ripe, and leaving them suspended on the vine till the watery parts evaporate and the sun dries and candies them; those cured by the latter mode are preferred.

Raisins contain more saccharine matter than the fresh grape; hence are more laxative and nutritive, and less cooling, from the watery parts being expelled. They are demulcent and emollient, and have been used to allay cough and stranguary. They are only employed as articles of diet, or to cover the taste of unpleasant drugs.

The chief use of the grape is the preparation of wine, which is an article of such general use, that it is only necessary to mention it as a medicine.

When the grapes are perfectly ripe, they are gathered and immediately pressed, to separate the juice from the skins and seeds; this constitutes what is called must, which is placed in vats of a certain temperature; in a short time the different elements act upon each other in a peculiar manner, so as to produce fermentation, which continues for a certain time, till the original juice 
is converted into wine, after which it must be put into casks, to prevent its ruming into the acescent fermentation.

The ouly wine mentioned in the Pharmacopoins is the Vinum Album Hispanicum, or Sherry; but we shall not confine ourselves to this one species, but speak of them generally. The difference of colour depends on the epidermis of the grape: thus, if the fermentation be allowed to proceed with the rind of the grape in the must, the wine is of a dark colour, and is called Red or Port Wine; and the astringency of this wine is owing to the astringency of the rind being extracted during fermentation: but that juice which is previously deprived of its husks, is converted into White or Sherry Wine.

Wine is liable to considerable variation, as regards. its strength and properties, from the difference of the grapes and the mode in which the fermentation is conducted.

They are composed of tartaric, malic, and carbonic acids; extractive and colouring matter, and spirit or alcohol, which is: the most essential ingredient, and one that exists in very different proportions in wine.

When taken in small quantities, it proves an useful cordial and stimulating remedy, acting as a mild diaphoretic and diuretic; it also increases the circulation, and gives tone to the stomach and system at large; but if taken in excess, it acts as a powerful stimulus, by deternining blood to the head in unusual quantities, produces intoxication and a sense of delirium; these effects are followed by symptoms of an opposite nature; at first, general lassitude and drowsiness; after this, there is a total loss of sense and profound stupor, which will sometimes continue for several days and terminate fatally, and it not unfrequently occasions apoplexy. 'These symptoms vary in degree, according to the quantity of wine taken and the habits of the individual. Where persons have been in the habit of indulging for a length of time in the use of wine, it lays the foundation of various chronic diseases, which eventually destroy them; such as obstructions or indurations of the liver, which is a very frequent consequence of such practices, and often terminates in incurable dropsy. In addition to its action upon the body, it sometimes deranges the mental faculties, and brings on insanity. 
The use of wine is indicated in most states of debility and languor, but more especially in those diseases that shew a disposition to putrescency, as Typhus Fever; the delirium which is present in this fever is no obstacle to its use, for it relieves that state of brain which gives rise to it, and increases the fulness of the pulse, without increasing its frequency or adding to the fever. In Cynanche Maligna, and in Erysipelas, where gangrene is about to take place, or has already commenced, and in all cases of gangrene, it is to be employed; it will be unnecessary to detail all the diseases that require it, and that must depend on the symptoms present and a variety of circumstances. We should be guided in some measure by the cravings of the patient as to the kind of wine employed; however, when there is a disposition to putrescency in the primæ viæ, those which contain the greatest quantity of carbonic acid are to be preferred, as new wines, for example, Champaigne, Sherry, \&c. : and where, again, there is a disposition to diarrhæa, or acidity of the stomach, the older wines are preferable, especially Port, which is somewhat astringent. It would be impossible to lay down rules as to the quantity of wine that should be taken in these cases; we must be entirely regulated by the constitution and habits of the patient, and other circumstances: it should generally be given in the diluted state. It is occasionally employed externally to sloughing sores, as an antiseptic and stimulant.

It may be proper just to notice here an article which is a product of wines, viz. supertartrate of potash, which is the deposit that takes place upon casks, from old wines, and is commonly called Tartar; it is not employed in this state, but after it has been purified, it becomes a salt of considerable utility as a purgative, diuretic, and refrigerant, and is frequently employed in dropsies, either alone or combined with other and more active purgatives. Dissolved in Decoct. Hordei, it makes an useful beverage in fever and inflammatory complaints.

Vinegar is also to be obtained from the vine; it is not, however, generally procured from this tree. It is seldom employed in its impure state, except as an external application to promote absorption of extravasated blood, \&c.; and diluted with water, it may be advantageously employed to sponge the body in typhus fever, particularly if there be petechia, or considerable disposition to putrefaction. 



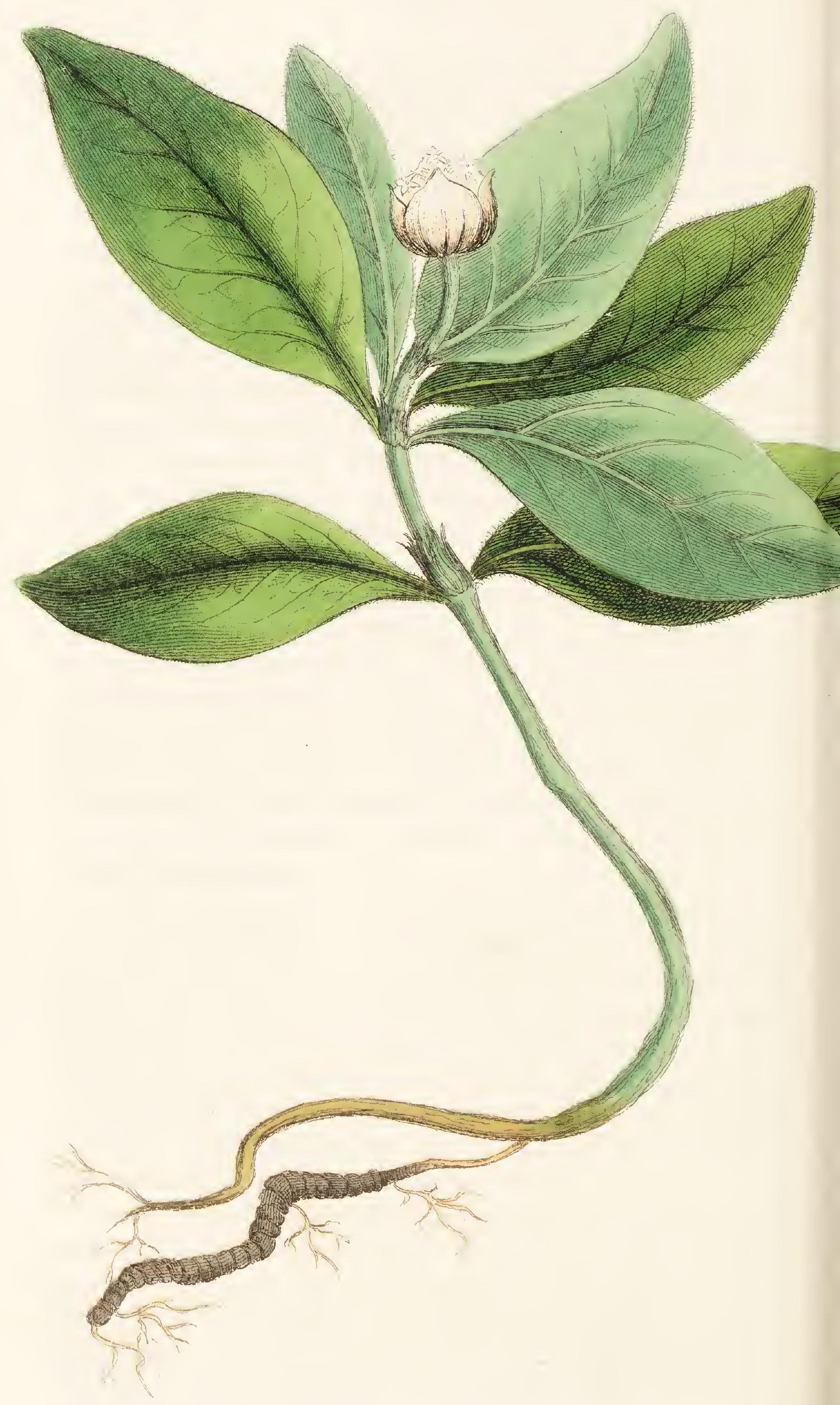

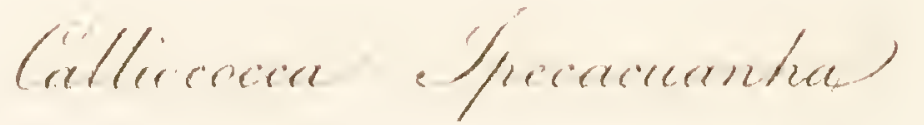




\section{CEPHAELIS VEL CALLIOCOCCA IPE- CACUANHA,-IPECACUAN.}

Radix.

\section{Class V. Pentandria.-Order I. Monogynia. Natural Order. AgGRegate.}

Generic Character. Calyx superior, quinquefid. Corolla hypocrateriform, quinquefid. Stigma two-parted. Berry dispermous, bilocular, and unilocular.

Specific Character. Cápitula pedunculate and terminal, leaves ovate-lanceolate.

T $_{\text {HIS }}$ plant grows in shady and moist place in Rio Janeirio, Paulensia, Mariannia, and in other provinces of the Brazils. It flowers in December, January, and February, and its berries ripen in May.

The root is perennial, simple, or somewhat branched; three or four inches or more in length, and two or three lines in thickness; often furnished here and there with short radicles: it is externally of a brown colour, variously bent, and furnished with rough, unequal, prominent rings. The stalk is procumbent, round, and about the thickness of a quill, from five to more inches in height; it is smooth, brown, and knotted towards the lower part, but at the apex it becomes leafy; the first year it is erect, but afterwards becomes sarmentose, and sends off fresh erect stems. The leaves are caducous, so that not more than from six to eight remain at the apex of the stalk; they are opposite, spreading, and ovate-lanceolate, three or four inches long 
and one or two broad, of a deep green colour superiorly, occasionally somewhat pubescent; below of a whitish green colour, downy, with lateral veins; stipules sessile, linear, fimbriated, and in some degree embracing the stem. The flowers are aggregated in a solitary head, which is nearly naked, pedunculate, and terminates the stalk; the involucrum is tetraphyllous, slightly undulated,:- and downy; the external largest, but all larger than the florets; the calyx is white, short, five-toothed, and persistent : corolla monopetalous, with a cylindrical tube, larger than the expanded part, divided into five acute, ovate, recurved segments; filaments capillary, short, and inserted into the upper part of the tube, supporting oblong, linear, and erect anthers; style filiform, length of the tube of the corolla; two oblong obtuse stigmas, the length of the anthers; the germen ovate, surrounded by the calyx, and becoming soft and of a reddish brown colour, afterwards turning black, and containing two eliptical seeds.

We meet with two kinds of Ipecacuan in the shops, one coming from Peru and the other from the Brazils, distinguished by their colour: the former being brown, and the latter of an ash colour, which is senerally preferret; it is in short wrinkled, variously contorted pieces, about the thickness of a quill, knotty, and full of deep circular fissures; its fracture is resinous. This is the true Calliococca Ipecacuanha.-From various experiments, it appears that the chief virtues of the I pecacuan reside in the cortical part; therefore, in proportion to its resinous fracture and compactness is the article preferred. The white is much inferior to either of the other varieties.

Good Ipecacuan should have a slight nauseous smell, with a bitter, sub-acrid, and somewhat mucilaginous taste. Its best menstruum is proof spirit; a tolerably active emetic may however 
be procured by simply infusing the Ipecacuan in boiling water. It was introduced into Europe about the beginning of the seventeenth century, at which time it was considered a specific in Dysentery. It is one of our safest and most useful emetics, and may be employed when the stomach is in such a state that it will not bear others, either on account of their being too active, or from the sedative effects which some leave behind them. It is a most useful emetic at the commencement of Typhus Fever, and will often cut short the disease at its outset; but, in the more advanced stage, it would be injurious. 'A full dose of it, given about an hour before the paroxysm of an intermittent is expected, will sometimes check it. It is a medicine of considerable power in Dysentery; the modus operandi of it in the cure of this disease, is probably by increasing the peristaltic action of the intestines, and at the same time determining to the skin, and not by its astringency, an opinion which is maintained by some authors; and its efficacy in this disease is much improved by combining it with Rhubarb, or in some instances with Calomel and Opium. As an expectorant it proves very useful in some affections of the chest, given in small and repeated doses, to excite nausea : it is very useful in chronic catarrh, asthma, dyspnœa, chronic hæmorrhage from the lungs and uterus. In Hooping Cough, after the active symptoms have been subdued, the Ipecacuan combined with Ext. Conii, is one of our most useful remedies; for a child grs. iij. of Ext. Conii, and gr. ss. ad gr. j. of Ipecacuan.

In Rheumatism, combined with Opium, it is a most useful and desirable diaphoretic. Whenever there is a disposition to active inflammation or hæmorrhage, it should be avoided; it is not generally applicable to persons of a full plethoric habit, who are pre-disposed to apoplexy. In Croup, the Ipecacuan is a desir- 
able emetic, after the inflammation has been checked by leeches, \&c. Its dose to excite nausea is from gr. $\mathrm{j}$. to grs. ijj. As an emetic, grs. viij. to $3 \mathbf{j}$.

Officinal Preparations, Vinum Ipecac.; Pulv. I pecac. Comp. 



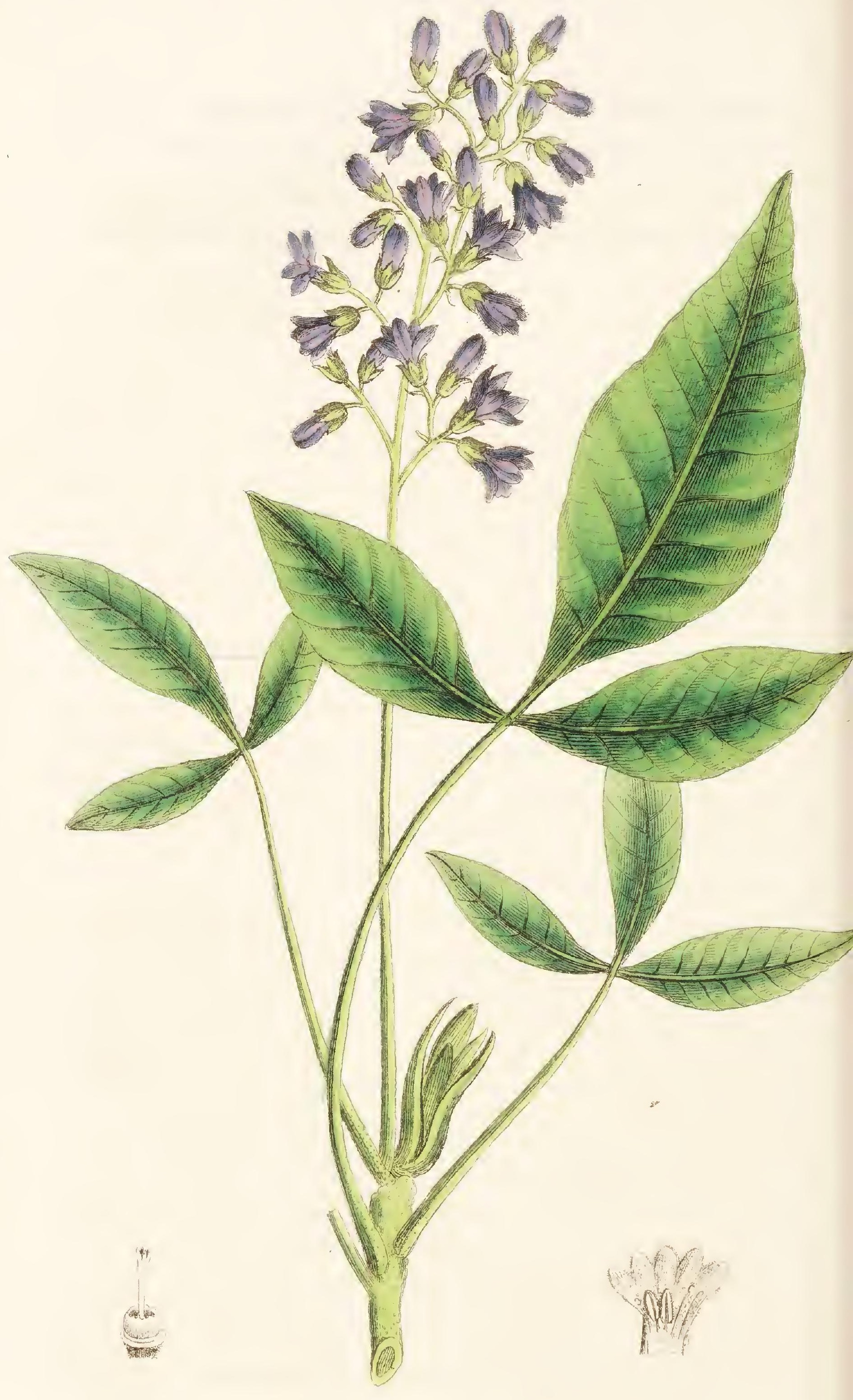

Pompliandia Srifuliatas 


\section{BONPLANDIA TRIFOLIATA-CUSPARIA} FEBRIFUGA-ANGUSTURA.

Cusparia Bonplandia, or Angustura Bark.

Cortex。

\section{Class V. Pentandria.--Order I. Monogria.}

Natural Order. Quassia.

Generic Character. Calyx, five-parted, petals five, and inserted into the receptacle. Nectaries, five, covering the germen. Capsule, five-celled, cells monospermous.

Specific Character. Three-leaved.

Thus tree is a native of South America, growing abundantly in woody situations.

It is an evergreen, both majestic and elegant, rising, according to Humboldt, to the height of from sixty to eighty feet. The trunk is straight, cylindrical, and divided at its summit into numerous alternate branches. The bark is of a greyish colour, about three lines in thickness. The leaves are alternate, from one to two feet in length, of a beautiful green colour and aromatic odour, composed of three leaflets, supported by a common cylindrical petiole, from ten to twelve inches long. The leaflets are oblong, glandular, and membranous. The flowers are whitish, placed in at 
terminal raceme; the calyx is inferior, persistent, tomentose and divided into five segments : the corolla is funnel-shaped, composed of five petals, so united below as to appear like one tube; stamina shorter than the petals to which they are attached; pistillum formed of five distinct ovaries, from the centre of which a single style rises, terminating in five fleshy, green stigmas : the fruit is composed of five oval, twovalved capsules, each containing a single seed.

We were ignorant for a long time of the true history of the Cusparia; and it was not till the year 1778 that we received accounts of its superior virtue in intermittents, at which time it was held in great estimation at Dominica. In the shops it is commonly called Angustura or Cusparia, but its true systematic name is Bonplandia Trifoliata.

We generally receive it into this country packed up in casks, containing pieces of various sizes, being for the most part broad and thin, externally covered with a grey epidermis, and internally of a brownish yellow colour; its fracture is short and resinous, having an intense bitter but somewhat aromatic taste, leaving a strong sense of heat on the tongue; the odour is peculiar. The active parts of the bark are most completely extracted by proof spirit. Water, however, extracts both the mucilaginous and bitter parts; yet this preparation is not equal in strength to the tincture. It affords a white essential oil by distillation.

As there is a spurious article sold under the name of Angustura, it is necessary to have some acquaintance with it to enable you to distinguish it from the genuine drug. The spurious, (which is the product of a tree called Angusturo 
Pselido-ferruginia) is beset with warty excrescences, of a dirty yellow colour, on its inner side, sometimes black, of a coarse texture, very brittle, fracture even, yellowish white or brown; not at all resinous, but rather mealy, exhibiting two distinct layers; its powder is of a grey colour, similar to Ipecacuanina. The smell of it is very similar to the genuine drug; its taste is also extremely bitter, not aromatic, but very disagreeable. Its infusion is of a dirty brown colour, and not clear like the Infus. Cusparia. For a further account of the difference between these two articles, see a paper read by L. A. Planche before the Society of Medicine at Paris.

This drug has been brought forward as a remedy equal to the Cinchona in the cure of intermittents, and some have even stated that it is superior to it; this opinion is not, however, generally sanctioned by practitioners of the present day. No one will doubt its being a useful tonic and stimulant, and on this account it may cure intermittents; yet we cannot place that reliance on it which is justly due to the Cinchona. It is a useful medicine in some cases of dyspepsia, also in diarrhœa, depending on a weakly state of the intestines, or towards the termination of dysentery; it is frequently necessary to combine it with other medicines. When persons are convalescent after fever, if the bowels are in an irritable state, the Cusparia should be used as a tonic.

The best form of administering it is in infusion, unless you wish for its stimulative qualities, then give the tincture. When the spurious Angustura is given to dogs it destroys them much in the same way as the nux vomica, acting upon 
the spinal marrow and brain, in consequence of its being absorbed, for it is found to act with equal or more violence when applied to a wounded surface, or injected into veins, than if taken into the stomach-Vide Orfila. Dose grs. $x$ to $3 j$.

Oficinal Preparations:-Infusum et Tinctura Angusturæ. 



\section{ULMUS CAMPESTRIS.}

\section{Common Elm.}

Liber.

\section{Class V. Pentandria.-Order II. Digunia.}

\section{Natural Order. Scabride.}

Generic Character. Calyx five-cleft. Corolla none. Capsule compressed, membranaceous.

Specific Character. Leaves doubly serrate, unequal at the base.

The Elm is a large tree, very common to England, growing in most situations and soils : it flowers in April.

The height of this tree is very considerable; it sends off strong, spreading, lateral branches, which are covered with a rough, cracked bark of a brown colour. The leaves are rough, ovate, villous beneath, serrated, and of a dark-green colour. The flowers are in distinct gems, clustered, scarcely peduncled, numerous, of a flesh-colour, and sweet scent. The calyx is permanent, and divided into five segments; the filaments are tapering, and twice as long as the calyx, being furnished with short upright anthers; the germen is round and compressed, supporting two styles, which are termina ted by downy stigmata.

The inner bark of the tree is the only part medicinally 
employed, which is tough, of a yellowish colour, and bitter, mucilaginous, astringent taste, but is entirely destitute of smell. That bark is esteemed the most active, which is obtained from the branches, being much superior to the bark of the trunk. The external bark is fragile, and contains much less mucilage than the liber.

The EIm is a tonic, astringent, and diuretic. Its employment is chiefly confined to cutaneous diseases, especially useful in the lepra icthyosis, in which disease Dr. Lettsom considers it of the greatest utility. Although the Doctor has found it so very efficacious in this particular disease and some others, it is not generally given with such decided benefit; yet we must allow that the free use of the Decoct. Ulmi, in some very obstinate eruptive diseases, has been attended with decided advantage. It is not much employed in other diseases, except of this class; yet, observing its sensible properties and use in these complaints, we might expect some good effects. from it as an astringent or diuretic. The decoction should be taken in the quantity of a gill, three or four times a day. It has been given in ascites with apparent advantage. As an astringent lotion it is sometimes applied to irritable sores. Ofhicinal Preparation-Decoct. Ulmi. 



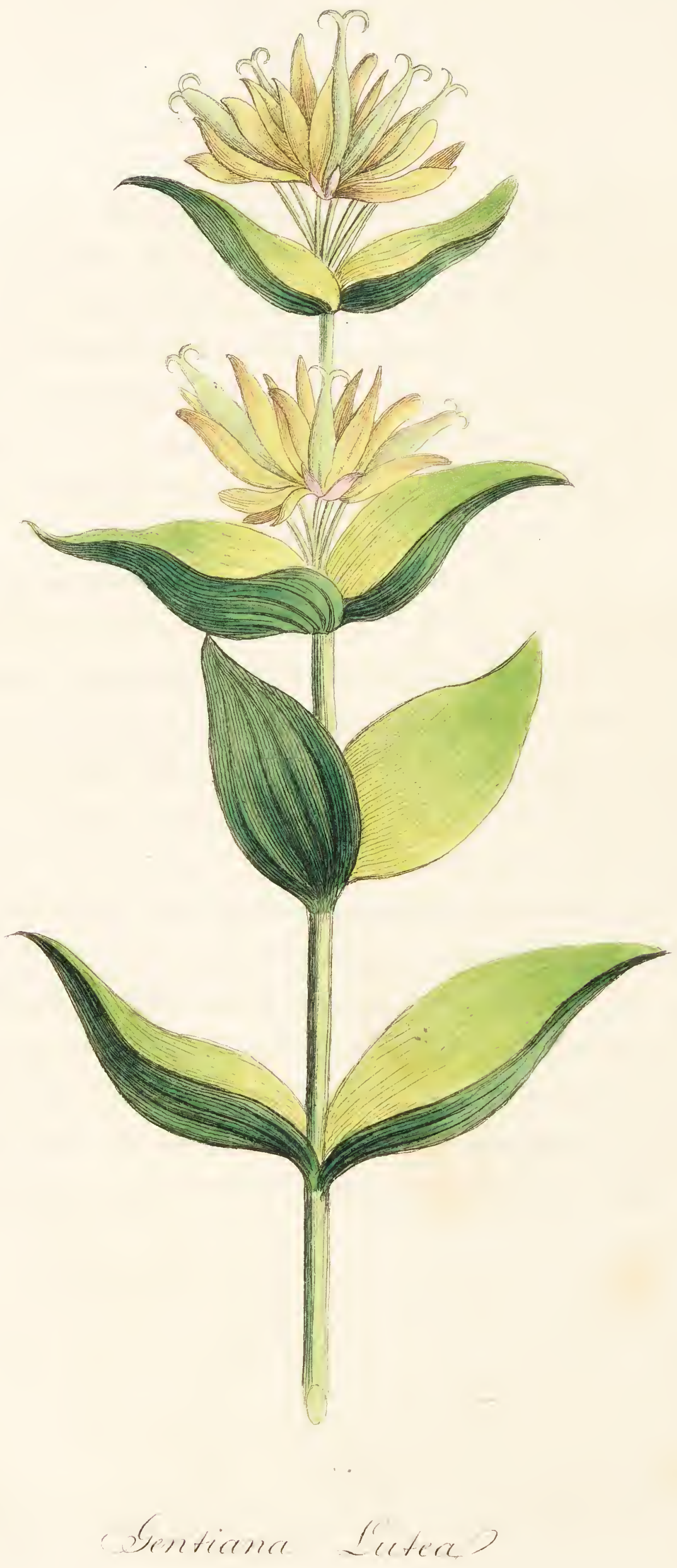

Plare 33 


\section{GENTIANA LUTEA.}

Gentian, Felwort.

Radix.

\section{Clase V. Pentandria-Order II. Digynia.}

Natural Order. Rotacex.

Generic Character. Corolla one-petalled. Capsule two-valved, one-celled. Recaptacles two, longitudinal.

Specific Character. Corolla five-cleft, wheel-shaped, verticillate; calyces, with spathes.

THIs perennial plant is a native of the Appennines, $\mathrm{Py}-$ rennees, \&c. occupying a considerable tract of these mountains. The gentian of the shops, however, is imported from Germany. It flowers in June and July.

The root is long, thick, and cylindrical, covered externally with brown bark. The leaves at the lower part of its stem are large, petioled, oblong, and pointed; those in the upper part are concave, smooth, egg-shaped, sessile, and almost embracing the stem. The flowers are in clusters at the upper joints, large, yellow, and standing upon peduncles; the calyx is a membranous, deciduous spathe; the corolla is divided into five or more eliptical 
spreading segments; the filaments are shorter than the orolla, and furnished with long, erect anthers; the germen is conical, furnished with two reflected stigmas; the capsule is conical, and contains numerous seeds.

In some parts of the world other species are substituted for the Lutea: viz. the Purpurea and Rubra, besides several other species; but experience proves that the Lutea is the most efficacious.

The root, of which part alone is employed medicinally, is externally of a brownish colour, and internally yellow and spongy; its taste is pleasantly bitter, without any aroma or odour. We should be cautious in selecting this drug, as we are informed from very good authority that the powder has been mixed with another root of very deleterious properties, and in consequence of this has occasioned convulsions, paralysis, and in some instances death; it will, perhaps, be impossible to find out this deception when the article is powdered; but, in the whole state, we may ascertain it by the deleterious being of a lighter brown colour, sometimes almost white, and its taste is very acrid and pungent, and more mucilaginous than the gentian. The leaves and twigs possess considerable bitterness, but they are not equal to the roots.

The gentian stands at the head of the class of bitters, which property it possesses to a very remarkable degree, without any astringency or aroma; very few patients object to take this medicine; and it is found to agree with most stomachs, even should they be in an irritable state. The virtues of it are very completely extracted both by 
spirit and water. This root is a tonic which has been in constant use from the earliest times, as we are informed, by men of considerable eminence; but its virtues (as was frequently the case with other remedies) were held in too high estimation by them. As a tonic however, it may be administered with the best effects in dyspepsia, particularly where there is weakness of the stomach : also in debilitated states of the constitution, brought on from various causes, or in diseases which exhaust the power of the system, as diarrhœa, dropsy, fevers, \&c. but in the last disease it must not be given till the patient is convalescent, as it would otherwise add to the mischief by increasing the febrile excitement. In nervous diseases of women the Inf. Gentian. Comp. combined with some cordial tincture, will materially assist in their relief. In general it may be employed, in combination with other remedies, for the relief of gout.

It was formerly much used for the cure of intermittents, before the introduction of the Cinchona; and even now in some constitutions, where we cannot venture to give the cinchona, either from peculiarity in the habit of the patient, or from particular circumstances of the case, this may be advantageously employed. It would be unnecessary to add the whole catalogue of complaints in which the gentian would be serviceable, it will be sufficient to say that wherever a bitter is required, none is preferable to this. The Extract is a very elegant preparation, and at the same time possesses the whole virtues of the drug in a concentrated form: combined with rhubarb and car- 
bonate of soda, it forms a very useful aperient tonic for dyspeptics. When given in substance the dose is from $\mathrm{gr}^{\mathrm{x}} \mathrm{x}$. 3j. Officinal Preparation:-Inf. Gentian. C. Extract. Gentian. Tinctura Gentian. C.Vinum Gentian. C. 



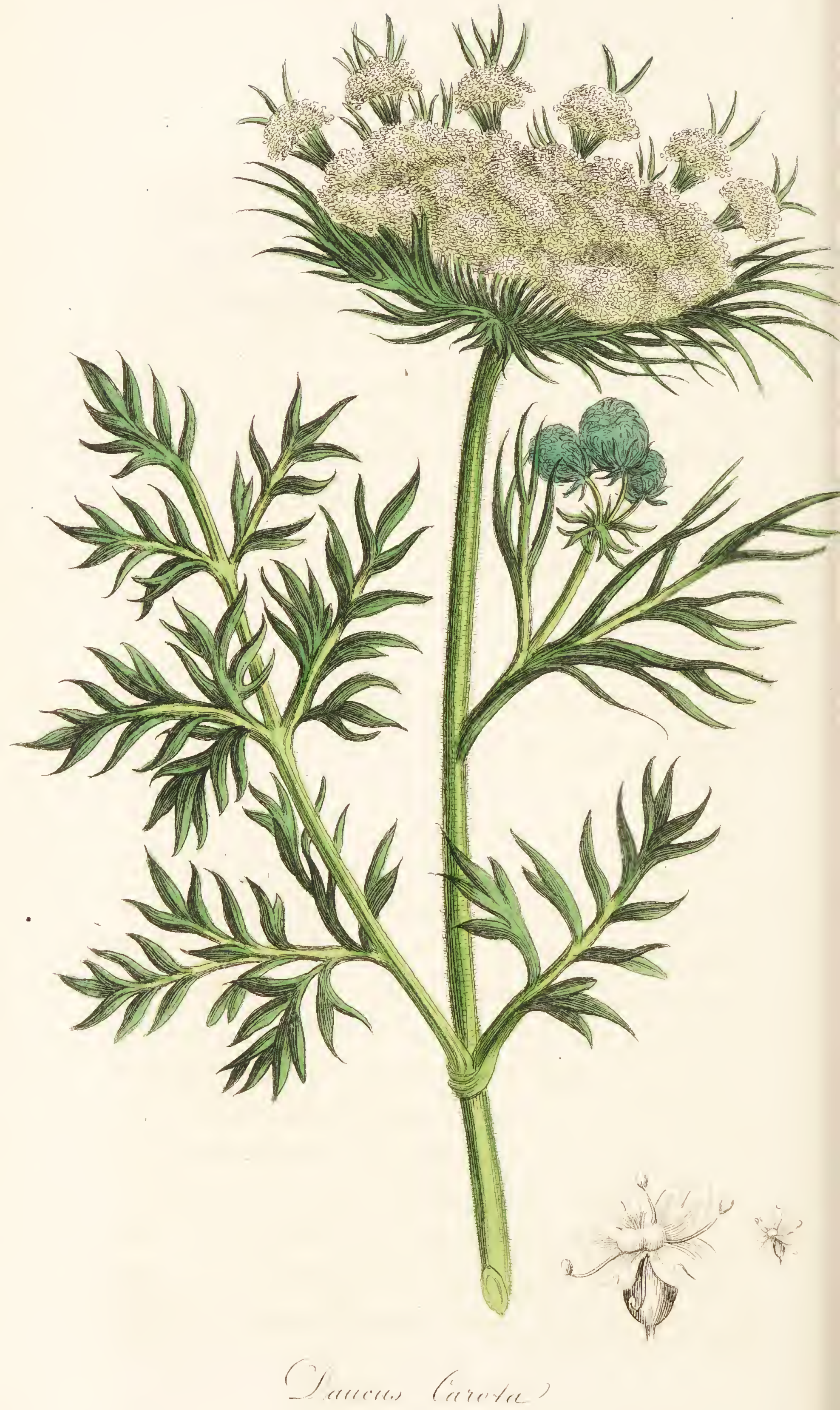




\section{DAUCUS CAROTA. \\ Common Carrot.}

Agrestis semina; Hortensis, radix.

\section{Class V. Pentandria. - Order II. Digynia.}

Natural Order. Umeeldate.

Generic Character. Corolla somewhat radiated. Florets of the disk abortive. Fruit hispid with hair.

Specific Character. Seeds hispid, petioles nerved on the under side.

THIS indigenous biennial plant grows abundantly in England, in a wild state, and is likewise much cultivated in our gardens as an article of diet. It flowers from June till August.

The root is spindle-shaped, fleshy, and of a yellow or orange colour. The stem is round, branched, furrowed, and about two feet in height. The leaves are large, petiolated, many times pinnated and hairy. The flowers are in many-rayed compound umbels, and, when in flower, flat on the top; but, as the seeds ripen, they become condensed into a concave form. The involucrum consists of several 
long trifid leaves; the partial involucrum is more simples the corolla is five-petalled and of a white colour; filaments capillary, supporting simple anthers: the germen supports two reflexed styles, which terminate in blunt stigmata; the seeds are two, egg-shaped, convex, rough on one side and flat on the other.

The wild and cultivated plants differ in their properties; the former is preferred for its seeds, which are more aromatic and pungent than those of the cultivated species, whilst the root is more ligneous, thinner, and less succulent. Every one is acquainted with the properties of the cultivated carrot. As an article of food, it is a vegetable possessing a considerable quantity of nutriment, which is known from proportion of saccharine matter which it contains. If we allow the juice of the carrot to ferment, a spirit may be obtained from it. Murray seems inclined to think that a decoction of carrots is useful in calculous affections and apthous swellings of the throat; we are however very much inclined to doubt its efficacy in the former disease, except as a diluent. Its chief medicinal use is as an external application to unhealthy and foetid sores, especially those of a cancerous nature; they are only to be considered however as palliatives in such cases, allaying pain and correcting the foetid discharges, by their antiseptic property, which depends on the saccharine matter they contain; they may also be used in gangrenous, scorbutic and other ill-conditioned ulcers, with the greatest relief. Where the parts are not too tender to forbid the use of the raw carrot, that is preferable to any other state; but, where they 


\section{1}

cannot be borne, if boiled and beat up into a soft pulp, it will excite no irritation.

The seeds are of a grey colour, aromatic odour, and a warm pungent taste. The activity of the seeds is but imperfectly extracted by water, their best menstruum is rectified spirit, by distillation a small quantity of essential oil may be obtained, of a yellow colour, pungent taste and aromatic odour. Their medicinal properties are carminative and diuretie, hence their utility in flatulences, \&c. They are but seldom used at the present day, as we are possessed of more active and efficacious medicines of similar virtue. The best way of giving the seeds is in powder. The dose is from $Э \mathbf{j}$. to 3 iss. It enters into no officinal preparation. 




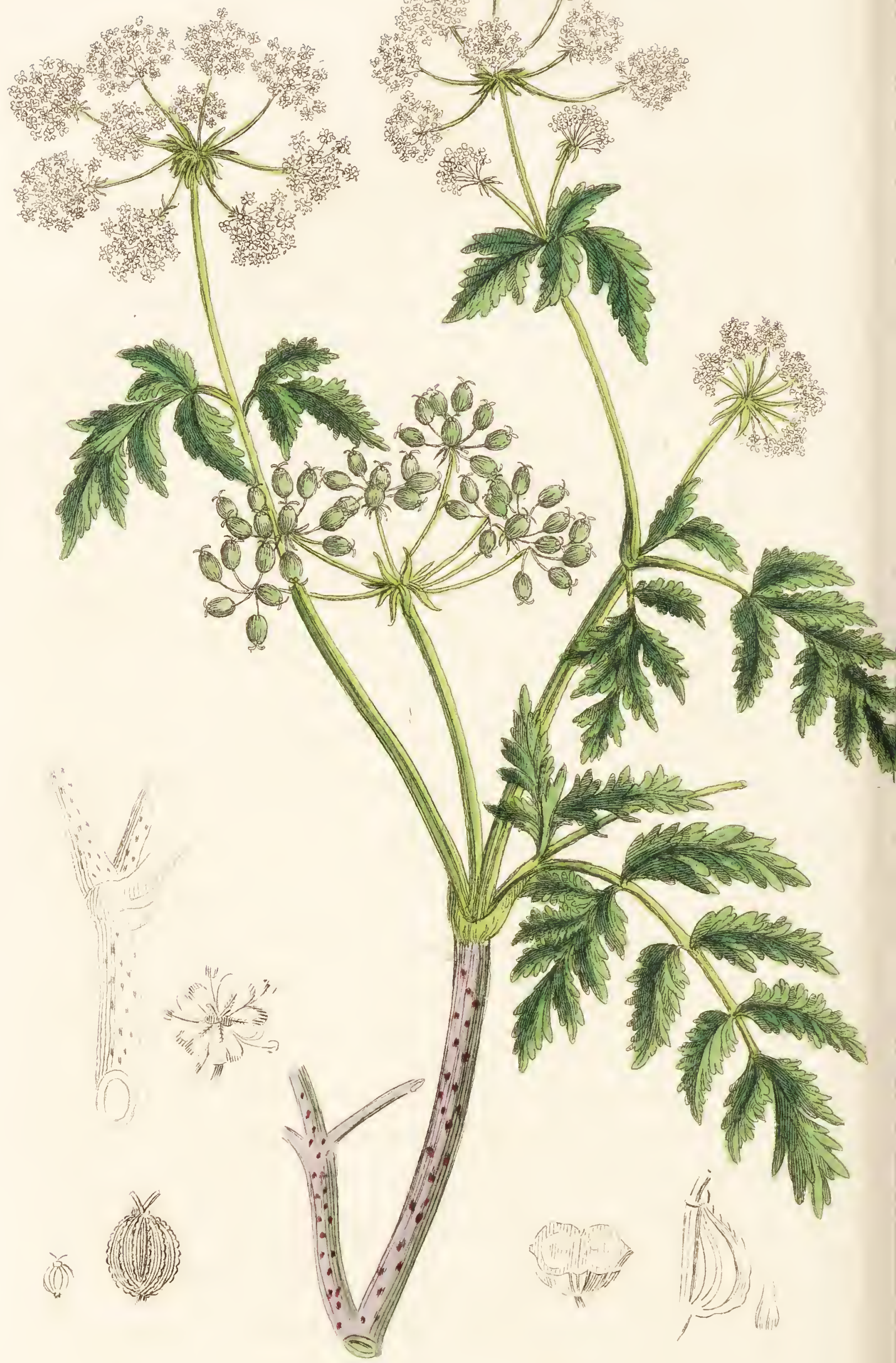

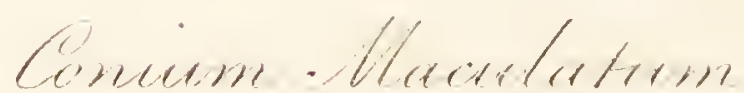


35.. CONIUM MACULATUM-CICUTA.

\section{Common Hemlock.}

Folia.

\section{Class V. Pentandria.-Order II. Digrnia.}

Natural Order. Umbellate.

Generic Character. Partial involucrum placed only on one side, three-leaved. Fruit nearly globular, five-striated, notched on both sides.

Specific Character. Seeds striated.

Heмьоск is a large biennial umbelliferous plant, growing in the neighbourhood of dunghills, ditches, and in most. shady places, flowering in June and July.

The root is fusiform, about as thick as the finger, yellowish externally and whitish within, exuding, when cut, a milky juice. The stalk is cylindrical from three to five feet high, thick, hollow, branched, leafy, smooth, shining, and beset with purple spots. The lower leaves are large, tripinnated, of a bright green colour, standing upon long foot-stalks, which proceed from the joints of the stem; the smaller or upper leaves are bipinnate. The flowers are forming open, numerous, umbels, which are both partial and universal. The involucrum consists of from three to seven short, reflected, lance-shaped leaflets, white at the margin: the partial involucrum is composed of three or four leaflets 
which are disposed on the external side of the umbel. The fowers are small, composed of five petals, unequal, heartshaped, and inclining inwards, and an entire calyx; stamina the length of the petals, supporting whitish anthers; the styles are filiform, larger than the petals, diverging and terminating in round stigmas. The fruit is oval, striated, containing two brownish seeds.

By attending to the botanical description given above, and more especially to the spotted and smooth appearance of the stalk, with the dark green colour and disagreeable odour of the leaves, we shall be enabled to distinguish it from the other umbelliferous plants, which it appears at first sight strongly to resemble. We should more particularly avoid mistaking the Cicuta virosa for it, which is a very deadly poison; we have different instances of its pernicious qualities in several works; the roots especially of that plant, where mistaken for esculent herbs, destroy the unfortinate persons who partake of them. Other plants have been mistaken for it, as the $\mathbb{E}$ thusa Cynapium, Cherophyllun Bulbosum, \&c. The leaves should be gathered when the plant is in full flower, at which time they are most active; when gathered they should be dried as quickly as possible, and then kept from the light, which impairs both their colour and medicinal properties. When dried it has a narcotic, strong and heavy odour, with a nauseous bitter taste. The Hemlock is an active medicine of the narcotic class, and when taken in over-doses produces very distressing and alarming symptoms, even sometimes deztroying life. Some anthors suppose it was a species of 
cicuta that was employed for the destruction of Socrates; but the term cicuta is used in so vague a manner by the ancients, that it is impossible to ascertain what plant they refer to: there is no doubt but they were acquainted with the poisonous qualities of the plant, as the description of symptoms occasioned by it perfectly coincide with our observations at the present day; such as vertigo, sickness, dimness of sight, anxiety, partial loss of senses, sometimes amounting to madness, cardialgia, convulsions; and generally the patient falls into a state of stupor, from which he is with difficulty roused; this is accompanied by a laborious respiration, and every symptom of apoplexy, which often carries off the patient. An active emetic is the first thing to be administered, then let him drink copiously of water and vinegar, which in some measure neutralizes the narcotic influence of the conium. If the apoplectic symptoms be urgent, it will be adviseable to open the jugular vein, or a vein in the arm, to relieve the congestion of blood in the head. Its influence is directed to the nervous system, but more especially to the brain; and it appears probable from several experiments, that it is absorbed and carried into the system by this mode, in order to effect the brain, for it acts with more power and activity when injected into veins, than when taken into the stomach. Many herbivorous antimals eat Hemlock with impunity.

Baron Stoerck was the first that directed our attention particularly to the conium as a medicine of considerable power in the cure of many diseases; we must not, however, give credit to all the assertions of this professor, as that 
would lead us into the greatest errors; for numerous experiments have been made by men of the greatest respectability, for the purpose of ascertaining the real virtues of this plant, and they have found it fall far short of their expectations. The baron mentions his successful treatment of scirrhus and cancer, by the external and internal use of the Hemlock; this alone will be a sufficient specimen of his extravagant notions of this medicine; it will, no doubt, allay the pain and correct the fotid discharges from cancerous sores, but if we employ it with the idea of effecting a radical cure, we shall be very much disappointed. To mention the diseases which Stoerck says he has cured with this medicine, would occupy many pages; therefore we shall content ourselves with merely mentioning a few, as gout, diseased bone, cataract, elephantiasis. The mention of these few diseases will be sufficient to give an idea of his incorrect views; and such statements are calculated much to deceive young practitioners. We are far from considering Hemlock as a medicine of no power; on the contrary, it is a remedy of considerable utility in the hands of judicious and candid practitioners. As a sedative, we may expect much advantage from its use in many discases; eren in cancer, by allaying irritability and pain, the patient will be relieved from constant sufferings. In hooping-cough, combined with ipecacuanha, (as indeed we mentioned when speaking of that article, it is a very desirable remedy. In affcctions of the chest, as phthisis, the extract conii, either alone or combined with ipecacuanha or zinci sulphas, it will allay the irritability of the lungs, and procure relief for 
the patient. It is reported to have cured syphylitic symptoms, and we have this from very good authority; yet we do not think any one would be so unwise at the present day as to depend on it for the radical cure of syphilis.

We must not place too much faith in it at all, or we shall be disappointed; for it is a medicine subject to the greatest variety, as regards its activity. The seeds are used by some, and said to equal the leaves; and Stoerck mentions the root, in its recent state, as the most active part of the plant, both as an external and internal remedy. The powder of the dried leaves is the most effectual and desirable form for administering the Hemlock; or the expressed juice of the fresh leaves; but the extract, obtained from a decoction of the leaves, is far less active, and not at all to be depended on. When employing a fresh parcel of either preparation, it will be proper to recommence with a small dose, to whatever extent it may have bcen carried previously; if we neglect this precaution, our patients' lives are in danger. Dose from gr. $\mathrm{ij}$. to $\exists \mathrm{j}$. of the powder. The extract may be carried to a greater extent. Officinal Preparations:-Ex. Conii. 




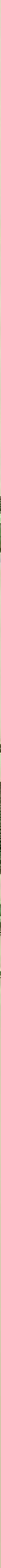




\section{FERULA ASSAFGETIDA.}

Assafatida, or Devil's Dung.

Gummi-Resina.

Class V. Pentandria.-Order II. Digunia.

Natural Order. Umbellate.

Generic Character. Fruit oval, compassed, plane, three streaks on each side.

Specific Character. Leaves alternately sinuate.

Thrs Assafoetida is an umbelliferous plant of considerable size, growing chiefly on the mountains in the provinces of Chorasaar and Laar in the South of Persia.

The root is perennial, tapering, and ponderous, and when fully grown the size of a man's arm, covered with a blackish coloured bark, and beset with numerous rigid fibres near its top: internally white and fleshy, containing a thick, milky, fœtid juice. The stalk is round, smooth, striated, erect, and two or three yards in height; about seven inches in circumference at its base, surrounded by several radical leaves, about two feet long, bipinnate, with alternate pinnules, smooth, sinuate, lobed and of a deep green colour and fotid smell. The flowers are disposed 
in plano-convex, terminal umbels. The seeds are oval, flat, foliaceous, of a reddish brown colour, rough and marked with longitudinal lines, having a porraceous bitter taste.

The gum resin is obtained from the root of the plant, when it is in full perfection, at that season of the year when the radical leaves are decaying; at this time the root is about four years old, the stalk is to be twisted from the root, from which the dirt is also to be removed: in this state it is left for forty days, being previously screened from the sun; at the expiration of this time a transverse incision is made through the upper part of the root, from which a milky juice freely exudes, and in twenty-four hours this is removed, and another section made, taking care to shelter them from the sun after each incision, this is to be repeated for many days till the whole of the juice is extracted, after which the root soon perishes. The whole of the juice which is of a milky nature, is collected into one vessel, and exposed to the sun and air to harden, by which it is materially changed in its appearance. We receive it in this country in irregular various sized masses, externally of a brownish colour, but, upon being broken, it displays tears of a whitish, reddish, and violet hue; that is accounted the best which contains a number of white and pale red tears. Its smell is exceedingly strong and disagreeable, like garlick; its taste is bitter and acrid. The properties of this gum-resin are much impaired by age, as, by long keeping, its odour is dissipated, in which the activity of the drug chiefly resides. 
The Assafoetida' is composed of a gummy and resinous matter, yet we cainot obtain a transparent tincture with proof spirit, but it is quite milky, unlike that procured with the rectified spirit which possesses the properties of the Assafoetida in a concentrated state. By distillation it affords a small quantity of pale essential oil, of an extremely strong smell. When rubbed up with water it forms a white, smooth emulsion.

The medical properties of this drug are numerous; viz. stimulant, antispasmodic, emmenagogues, expectorant and anthelmintic. As an antispasmodic we have evidence of its utility in hysterical eases, both during the paroxysm, and as means of preventing its recurrence: from its diffusive nature the influence of it is almost immediate: and Dr. Cullen mentions that he has found it very useful in the form of Enema, where, from the urgency of the symptoms the patient has not been able to swallow any thing. In Hypochondriasis, colic and dyspepsia, this remedy proves very serviceable in correcting spasm, which is a common attendant upon these diseases. In mild cases of spasmodic asthma, perhaps the Pil. Assafoetida will relieve as much as any medicine, by allaying the spasm and promoting expectoration, and in other chronic pulmonary complaints. By some females the Tinct. Assafœetidæ is held in high estimation, especially by those who are the subjects of hysterical affections and other nervous diseases, and it frequently proves very useful in such constitutions. In the form of Enema it is sometimes administered to expel worms. As an emmenagogue it is only applicable to 
such females as are of a languid, chlorotic habit, especially when there is want of energy both in the nervous and vascular systems.

When we wish for its immediate operation, as in a paroxysm of asthma or hysteria, the best form for administering it is either in Tinct. Assafoetidæ orSp. Ammon. Fætid. but in chronic cases, it will generally be preferred in the form of a pill, on account of its exceedingly disagreeable taste and smell. Some authors mention it as a useful external application in indolent tumors. The dose is from grs. v. to 3 SS.

Officinal Preparation. Mist. Assafœtidæ, Tinct. Assafœetidæ, Sp. Ammon. fœetid, Pil. Galb. C. Pil. Aloe cu Assafoetid. 


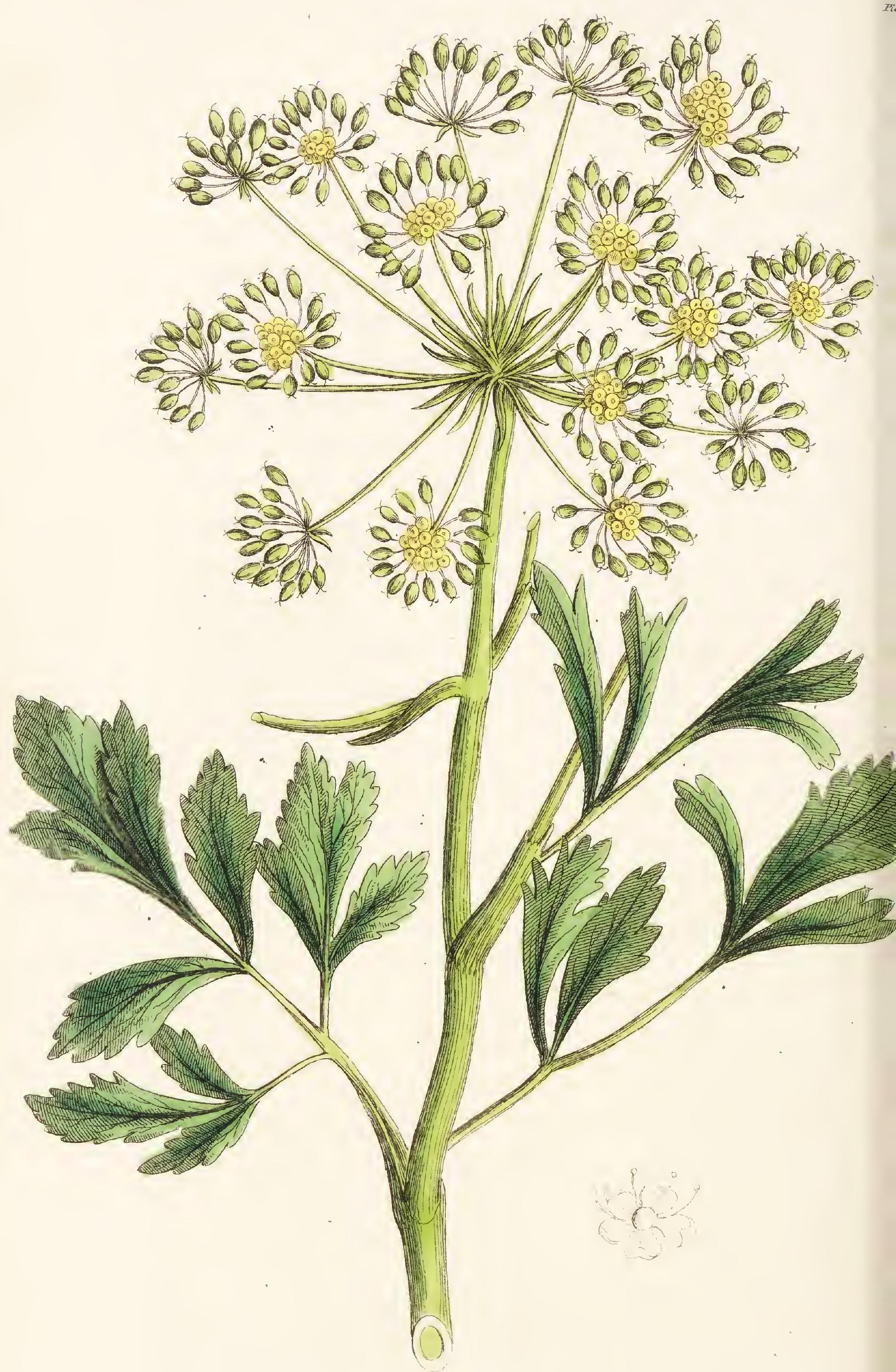


37. BUBON GALBANUM.

Loveageleaved Bubon-Galbanum.

Gumi-Resina.

Class V. Pentandria, - Order II. Diginga.

Natural Order. Umbellate.

Generic Character. Fruit, ovate, striated, and villose.

Specific Character. Leatlets ovate, wedge-shaped, sharp, finely serrated; umbels, few; seeds smooth; stems shrubby and glaucous.

The Galbanum is a perennial plant, native of Africa, in the neighbourhood of the Cape of Good Hope, flowering in June and July.

The stalk is commonly several feet in height, of a purplish colour, and covered with a glaucous exudation; towards the lower part it is woody and naked, but the upper part is jointed, branched, and leafy. The lower leaves are subtripinnated, standing on vaginant footstalks; the upper ones are nearly simple, three-lobed, irregularly serrated, and of a greyish colour. The principal umbel, which terminates the stem, is large, plano-convex, and composed of numerous radii; the lateral umbels are few and of a smaller size. The involucres consist of twelve narrow, lance-shaped, mem- 
branous, whitish leaflets, bent downwards, but the involucels consist only of six leaflets. The flowers are all fertile; the petals are equal, of a yellowish colour, with their tips inflected; the stamina are longer than the petals, supporting yellow anthers; the germen round, terminating in two short tapering styles: the seeds are oblong and of $a$ brownish colour.

The Galbanum of commerce is the gum-resin that is obtained from the stalks of the plant, from which it sometimes exudes spontaneously; but it is usually procured by making incisions into the stalks a few inches above the root, from thence the juice gradually trickles, and by exposure to the sun and air becomes of a proper consistence. That which is intermixed with the stalks and seeds is preferred by many, but its goodness depends on the number of white tears which it contains: we do not generally meet with many of these particles, for it most frequently comes to us in agglutinated, irregular masses of a light brown colour; when very dark and of the consistence of wax, it should be rejected as impure. A gum-resin may be procured from other species of Bubon, but much inferior to the true Galbanum both in taste and smell: that which is used in this country is chiefly imported from the Levant. It has a strong and disagreeable smell, with a bitterish, warm, and somewhat biting taste. When triturated with watcr it forms a milky mixture, in which the whole virtues of the drug reside; but, in consequence of its being so extremely nauseous, very few patients can take it in this form. It contains more gummy than resinous matter, therefore 
proof-spirit is not sufficiently pure to dissolve it; but the best menstruum is two parts of rectified spirit to one part of water: by distillation it affords a considerable quantity of essential oil.

Galbanum possesses properties very similar to the Asafoetida and other foetid gum-resins, and only differs from the former in being less active. Its medical properties are, antispasmodic, expectorant, \&c. hence its utility in hysterical cases, flatulences, asthmas, and other affections of the chest, where there is difficult expectoration: as an emmenagogue also the Galbanum may be administered with advantage. The best way of giving it, is in the form of pills, for when any of the fluid preparations are given, they seldom fail to disagree with the patient. It is recommended as an external application to discuss indolent tumours, and the best form for this purpose is the Emp. Galban. Comp. which may also be employed as a warm stimulating plaster in chronic inflammations, and to pains of long standing. The dose is from grs. $x$. to $3 \mathrm{j}$. Officinal Preparations:Pil. Galban. Comp. Tinct. Galban. Emp. Galban. Comp. Emp. Galbani. 



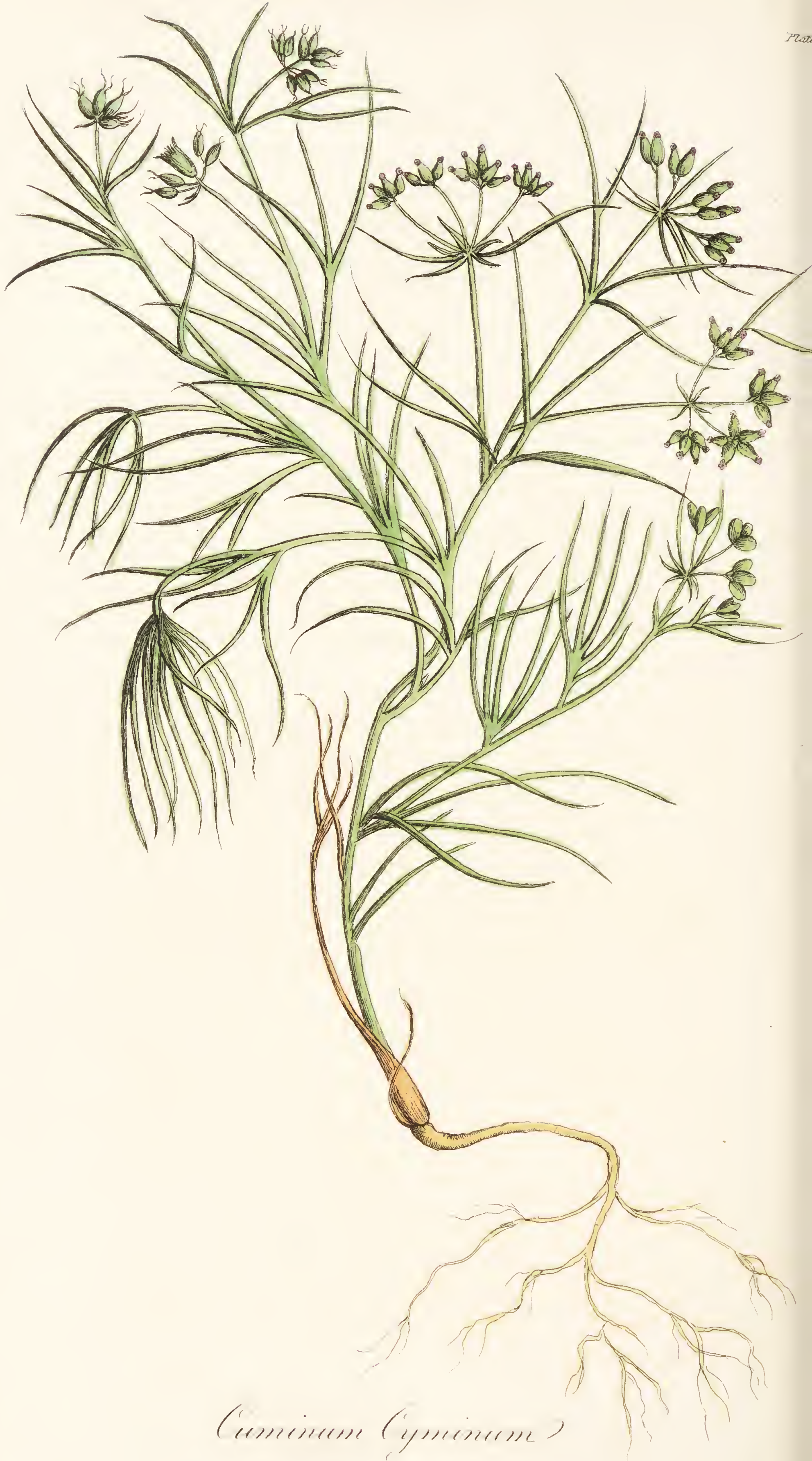




\section{CUMINUM CXMINUM.}

\section{Cummin.}

Semina.

Class V. Pentandria.-Order II. Digynua.

Natural Order. Umbellate.

Generic Character. Fruit, ovate, striated. Partial Umbels, four. Involucre, four-cleft.

The Cummin is an annual plant, a native of Egypt, and cultivated also in Malta and Sicily, from whence we receive the seeds. The plant very much resembles fennel in appearance, but is much smaller.

The stalk is about six inches in height, round, slender branched, and often procumbent. The leaves are narrow, linear, pointed, and of a dark green colour. The flowers are purple, composed of numerous four-rayed umbels, with a partial umbel, having seldom more than four flowers: both the partial and general involucres consist of four narrow pointed leaflets: the corolla is composed of five unequal petals, bent inwards, and notched at the apex; the filaments support simple anthers; the germen is ovate, large, and inferior, having two minute styles terminating in simple stigmas; the seeds are two, oblong and striated. 
Cummin seeds, which are the officinal parts of the plant, are of a brownish colour, having a warm, bitterish, unpleasant taste and aromatic odour: when infused in water their odour is extracted without any of their taste. A yellow oil is obtained by distillation, which has an acrid taste, and possesses the unpleasant odour of the seeds. Rectified spirit entirely extracts the virtues of the seeds.

Cummin is stomachic, carminative, and slightly antispasmodic. This is perhaps as powerful a carminative as any other medicine of this class: but, in consequence of its disagreeable taste and odour, is now almost entirely abandoned as an internal remedy. The Empl. Cumini, the only officinal preparation, is an useful warm application, both as promoting the absorption of indolent tumours, and correcting the unhealthy appearances of sloughing ulcers, such as irritable bubos, which frequently run into a sloughy state from the improper use of mercury; phagedenic sores may sometimes be much improved by this application, where others have failed, if we attend to the constitution at the same time. The dose is from grs. x. to 3 ij. 



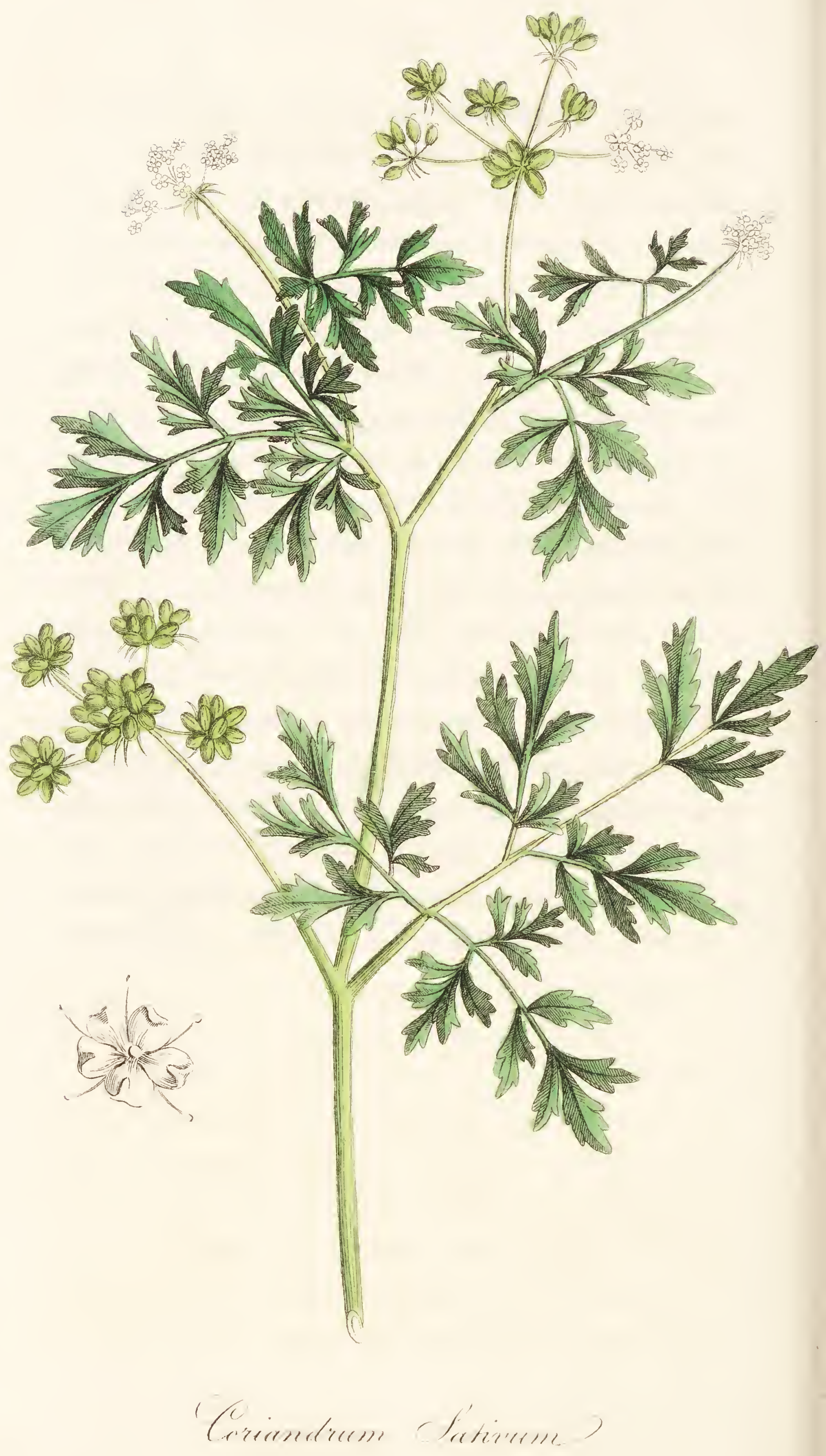




\section{CORIANDRUM SATIVUM.}

\section{Common Coriander.}

Semina.

Class V. Pentandria,-Order II. Digmia.

Natural Order. Umbellate.

Generic Character. Corolla, radiated. Petals, inflex-emarginate. Involucrum, universal; the partial ones halved. Fruit, spherical. Specific Characler. Fruit, globose.

ThE Coriander is an annual plant, and native of the South of Europe; it is very plentiful in Italy, Spain, and France, where it is often in such abundance as to prevent the growth of corn: it is frequently to be met with on the roadsides and amongst rubbish in this country: it flowers in June, and the seeds ripen in August.

The stem is about two feet in height, erect, branched, round, smooth, and slightly striated. The leares are compound, the lower ones being pinnated and cut into several irregular lobes, resembling those of common parsley: the upper are divided into narrow, linear-pointed segments. The flowers are of a white or reddish colour, and placed on terminal umbels; the general and partial umbels are 
both composed of many rays, with an involucre of one linear leaf and involucel of three lanceolate leaves: the calyx is fve-parted; the petals are also five, oblong, and inflected at the tips, and at the circumference the outermost are the largest; the filaments are slender and furnished with roundish anthers; the germen is globular, inferior, and supports two short styles, terminating in simple stigmas, and divisible into two concave hemispherical seeds.

The whole of this plant when in its recent state has a very disagreeable smell, and it is thought that its name was derived from ropss cimex, in consequence of its stinking abominably of bugs: the unpleasant odour of the plant is however destroyed by drying, and the seeds, which are striated and of a light colour, then have an aromatic odour, and a moderately warm pungent taste. A small quantity of pungent essential oil may be obtained by distillation, in which the activity of the Coriander resides. Rectified spirit extracts their active particles most completely, which is very imperfectly effected by water.

These seeds, like others of the same class of plants, possess carminative and stomachic properties; and they are seldom, if ever, employed alone, but chiefly as adjuncts, to correct the effects or conceal the properties of other medicines. They may be employed in flatulencies, to improve the weakly state of the stomach, which is often the cause of that complaint. Murray mentions, that an Infus. Coriandri has been given for the cure of quartan fever, taken a short time before the paroxysm. The dose is from gr. $\mathrm{x}$. to $3 j$. It enters into no officinal preparation. 



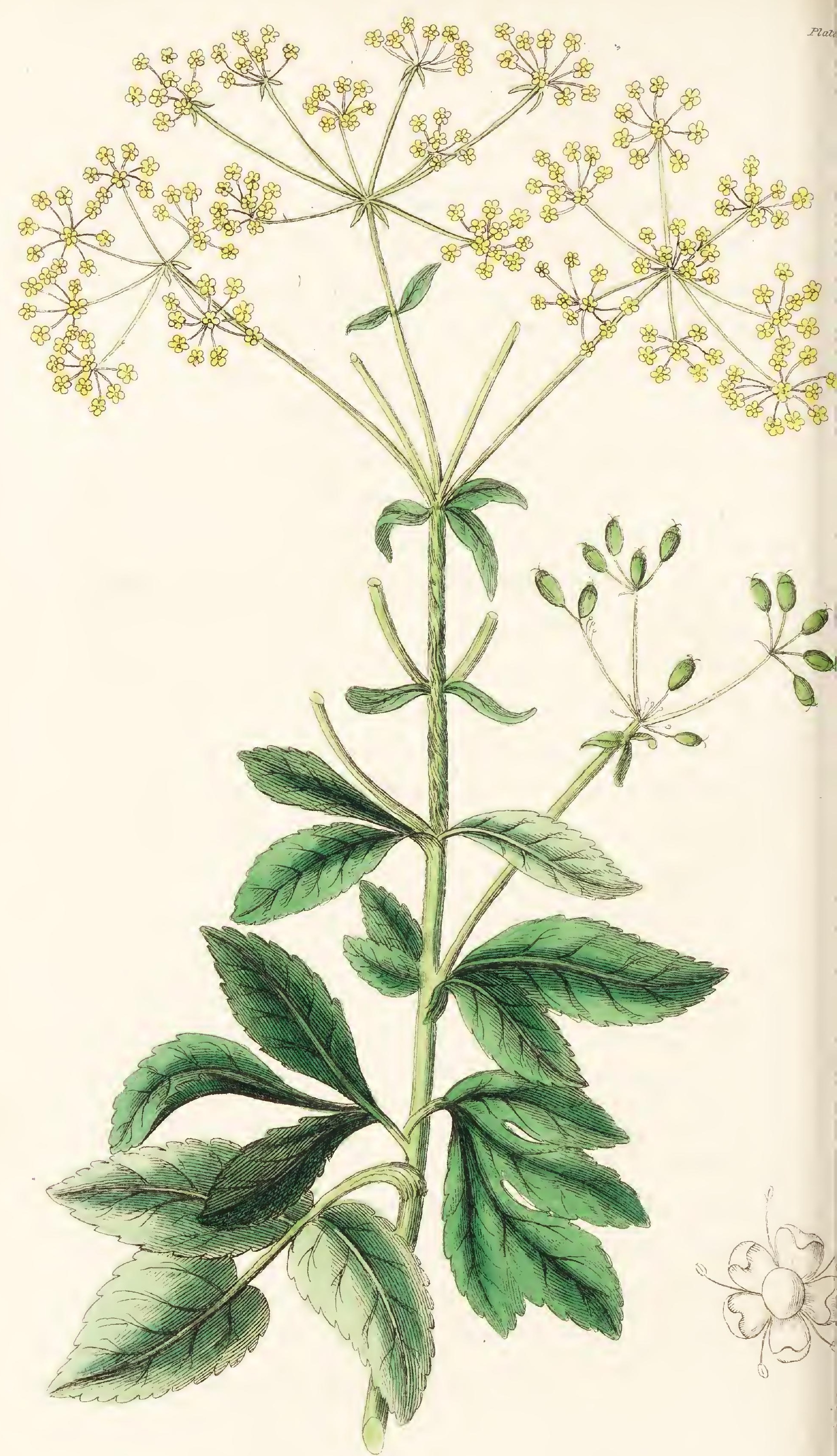

- Pessivenere (jenfermerne) 


\title{
40. PASTINACA OPOPONAX.
}

\author{
Opoponax, or Rough Parsnep.
}

Gummi-Resina.

Class V. Pentandria.-Order II. Digynia.

Natural Order. Umbeliate.

Generic Character. Fruit, eliptical, compressed flat;

Petals, involute, entire.

Specific Character. Leaves, pinnate; leaflets excised at the base in front.

THE Opoponax is a perennial plant, native of the South of Europe; most abundant in Italy and Sicily.

The root is thick, fleshy, tapering, and of a yellow colour. The stem is about six feet in height, strong, branched, and rough at the base. The leaves are pinnated; the pinnæe are oblong, veined, and serrated. The flowers are disposed in flat umbels, which terminate the stem; they are of a yellow colour: both the general and partial umbels consist of several rays; the general and partial involucres are commonly wanting; all the florets are fertile; the petals are five, incurvated; the filaments spreading, and longer than the petals, supporting roundish anthers; the germen is inferior, supporting two reflexed styles: the fruit eliptical and flat, containing two seeds. 
This plant, although it is met with in this country, does not come to that perfection which it does in its native soil ; therefore all the Opoponax used in the shops is imported chiefly from the East Indies and the Levant: and we receive it either in tears of a reddish colour, or more commonly in irregular masses of a brownish red colour, interspersed with some whitish tears. It is procured by making incisions into the lower part of the stalk, near the root, when a juice exudes, which concretes by exposure to the sun and air. It is of a lighter colour internally than externally, and when broken has a somewhat variegated appearance, with a disagreeable odour, and a warm bitterish taste. It forms, when triturated with water, a whitish emulsion, which upon standing deposits some resinous matter. Spirit takes up but a small quantity of Opoponax; and when exposed to distillation with water, but a very small quantity of essential oil is procured. It is composed of gummy matter and resin; the former in the largest quantity. The medical properties of this drug are emmenagogue, expectorant, and antispasmodic. It is sometimes given in combination with other medicines of the same class in chronic asthma, and cases where expectoration is difficult; but it is rarely employed by modern practitioners, in consequence of its being much inferior to the other foetid grum-resins, which we might à priori expect from its sensible properties being less obvious. The dose is from grs. x. to $3 \mathrm{ij}$. It enters into no officinal preparation, but formerly it was contained in the Pil. Galban. Comp. of the London Pharmacopœia, but now a larger quantity of Galbanam supplies the place of the Opoponax. 



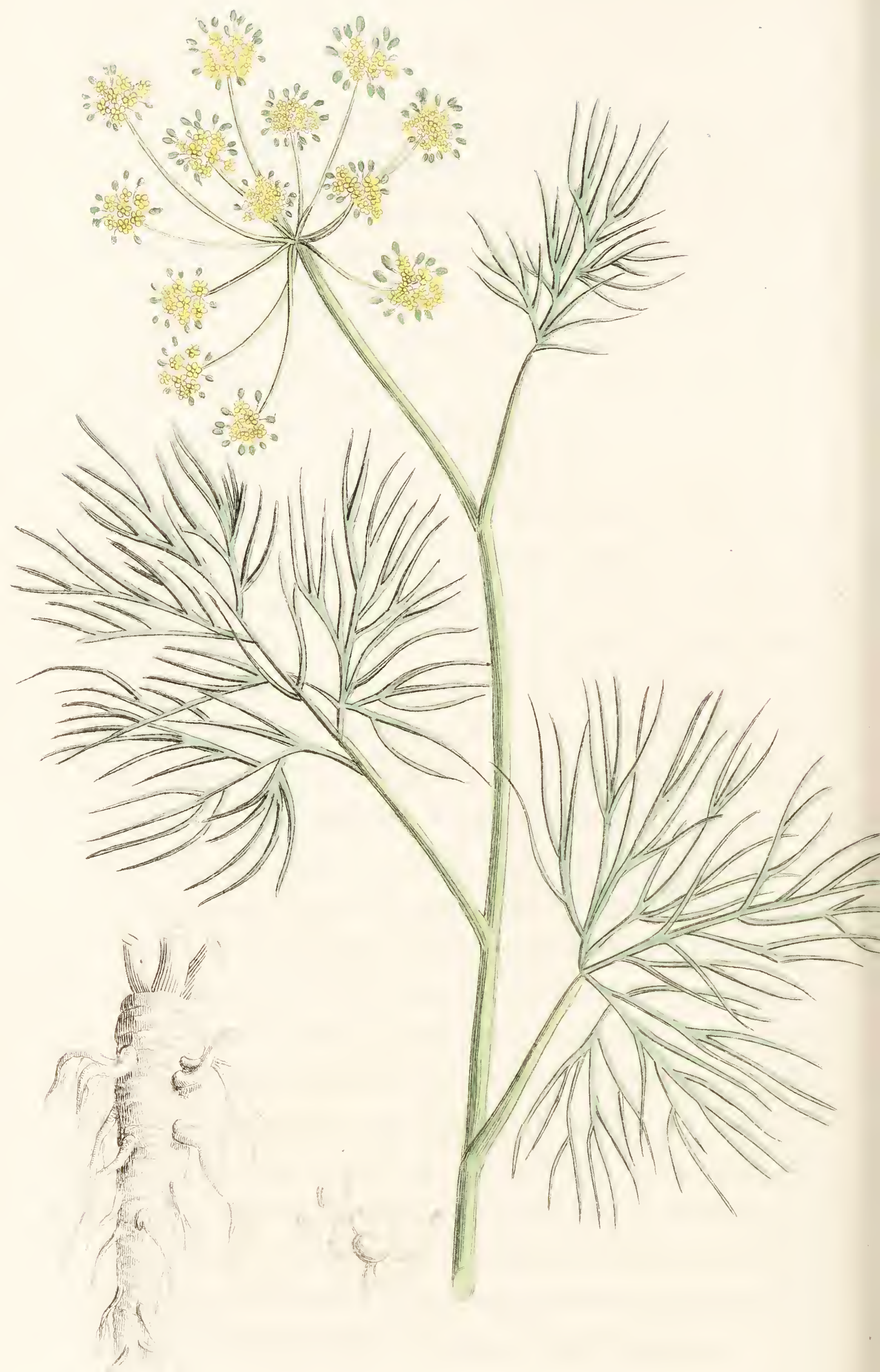




\section{ANETHUM FOENICULUM-FOENICULUM DULCE.}

Common Fennel.

Radix et Semina.

\section{Class V. Pentandria.-Order II. Digynia.}

Natural Order. Umbellatæ.

Generic Character. Fruit, subovate, compressed, striated. Petals, involuted and entire. Specific Character. Fruit, ovate.

THIS is a perennial plant, growing on rocky soils in the South of Europe; it is also to be met with in considerable quantities in similar soils in England, where it is much cultivated in gardens for culinary purposes.

The root is tapering and fibrous, from which spring several stalks four or five feet in height, erect, branching, striated, and round. The leaves are alternate, tripinnate, and proceed from the joints upon sheathy footstalks; the leaflets are long, linear, pointed, and of a dark green colour. The flowers are produced in large, terminal, flat, manyrayed umbels; the corolla is composed of five yellow, ovate, emarginate petals, having their points turned in- 
wards; the filaments are spreading, and shorter than the corolla, bearing double anthers. The germen is smooth, striated, and covered by the nectary, supporting two short styles: the seeds are oval and three-ribbed.

There are two varieties of the species Foniculim here described, which are used medicinally, the Foniculum Vulgare and Feniculum Dulce; it is from the latter the seeds are procured, and from those plants which grow in warm climates, for they never come to perfection in this country: the roots, however, which are chiefly afforded by the former variety, are generally the product of English plants. The seeds are not exclusively obtained from the Foniculum Dulce, for the seeds of the other variety possess similar properties, though in an inferior degree; they are sweeter, as the name indicates; but less pungent, and not so warm. The virtues of the fennel-seeds are extracted but imperfectly by water; by distillation they afford a considerable quantity of essential oil, which possess the whole properties of the seeds in a concentrated form. By expression, a quantity of oil may be obtained nearly inodorous and insipid.

The root is of a brownish colour externally, and white and ligneous wirhin; of a sweetish taste, and slightly aromatic, but much inferior to the seeds; the virtues of it arre extracted both by water and spirit. This part of the plant is said to be aperient, diuretic, and carminative; but if it do possess such properties, it must be in a very slight degrec.

"The seeds are carminative and stomachic, but not equal 
to the dill, carraways, \&c. hence they are seldom used. The best mode of administering the secds is in powder, in doses of from grs. xr. to 3 i

Officinal Preparation:-Aq. Foniculi. Oleum Foniculi. 




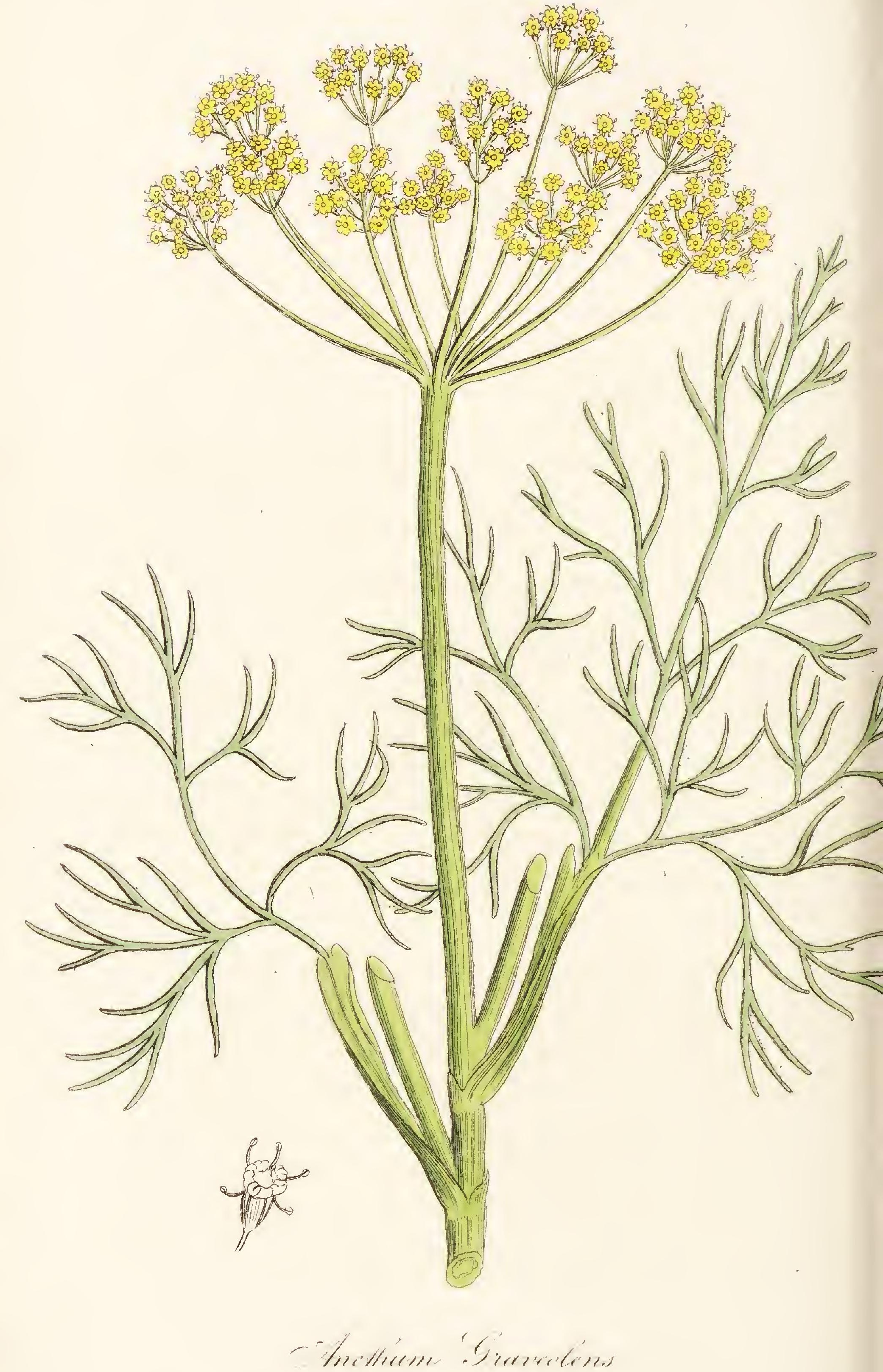


42. ANETHUM GRAVEOLENS-ANETHUM.

\section{Common Dill.}

Semina.

Class V. Pentandria.-Order II. Digynia.

Natural Order. Umbelintæ.

Generic Character. Fruit, subovate, compressed, striated. Petals, involuted, entire.

Specific Character. Fruit, compressed.

THIs annual umbelliferous plant is a native of Spain and Portugal, and other warm climates; and is also cultivated in this country, flowering in June and July.

The root is strong, tapering, and sends off strong fibres; several erect stems proceed from the same root, which are smooth, grooved, jointed, branched, and about two feet in height. The leaves are alternate, smooth, and doubly pinnated, standing upon sheathing footstalks; the pinnæ are linear and pointed. The flowers are in large, flat, terminal umbels; it has no involucrum: the corolla is composed of five ovate, obtuse, concave, yellow petals, with their points inflected; the filaments are yellow, and longer than the corolla, with roundish anthers; the germen is inferior, and covered by the nectary, supporting two styles, which ter- 
minate in obtuse stigmas. The seeds are two, oval, flat, striated, and surrounded by a membranous expansion.

The seeds, which are the only officinal parts of the plant, contain the whole of its properties, and are much superior to the leaves, root, or any other part. They have a moderate warm pungent taste, and a peculiar aromatic odour: their whole virtues appear to reside in an essential oil, which they yield in considerable quantity by distillation. Water very imperfectly extracts their virtues; spirit is the best menstruum. A few drops of the essential oil will generally answer every purpose you may wish from the sceds; and the distilled water (which is only, a solution of the oil) is a very useful vehicle in rendering medicines more palatable, and at the same time possesses slightly stimulating properties. The seeds are stomachic and carminative, and are given in the flatulent colic of children, dyspepsia, \&c. but they are chiefly employed as an adjunct to other medicines. Dose from grs. $x$. to $3 j$.

Officinal Preparation:-Aq. Anethi. 


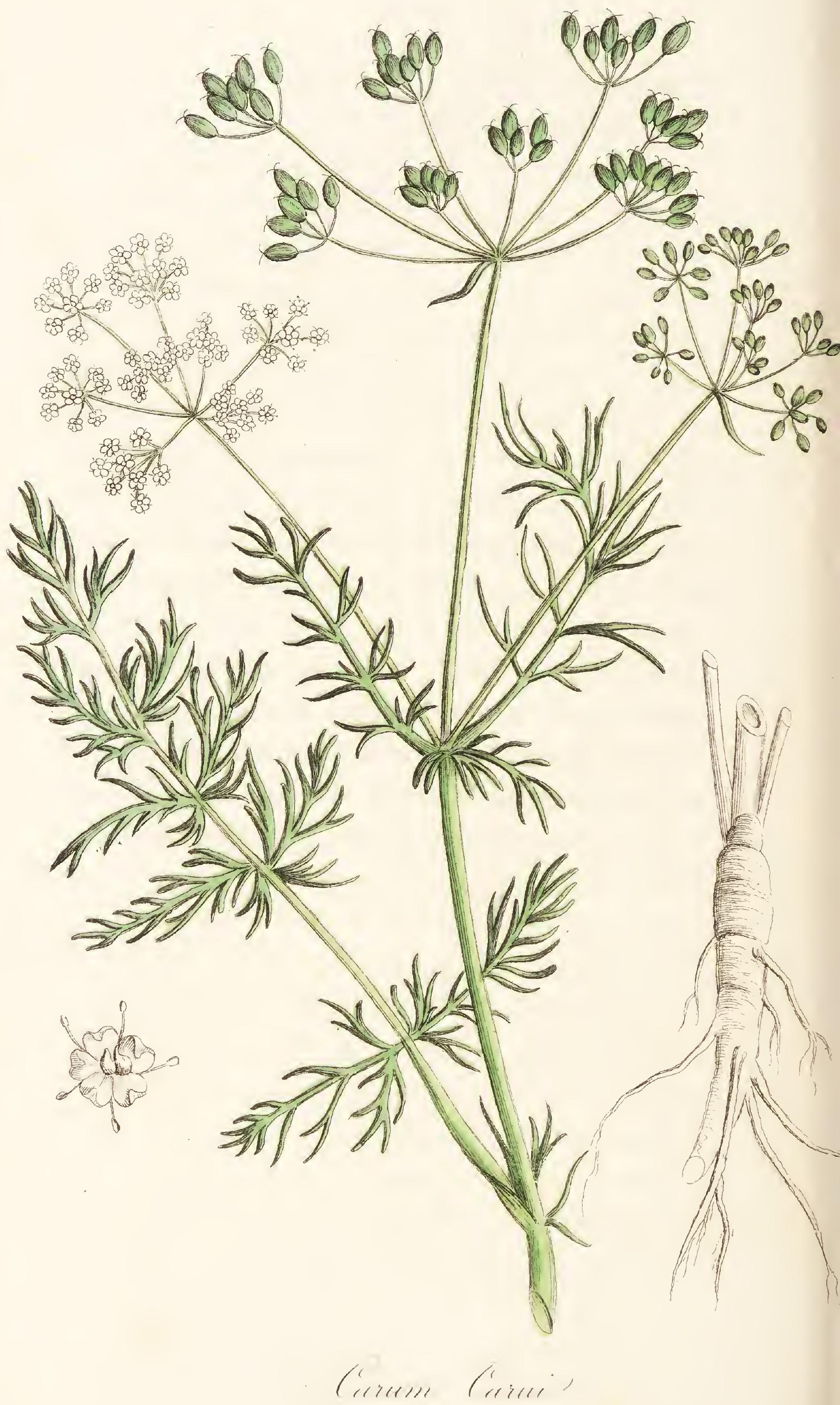




\section{CARUM CARUI.}

\section{Common Carraway.}

\section{Semina.}

\section{Class V. Pentandria.-Order II. Digynia.}

\section{Natural Order. Umbellate.}

Generic Character. Fruit, ovate, oblong, striated. Involucre, one-leafed. Petals, keeled, inflexemarginate.

$\mathbf{T}_{\text {HIS }}$ umbelliferous plant is a native of the Northern parts of Europe; it is not, however, met with in any considerable quantities in Britain, except when cultivated for culinary purposes. It flowers in May and June, and the seeds ripen in August.

The root is biennial, fusiform, and of a whitish colour. The stalk channelled, round, smooth, branching, and two or three feet in height. The leaves are long, smooth, and subdivided into many pinnulæ, which are narrow, linear, point= ed, and of a deep green colour. The flowers are in numerous terminal erect umbels, and in most instances consist of ten radii, furnished with a partial and general involucre each composed of four narrow leaflets, but they are sometimes altogether wanting. The corolla is composed of five nearly equal petals, obtuse, curled inwards, and of a white colour, the filaments are slender, supporting small round anthers; the germen inferior, and supports short capillary 
styles, with simple stigmas; the seeds are two, oblong blunt, striated, and of a brown colour.

Carraway seeds have an agreeable aromatic odour, with a moderately warm and bitterish taste. 'The leaves and root also possess similar properties, but are much inferior to the seeds.

The seeds contain a considerable quantity of pungent essential oil, of a yellow colour, which may be procured by distilling them in water. The leaves also afford a similar oil, but in less quantity. The activity of the seeds appears to reside almost exclusively in the oil, and rectified spirit extracts most of it, and is therefore a better menstruum than water, which becomes very imperfectly impregnated with the properties of the seeds by infusion; but the best mode of administering this medicine is either in the powder or the oil. Carraway seeds are carminative and stomachic ; and in consequence of possessing these properties are employed in flatulencies, hysteria, \&c.; by some they are considered to have the power of promoting expectoration, and also to increase the secretion of milk in nurses: but it is very doubtful whether they possess these latter properties. The chief purposes for which Carraway Seeds are used, are of a culinary nature : they also occasionally prove useful adjuncts to other medicines.

Dose from grs. $\mathrm{x}$. to $3 \mathrm{ij}$. Officinal Preparations :-Ol. Carui., Aq. Carui, Spir. Carui. 



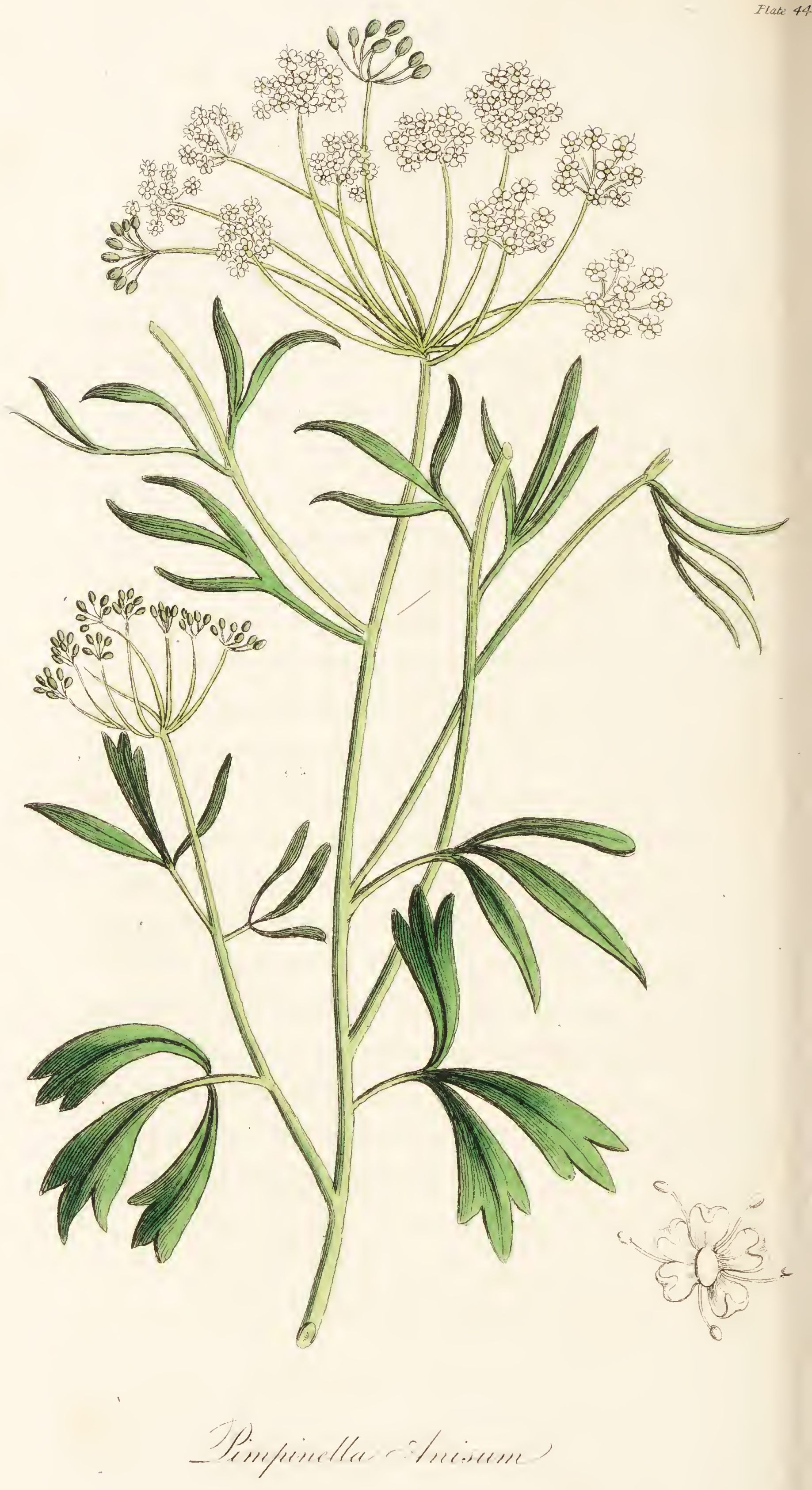




\section{PIMPINELLA ANISUM.}

\section{Anise.}

Semina.

\section{Class V. Pentandria.-Order II. Dignnia.}

\section{Natural Order. UmbenLate.}

Generic Character. Fruit, ovate, oblong. Petals, inflected. Stigmas, nearly globular.

Specific Character. Radical leaves, trifid and incised.

$\mathbf{T}_{\mathrm{HE}}$ Anise is a small, delicate, annual plant; a native of Egypt, Syria, and other Eastern countries; it is also cultivated in some of the Southern parts of Europe, and in this country also; it does not, however, generally arrive at maturity in England; those seeds imported from Spain, which are smaller than others, are preferred to the larger varieties which are more mucilaginous. It flowers in July and ripens its seeds in August.

The root is small and tapering; the stalk smooth, branched, striated, jointed, and about a foot in height. The lower leaves are roundish, lobed, and toothed; whilst the upper ones are divided into narrow pinnated segments. The flowers small, white, and disposed in flat terminal umbels without involucres. The corolla consists of five ovate petals, which are bent inwards; the filaments tapering, and supporting roundish anthers. The germen is egg 
shaped, with short styles and simple stigmas; the seeds oblong, striated, and of a green colour.

Aniseeds have an aromatic odour, and a pleasant, warm, sweetish taste. Rectified spirit completely extracts the virtues of the seeds, and water very imperfectly. By distillation, a yellowish essential oil is procured, which possesses the properties of the seeds, and is less pungent than most essential oils, on which account it is generally preferred for children; this oil has the peculiar property of congealing when exposed to cold, in a similar manner to the Ol. Olivæ, By expression an oil may also be obtained, which is nearly insipid and inodorous; but as it is commonly mixed with some of the essential oil, the properties of the Anise may be detected in it.

Other species of the Pimpinella were once used by practitioners, but this is now the only one employed; all other kinds are now entirely discarded from practice.

The medical properties of Anisceds are carminativc and stomachic: they are frequently given to children to relieve flatulent colic, dyspepsia, diarrhœa, \&c. and are recommended, like the former seeds, to promote expec.toration and the secretion of milk. This medicine, like the Carraway Seeds, is very seldom employed alone, but chiefly as an adjunct to medicines of superior efficacy, and to disguise others.

Dose from grs. $\mathrm{xx}$. te $3 \mathrm{ij}$. Officinal Preparations:-Ol. Anisi. Spir. Anisi。 




\section{SAMBUCUS NIGRA.}

\section{Common Black Elder.}

Flores, Baccæe et Liber.

\section{Class V. Pentandria.-Order III. Trigynia.}

\section{Natural Order. Dumosæ.}

Generic Character. Calyx, five-parted. Corolla, five-cleft. Berry, three-seeded.

Specific Character. Cymes, five-parted; leaves, pinnate; stem, arboraceous.

THE Elder is a small, shrubby, indigenous tree, which grows wild in hedges, flowering in May, and its berries ripening in September.

The stalk is branched, and particularly towards the top, about twelve or fourteen feet in height, and covered with a rough greyish bark. The wood is hard, white, and internally filled with spongy pith. The leaves pinnated, being composed of five, oval, pointed, serrated leaflets of a deep green colour. The flowers are small and white, being disposed in terminal clustres; the calyx is permanent, superior, and five-cleft ; the corolla monopetalous, wheel-shaped, and somewhat convex; the berries globular, and when ripe, of a purplish black colour.

The flowers of the Elder, which are the parts of the plant most frequently used medicinally, possess a strong but not unpleasant odour, which is given out to spirit and water by distillation, and at the same time a small quantity of butyra- 
ceous essential oil is obtained. An infusion of the recent flowers is slightly aperient; their odour is impaired by drying. They are employed chiefly in cruptive diseases, and are said also to promote the expectoration from the luug. Their chief use is as an external application in the form of ointment, but do not appear to add to the efficacy of the ointment.

The berries are round, small, inodorous, of a blackish colour; their taste is sweetish, and not unpleasant. By expression they afford a fine purplish juice, which contains saccharine matter and malic acid. They are slightly aperient and were formerly much used in several chronic disorders, but have now fallen into disuse. The berries of the Sambucus Ebulus are sometimes substituted for them, but it is of very little consequence, as their properties are very similar.

The inner bark has scarcely any smell or taste: on being chewed, it first impresses a sweet taste on the tongue, but this is soon followed by a slight but permanent acrimony. Both water and spirit extract its virtues; a decoction of this bark is strongly recommended by Sydenham as a hydragogue, and at the same time it proves emetic, if the dose be large; and he strongly' recommends it in dropsy: but it is now, in common with the other parts of this plant, nearly laid aside. The leaves possess similar properties to the bark.

Dose of the inner bark from grs. v. to $9 i j$. and the flowers may be given in a rather larger dose. The juice $\bar{z}$. to $z$ iss. Officinal Preparation:-Succus Spissatus Sambuci Nigræ. Ung. Sambuci. 



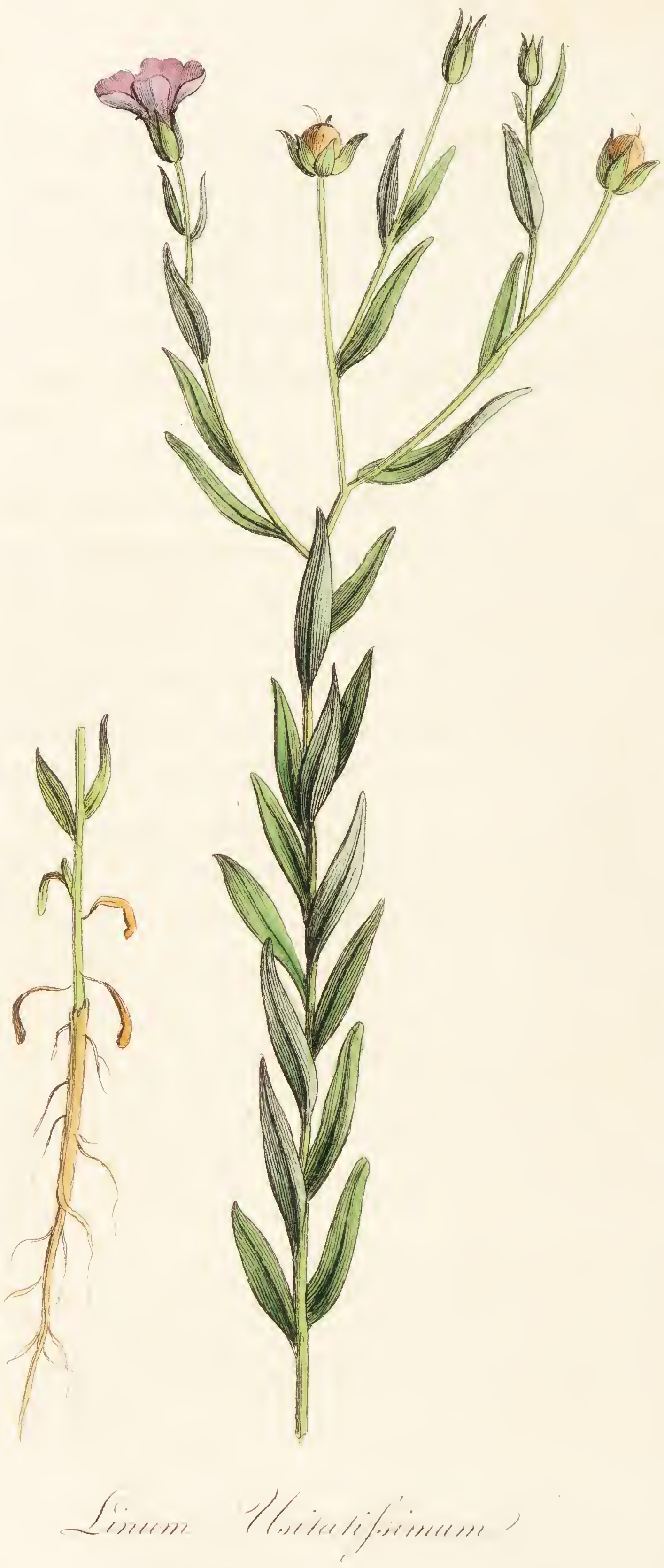




\section{LINUM USITATISSIMUM.}

\section{Common Flax.}

Semina.

Class $\mathrm{V}$. Pen'tandria-Order V. Pen'tagynia.

Nalural Order. Grutnales.

Generic Character. Calyx, five-leaved. Petals, five.

Capsule, five-valved, ten-celled. Seed, solitary.

Specific Character. Calyces and capsules mucronate; petals crenate; leaves lanceolate, alternate; stem, commonly solitary.

$\mathbf{T}_{\mathrm{HIS}}^{\prime}$ useful annual plant is a native both of the Northern and Southern parts of Europe, growing chiefly in cornfields. In Egypt it is generally larger than we meet with it in other countries; it is cultivated in England in large quantities, both for medicinal and economical purposes. It flowers in July, and the seeds ripen in September.

The root is simple and fibrous. The stem is erect, round, leafy, smooth; and branched towards its top, rising from one to two feet in height. The leaves are lanceolate, entire, acute, smooth, sessile, nearly vertical, and placed alternately on the stem and branches. The flowers are solitary; the calyx consists of five, pointed, somewhat ovate, keeled segments; the corolla is of a sky-blue colour, funnel-shaped, and divided into five, oblong, striated, notched, petals; the 
filaments are tapering, erect, and united at the base, supporting simple anthers; the germen is oval; styles filiform and erect, and furnished with reflected stigmas; the capsule globular; each cell contains one seed.

The Common Flax is an article of such general use for various economical purposes, that its cultivation has attracted the attention of people of this country; but, although it is raised in considerable quantities in some districts, the greater proportion is imported from the Baltic.

The Seeds, which are the only officinal parts of this plant, should be collected when they are perfectly ripe, (at which time also the whole plant is gathered for other purposes,) and then exposed to the sun, where they soon become dried and ready for use. They are of a brownish colour, glossy, oval, flat, and smooth, having a sweetish mucilaginous tuste, without any smell. They contain a considerable quantity both of mucilage and oil, the former appears to reside in the cuticle, and may be extracted by infusion or decoction in water. The oil is procured by expression, which should be performed without heat, but where this process is carried on upon a large scale, the manufacturers commonly employ heat, as they are then enabled to obtain a larger proportion of oil from a given quantity of seeds; and it is probably on this account that the oil of commerce so soon becomes rancid. There is always some mucilage mixed with it, but the quantity depends on the mode of expression and the force employed.

Linseed Oil is less palatable than the other fixed oils, and consequently is seldom administered internally. It does not 
congeal by exposure to cold like olive oil. Its chief employment, medicinally, is as an external application; and, mixed with lime water, forms a very servireable remedy to burns and scalds, keeping them in a moist and comfortable state.

Linseed is a very useful emolient and demulcent; the best form for giving it, is either in decoction or infusion, in which state it is frequently employed as a beverage in various acute diseases, particularly in affections of the urinary organs, where the patient suffers considerably from the acrimony of the urine; and also in the first or inflammatory stage of Gcnorrhœa, when the ardor urinæ is very distressing; by drinking daily about a quart of linseed-tea, with nitre, this symptom will be much -abated; this beverage is also serviceable in inflammatory fevers, \&c. In Catarrh, Cynanche, Diarrhoea, \&c. the Infus-Lini is a desirable beverage. The oil, mixed with an equal quantity of Tinct. Rhei. will often relieve a dysenteric state of bowels, and we may occasionally add to this a few drops of the Tr. Opii.

Linseed-meal, which is merely the seeds deprived of their oil by expression, and ground into powder, will form a very useful and cheap suppurating cataplasm. The seeds are seldom given in substance, and the dose of the infusion or decoction is ad libitum. Officinal Preparations :-Inf. Lini et $\mathrm{Ol}$. Lini s , 



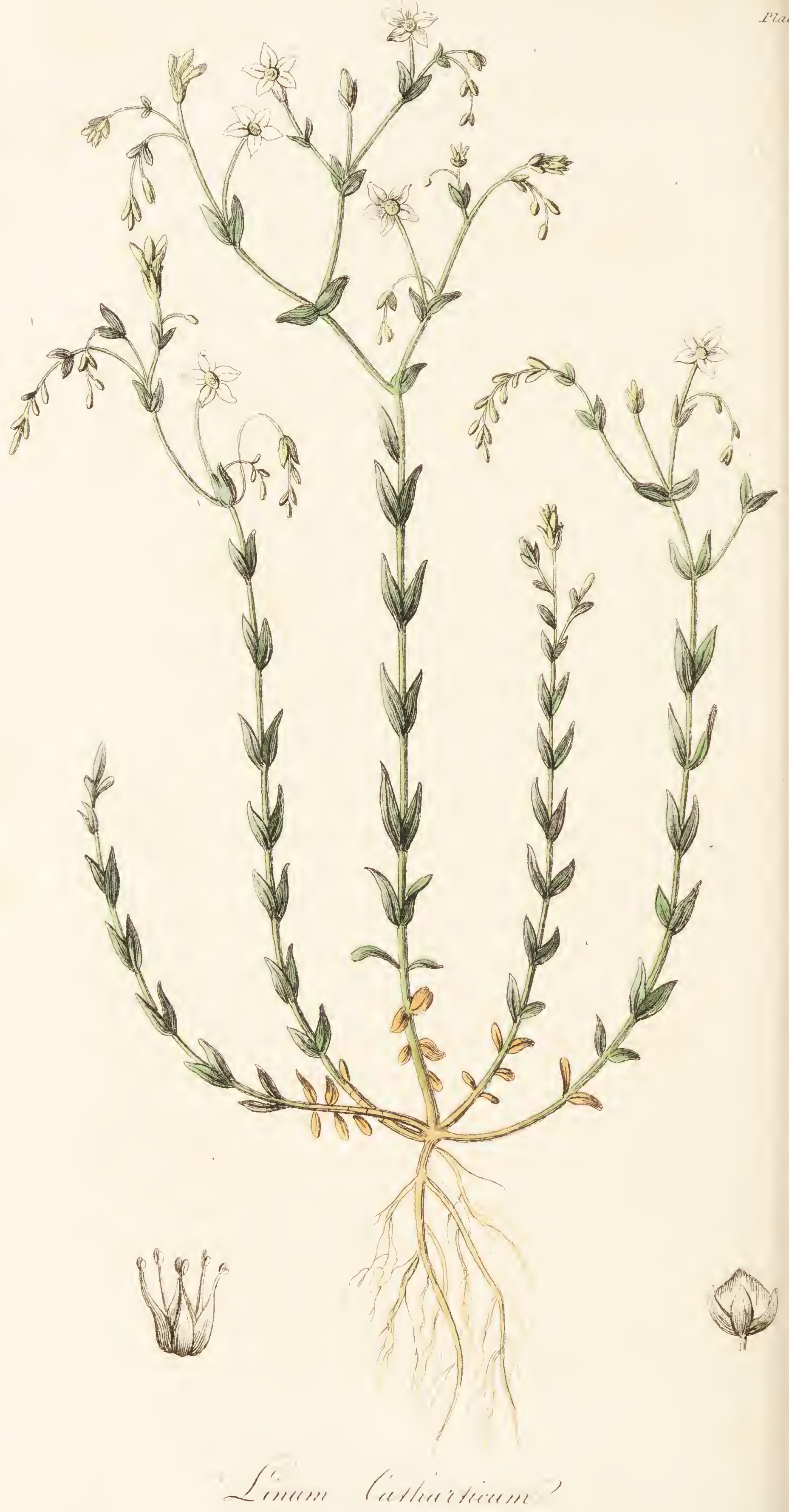




\section{LINUM CATHARTICUM.}

\section{Purging Flax.-Mill Mountain.}

Herba.

Class V. Pentandria - Order V. Pentagyina.

Nalural Order. Gruinales.

Generic Character. Calyx, five-leaved. Petals, five. Capsule, five-valved, ten-celled. Seed, solitary.

Specific Character. Leaves opposite, ovate-lanceolate; stalk dichotomous; corollas acute.

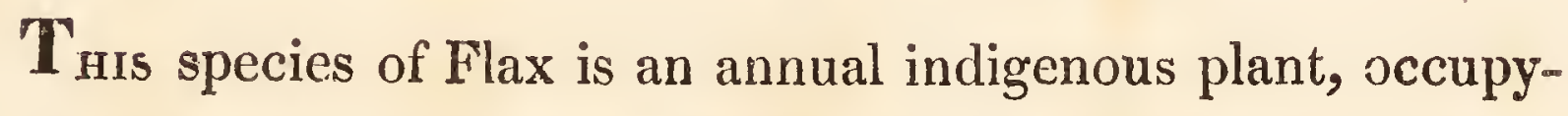
ing dry meadows and pastures, and flowering from $\mathbf{J}$ une to August.

The root is small and fibrous, from which arise four or five delicate, erect, leafy, and smooth. stems, from three to nine inches in height, and supporting several flowers. The leaves are in pairs, of an ovate-lanceolate shape, entire, midribbed, green on the upper surface, and downy beneath. The flowers are small, pentapetalous, white, and hang down before they open, but afterwards becoming erect; the calyx is divided into five pointed, one nerved segments; the petals obovate, acute, white and spreading; the filaments united below; germen roundish, with capitate stigmas.

This herb has a very bitter disagreeable taste, but possesses scarcely any odour. The medicinal properties of it are pur- 
gative, as its name implies; and it is reported by old authors to be a very safe and effectual one. Its virtues are completely extracted by water, and it may be administered either in infusion or in substance. It is a medicine, however, that has fallen very much into disuse, and might very well be dispensed with altogether.

Dose from $9 \mathrm{j}$. to $3 \mathrm{j}$. It enters into no Officinal Preparation. 


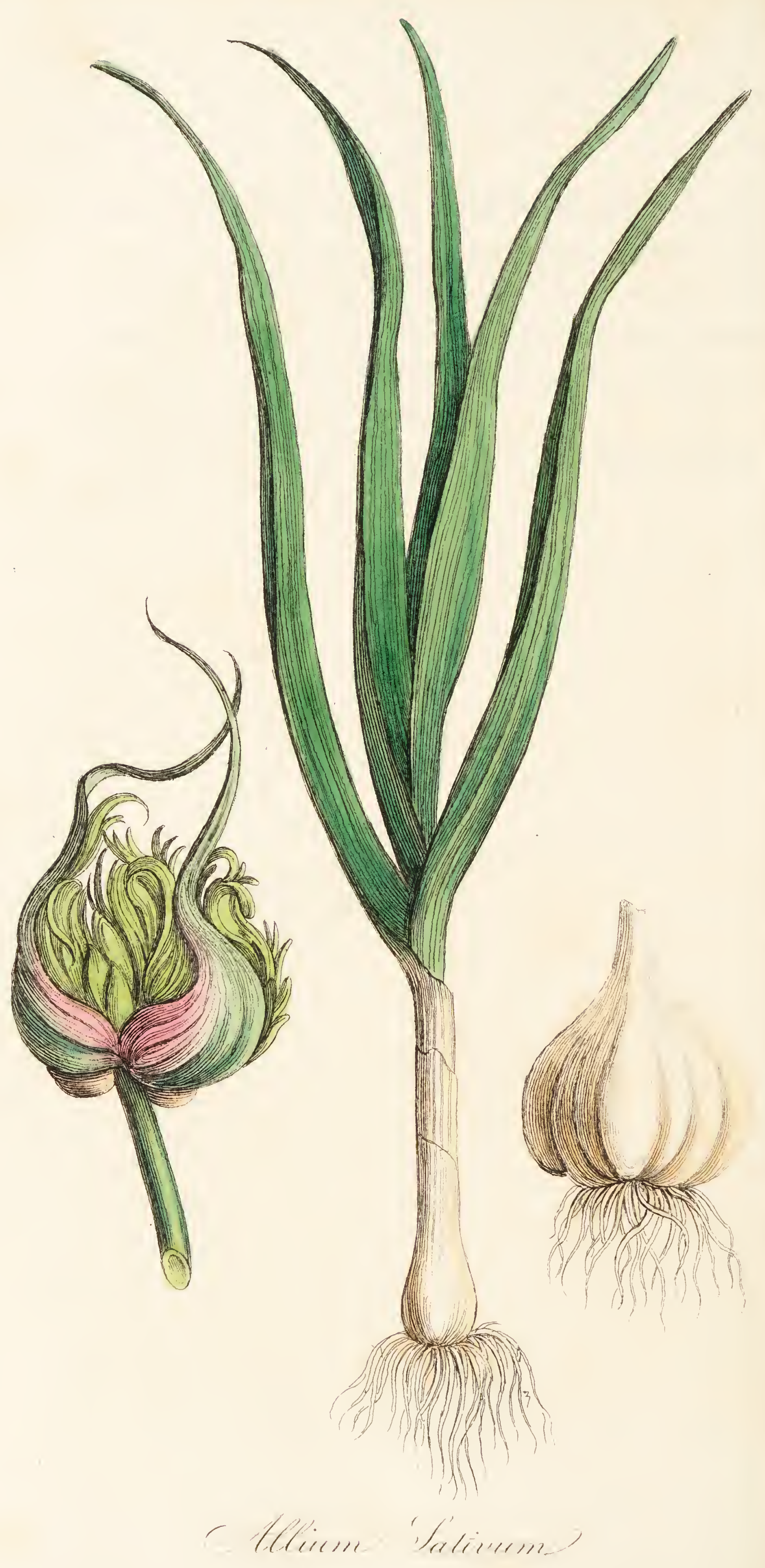




\section{ALLIUM SATIVUM.}

\section{Common Garlick.}

Radix.

\section{Class VI. Hexandria.-Order 1. Monogymia.} Natural Order. Lilitacez.

Generic Character. Corolla, six-parted, spreading. Spathe, many-flowered. Umbels, heaped together. Capsule, superior.

Specific Character. Stalk with plane leaves, and bearing a bulb, which is compound; stamina, tricuspid.

Trs perennial plant is a native of Sicily, and much cultivated in our gardens for culinary and medicinal purposes. It flowers in July, and the root arrives at perfection in August. The root is roundish, and consists of five or six small ovate bulbs, contained in one common membrane, from the lower part of which proceed numerous whitish fibres. From the root rises a simple hollow stalk, about two feet in height, terminating in a cluster of flowers, enclosed in a spathe. The leaves are long, flat, and resemble grass, proceeding in greatest number from the root. The flowers are small, white, composed of six oval petals; the filaments are tapering, shorter than the corolla, and terminating in erect anthers; the germen is superior, short, angular, supporting 
a simple style, with a sharp stigma; the capsule broad, three-lobed, three-celled, and containing roundish seeds.

The whole of this plant possesses a very pungent, diffusive, and unpleasant smell, with a pungent acrimonious taste; but these properties are more particularly resident in the root, which alone is medicinally used. The roots, i.e. the bulbous parts of them, are fleshy, white, and contain a white limped juice; upon being dried they lose more than one half of their weight, without having their sensible properties much impaired; hence it is necessary to give the dried root in smaller doses than the fresh. Both water and vinegar, if allowed to stand on the bulbs, completely extract their virtues. By distillation with water, a thick yellow essential oil is procured, which contains the whole properties of the Garlick; the decoction therefore is quite an inert preparation, as the oil is dissipated by the boiling. Alcohol extracts their virtues more easily when dried.

The medical properties of Garlick are stimulant, diuretic, expectorant, \&c. This medicine is of so diffusive a nature, that after it has been taken for a short time, it may be detected in the urine, perspiration, and other secretions of the body; it is said to have the power of producing an alliaceous smell in the mouth when applied to the soles of the feet. Many persons employ it as a condiment instead of onions, and some constitutions might be improved by its use, as it is considered to promote digestion; but if taken in excess, it occasions very distressing symptoms. In affections of the chest, Garlick is a desirable remedy, such as asthma, 


\section{3}

catarrh, and other chronic affections of the pulmonary organs; also in some hysterical affections, scurvy, \&c. and in some species of dropsy where unconnected with visceral disease. It is reported to have been very serviceable in typhus fever and intermittents. It is a medicine that will not be useful in all constitutions, but is chiefly adapted for those of indolent and phlegmatic habits. As an external application it proves a very useful rubefacient, and perhaps inferior but to few in power, where they are necessary. There are various forms of giving this medicine, viz. In substance, pills, infusion, \&c.; but perhaps the best and most palatable preparations are the Syrupus vel Oxymel Allii of the former London Pharmacopœia.

Dose $3 \mathrm{j}$. to $z \mathrm{ij}$. -No Officinal Preparation. 



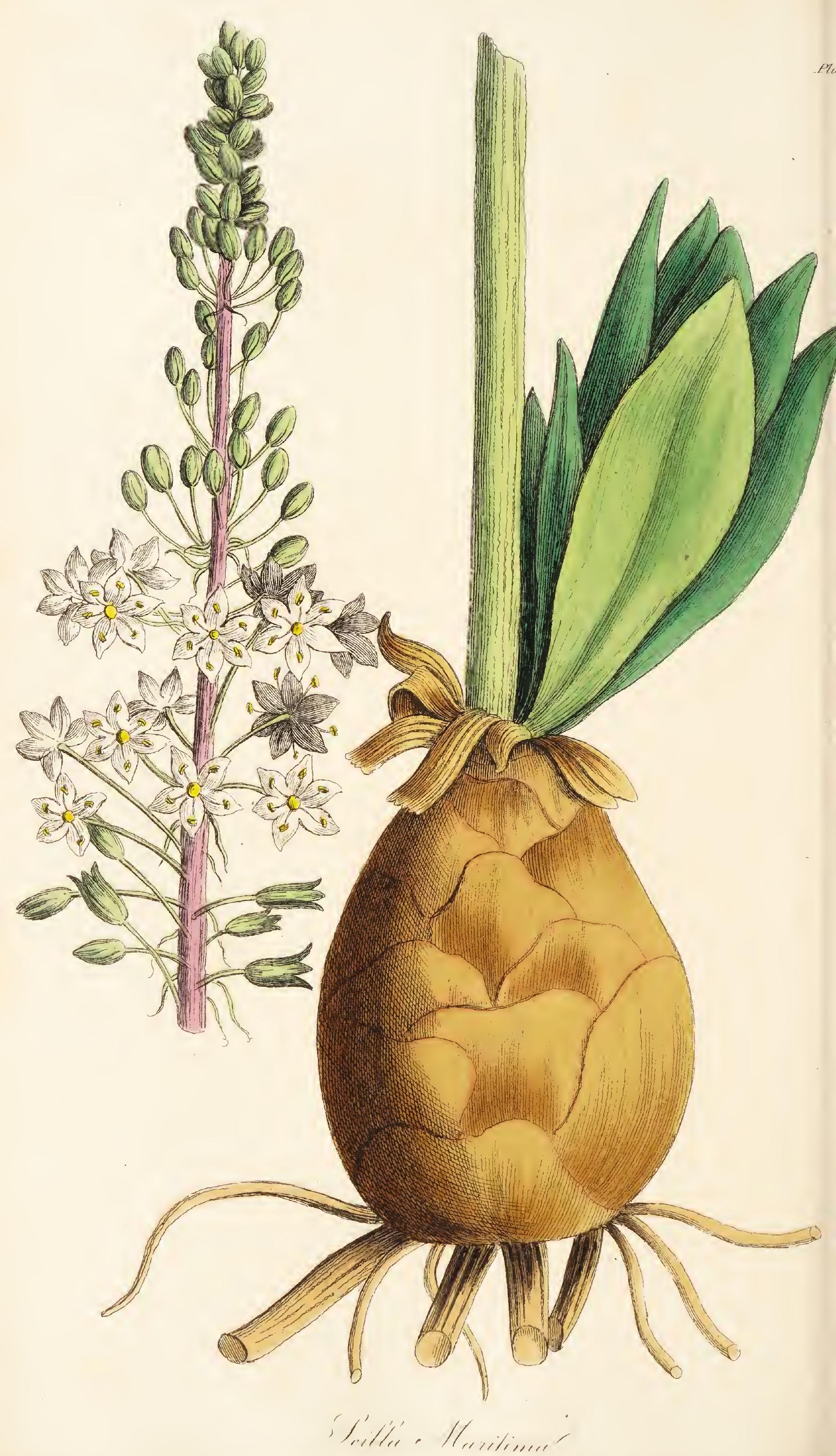




\section{SCILLA MARITIMA.}

Officinal Squill, or Sea-Onion.

Radix.

Radix.

Class VI. Hexandria.-Order I. Monogynia. Natural Order. Coronarie.

Generic Character. Corolla, six-petalled, spreading and deciduous. Filaments, thread-like.

Specific Character. Naked, flowered; with refracted bractex.

Thrs perennial plant is a native of Spain, Portugal, Sicily, and 'also of the southern parts of Africa, occupying the sands on the sea-shores.

The root is large, varying from the size of an apple to that of a child's head, pyriform, bulbous, and composed of fleshy scales, and there are numerous fibres proceeding from the base of the bulb. The stalk is smooth, round, and succulent, about three feet in height. The leaves are radical, sword-shaped, straight, pointed, and of a deep green colour. The flowers are of a whitish colour, and produced in a long close spike, upon purplish peduncles, with a linear, twisted, deciduous bracte at the base of each: the corolla consists of six petals, which are ovate and spread- 
ing, with a reddish mark in the centre of each; the filaments are tapering, shorter than the corolla, and furnished with oblong anthers placed transversely; the germen is roundish, supporting a simple style and stigma; the capsule is oblong, smooth, three-celled, and contains several seeds.

There are two varieties of the Squill, the alba et rubra; but there is not found to be any essential difference in their sensible or medicinal properties, and the distinction seems merely to depend on the external colour of the bulb, for when cut into, both are of a whitish colour internally, and may be used indiscriminately; still, however, some prefer the red variety, and consider it the most active of the two.

The greater proportion of the bulbs used in this country are imported from the Levant.

The fresh bulb abounds with a viscous juice, which is so very acrimonious, as to excite an intolerable degree of itching of the hands if but slightly applied, as in the act of cutting them; and if kept in contact with the skin for any length of time, vesications will be produced: it is also very acrimonious and nauseous to the taste, and at the same time very bitter; it is inodorous both in, the recent and dried state. By drying, a Squill loses four parts in five of its weight, which is said to be little more than water; hence the strength of the dried root very much exceeds that of the fresh, and requires to be given in much smaller doses. The virtues of it are completely extracted by spirit of wine, water, wine, and vinegar. Alkalies are said to lessen its acrimony and bitterness. 
This drug has been known as an article of considerable activity from very early times; on this account the ancients were very cautious and circumspect in exhibiting it; and used to employ means to lessen its acrimony, which were of such a nature that they must have very much impaired its activity and virtues. Considerable caution is certainly necessary when administering it, for cases are related, where, when incautiously or accidentally used, it has occasioned most alarming and distressing symptoms, and, in one or two instances, death itself. The symptoms which follow an over-dose, are nausea, vomiting, purging, sometimes of blood, with tenesmus, strangury, and occasionally bloody urine, and to these are sometimes added nervous derangement; and Murray mentions that it has occasioned death, by producing inflammation and gangrene of the stomach and bowels. It is equally destructive to many brutes as to the human subject. It would be very difficult, if not impossible, to give rules to be followed where Squill is taken in such quantities as to disagree with a person; the first thing would be to hasten its operation, by giving freely of diluents, so as to unload the stomach of its contents; aperients should afterwards be administered, as Ol. Ricini; but we must be guided in our treatment by the symptoms present. The medical properties of the Squill are diurectic and expectorant in small doses; and emetic and purgative in larger. As a diuretic it may be employed with the greatest safety and best effects in dropsies, particularly in those species of the disease connected with an indolent habit of body; or even in the more 
active forms of the disease if combined with the $\mathrm{H}_{y}$ drarguri Submurias or Digitalis; of course the nature of the combinations will depend on the urgency of the case and the symptoms attending it: its diuretic effects are said to to be assisted by opium. Its expectorant qualities are very obvious in asthmatic patients and chronic affections of the chest, connected with a secretion of thick tough mucus, which is with great difficulty expectorated without the aid of some expectorant. As an emetic it was once in general use, but is now much less frequently employed than formerly, and indeed where we simply wish to evacuate the contents of the stomach, it is too violent in its operation to be a desirable one; but in some affections of the chest and throat, especially in croup, it is certainly a desirable emetic, as it renders the expectoration of the mucus more easy. It is never administered as a purgative, and we only know that it possesses this property by its being accidentally given in too large doses.

The best way of exhibiting it is the dried bulb, in the form of powder, pill, or oxymel, \&c. according to the way we may wish it to operate.

The most desirable manner of drying it, is (as directed by the London College) by cutting it transversely into thin slices, and then exposing it to a moderate warmth, for if the heat be too great, its sensible qualities become much impaired, and it is rendered almost inert; and when dried, its medicinal properties are gradually becoming dissipated, on which account it is necessary to have a fresh supply annually at least. 
The dose of the Squill as a diuretic and expectorant, is from gr. ss. to grs. iv. and as an emetic five or six grains will be sufficient. Officinal Preparations:-Oxymel Scillæ, Acetum Scillæ. Pil. Scillæ C., Tinct. Scillæ, Pulv. Scillæ, Syr. Scillæ. 




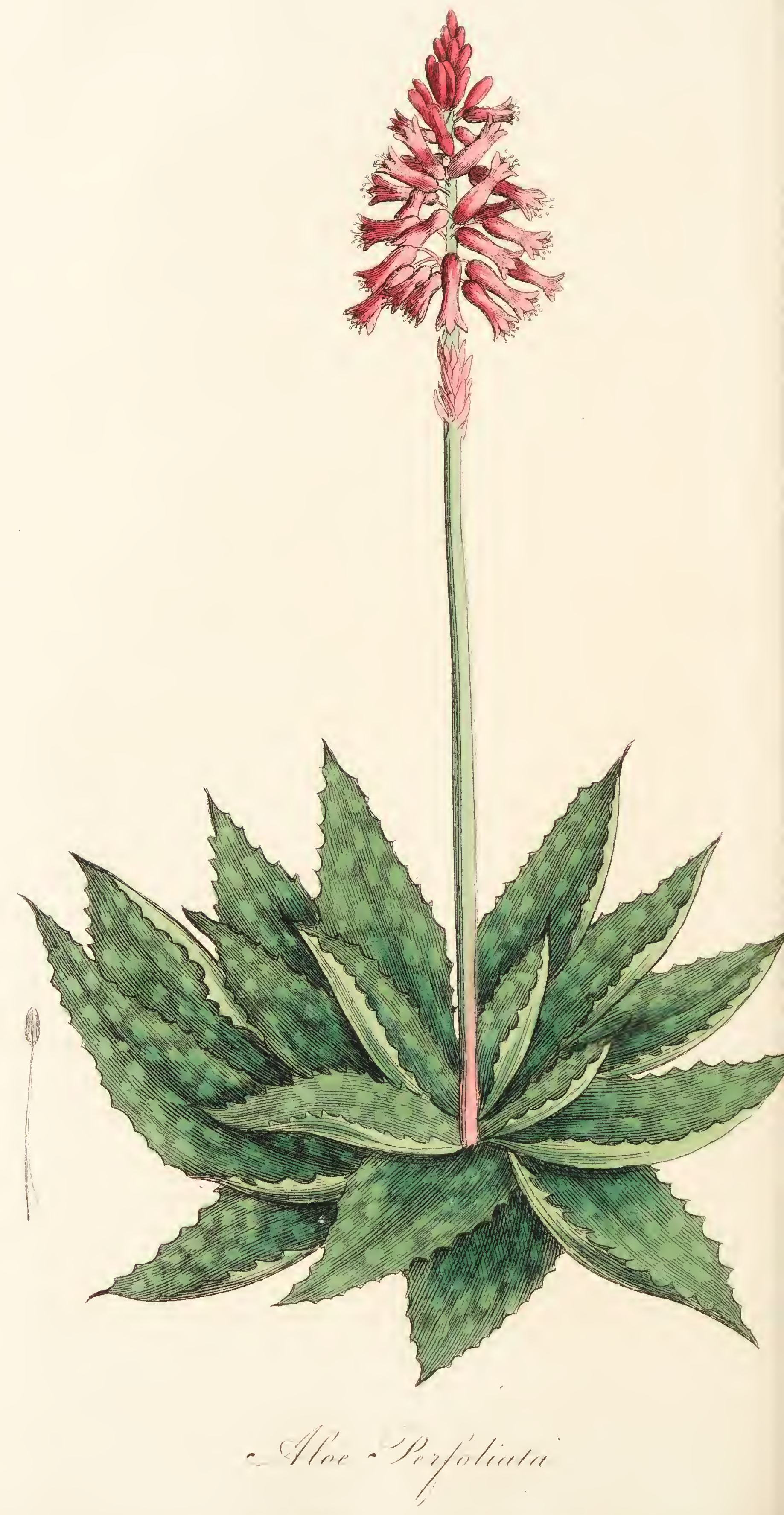


50.
ALOE PERFOLIATA SOCOTORINA- ALOE SPICATA-SOCOTRINE, OR SPIKED ALOES.

Extractum vel Succus Spissatus.

Class VI. Hexandria.-Order I. Monogynia. Natural Order. Coronariz.

Generic Character. Corolla erect, with a spreading, smooth and nectariferous bottom. Filaments, inserted into the receptacle.

Specific Character. Flowers spiked, horizontal, bell-' shaped, leaves on the stalk, plane, embracing the stem, toothed.

There are several varieties of the aloe, described by Linnaus as belonging to the Aloe Perfoliata; it is the spiked aloe, which is best.

The stem is round, smooth, about four inches in diameter, from three to four feet in height, and leafy towards the top. The leaves are numerous, spreading, thick, fleshy, succulent, and beset with acute teeth. The flowers spread horizontally, in close spikes; the calyx is wanting: under each flower is an ovate, broad, acute bracte, shorter than the corolla, which is six-petalled, and contains some honey 
juice; the filaments are tapering, yellow, inserted into the receptacle, and terminate in oblong anthers. The germen is oblong, supporting a slender style, upon which is an obtuse stigma; the capsule is three-celled, and contains numerous seeds.

We are informed by Murray, that about fifty miles from the Cape of Good Hope, the Aloe grows in great abundance, a whole tract of land being almost entirely covered with it, and it is said to prove a very strong defence against the invasion of foreign powers; it is cultivated also in the islands of Barbadoes and Jamaica; but the true Socotrine Aloes is imported from the island of Socotora in the Indian Ocean. We do not, however, always have that Aloe which comes from Socotora, for it frequently happens that the American Aloe is substituted for it, and is but little if at all inferior.

The juice of this plant does not arrive at perfection till the plant is two or three years old, at which time the most succulent leaves are cut off near the root, and placed perpendicularly by the side of each other in tubs, to afford an opportunity for the juice to exude, which is afterwards collected into a large shallow vessel, and exposed to the rays of the sun till it becomes of a proper consistence. Sometimes the leaves are cut in small pieces and then set aside for the juice to exude; by either of these modes the best kind of Aloes is procured: an inferior sort is obtained by boiling the sliced leaves in water for a short time, then removing them and adding more, and repeating this till the liquor becomes of a dark colour, when it is evaporated to a 
proper consistence: the Aloe obtained by this process, and also that which is procured by expression from the leaves, are both of inferior quality to the former, which is procured by a natural exudation and evaporation of the juice; but in consequence of the extreme tediousness of the process, it is seldom made in that way.

Socotrine Aloe is of a reddish yellow colour, with a shining appearance, easily broken, and when powdered, of a golden hue, having a bitter and somewhat aromatic taste, with a peculiar aromatic odour, somewhat like myrrh; in warm weather it is pliable between the fingers, but in winter is very easily pulverized.

This kind of Aloe is imported into this country wrapt up in skins, in order to keep it in a moist state; sometimes, during its preparation, the exudations from other trees are mixed with the juice, by which means it is rendered less active.

Aloe is composed of a resinous and gummy matter, which exists in different proportions in the different kinds of Aloe: the Socotrine contains more gum and less resin than the common Barbadoes Aloe.

This inspissated juice is a stimulating cathartic, acting chiefly upon the lower part of the large intestines; it does not much increase the secretion from the bowels, but promotes their peristaltic action, and by that means causes the expulsion of any accumulation in them; from its operation being almost. exclusively confined to the lower portion of the intestinal canal, it is said to possess emmenagogue properties; but if such power can be ascribed to it, 
it must be in a very inferior degree, and Aloes are very rarely given with this view, unless combined with other and more active medicines of that class. Aloes are not a proper purgative in all constitutions, but is best adapted to those of sluggish, indolent habits, and of the melancholic temperament, where the intestines are very commonly in a sluggish inactive state: It should not be employed in those persons who are either the subjects of piles, or who are disposed to that complaint; it ought also to be dispensed with in plethoric and irritable habits. If given during pregnancy, it should be with the greatest caution, otherwise miscarriage may be induced. In chorea it is often an useful purgative, and Dr. Hamilton recommends it in many other diseases.

When applied externally to wounds, its purgative qualities show themselves by the alvine evacuations which follow.

The Hepatic or Barbadoes Aloe may be procured in a similar manner to the above, but in general there is not so much care taken in its preparation. It is of a darker colour, with a less shining appearance, firmer texture, and more ungrateful taste; and its odour is stronger with less aroma than the Socotrine Aloe. Its medical properties are similar to the former, and it is often substituted for it.

The Caballine, or Horse Aloe, is a very inferior article to either of the former; it is much darker, approaching nearly to black, and has a very umpleasant smell and taste; it is not employed medicinally except by farriers. The best and most common form of administering $A$ loes, is in 
pills, either alone or combined with other medicines, for it is so exceedingly nauseous to the taste, that persons will not take it unless very much disguised.

The dose is from grs. iij. to 3 ss. but it is seldom given alone. Officinal Preparations:-Pulv. Aloes Comp. Pil. Aloes. Pil. Aloes Comp. Pil. Aloes et Myrrh. Pil. Aloes et Assafoetida. Pil. Scammon. C. o Aloe. Tinct. Aloes. Tinct. Aloes Comp. Tinct. Aloes Atherea. Tinct. Aloes et Rhei. Vin. Aloes. Decoct. Aloes Comp. Extract Aloes. 



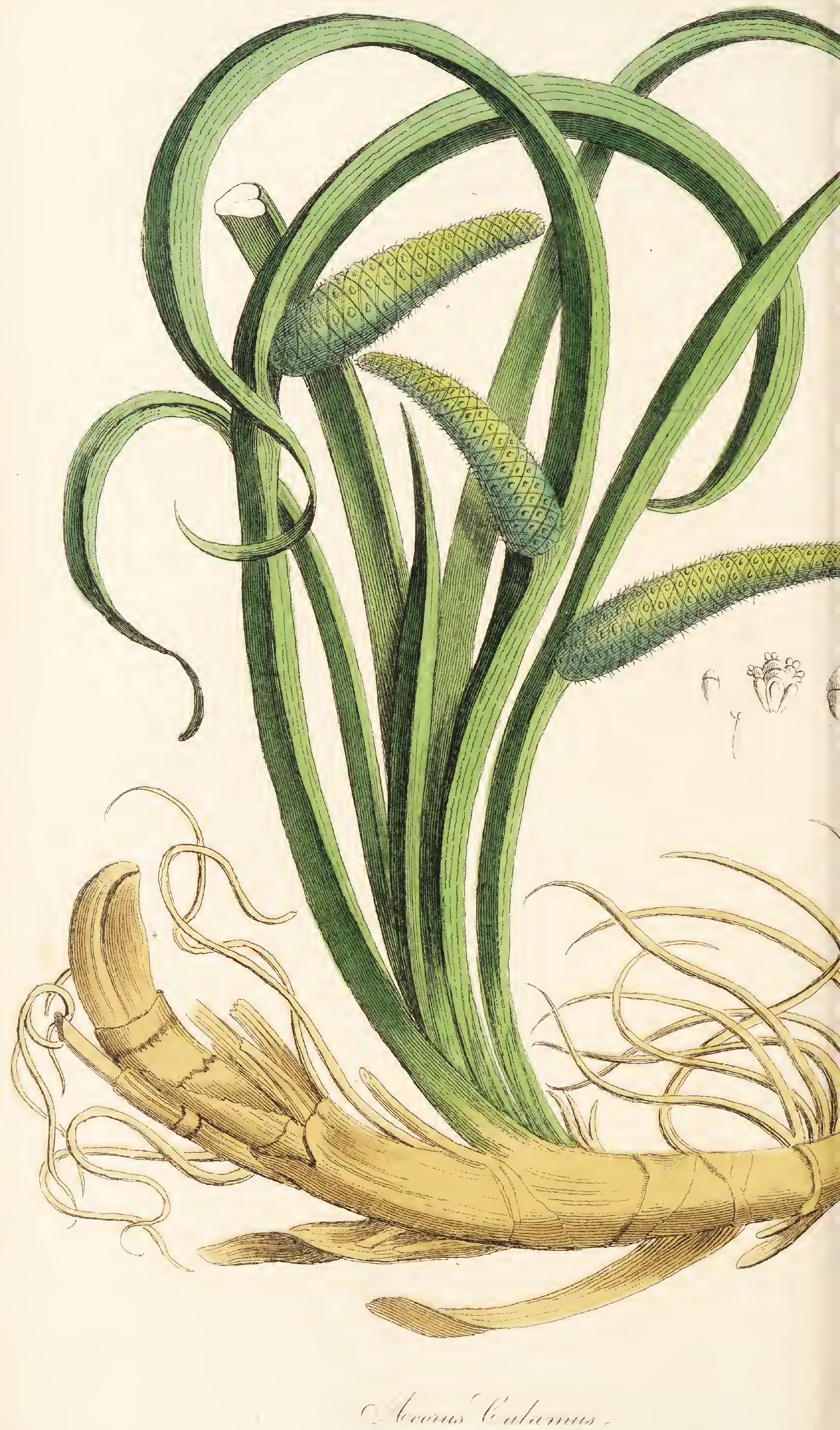




\title{
51. ACORUS CALAMUS-CALAMUS ARO- MATICUS.
}

Calamus, or Srweet-scented Flag.

\begin{abstract}
Radix.
$-$

Class VI. Hexandria.-Order I. Monoginia.

Natural Order. Piperite.

Generic Character. Spadix, cylindrical, covered with florets. Corolla, six-petalled, naked. Style, wanting. Capsule, three-celled.
\end{abstract}

Specific Character. Point of the scape very long and leafy.

The Acorus grows plentifully in marshy situations in many parts of England, and in other European countries; and in the East Indies it grows both in dry and moist situations. The roots used in this country were formerly imported from the Levant; but now great quantities are brought from Norfolk, which are not at all inferior to the exotic roots.

The root is perennial, horizontal, crooked, fibrous, and rather. inclined to be flat; composed of numerous rings: they are nearly an inch in thickness, externally of a yellowish colour, and internally whitish and spongy. The leaves are about three feet in length, sword-shaped, generally waved 
on one side, and of a bright green colour. The flowers are small and numerous, produced in a conical spike, about three or four inches long, and situated at the edge of the leaf: they have no calyx; the corolla is composed of six small, erect, membranous petals, inflected at the apex; the filaments are alternate, longer than the corolla, and support double anthers; the germen is elliptical, supporting a pointed stigma.

The root when dry is of a brownish colour externally, but within of a light yellowish colour; it has a fragrant odour, and a bitterish, warm, aromatic taste.

The bitter principle of the plant is extracted by water, whilst spirit only becomes impregnated with its aroma; upon distilling water from the roots, it becomes impregnated with their aroma, and at the same time a small quantity of essential oil is procured, possessing the grateful odour of the plant.

The leaves have an agreeable aromatic odour and bitterish taste, and are much milder and more agreeable than the roots.

The medical properties of the sweet-flag root are aromatic and stomachic, and is, indeed, as pleasant and useful a tonic as we are acquainted with; it is said to be antiscorbutic and anti-putrescent, but we have not experienced such properties in it in so remarkable a degree as to entitle it to either of the above epithets. The disease in which it is most particularly serviceable, is intermittent fever; and here it certainly is of the greatest utility, for it will often as completely set aside a paroxysm as the Cinchona: and in some 
constitutions it is preferable to the bark, which in delicate stomachs is frequently rejected, which very rarely happens with the Acorus Calamus; the powder must be given in the quantity of 3 ss. or $3 \mathrm{j}$. three or four times a-day. It may be employed in any case where a mild tonic is required.

The dose is firom grs. xv. to $3 \mathbf{j}$--Officinal Preparations, none. 



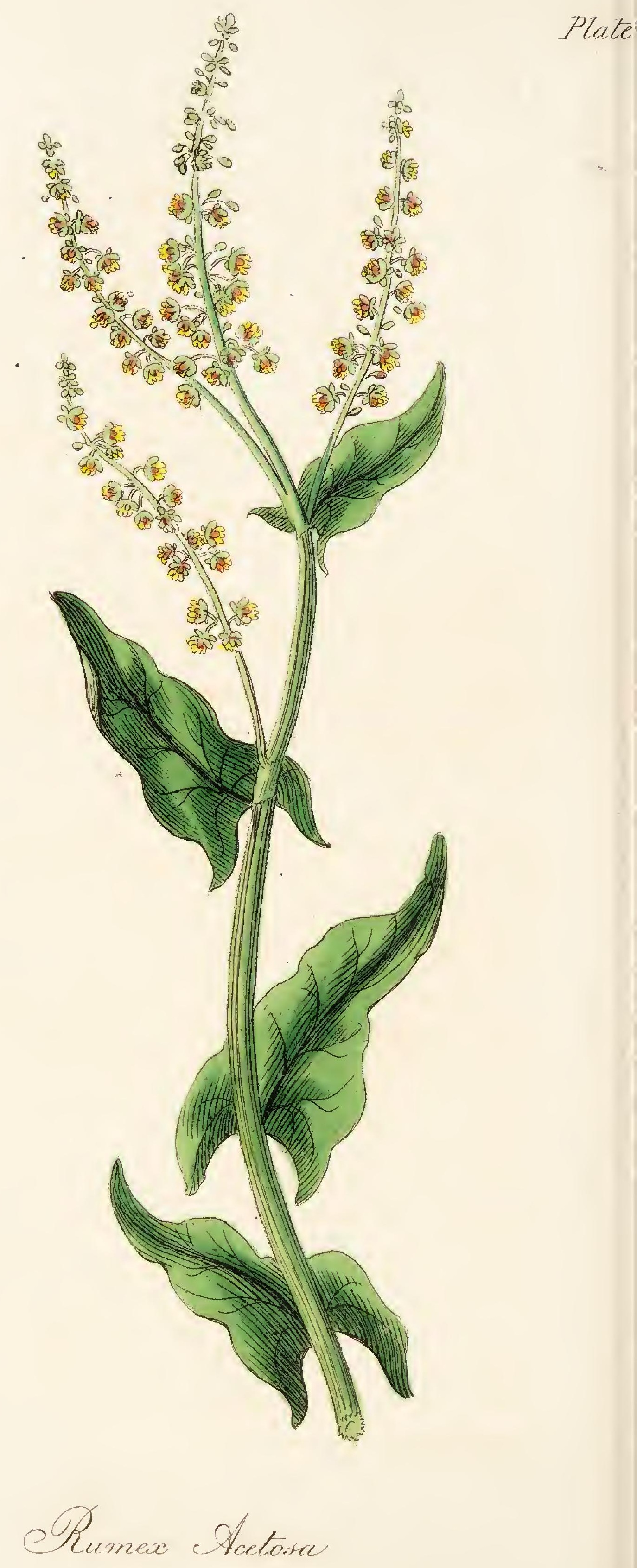


59. RUMEX ACETOSA-ACETOSA.

Common Sorrel.

Folia.

\section{Class VI. Hexandria.-Order III. Trigynia.}

\section{Natural Order. Holoracex.}

Generic Character. Calyx, three-leaved. Petals, three, converging. Seed, one, three-sided.

Specific Character. Flowers, diœcious, leaves, oblong, sagittate.

'THIS perennial plant grows abundantly in meadows; and it is sometimes cultivated in gardens, where it thrives more and becomes larger: it flowers in June.

The stem is erect, striated and leafy, rising from one to two feet in height, and is partially of a purplish red colour. The leaves are oblong, ovate, arrow-shaped, and of a bright green colour : the radical ones are petiolate and obtuse; those of the stem without footstalks, placed alternately and pointed. The flowers are diœcious, and are disposed in terminal branched spikes, standing upon short slender peduncles: the corolla is divided into three petals, and the calyx into three oval segments; the filaments are short, bearing erect large anthers: styles short, supporting large bearded stigmas, and proceeding from a triangular germen. 


\section{2}

The leaves of this plant have a mild acid taste, without any particular flavour, and without any odour; their properties depend on a salt which they contain called the super-oxalate of potass, and in this salt we have all the efficacy of the sorrel concentrated.

They are refrigerant, diuretic, \&c.; employed in the form of decoction, or what perhaps is more grateful, eating the fresh leaves; by this means we may allay thirst in inflammatory and febrile affections : they are also said to be antiscorbutic, and, from their possessing this property, the concrete juice is sometimes taken by sailors to guard against and to cure scurvy. Sometimes it is applied externally to unhealthy and foetid ulcers; and, from its correcting the state of these sores, has been called anti-putrescent. At the present day, however, it is nearly discarded.

The Rumex Aquaticus, or Water Dock, has a powerfully astringent taste, and was once celebrated for its supposed efficacy in the cure of scurvy, and some cutaneous affections, but it is now almost entirely laid aside.

The dose of the Acetosa is ad libitum.-No Officinal Preparation. 


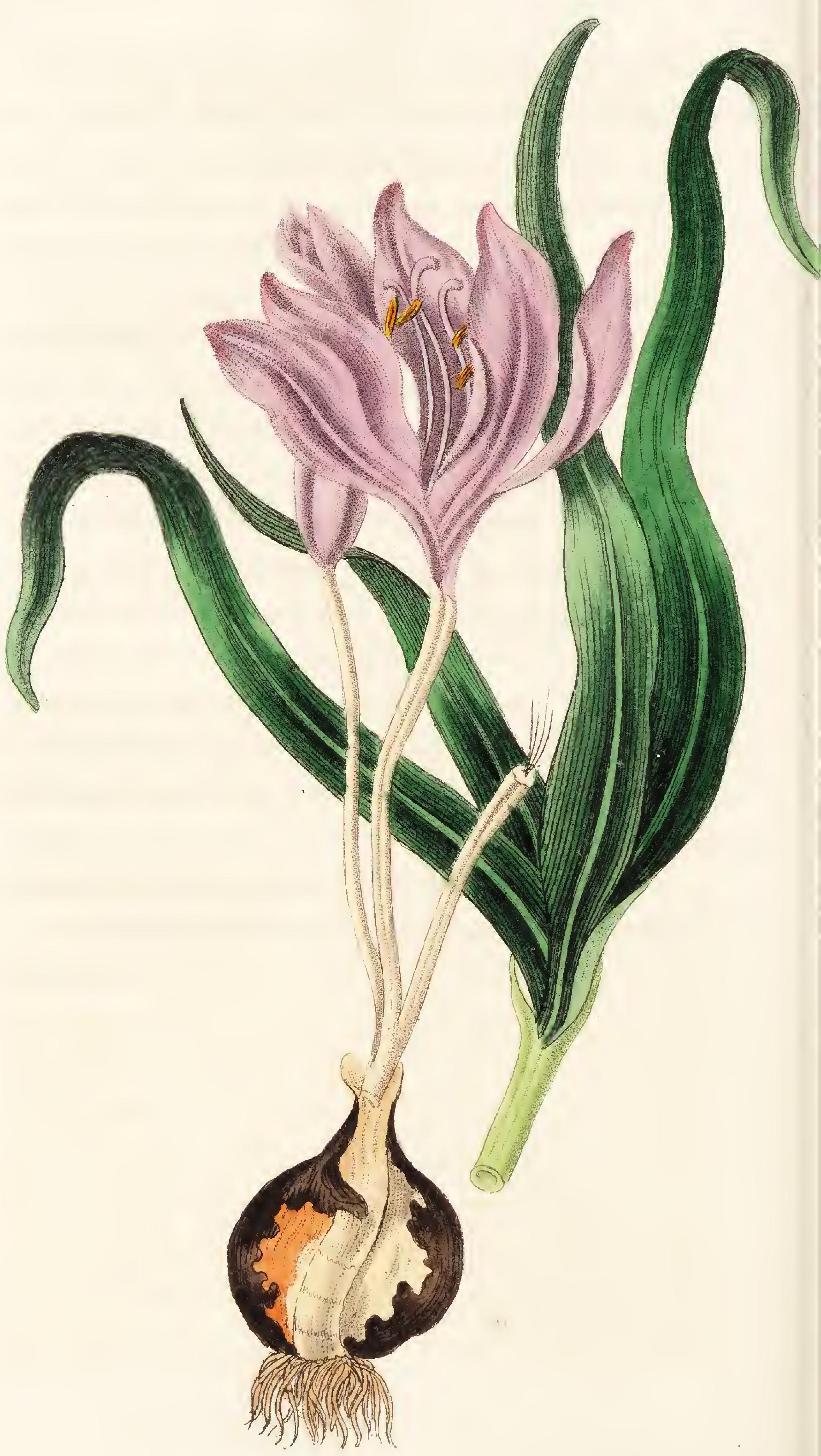

Golcterenen: Vetenenete 
53. COLCHICUM AUTUMNALE.

\author{
Common Meadow Saffron. \\ Radix vel Bulbus Recens.
}

\title{
Class VI. Hexandria.-Order III. Trigunia.
}

\section{Natural Order. SPathaceÆ.}

Generic Character. Corolla, six-parted, with a rooted tube. Capsules, connected, inflated.

Specific Character. Leaves, flat, lanceolate, erect.

This perennial plant grows in moist meadow-grounds in the more temperate countries of Europe, flowering at the beginning of autumn without leaves, and bearing the fruit subsequently to the leaves.

The bulb is double, solid, succulent, and covered with a brown membranous coat. The lcaves make their appearance in spring, and are radical, spear-shaped, and somewhat waved. The flower appears in autumn, immediately succeeding the decay of the leaves, it is large, of a purplish colour, and springing from the root by a long naked tube; the calyx wanting: corolla, monopetalous and divided into. six, lance-shaped keeled segments of a pale lilac or purple colour: the filaments are tapering, shorter than the corolla, terminating in yellow erect anthers: styles slender and reflexed at the top, supporting simple pointed stigmas: the 
capsule is three-lobed, three-celled, placed upon a strong peduncle, and contains numerous seeds. The old bulb begins to decay at the time of flowering (in autumn), at which time the new one is forming, and in the following May is perfected; the old one being entirely wasted, the new bulbs should be dug up at this time, for they possess more activity than those procured in autumn: some, however, recommend that they should be dug up in autumn, but they are certainly much inferior at that time of year; and it is no doubt owing to the bulb being sometimes gathered at different seasons that we have such various accounts of the efficacy of the Colchicum : in autumn it has a sweetish taste, but in summer is highly acrimonious; the nature of the soil is said to have some influence on it.

The Colchicum has no smell, but a bitter acrimonious burning taste, and these properties are in a great measure destroyed by drying, which would shew that the acrimony of the bulbs resided in some volatile matter, probably an essential oil: the dried bulb has a slight degree of acrimony. Stoerck states, upon the tongue being applied to the fresh root, it rendered it rigid, and destroyed its feeling for some time; and many other authors speak of its acrimony and deleterious properties in very strong terms.

This bulb is a very powerful and active medicine, which we have opportunities of witnessing in its effects upon brutes; in them it occasions violent vomiting and purging, which is followed by inflammation of the stomach and bowels; independent of the effects from its immediate application to these parts, it becomes absorbed, and 
acts upon the nervous system; for when applied to the skin it produces similar effects as when taken into the stomach, which must depend on its being absorbed and carried into the circulation. We have melancholy instances upon record of its fatal effects upon children, who have accidentally partaken of the bulbs, in whom it occasioned the symptoms mentioned above. All parts of the plant possess similar properties, although less active than the bulb.

The medical properties of the Colchicum. are diurecic, purgative, emetic, Sc.

Baron Stoerck particularly directed his attention to this drug in the cure of dropsies and several other complaints; and it is still much used on the continent. In England, however, the Colchicum is not very generally employed, in consequence of the uncertainty of its operation and the great caution which is required whilst administering it. In the cure of the gout it has acquired considerable celebrity; for that troublesome and painful disease it has been taken by many persons with the best effects, acting almost as a charm in setting aside a paroxysm; and one of the most celebrated men in this country is constantly in the habit of taking it with the most happy results in curing paroxysms of gout. In some, however, it produces the most distressing symptoms, such as violent vomiting and purging, to which succeed symptoms denoting derangement of the nervous system. We must, therefore, still consider ourselves very much in the dark as to its general application in practice: experience alone can determine in what constitutions it may be given with impunity and with advantage. In the subacute and 
chronic forms of rhcumatism we have administered it, with evident relief to the patient, in doses of 3 ss. ter quaterve quotidie. The most essential and indeed only active ingredient in the Eau Medicinale, is a vinous infusion of Colchicum: and a form of this description is a more preferable way of giving it than any other; the dose of a saturated vinous infusion is from $m$. $x x$. ad $3^{i j}$. it is necessary to increase the dose gradually.-Officinal Preparations: Acetum Colchici. Oxymel Colchici. Syr. Colchici. 


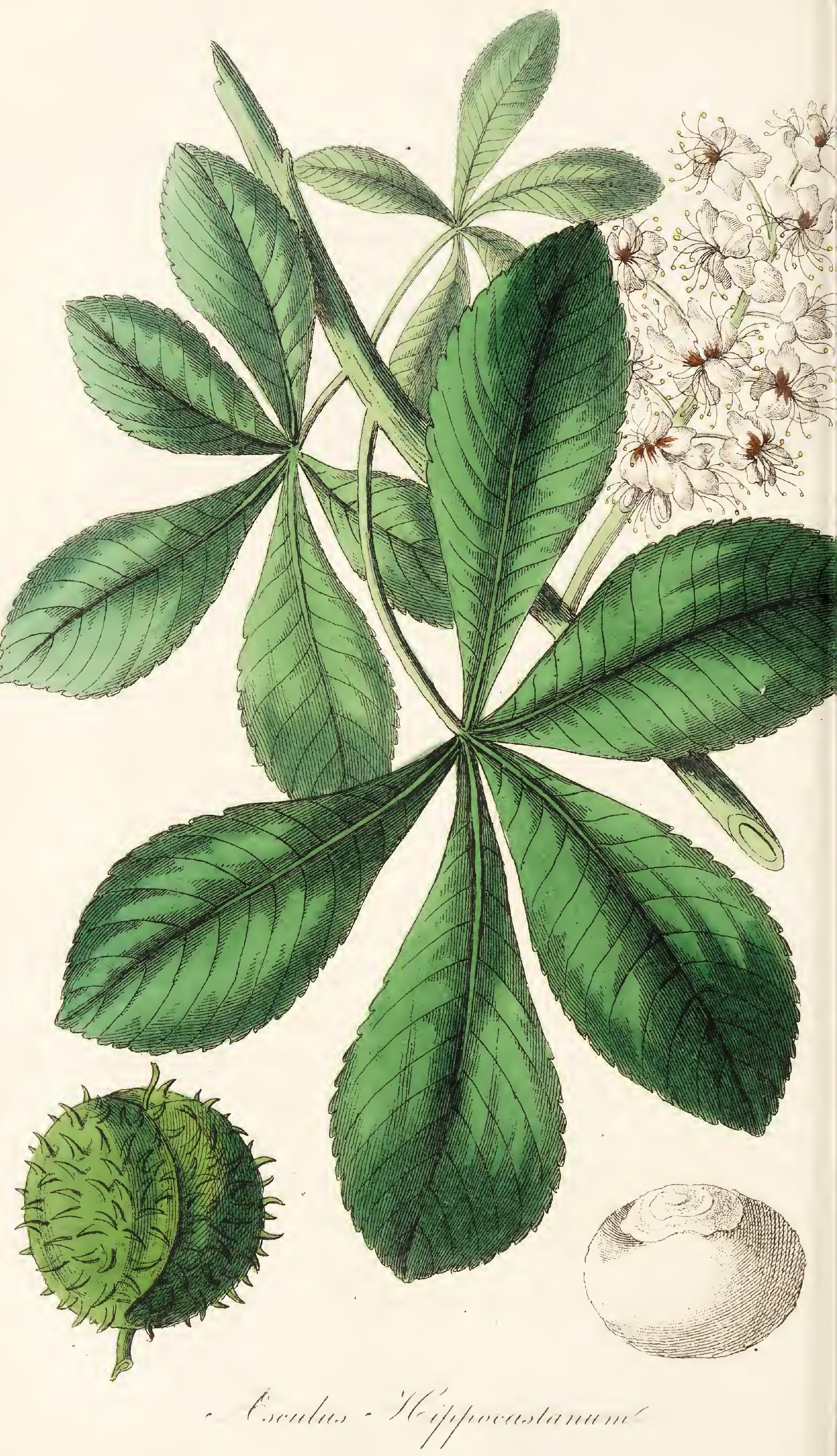




\section{AESCULUS HIPPOCASTANUM. \\ Common Horse Chesnut.}

Cortex.

\section{Class ViI. Heptandria.-Order I. Monogynia.} Natural Order. Trinilate.

Generic Character. Calyx, one-leaved, five-toothed, swelled out. Corolla, five-petalled, irregularly coloured, and inserted into the calyx.

Specific Character. Flowers, heptandrous.

THIs tree is a native of the northern parts of Asia; is cultivated in many parts of Europe, and in this country is very common in parks and pleasure-grounds, where it is cultivated on account of its beauty, flowering in April and May.

It is a tree which rises to a considerable height, and from the upper part sends off numerous branches. The leaves stand on long footstalks, and are large, digitated, divided into seven large, oval, serrated, ribbed, pointed leaflets, which proceed from one common centre. The flowers which are peduncled, are disposed on the branches in large, conical, terminal spikes: the calyx is tubular and divided at the edge into five short, blunt segments: the petals are ovate, spreading, slightly undulated at the margin, inserted into the calyx, and of a white colour, with irregular spots of red and yellow; the filaments are awl-shaped, curved, 
length of the corolla, and supporting pointed anthers: the germen is cylindrical, having a pointed stigma. The capsule is roundish, tough, and of a green colour, three-celled, beset with spines, and containing two nearly round seeds.

The bark of the chesnut is inodorous; but has an astringent and agreeable bitter taste; it should be collected from those branches which are neither old nor young: it may be preserved for several years without having its virtues impaired, for they do not reside in any volatile matter, but in a substance called tannin, which may be extracted from the bark by spirit or water.

The medical properties of it are astringent and tonic. It has been employed for the cure of intermittent fever, and recommended as a substitute for the Peruvian Bark: but experience tells us that it is much inferior to that article in the cure of this disease; it has also been attempted to substitute it for other tonics but without avail. It is sometimes applied externally to gangrenous sores, with apparent good effect.

The seeds contain a great deal of farinaceous and nutritive matter, and when deprived of their bitter and astringent principles, constitute a very good article of food for cattle; and it has been substituted for bread in times of scarcity, though but a very poor one: it also relieves some diseases of cattle.

The dose of the bark in powder is ${ }^{\mathrm{j}} \mathrm{j}$ to $3 \mathrm{j}$; or a decoction perhaps is preferable. The decoction may be employed with advantage as an injection in obstinate cases of Leucorrhœa, \&c. 



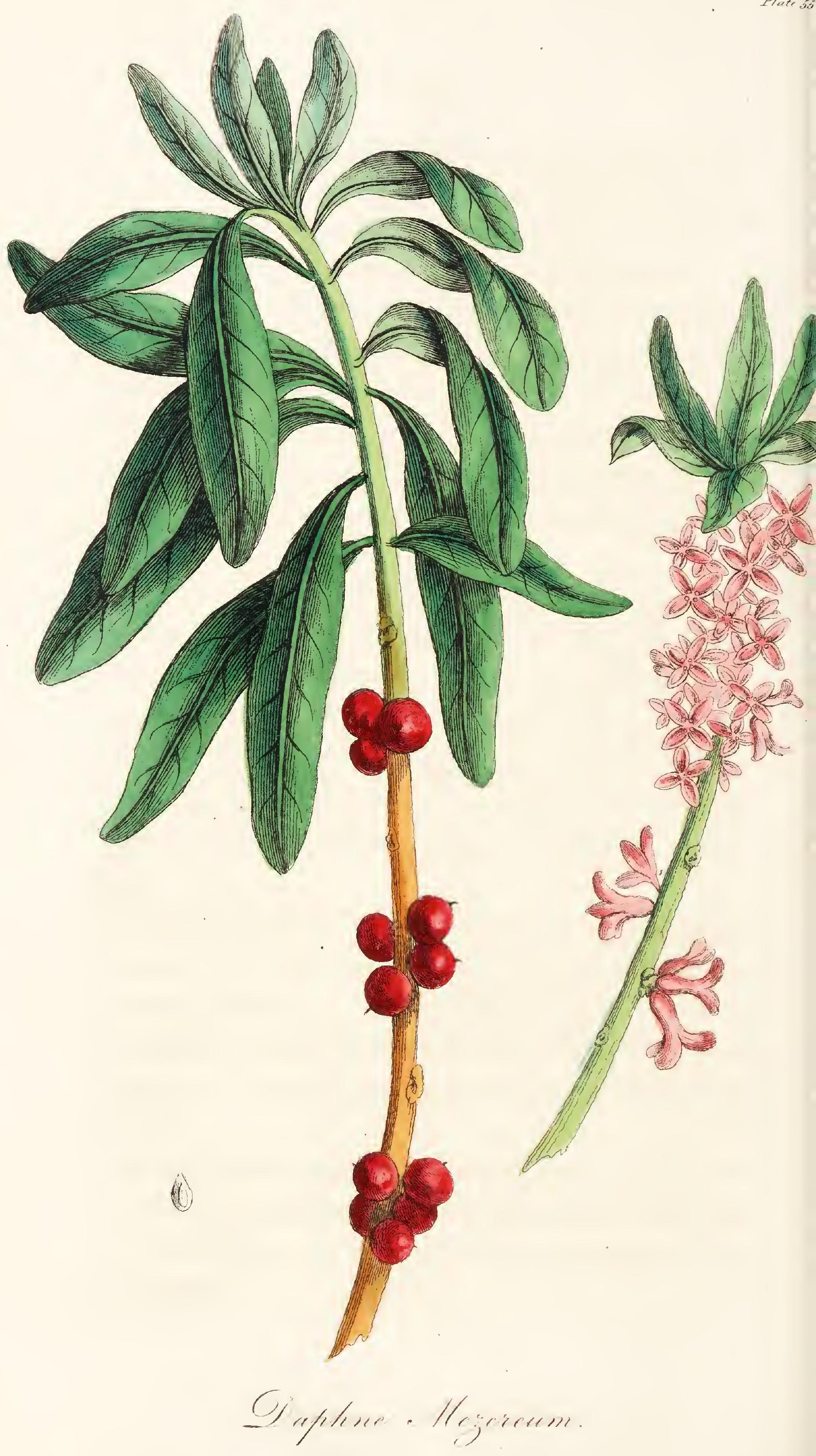




\title{
55. DAPHNE MEZEREUM.
}

\author{
Mezereon, or Spurge Olive.
}

Radicis Cortex.

\section{Class VIII. Octandria.-Order I. Monogynia.}

\section{Natural Order. Veprecule.}

Generic Character. Corolla four-cleft, corollaceous, withering, inclosing the stamens. Drupe oneseeded.

Specific Character. Flowers sessile, placed in threes on the stems, leaves lanceolate, deciduous.

The Mezereon is a native of Germany, and grows wild in some parts of England, also in mountainous situations in the north of Europe, and is frequently cultivated in our gardens both as an ornament and for medical purposes. It flowers about the beginning of February, and the berries ripen in September.

This shrub usually grows to the height of about five feet, sending off several strong branches, covered with a smooth, pale, olive-coloured cuticle. The root is smooth, pale, of a fibrous texture, and covered with an olive-coloured bark. 
The leaves, which are proceeding from the terminations of the branches, are tender, lance-shaped, deciduous, sessile, entire, of a pale green colour, and appear after the expansion of the flowers. The flowers surround the branches in clusters, are of a pale rose colour, with a sweet smell, and have a deciduous bracte at the base of each cluster; they are sessile, monopetalous, tubular, with the limb divided into four oval, spreading segments; the stamens are alternately shorter; the germen is oval, and supports a flat stigma on a very short style, and becomes a red, pulpy berry, containing one seed.

There are several varieties of this shrub, which differ chiefly in their botanical character, for the roots are frequently gathered indiscriminately, and do not appear to possess properties at all dissimilar.

The bark of the branches, as well as that procured from roots, possess acrid properties; but the latter is preferred, and is indeed the only officinal part of the plant directed in our Pharmacopœias. The roots should be dug up in autumn, after the leaves have fallen, and then the bark is stripped from them and dried; it is slender, of a reddish colour, and often covered with a brown epidermis.

The acrimony of this bark is very considerable, and when fresh, if applied to the skin, it causes inflammation and vesication; and when dried the acrimony remains; for if the dried root be chewed a short time, it occasions a most intolerable burning heat in the tongue and mouth, not easily dissipated. Water and spirit both extract the acrimony of the bark, but this is most completely effected by the latter. If 
water be distilled from the bark, it becomes slightly acrid, but you cannot trace the peculiar flavour of the Mezereon in it.

The berries possess very active virtues, and are ranked amongst the acrid poisons; their properties resemble those of the bark, and in some instances act with such violence as. to occasion spitting of blood, and fatal diarrhœa, \&c. there are many documents stating the distressing vomitings and purgings which have frequently followed over-doses of the berries; the bark of the root has also proved fatal. They destroy dogs by exciting inflammation of the parts to which they are applied; and, if it be in an organ of importance, as the stomach, the nervous system sympathizes and becomes considerably deranged. When the berries or bark are taken in over-doses, we should exhibit diluents, emollients, and laxatives, in order to expel the poison from the alimentary canal; and after this, if the nervous system has been much excited, give opium in repeated doses to allay irritation. If inflammation of the stomach or intestines should follow, we must have recourse to the lancet and other antiphlogistic remedies.

The Mczereon has been for some time held in high estimation for the cure of the secondary symptoms of syphilis, as nodes, eruptions, \&c.; and, if we may give credit to Dr. Russel's accounts, venereal nodes readily give way to its exhibition; repeated trials of it have been made by many practitioners, and their experience tends rather to invalidate than confirm the observations of Dr. Russel. The decoction has been given with advantage in chronic rheumatism, 
some cutaneous affections, \&c. but it is a remedy seldom employed in the present day, except in combination with others; for its exlibition requires caution, else romiting and purging may be produced. As an external application it may prove very serviceable, by exciting local irritation and inflammation, and in some cases would be preferable to blisters; in France it is frequently used to produce serous discharge.

The dose is from gr. $i$. to grs. $x$. It is an ingredient in the Decoct. Sarsaparillæ Comp. which is the form that we commonly exhibit it in; there is also a Decoct. Mezerei. 



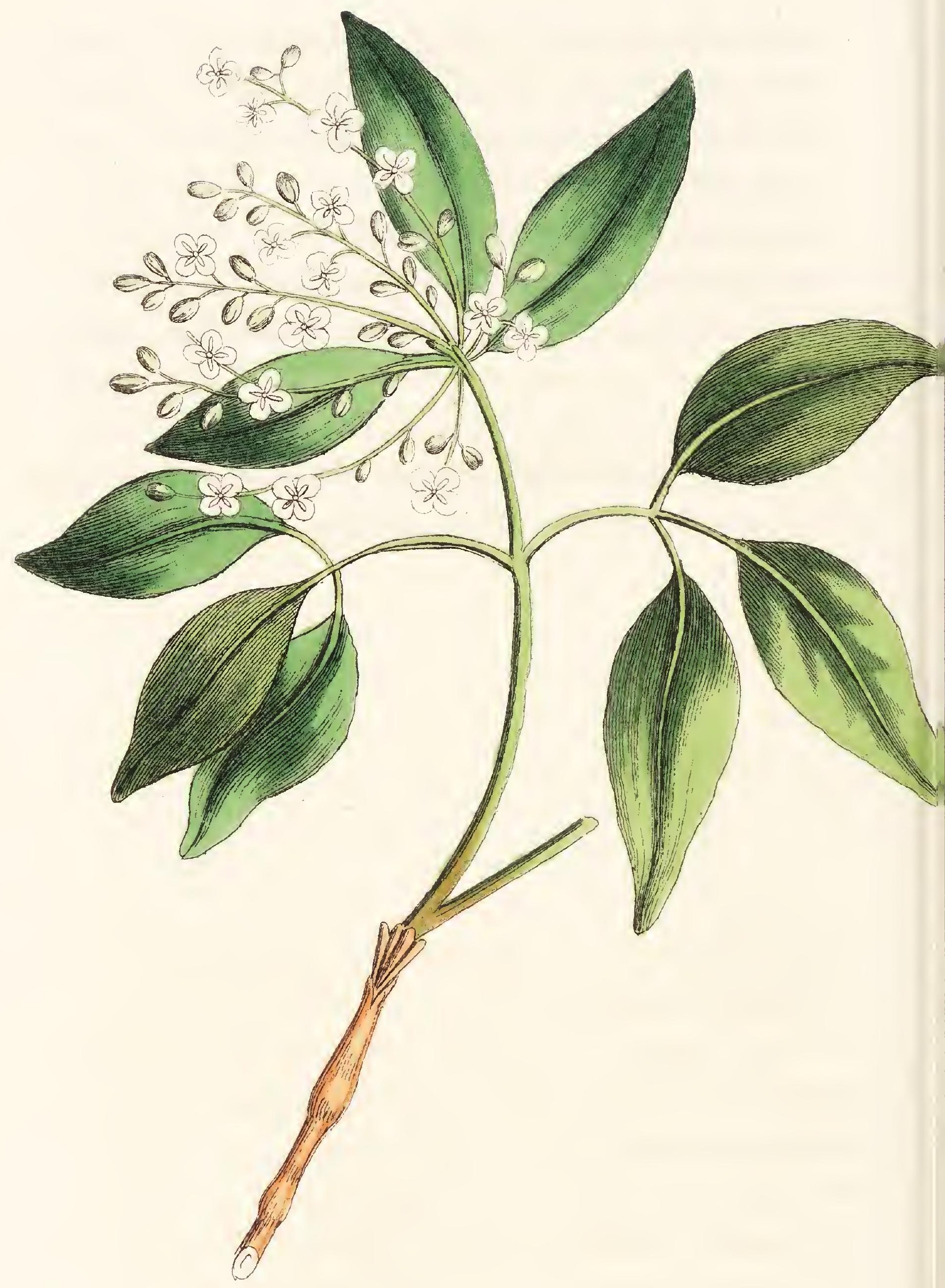

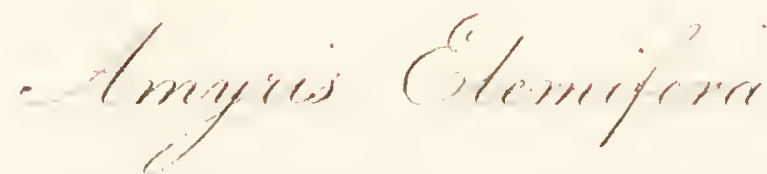




\section{AMYRIS ELEMIFERA.}

Elemi.

Resina.

Class VIII. Octandria.-Order I. Monogrnia.

Natural Order. Dumosæ.

Generic Character. Calyx four-toothed. Petals four, oblong. Stigma four-cornered. Berry drupaceous.

Specific Character. Leaves ternate, pinnate with five lobes, downy underneath.

The Elemi tree is a native of Carolina and the Brazils.

It is of moderate size both as to height and bulk. The leaves are opposite on footstalks, ternate, and sometimes pinnate, with pointed leaflets of a bright green colour, shining and downy on their under surface. The flowers are small, white, with the petals inflexed at the tips, and are disposed in terminal corymbs. The fruit resembles an olive.

The resin is procured by making incisions into the bark of the tree in dry weather, from which a resinous fluid 
exudes, which hardens by exposure to the sun. It is brought to us in oblong, roundish cakes, generally wrapped up in flag leaves: the best is softish, somewhat transparent, of a pale, yellowish colour, somewhat inclining to green : its smell is strong, rather agreeable, resembling slightly that of fennel; in taste moderately bitter. It is stated that the products of other trees resembling this are sometimes substituted for or mixed with the genuine resin, and other frauds are occasionally practised.

As the Elemi is almost entirely composed of resinous matter, water extracts but little from it; its proper menstruum is rectified spirit; however, a small quantity of gummy matter is remaining after it has been digested in the spirit. By distillation with water it yields a small quantity of thin, pale, essential oil, possessing all the fragrance and taste of the Elemi.

The medicinal use of this resin is very limited, it is a stimulant, and as such is occasionally exhibited; but its employment now is chiefly external in the form of ointment or liniment.

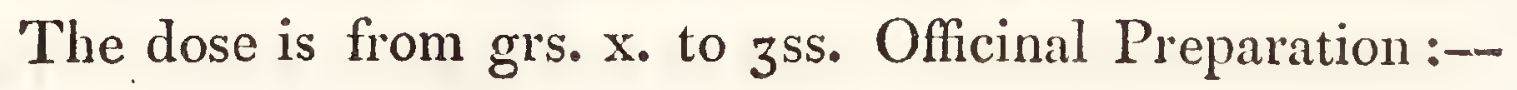
Ung. Elemi Comp.

The Amyris Gileadeuse is another species, affording a liquid resin, which was held in high estimation by the ancients, and by them employed in many diseases under the name of Balm of Gilead; but later experience does not confirm their statements, and it has now fallen into disuse. 



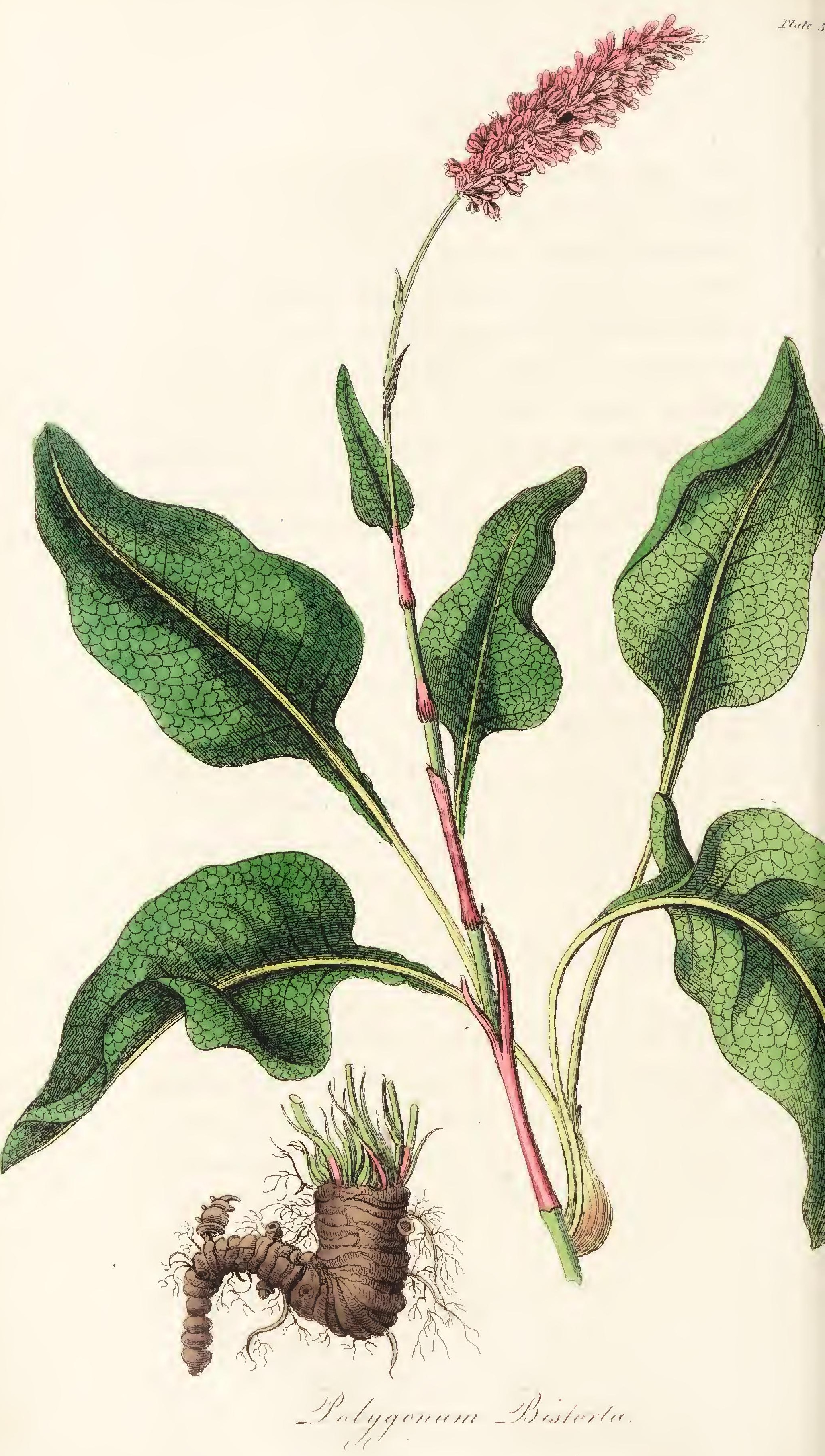




\section{POLYGONUM BISTORTA.}

\section{Great Bistorl, or Snakerweed.}

Radix.

\section{Class VIII. Octandria.-Order III. Trigunia.}

Natural Order. HoloraceE.

Generic Character. Corolla five-parted, calycine. Seed one, angular.

Specific Character. Stalk, perfectly simple, with a rough spike, leaves ovate, running into the pe. tiole.

THE Bistort is a perennial plant, growing in the mountainous parts of Germany, and in moist meadow grounds in many parts of England; flowering in May and June.

The root is about as thick as the finger, compressed, woody, and tortuous, having rings upon it, and numerous fibrillæ: the stalk is about two feet in height, simple, foliaceous, jointed, solid, smooth, bending, and swelled at the joints. The radical leaves are ovate, pointed, on long winged footstalks: those on the stem are narrower, embrace the stem, and are nearly sessile; the whole of them are undulate, veined, of a green colour superiorly, and glaucous beneath. The flowers are small, stand upon short footstalks, and terminate the stalk in a close oblong spike, above an inch long: the corolla is tubular, of a pale rose 


\section{6}

colour, and divided into five obtuse segments, with nectarious glands at the base: the floral leaves are membranous and withering: the filaments are tapering, longer than the corolla, and support purple anthers: the styles are long, crowned with small round stigmas, and proceeding from a triangular germen of a red colour: the seeds are shining, and of a deep brown colour.

The root of Bistort is externally of a blackish brown colour, and internally reddish; it has an astringent bitter taste, without any particular flavour, and is inodorous. Both water and spirit extract the virtues from the root.

Dr. Cullen speaks very favourably of Bistort as an astringent, and is of opinion that it is not inferior to any of the other vegetable astringents. It possesses both tonic and astringent properties, and may be advantageously given in some cases of diarrhœe, as where there is an immoderate discharge, unconnected with febrile or inflammatory symptoms, or tenesmus. Cullen mentions its utility in intermittent fevers, and we may employ it with safety in such cases; still it is inferior to several other vegetable tonics and astringents in this disease. There are other complaints that require astringents in which this remedy may be employed. It has been used as an external application in scorbutic and ill-conditioned ulcers. In Siberia, when the roots have been deprived of their bitterness and astringency by infusion and boiling in water, they are sometimes used as an article of diet. Bistort is seldom administered alone at the present day, but is generally combined with other astringents.

"The dose is from gres. $x$. to $3 j$. 



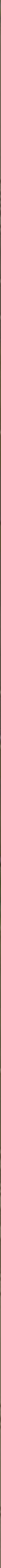




\section{LAURUS CINNAMOMUM.}

The Cinnamon-Tree.

Liber.

Class IX. Enneandria.-Order I. Monogynia.

Natural Order. Holoraceæ.

Generic Character. Calyx none. Corolla calycine, six-parted. Nectary of three two-bristled glands, surrounding the germen. Filaments interior, glanduliferous. Drupe one-seeded.

Specific Character. Leaves, three-nerved, ovate, oblong, nerves disappearing towards the end.

The Cinnamon tree is a native of Ceylon, and it is very plentiful in other situations, as Sumatra, Java, Malabar, \&c. It has been cultivated in the Brazils, also in England; but that which grows in Ceylon is generally considered the best: it flowers in January.

This trees is generally from twenty to thirty feet in height; the trunk is slender and branched, covered with a brown ash-coloured bark. The leaves stand in opposite pairs on short footstalks, they are oblong, obtusely pointed, trinerved, and of a bright green colour. The flowers are 
produced in axillary, terminal pannicles: the petals are oval, pointed, concave, spreading, and of a whitish colour: the filaments are in ternaries, flattish, erect, shorter than the petals, and the three innermost having small glands at the base: the anthers are double: the style is simple, proceeding from an oblong germen, and supporting a trian. gular stigma. The fruit is an oval, pulpy berry, of a blue colour, resembling an acorn, and containing an oblong nut.

The leaves of the Cinnamon tree vary in their shape, depending probably on soil and climate, which has led to the enumeration of several varieties, but there is scarcely any difference to be discerned in them as regards their medicinal properties. Seba mentions ten varieties.

The bark comes to perfection earlier or later, according to the soil; for that which grows in a white sandy soil is said to be fit for barking in five years; but those in a wet and marshy soil require seven or eight years; and others, in shady situations, are fourteen or fifteen years before they arrive at perfection. There are two scasons of the year in which the inner bark (which is the officinal part) is collected, viz. from April to August, which is called the great harvest; also from November to June, the lesser harvest.

When the branches have been lopped off the trees, the epidermis is separated from them; then they are cut longitudinally to allow of the bark being taken off entire; after this they are spread out to dry, when they curl up into cylinders: when dried they are tied up in bundles of about thirty pounds' weight; after which they have to pass through the hands of inspcctors, who are appointed by government 
to ascertain whether it be the genuine drug: this duty is generally performed by medical practitioner's: lastly, they are packed in bales of eighty or ninety pounds each, having the interstices filled up with black pepper; in this state they are ready for exportation.

The best Cinnamon is somewhat pliable, about the thickness of stout writing paper: it breaks into splinters : is of a light yellowish colour, with a sweetish aromatic pungent taste, and agreeable fragrant odour.

The venders of Cinnamon are in the habit of occasionally mixing Cassia with it, and also of selling that Cinnamon from which a quantity of oil has been distilled; the former fraud is readily detected by the difference in the external characters of the barks; the Cinnamon is much thinner than Cassia, and the latter breaks with a smooth fracture, and has a more mucilaginous taste than the former: the latter fraud is only to be discovered by the taste and smell being weaker. Both water and spirit extract the virtues of the Cinnamon when infused upon it; but the spirituous infusion or tincture is much superior to the watery infusion in strength. By distillation with water it affords a small quantity of essential oil, which is an agreeable aromatic, and so very pungent, that it can scarcely be applied to the tongue without exciting vesication: it is of a golden yellow colour, and heavier than water; and sometimes crystals of camphor are deposited from it; the water employed becomes gratefully impregnated with the flavour of the Cinnamon, and what remains after the distillation possesses none of the propertics of the spice, but merely a degree of 
astringency. There is but very little oil distilled in this country.

Cinnamon is very frequently employed to cover the taste of other medicines: its medicinal properties are aromatic, tonic, and astringent. Sometimes it is employed in flatulencies of the stomach, depending on a weakened state of that organ; and in other cases, where slight stimuli are required, this bark may be used: it very rarely happens that it is employed alone, but generally as an adjunct to. other medicines. Sometimes it is given in low nervous affections, flatulent colic, \&c. The distilled water is a very useful vehicle for nauseous medicines; unless stimuli are contra-indicated, for even this possesses some stimulating properties. The essential oil is a very useful stomachic, but retains none of the astringency of the bark, which, however, is but slight, and it is seldom that Cinnamon is administered as an astringent.

Dose from grs. x. to 3 ss. Officinal Preparations:Tinct. Cinnamomi, Tinct. Cinnam: Comp. Spir. Cinnamomi, Aqua Cinnamomi, Pulv. Cinnam. Comp. 



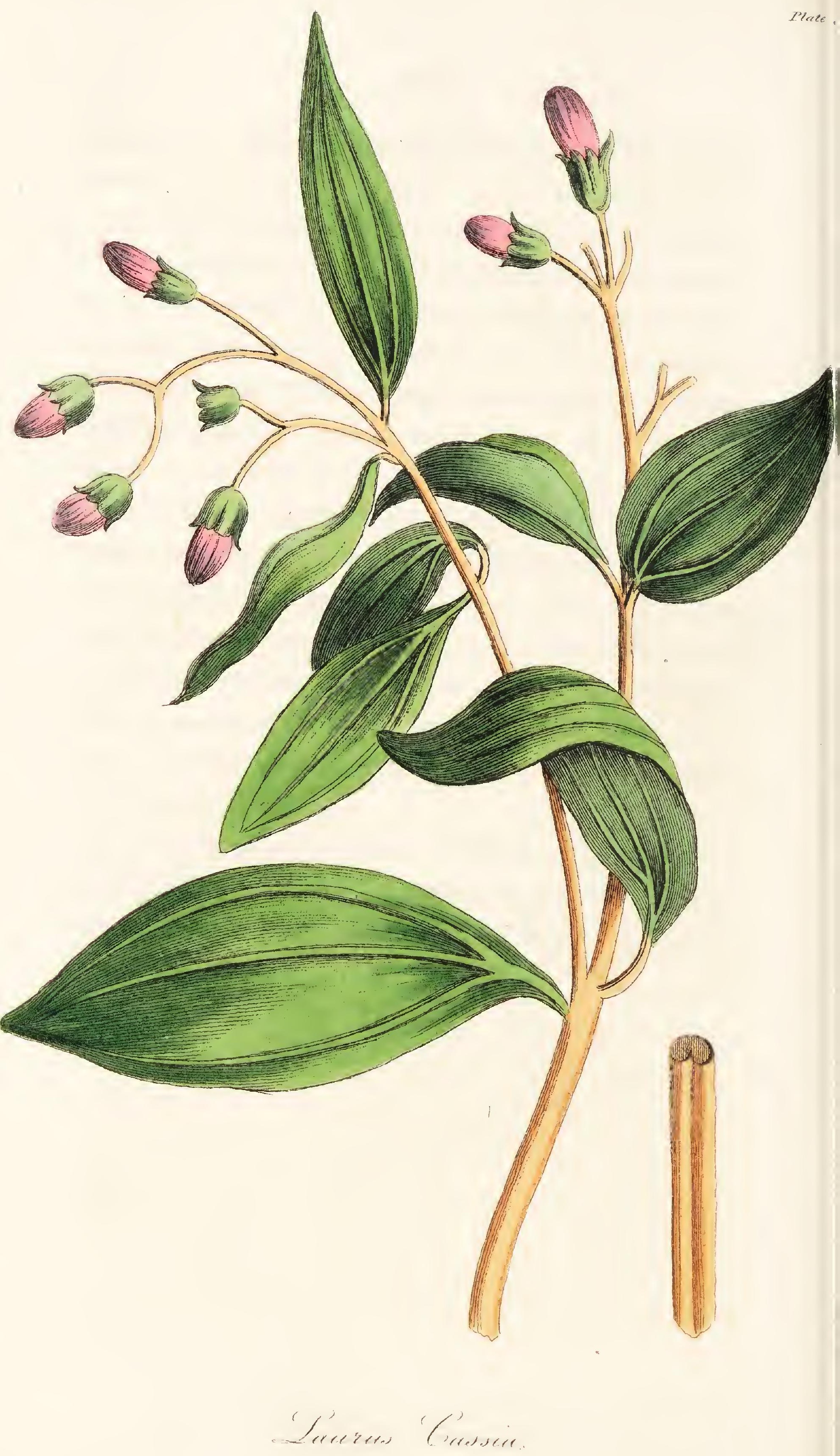




\section{LAURUS CASSIA-CASSIA LIGNEA.}

\section{The Cassia Tree.}

Cortex et Flores nondum expliciti.

Class IX. Enneandria.-Order I. Monogynia.

Natural Order. Holoraceæ.

Generic Character. Calyx none. Corolla calycine, six-parted. Nectary of three two-lobed glands surrounding the germen. Filaments interior, glanduliferous. Drupe one-seeded.

Specific Character. Leaves three-nerved, lanceolate, with the nerves united above at the base.

Tris tree is a native of Ceylon, Malabar, \&c. very much resembling the Cinnamon: the bark is chiefly imported from the East Indies.

It is about fifty feet in height, very much branched. The leaves are eliptical, narrow, pointed, nerved, entire, of a deep green colour above and grey beneath. The flowers are in axillary clusters, they are white, small, monopetalous and divided into six star-like points: the calyx is bellshaped, coriaceous, divided into five or six unequal teeth, inclosing an ovate, black berry. 
The Cassia tree, like Cinnamon, varies according to the soil in which it grows, and thrives better in lofty than in moist shady situations.

The process of gathering and drying the bark is similar to that employed for Cinnamon; it resembles that bark in smell and taste, but is more pungent and mucilaginous, not so agreeable to the palate, and not unlike it in external appearance; but is harder, thicker, and with more difficulty broken. It is sometimes substituted for Cinnamon, a fraud of no very material consequence as regards its medical use, as their properties are alike, and only requires to be given in larger doses.

The Cassia buds, which are the flowers unexpanded and dried, are of a dark brown colour, resembling a nail with a round head, being surrounded with an hexagonal calyx, which gradually terminates in a point; they have an aromatic odour and agreeable pungent taste. An essential oil may be procured from them by distillation very much resembling Ol. Cinnamomi, and the distilled water possesses the properties of the Aqua Cinnamomi. Both the bark and buds give out their virtues to water and spirit by infusion and distillation.

The medicinal qualities and uses of the Cassia so much resemble those of the Cinnamon, that it would be needless to repeat the observations made when speaking of that drug; it must however be considered rather inferior to Cinnamon.

The dose is from grrs. $x$. to 3j. Officinal Preparation:Aqua Cassixe. 



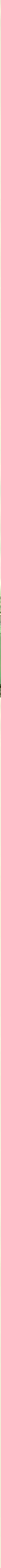

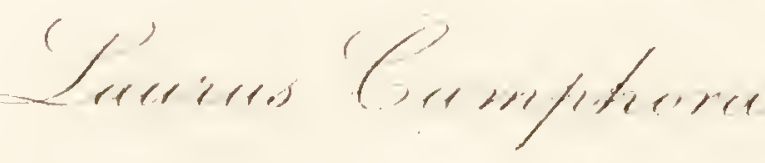




\section{LAURUS CAMPHORA.}

\section{Camphor Tree.}

Concretum sui generis distillatione paratum.

Class IX. Enneandria.-Order I. Monogynia.

Natural Order. Holoraceæ.

Generic Character. Calyx none. Corolla calycine, six-parted. Nectary of three two-bristled glands, surrounding the germen. Filaments interior, glanduliferous. Drupe one-seeded.

Specific Character. Leaves, three-nerved, lanceolate-ovate.

THis laurel is a native of Japan, where it grows in considerable abundance, without cultivation, and arrives at very great perfection there, being sometimes several yards in circumference; it grows also in Sumatra on the borders of the sea: in our green-houses it is often met with, but does not come to perfection in this country.

This is a very majestic tree growing to a considerable height, divided into numerous branches and covered with a smooth greenish bark. The leaves which stand on long footstalks, are acutely lanceolate, entire, smooth, nerved, of 
a pale yellowish green colour on the upper surface, on the under glaucous; but sometimes are in an irregular form. The flowers are small, white, standing in short pedicles on clusters, and terminating long, naked, axillary peduncles: the corolla is composed of six, small, ovate, unequal petals, surrounding a tuberculated bristly nectary: the filaments are shorter than the corolla, and furnished with round anthers: the germen is roundish, with a simple style and obtuse stigma: the fruit resembles that of the Cinnamon, i. e. like an olive.

Every part of the tree smells strongly of Camphor; but it is only obtained from the trunk, branches and root, for the leaves, berries, \&c. do not contain it in sufficient quantity, as to answer the purpose of distilling the Camphor from them. The trunk and branches are cut into pieces and put into a still which contains water, and at the doom or summit of which straw is placed: upon the application of heat the Camphor is disengaged from the wood and rises to the upper part of the still, where it becomes condensed and mixed with the straw. When collected from these vessels it is in a very impure state, being mixed with wood, dirt, \&c. having the appearance of small dirty granules; after this it is mixed with a quantity of quick-lime and re-distilled; the lime is for the purpose of detaining any empyreumatic oil or other impurities that may be present: this process was formerly almost exclusively carried on by the Dutch, but is now as much done in this country; large glass vessels are employed for the purpose, which are of a round flat form, having a neck in the centre; these, when supplied, are placed on sand baths and exposed to heat; the 
Camphor soon rises and attaches itself to the upper part $o_{f}$ the vessel, forming, when the process is completed, a round cake, concave on one side and convex on the other, two or three inches thick, with an aperture in the centre.

A considerable quantity of Camphor is procured from another tree which grows in Sumatra, where it exists in lumps in the trunk and branches, and is in a tolerably pure state: the chief of the Camphor used in this country is imported from Sumatra, but this also requires a similar pusification to the former.

Several species of Laurel contain Camphor, besides other trees of a different genus: it is described to flow from some trees in a liquid state when incisions are made into them, and to concrete by exposure to the air. It is also to be met with in several essential oils, from which it is sometimes deposited in small crystals, and it may be obtained by artificial means. When pure, it has a fragrant smell, somewhat like rosemary, but much stronger, and a bitterish, aromatic, pungent taste, followed by a degree of coolness: it is white, semi-transparent, unctuous to the touch, friable, breaking with a shining, crystalline fracture, but somewhat ductile, and not easily pulverized without the aid of spirit of wine; it is lighter than water, and when exposed to the air will gradually dissipate; it melts at $260 \mathrm{deg}$. of Fahrenheit, and sublimes unaltered in close vessels; burns with a brilliant flame without much smoke; it is completely soluble in spirit of wine, and in the mineral acids, but is nearly insoluble in water, though, when triturated with it, water becomes tolerably impregnated with its flavoux. 
The medical properties of Camphor are stimulant, narcotic, and diaphoretic. The Greeks make no mention of it, but the Arabians were in the habit of employing it as a refrigerant. When Camphor is taken into the stomach in over-doses it occasions pain in that organ, and when it becomes absorbed and carried into circulation it produces vertigo, delirium, convulsions, \&c. indicating derangement of the nervous system, and its chief operation is on the brain and nerves; it also occasions inflammation of the parts to which it is applied, unless speedily removed: its operation is most violent when injected into the veins. Where Camphor does disagree in the way already mentioned, our first step should be to dilute and expel it from the stomach, and then to correct the other symptoms by ammonia, wine, \&c. and, if the breathing should have ceased, have recourse to artificial respiration. Opium is recommended by some as a certain antidote against Camphor.

It is useful in fevers of a nervous and typhoid type, particularly when accompanied with much watchfulness and low delirium, and, from its supposed anti-putrescent properties, has been given in putrid sore throat, and also in other cases which shew a disposition to putrescency: it is also employed as an antispasmodic in hysteria, epilepsy, \&c.: it is used in acute as well as chronic diseases, such as both forms of rheumatism, and there are very few diseases which have not occasionally been treated with it; but even now its modus operandi is not clearly understood: it affords considerable relief to some females of a nervous hysterical habit, who are subject to spasmodic affections about the chest and stomach. 
Camphor is seldom administered in a solid form, as it is very apt to disagree with the stomach and become rejected: very frequently we employ the Mist. camphoræ as a vehicle for other medicines, and it seems to render their operations more diffusive; it is more useful in combination with other medicines than alone, as with ammonia, opium, æther, \&c. It seems to possess some anti-putrescent power as an external application, and dissolved in rectified spirit forms a lotion useful in bruises and sprains.

Dose from grs. ij. to $\ni_{j}$. Officinal Preparations:Spir. Camphor. Tinct. Camph. Comp. Mist. Camph. Emulsio Camphorata, Acidum Acetosum Camphoratum. Linim. Camph. Lin. Camph. Comp. 




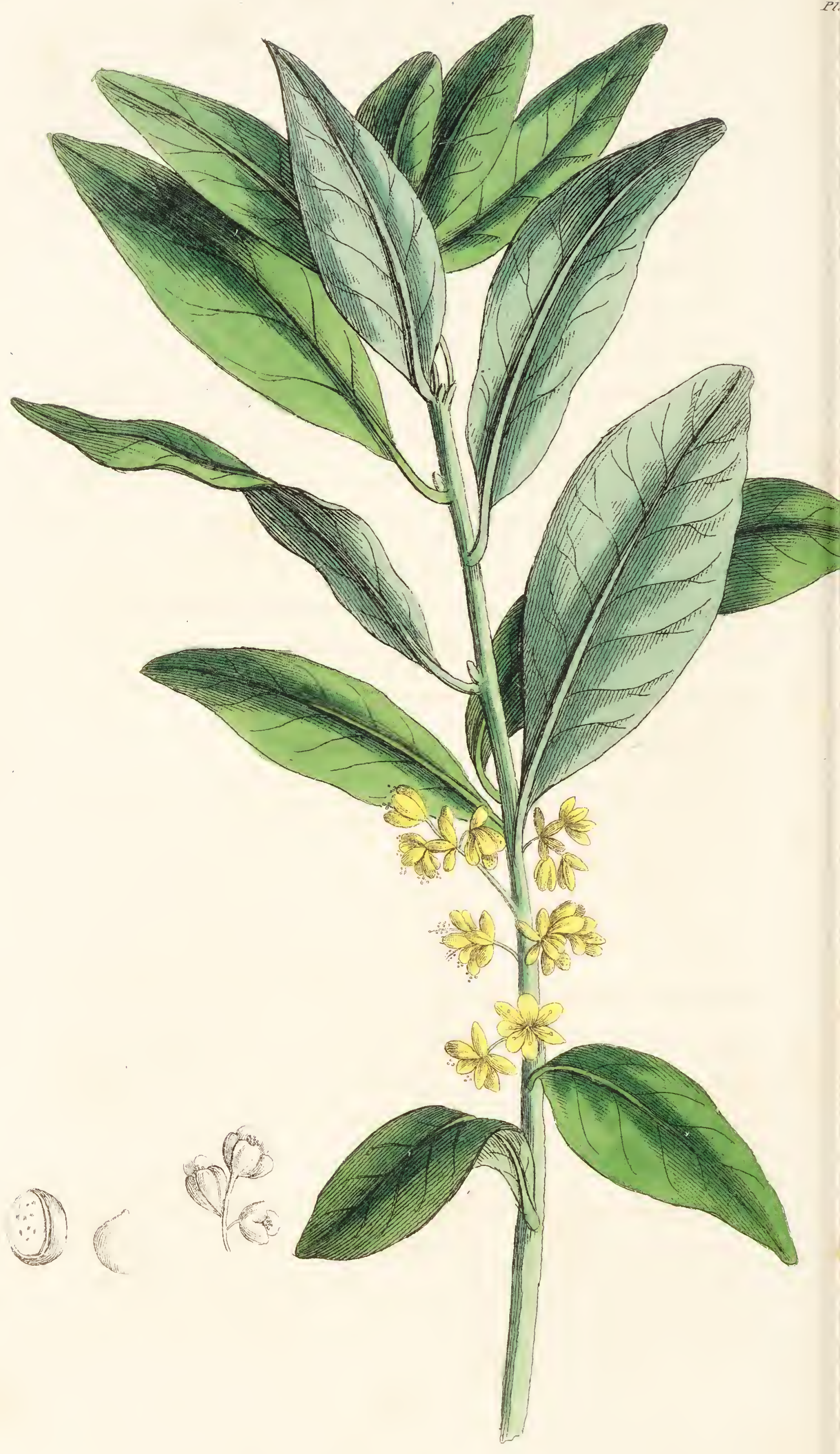

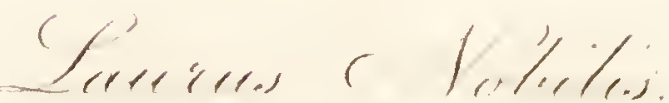


61. LAURUS NOBILIS.

Common Bay-Tree.

Baccæe et Folia.

Class IX. Enneandria.-Order 1. Monogynia.

\section{Natural Order. Holoracex.}

Generic Character. Calyx none. Corolla calycine six-parted. Nectary of three two-bristled glands, surrounding the germen. Filaments interior, glanduliferous. Drupe one-seeded.

Specific Character. Leaves lanceolate, veined, perennial, flowers four-cleft, dioecious.

THrs tree is a native of the warmer countries of Europe, as Spain, Italy, \&c. it is also cultivated as an evergreen in this country, but does not come to perfection here: it flowers in April and May, and its berries ripen in September.

This beautiful evergreen rises to the height of twenty and thirty feet, or more, in its native soil ; but in this country is of very diminutive size. The bark is smooth, and of an olive colour. The leaves are lanceolate, pointed entire, often 
waved at the margin, of a shining green colour, and firm texture; about three inches long, and one inch and a half broad, standing on short footstalks. The flowers are male and female in different plants; they are in small clusters, upon short peduncles at the axillæ of the leaves, and of a pale yellowish colour; the corolla is divided into four oval segments; the number of stamina is varying: calyx wanting: the style of the female flower is very short, and the germen becomes an oval fleshy berry, of a dark purple colour.

This Tree was held in high estimation by the ancients, and was used in the celebration of victories, being tied round the heads of the conquerors : from this circumstance many superstitious virtues have been attributed to it. The leaves have a slight and rather agreeable odour, with an aromatic, astringent, bitterish taste; they afford a small quantity of fragrant essential oil by distillation. Rectified spirit extracts from them a moderately warm and pungent extract.

The berries possess a stronger taste and odour than the leaves, and yield a larger proportion of essential oil by distillation: when fresh they afford, by expression, a considerable quantity of oil of a yellowish green colour, having the taste and odour of the berries; it is a mixture of the fixed and essential oil, and is procured in larger quantities when the berries are previously boiled, though it is less pure than the former. When dried the berries are rough and of a dark brown colour. The oil and berries are generally imported trom the Streights. 
The water distilled from the leaves contains a very small proportion of prussic acid, but it is in such a diluted state, that it is not likely to produce any deleterious effects upon the constitution of a person who might take it in moderation.

The berries and leaves were formerly used as stomachics in flatulent colic, hysteria, and other nervous affections; also in amenorthæa, in the form of infusion, but in modern practice they are seldom administered internally. Their external application is also very limited; for it scldom happens that they are used unless combined with other substances. The expressed oil is occasionally administered in the form of enema.

Dose of the leaves and berries from grs. $x$ to $9 \mathrm{ij}$. Officinal Preparations Confect. Rutæ, Empl. Cumini. 



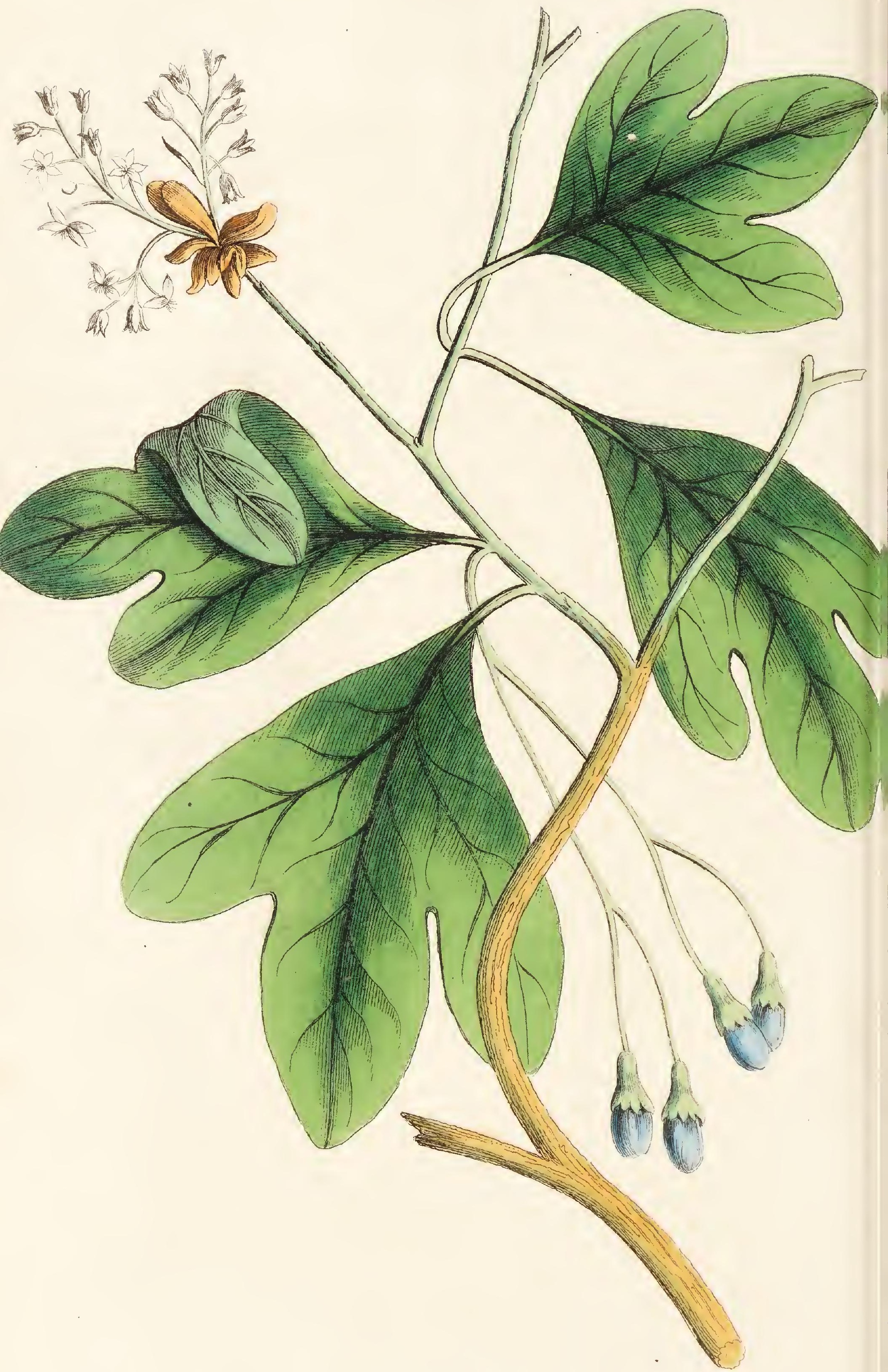

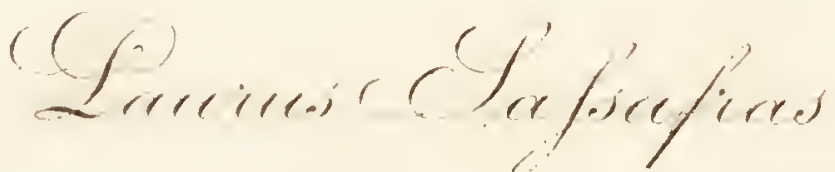


62. LAURUS SASSAFRAS.

Sassafras-Tree.

Lignum, Radix et Cortex.

Class IX. Enneandria.-Order I. Monogynia.

Natural Order. Holoracex.

Generic Character. Calyx none. Corolla calycine six-parted. Nectary of three two-bristled glands, surrounding the germen. Filaments interior, glanduliferous. Drupe one-seeded.

Specific Character. Leaves entire, three-lobed.

$\mathbf{T}_{\mathrm{HE}}$ Sassafras-tree is a native of North America, Virginia, Carolina, and Florida : it is also cultivated in shrubberies in Europe as an ornament, flowering in May and June,

This species of laurel grows to the height of from twenty to thirty feet, and is above twelve inches in diameter, covered with a rough, furrowed, grey bark: it divides towards the top into several branches, which are covered with a smooth green bark. The leaves are of different sizes, generally lobed, but sometimes oval and entire, of a bright green colour, downy on the under surface, petiolate, and placed alternately on the stalk. The flowers are produced 
in pendent pannicles immediately below the leaves, commonly male and female, on different trees: the corolla is divided into six narrow convex segments, of a yellowish colour; the male flowers have nine filaments with yellow anthers; the bractere are linear, and placed at the base of the pedicels; the berry is oval, and of a blue colour when ripe.

The Sassafras wood is imported in long, straight pieces, very light, and of a spongy texture, covered with a rough bark of a brown colour. The root is in large irregular branched pieces, soft, light, of a spongy texture, and a rusty white colour. The bark is externally of a greyish brown colour, and incernally feruginous, spongy, and divisible into layers.

The wood, root, and bark, all possess a fragrant odour, with a sweetish, subastringent aromatic taste; they yield, when distilled with water, a fragrant essential oil, of a pale yellow colour and penetrating pungent taste, which sinks in water. Alcohol completely extracts their virtues, and water but imperfectly.

Sassafras is a stimulating diaphoretic, and as such is sometimes employed in chronic rheumatism, and in those pains which are frequently resulting from the improper use of mercury; but the anti-syphilitic virtue which some ascribe to it is without foundation: the infusion or decoetion is also occasionally given in some cutaneous affections; but its operation is somewhat doubtful, and we can scarcely ascertain its power as it is seldom administered alone, but commonly combined with other more active medicines. 
It should either be taken in substance or infusion, for by boiling, the oil, in which the virtues of the drug principally reside, is in a great measure volatilized. The oil may be administered as a substitute for the Sassafias in substance, but it should be only in small quantities. The extracts are nearly inert, for they only retain the astringency of the Sassafias.

Dose from grs. $x v$ to $3 \mathrm{j}$. Officinal Preparations Oleum Sassafras. Dec. Sarsap. Comp. 




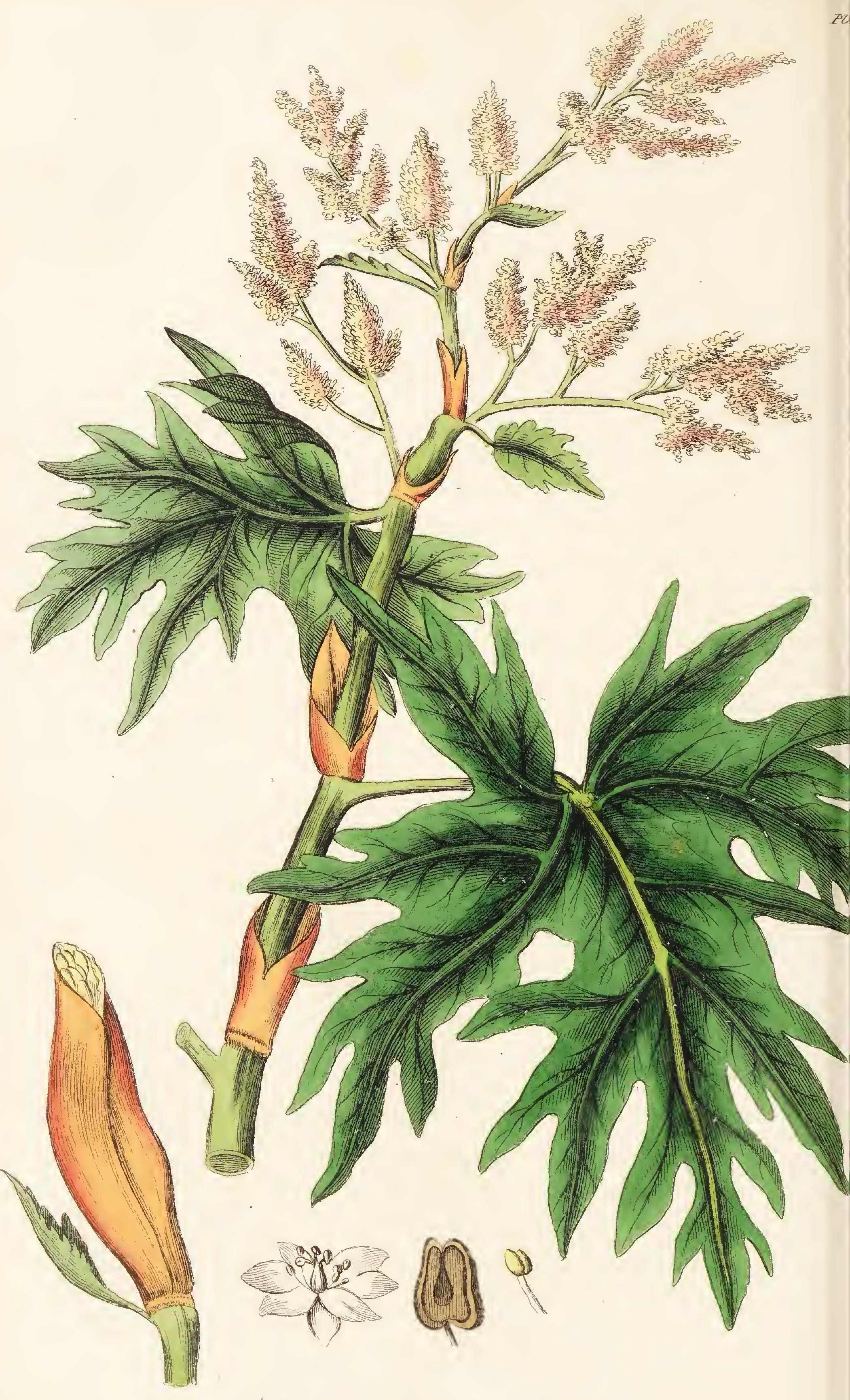

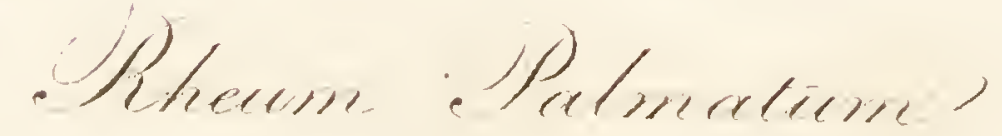


Palmated or Officinal Rhubarb. Radix.

Class IX. Enneandria.-Order III. Trigunia. Natural Order. Holoracez.

Generic Character. Calyx wanting. Corolla sixcleft, persistent. Seed one, three-seeded.

Specific Character. Leaves palmate, somewhat rugged, with a dilated sinus at the base; petioles indistinctly grooved above, rounded at the margin.

$\mathbf{T}_{\mathbf{H} \text { s }}$ perennial plant is a native of China, Siberia, and Tartary : it may also be easily raised in this country, and comes to tolerable perfection, flowering in April and May.

The root is thick, oval, branched, externally brown, and internally of a deep yellow colour. The stem is erect, round, hollow, jointed, slightly furrowed, branched at the top, and rising to the height of six or eight feet. The radical leaves are numerous, large rough, of a roundish shape, and deeply cut into lobes, which are irregularly pointed, and stand upon long, smooth petioles; those of the stem are sheathing, placed at the joints, and become gradually smaller as they approach the top of the stem. The flowers surround 
the branches in numerous clusters, forming a kind of spike : the corolla is divided into six small obtuse segments of a greenish white colour; the filaments are slender, the length of the corolla, and furnished with oblong double anthers; the style is very short, and supports three reflected stigmas; the germen is a triangular seed, with reddish membranous margins.

Doubts are still entertained by some authors whether this is the species which affords the officinal rhubarb, and indeed it is very probable that it is procured from different species, as the Palmatum, Undulatum, and Compactum, for they all possess similar properties, and vary but inconsiderably in strength. Itused to becultivated in considerable quantities in England, but although its cultivation was sanctioned and encouraged by the Society of Arts and Sciences, and it was little if at all inferior to the foreign rhubarb, no market could be found for it; therefore, of late years, its growth has been entirely neglected.

We meet with two sorts of rhubarb in the shops, the East India and Turkey; the former comes immediately from the East Indies in longish pieces, harder, heavier, and more compact than the Turkey, which is dried with greater care, and is not, as some have supposed, procured from a different species of plant: the latter is in roundish pieces, freed from the bark, having a hole through the middle of each, externally of a yellow colour, and internally variegated with reddish streaks, like a nutmeg. In 'Tartary the roots are dug up twice in the year, in spring and autumn, at which time they are cleansed, and deprived of their bark and smaller 
branches; afterwards they are divided transversely into moderate sized pieces and exposed to the air for several days; lastly, a hole is bored through each piece, by which they are suspended in a free current of air that they may become perfectly dry, for if packed up when in the least degree damp, they are almost sure to become mouldy. In China, they are first exposed to an artificial heat, and afterwards to the sun.

Good rhubarb, whether East Indian or Turkey, should be of a lively yellow colour, compact texture, heavy, easily pulverized, not porous, and worm-eaten, and when powdered of a bright yellow colour, having a peculial nauseous, somewhat aromatic odour, with a bitter, sub-acrid, astringent taste. Roots of inferior quality are sometimes rubbed over with some of the powder, and at other times with turmeric, to improve their appearance, but we should never decide upon its nature by the external appearance. The odour of rhubarb is impaired by keeping, and this is observed to take place much more rapidly when in powder, hence it should not be powdered in large quantities, for the purgative quality seems to depend, in part, upon the odlour of the root. It is chiefly composed of gummy and resinous matter, the proportions of which vary in different specimens: the purgative quality resides principally in the gum, hence the watery Infusion is a more active purgative than the tincture, but the most desirable way of administering it, is in substance. The medical properties of rhubarb are purgative, stomachic, and astringent.

It is a very useful purgative for dyspeptic persons, as it 
proves both aperient and tonic, and it is more particularly serviceable in these cases when combined with soda: its purgative effects are aided by neutral salts, as sulphat of potass, calomel, \&c. preventing the griping effects of the latter medicine, which is a frequent consequence when given alone. As a common purgative it is in too general use, for the astringent effects which succeed its primary operation, often frustrate the views with which it is given. If patients could be prevailed upon to chew the root and swallow only the saliva, it would prove a very desirable purgative as you would by that means avoid in a considerable degree its astringency: you also in a great measure avoid its astringency in the watery infusion. In some species of diarrhœa, where there is something irritating the intestine, the rhubarb is an useful medicine, and may sometimes be advantageously combined with astringents. When united with ipecacuanha, in small quantities, it is a most desirable remedy in dysentery and in diarrhœeas, which assume at all the dysenteric character, but alone it is not ad. viseable in this disease. It should not be administered alone where there is any fever or inflammation present; combined with an equal weight of extract of gentian and subcarbonate of soda, it forms a very good aperient and tonic pill. The dose will vary, according to the intent with which it is given: as a stomachic and astringent, from grs. $\mathrm{ij}$. to grs. viij : as a purgative, from grs. x. to $\overline{3}^{\mathrm{ss}}$. Officinal Preparations, Infus. Rhei, Tinct. Rhei, Tinct. Rhei Comp. Tinct. Rhei et Aloes, Tinct. Rhei et Gentian. Vinum Rhei Pil. Rhei Comp. Extr. Rhei. 


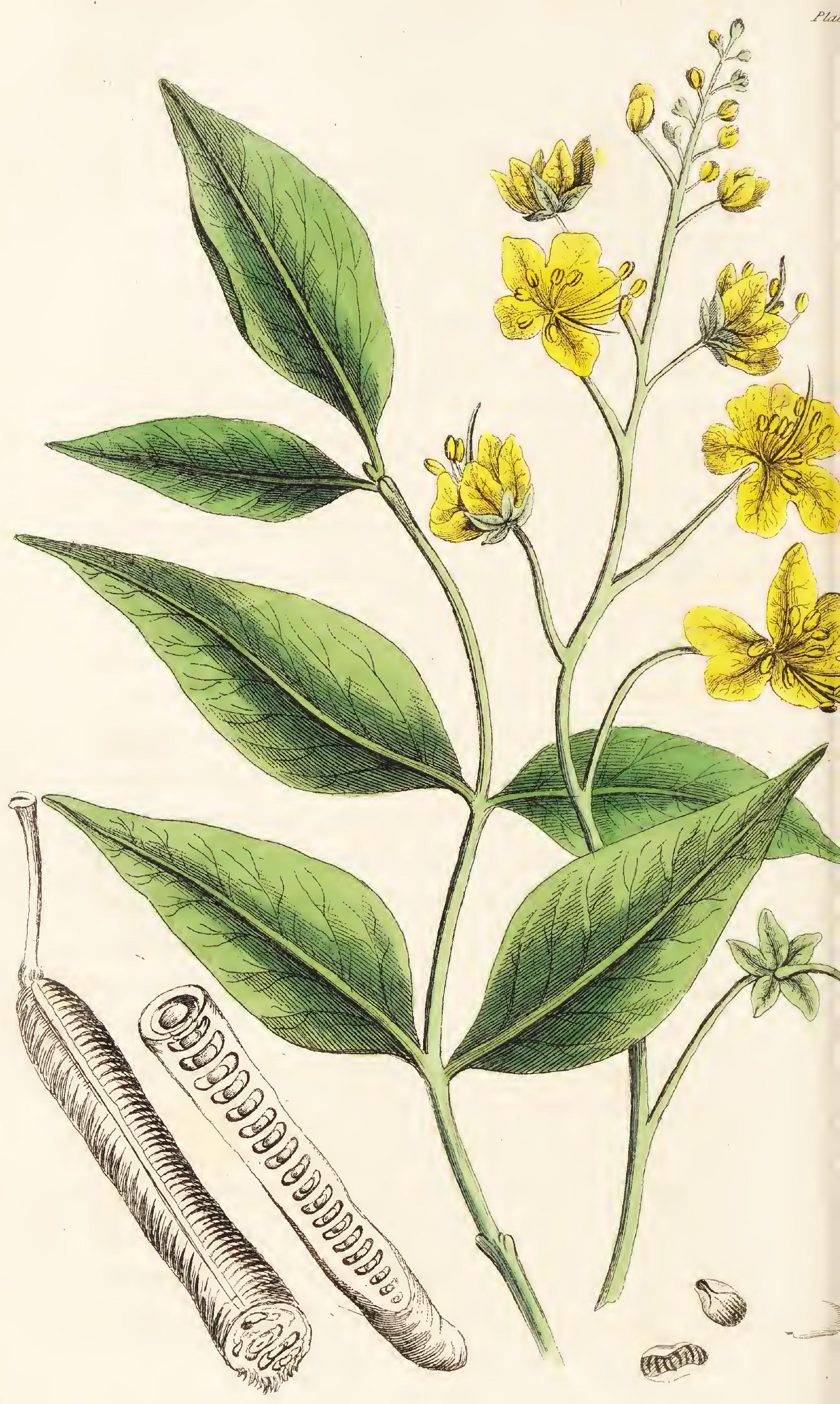

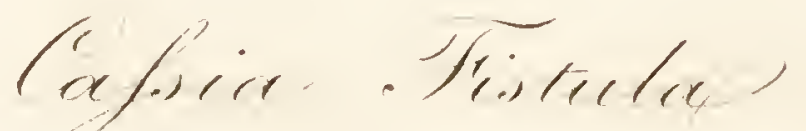


64. CASSIA FISTULA, CASSIA FISTULARIS.

$$
\text { Purging Cassia. }
$$

Fructus Pulpa.

\section{Class X. Decandria.二-Order I. Monogrnia.}

\section{Natural Order. Lomentacez.}

Generic Character. Calyx five-leaved. Petals five. Anthers, three superior, barren; the three lower ones beaked. Lomentum.

Spocific Character. Leaves with five pair of leaflets, ovate, sharp-pointed, petioles without glands.

THis tree is a native of Egypt and the East.Indies, and from thence has been introduced into the West, but that which grows in its native soil is generally preferred. It flowers in"June and Jüly.

The Cassia-tree rises to the height of 40 or 50 feet, haveing a large trunk, covered with a cineritious, furrowed bark, and much branched towards the top, resembling the walnut. The leaves are composed of four or six pairs of ovate, pointed, undulated, nerved pinnæ of a pale green colour, standing upon short footstalks. The flowers, which are placed on long, pendent, terminal spikes are large and of a golden 
colour; the calyx is composed of five, blunt, crenated segments; the corolla consists of five unequal, spreading, waved petals, the three undermost are long and incurved, the others exhibit large anthers.

The fruit is a long pendulous pod, about the thickness of the thumb, nearly two feet in length with two longitudinal furrows on one side, and one on the other : at first soft and green, but afterwards becoming woody, shining, and of a dark brown colour, divided into numerous transverse cells, each containing a smooth, oval, flat seed, embedded in a soft black pulp.

In Egypt the pods are gathered before ripe, and strewed in rooms closely shut, about half a foot in height, palm leaves being interspersed, they are sprinkled with water the too following days, and then allowed to rem ain in this situation for forty days, until they become black : the air is excluded to prevent the fruit from being injured by any fermentative process.

There are two sorts of Cassia distinguished in the shops, one brought from the East and the other from the West Indies: the former is gencrally preferred, being sweeter and possessing less acrimony than the latter ; it has also a blacker and smaller rind, and blacker pulp than the West Indian.

Those pods which are heaviest and do not rattle when shaken, are the best, as they contain the largest proportion of pulp, which should be of a shining black colour, baving a sweetish taste, followed by a slight degree of acrimony. It is soluble both in water and spirit, most completely in the former. The pulp is procured by boiling the bruised pods 
in water, and then pressing the pulp extracted through a sieve and evaporating to a due consistence.

Cassia pulp is a mild and safe laxative, and may be given as such with advantage to children, who can be easily prevailed upon to take it, as it is not at all disagreeable to the palate. The activity of it is somewhat varying, for it may sometimes be taken in the dose of one or two drachms, with the effect of procuring several evacuations, whilst at other times as many ounces are required: its operation is not unfrequently attended with griping, which may however be prevented by combining it with aromatics. When united with the potassæ supertartras it forms an useful cathartic in dropsies; it is seldom administered alone, but generally in combination with other medicines to disguise their taste, \&c. Dr. Cullen considers it a laxative of a very inferior nature, and that the pulp of prunes is of equal virtue. Dose from $3 j$. to 3 j. Officinal Preparations Pulpa Cassix Expressa, Confectio Cassiæ, Conf. Sennæ. 


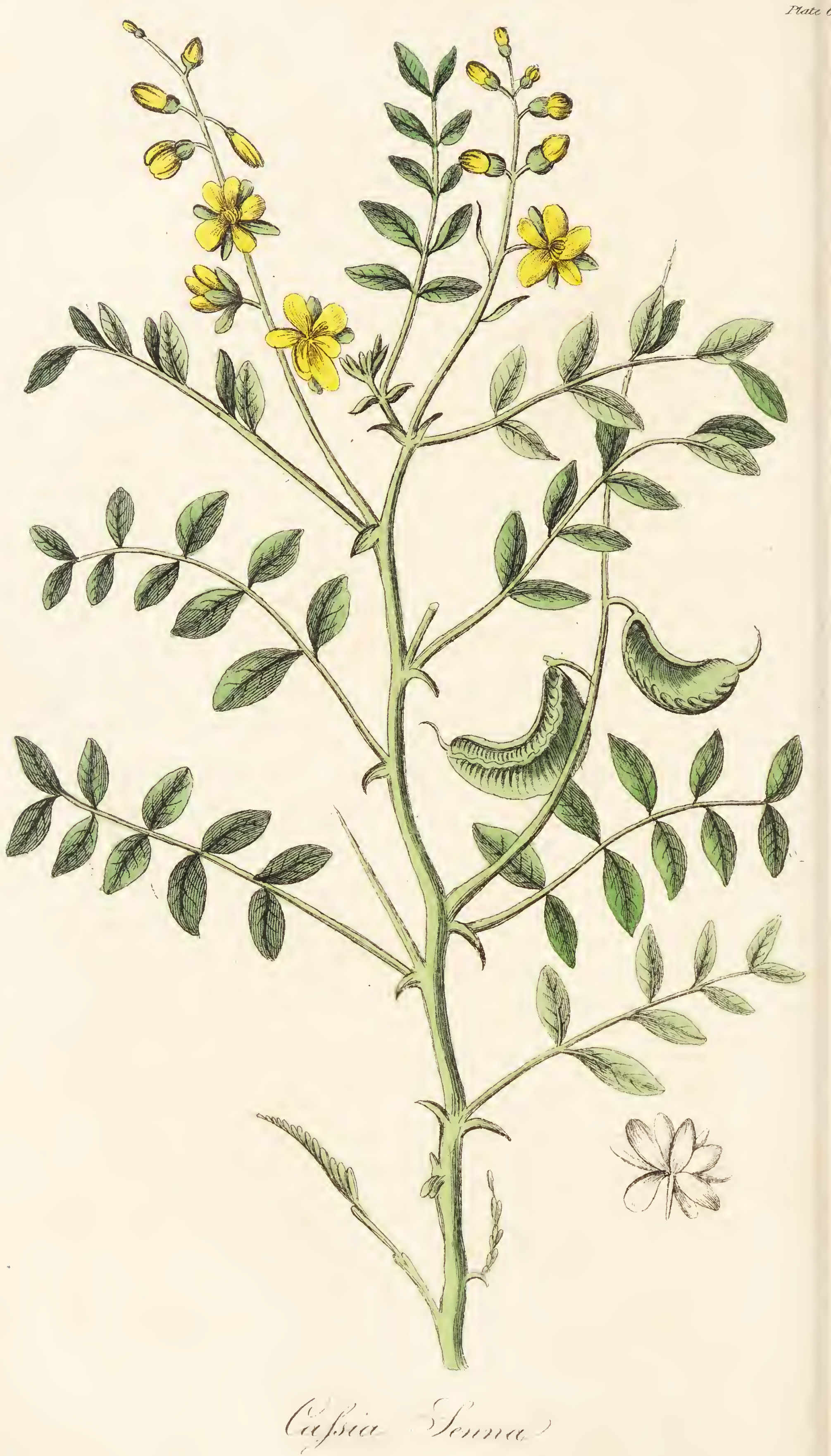




\section{CASSIA SENNA.}

\section{Senna, or Egyptian Cassia.}

Folia.

\section{Class X. Decandria.-Order I. Monogynia.}

\section{Natural Order Lomentacex.}

Generic Character. Calyx five leaved. Petals five, Anthers three superior, barren; the three lower ones beaked. Lomentum.

Specific Character. Leaves with six pair of leaflets, subovate, petioles without glands.

$\mathbf{T}_{\mathrm{HE}}$ Senna is a native of Egypt, and of some parts of Arabia, about Mocha; the chief of what is imported into this country comes direct from Alexandria, where it is sent from the different parts of Egypt in which it grows. It flowers in July and August.

The root is annual. The stalk is erect, smooth, branched, strong, and rises about two feet in height. 'The leaves are pinnate, placed alternately, and at their bases are narrow pointed stipules : each leaf is composed of four or five pair of oval, sessile, pointed, nerved leaflets of a yellowish green colour. The flowers are yellow, placed on long axillary spikes; the calyx is deciduous, composed of five narrow, 
obtuse, concave segments: the petals are roundish, concave, entire, and of unequal size; the three undermost filaments are longer than the others, and furnished with large, rostrated, curved anthers; the germen is long and flat, with a short incurved style, and obtuse stigma. The fruit is an ovate, reniform, membranous, compressed pod, divided by transverse striæ; seeds oblong and flat

Besides the Alexandrian senna, there are other kinds, which may be distinguished by the form of the leaves, being either narrower, longer, and more pointed, or larger, broader and veined; the former coming from Italy and the latter from Tripoli : it is also occasionally mixed with the leaves of trees of a totally different nature; and it is of consequence to detect such frauds, or we shall be deceived in the operation of our medicines: it is of bu little consequence, however, to distinguish the different varieties of the senna as their operation is similar. Its eultivation has been attempted in this country, but it does not arrive at perfection here.

The taste of senna leaves is nauseous, bitter, and somewhat aromatic; their odour is also ungrateful and sickly, especially when infused in water. It gives out its virtues both to water and proof spirit. The activity of the senna is much impaired by boiling, for it dissipates the more essential parts, which is proved by the comparative inertness of the extract.

Senna is a purgative of general use in this country, and is a very effectual one, yet it often occasions nausea from its disagreeable taste, and griping not unfrequently attends 
its exhibition; these effects, more particnlarly the latter, may be counteracted by aromatics, as cardamons, cinnamon, ginger, \&c.; but still with all the inconveniences attending its exhibition, it is a very useful and effectual cathartic, seldom failing to procure evacuations in a short time after it is taken, both removing any accumulations in the intestines and also increasing their secretion. The best form for administering it is in infusion, for water completely extracts the purgative qualities of senna. The infusion made with cold water is considered by some as the most effectual, for it does not extract so much of the nauseous principle. The more water employed, the more certain will be its operation. It is a medicine not calculated for a weakly stomach, in consequence of its nauseous taste. In substance it is very likely to occasion griping, and if taken in this form, it must be in large doses, and then but few stomachs can retain it: the Confect: Sennæ, however, where its operation is assisted by other medicines, and its griping effects prevented by aromatics, is a very palatable and desirable laxative. The tincture can seldom be administered as a purgative, for the dose required to fulfil that indication would contain more spirit than would be proper to take. Dose of the powdered leaves from $\ni_{j}$. to 3 iss. Officinal Preparations, Conf. Sennæ, Infus. Sennæ, Inf. Tamarindi en Sennæ, Pulv. Sennæ Comp. Tinct. Sennæ. 



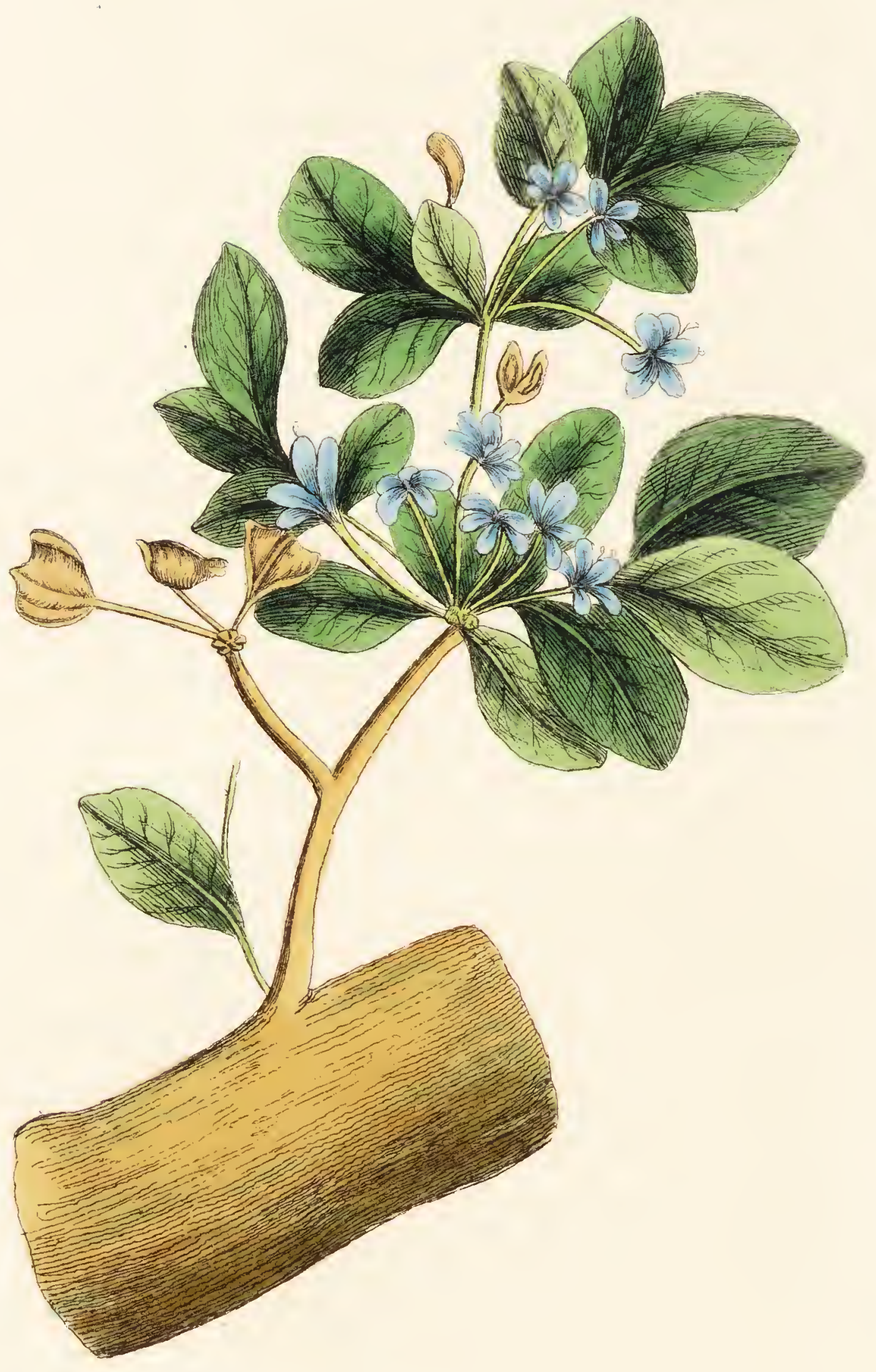

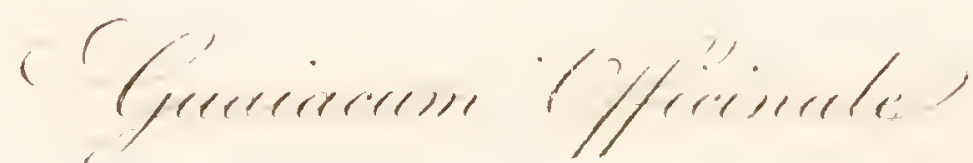




\section{GUAIACUM OFFICINALE.}

\section{Officinal Guaiacum.}

Lignum et Resina.

\section{Class X. Decandria.-Order I. Monogynia.}

\section{Natural Order. Gruinales.}

Generic Character. Calyx five parted, unequal. Petals five, inserted into the calyx. Capsule angular, three or five celled.

Specific Character. Leaflets in two pair, obtuse.

THE Guaiacum-tree is a native of Hispaniola, Jamaica, Barbadoes, and other of the warmer climates of America. It rises to the height of forty feet, and is four or five in circumference, sending off many divided, knotty branches.

The bark of the trunk is of a dark grey colour, variegated with greenish or purplish specks, but that of the branches is ash-coloured, striated and fissured. The leaves are pinnate, consisting of two, three, or more pinnæ, which are smooth, shining, veined, obovate, of a dark green colour, and nearly sessile. The flowers are in sort of clusters or umbels, upon long peduncles, which spring from the divisions of the 
smaller branches. The calyx is composed of five concave, oblong, obtuse, spreading, unequal, deciduous segments; the petals are eliptical, concave, spreading, and of a rich blue colour; the stamina are erect and villous, with yellowish, hooked anthers; the germen oval, with a short style and simple stigma: the seeds are solitary and ovate.

Some authors distinguish two sorts of Guaiacum, the $O f f i$ cinale and Sanctum, considering the latter as best, from the circumstance of its possessing more odour and having a more bitter taste ; but we cannot distinguish sufficient difference to warrant their being referred to distinct species; and it is probable that the difference in the specimens of the woods depends upon the age, soil, and other circumstances attending its culture. Every part of the plant possesses medicinal virtues, but it chiefly resides in the wood, which is the only officinal part.

The wood is either imported into this country in large pieces, weighing four or five hundred pounds, or at other times it is rasped before importation, or in fragments of different sizes. It is of a lightish yellow externally, but internally of a darisish brown, interspersed with streaks of a green and blackish colour. It is of a dense structure, more particu-

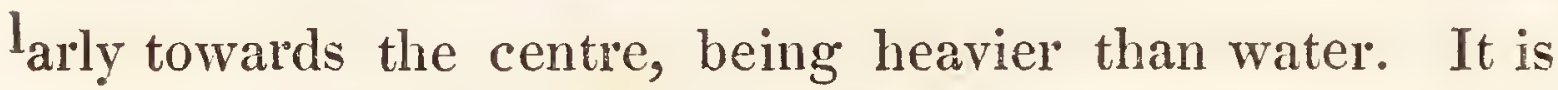
obtained both from the trunk and larger branches; when applied to a flame it readily burns from the resin which it contains; when chewed it leaves an impression of acrimony and bitterness upon the tongue; and has no smell unless heated, when it emits a slight aromatic odour. The activity of the wood resides in the resin. 
The bark is said by Murray to be heavier than the wood, and to possess more acrimony and bitterness; but it is so seldom to be met with now, that it would be difficult to decide upon this point : it certainly contains less resin and more gum than the wood. Rectified spirits extract the virtues from the wood, and by decoction in water also we in a great measure obtain its active principle.

A resinous juice exudes from the bark of the trees, commonly called Gum Guaiacum; and that which flows naturally is purer and considered more active, than what is procured by making incisions into the tree : it is obtained in largest quantities; however, by sawing the wood into billets, and boring a hole longitudinally through one of them; one end of these is laid on the fire, and the resin as it melts flows out at the other extremity into a calabash. Another mode of procuring it is by boiling the chips in salt and water, when the resin floats on the surface and may be skimmed off. Guaiacum is sometimes adulterated with exudations from other trees and also with common resin. It is brought to us in irregular masses of various sizes, not very pliable, of a resinous appearance and dusty green, sometimes of a reddish hue, intermixed with small fragments of the wood, it has a pungent taste, with a slight aromatic odour, and is almost entirely composed of resin; rectifieu spirit is its best menstruum.

The medicinal properties of Guaiacum are stimulant, diaphoretic, diuretic, \&c. It was frst introduced into this country as a most valuable remedy in Syphilis, and many testimonies have been handed down to us in favour of it, 
but when we come to put it to the test of experiment, it is found to fall much short of what we might be led, à priori, to expect; and we have not yet seen it effect a radical cure of the venereal disease; it merely ácts upon the system at large improving the general health, without having any specific operation upon the constitution; it is certainly useful after the mercury has been persevered in for a length of time, to keep up the health of the patient, which frequently fails in irritable constitutions; for, after the exhibition of the Decoct. Guaiac. Comp. the health is improved, and patients are again enabled to use mercury. The resin and wood are useful remedies in chronic rheumatism, gout, \&c. by determining to the skin, and producing diaphoresis. The resin is the most effectual, which may either be given in substance in the form of bolus, or diffused in water by the aid of some mucilaginous fluid, or the yolk of an egg: the spirituous preparations are suitable in some constitutions where there is want of action in the system, which is readily detected by the appearance of the patient; they are not, however applicable in all cases. The Decoction is recommended in certain cutaneous affections. Dose of the resin, from grs. x. to 3 ss. : the wood is never given in substance. Officinal Preparatians, Decoct. Guaiaci. Comp. Dec. Sarsap. Comp. Mist. Guaiaci. Tinct. Guaiaci. Tinct. Guaiaci Ammon. 



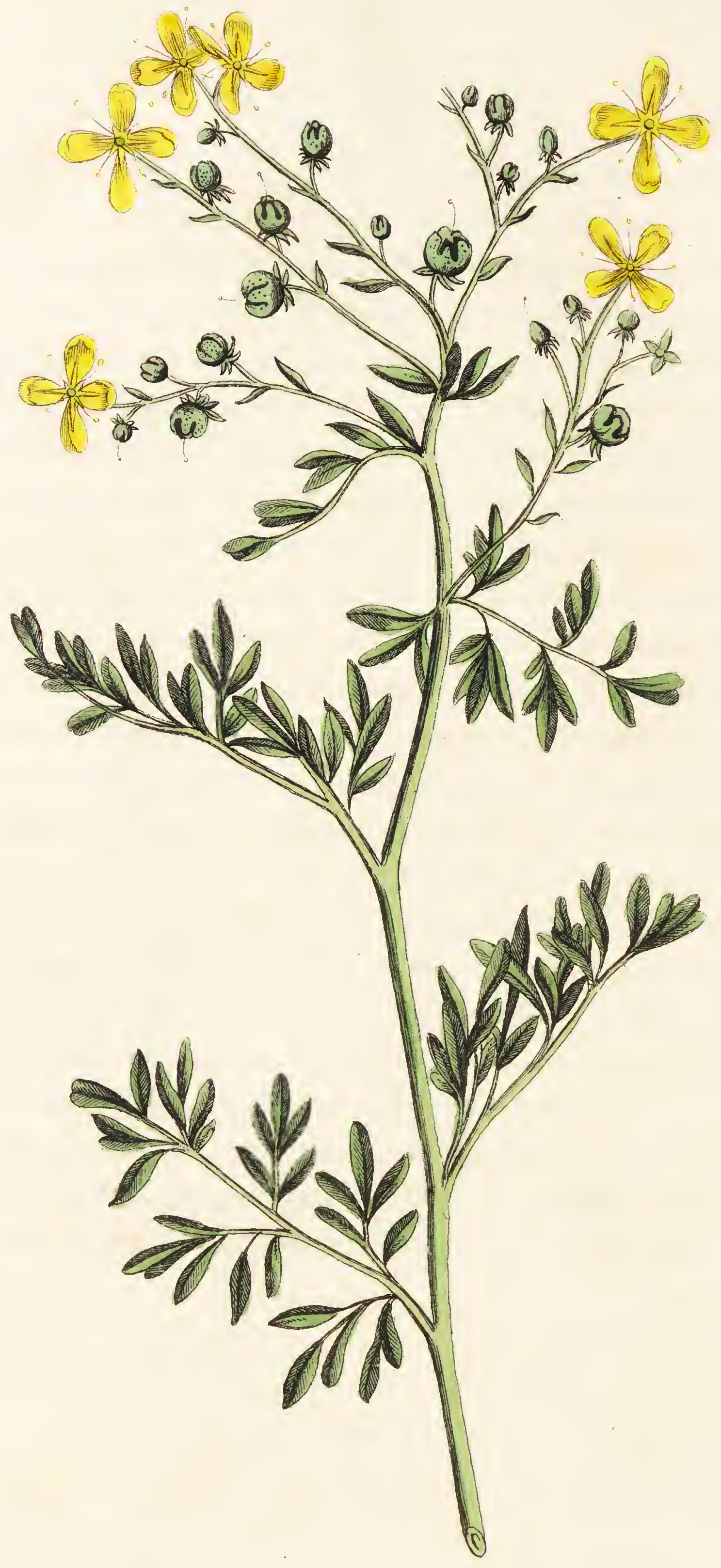




\section{RUTA GRAVEOLENS.}

\section{Common Rue.}

Herba.

\section{Class X. Decandria.-Order I. Monogynia.}

Generic Character. Calyx five-parted. Petals concave. Receptacle surrounded by ten melliferous points. Capsule lobed.

Specific Character. Leaves twice compound; lateral flowers quadrifid.

THis shrubby evergreen is a native of the South of Europe, growing in rocky, barren situations in France, Spain, Germany, \&c.: it is also a common production of our gardens, but the cultivated is not equal to the wild, as regards its medical virtues. It flowers in June and September.

The root is perennial, from which proceed several stalks, ligneous towards the bottom and covered with a grey, rough, striated bark: the upper branches are smooth and of a pale green colour. The leaves are doubly pinnate, with irregular, obovate, sessile, decurrent leaflets, obscurely crenate, of a glaucous or blueish green colour. The flowers are 


\section{$21+$}

produced in terminal, branched corymbs, or subdividing per luncles: the ealyx is conmonly divided into four, and sometimes into five segments, and the same with the corollas, the petals are concave, wrinkled at the edge, and of $\pi$ greenish yellow colour; the filaments are spreading, the length of the corolla, and supporting yellow quadrangular anthers: the germen is large, oval, punctured, and of a deep green colour, supporting a short style and simple stigma; the seeds are angular, rough, and blackish.

Rue has a strong, unpleasant smell, and a penetrating, warm, bitterish taste, and is so acrid, when fresh, as to occasion itching in those who gather it, and if much handled inflames and vesicates the hands.

The virtues of the plant are extracted both by water and spirit, most completely by the latter, and the colours of these infusions will depend upon whether the fresh or dried leaves are used; for by drying they change from a green to a yellowish colour. By distillation with water we procure an essential oil, of a yellowish or brownish colour, with a penetrating disagreeable odour, and pungent taste, similar to the Rue itself, and the residue affords by evaporation a pungent extract, possessing most of the properties of the plant.

Rue is an antispasmodic, stimulant, and emmenagogue: it has been occasionally exhibited in nervous affections, as Fysteria, Epilepsy, \&c.: its emmenagogue virtues are somewhat doubtful, yet as it may correct various nervous feelings connected with amenorrhoa, it should not be altogether despised. It was in much more general use amongst 
the ancients than in modern practice, and they ascribed virtues to it, which it certainly does not possess, such as antiputrescent powers, and preventing the effects of contagious diseases. Externally it is rubefacient in its recent state. Rue is very seldom ådministered by modern practitioners; when it is, the powdered leaves made into a conserve, or the Extract, are the most palatable and effectual preparations. Dose from grs. x. to Эij. Officinal Preparations, Oleum Rutæ, Conf. Rutæ; Extr. Rutæ. 
68. TOLUIFERA BALSAMUM, BALSAMUM TOLUTANUM.

\author{
Balsam of Tolu.
}

Balsamum.

\title{
Class X. Decandria.-Order I. Monoginia.
}

Natural Order. Lomentacez.

Generic Character. Calyx five-toothed, bell-shaped. Petals five, the lowest one largest, obcordate. Style none.

Th1s tree is a native of America, growing in the province of Tolu, near Carthagena.

The Tolu balsam-tree is of considerable height, having numerous branches and covered with a rough, greyish bark. The leaves, which stand on short petioles, are alternate, elliptical, entire, pointed, and of a light green colour. The flowers are in lateral clusters each on a slender pedicle; the calyx is bell-shaped, and divided into five teeth, having one projected beyond the rest: four of the petals are equal, linear, and somewhat longer than the calyx; the fifth is 


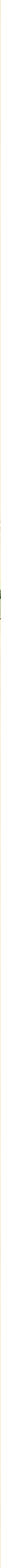

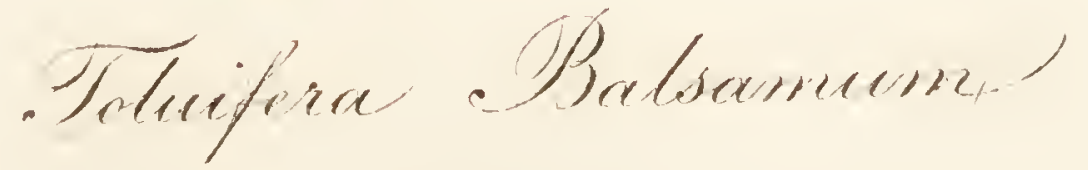



Large, inversely cordate, with a claw the length of the calyx; the whole five inserted into the receptacle; the filaments are very short, and furnished with large anthers; the germen is oblong, styleless, with a pointed stigma. The fruit is a round berry.

The balsam is procured by making incisions into the bark, from which it exudes in a fluid state, and is collected in spoons made of black wax, from which it is poured into other vessels, where it becomes more inspissated, and lastly is put into gourd-shells for exportation; this process is car. ried on in hot weather.

It is of a yellowish brown colour, inclining to a red, commonly thick and tenacious, but becoming harder and brittle by being kept, so as to be readily broken down between the fingers; it has a fragrant aromatic smell like lemons, and an agreeable warm, sweetish taste, with scarcely any pungency; when thrown into the fire it liquefies and then inflames; at the same time dispelling its odorous qualities; by decoction in close vessels water becomes impregnated with its aroma; but this is most completely extracted by distillation, when at the same time we procure a small quantity of very fragrant essential oil; and, if the distillation be pushed farther, Benzoic acid is obtained, which is the characteristic mark of this and all other balsams, for upon this acid their virtues chiefly depend.

When we wish to administer this balsam, it may either be mixed with mucilage, yolk of egg, or honey; it also unites readily with essential oils. If it be required to obtain the Benzoic acid, the balsam must be distilled without any 
water, and by this means we shall likewise procure an empyreumatic oil of a brownish colour.

Tolu balsam is a warm stimulating expectorant; but much less so than the others: it was formerly used in pulmonary and asthmatic affections, chronic catarrh, where. the expectoration is tough and viscid, and in similar cases with apparent advantage: it will not however be proper when there is any active inflammation present. It is more agreeable but less stimulating than the Balsam of Peru, and Copaiba; hence it is less frequently used in gleets, paralysis, chronic rheumatism, \&c. than the latter substances: in consequence of its agreeable odour and taste, it may improve the flavour of other and similar medicines. Dose from grs. $v_{0}$ to $3^{\text {ss. }}$ Officinal Preparations: Tinct. Toluifer: Balsami, Syrupus Tolutani, Tinct. Benzoini Comp. 


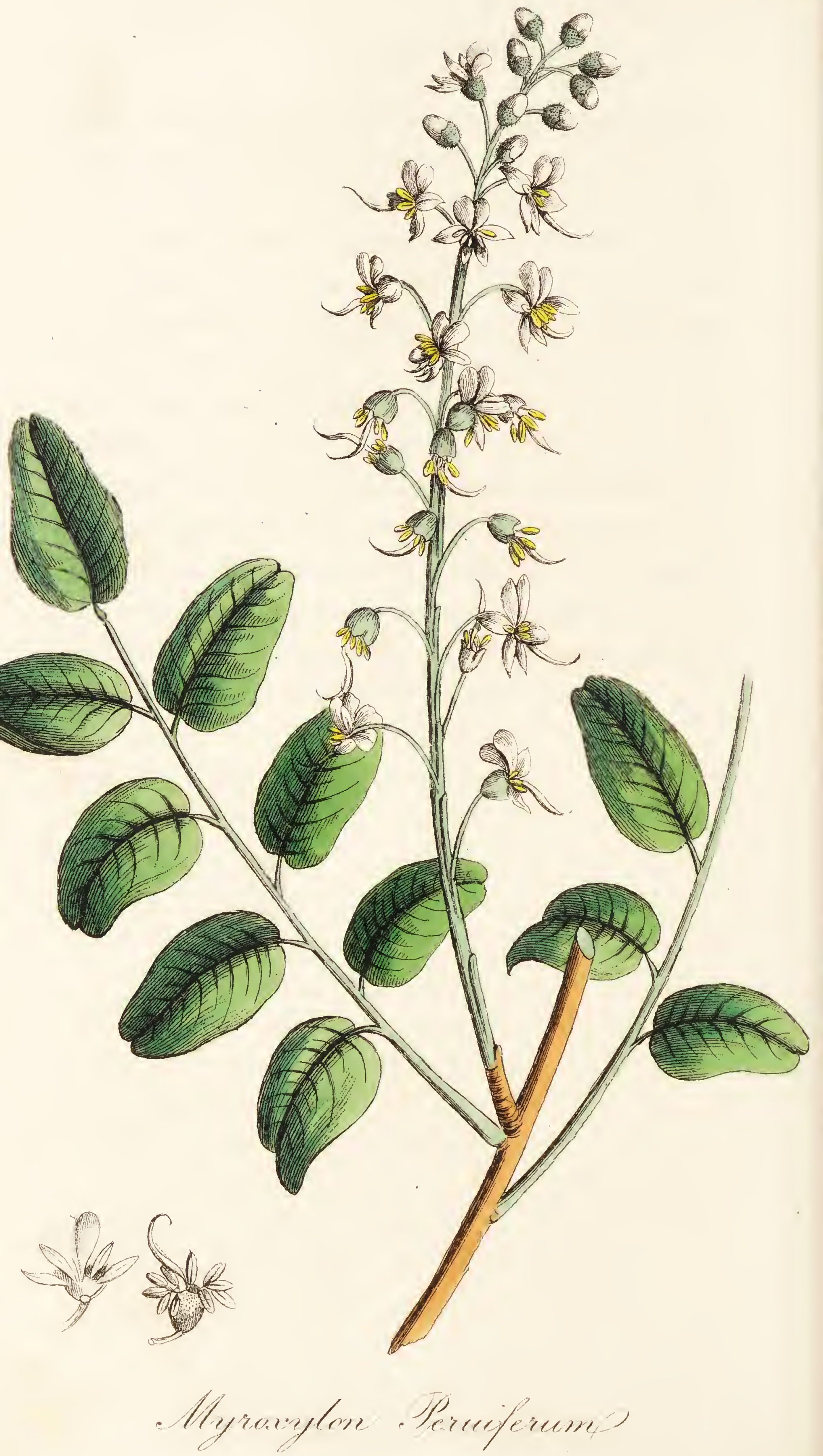




\section{MYROXYLON PERUIFERUM.}

Sreeet-smellingig Balsam-Tree.

Balsamum.

Class X. Decandria.-Order I. Monogynia.

Natural Order. Lomentacez.

Generic Character. Calyx bell-shaped, five-toothed. Petals five, the upper one larger than the others. Germen longer than the corolla. Legume with one seed at the point.

Specific Character. Leaves abruptly pinnate, alternate; leaflets nearly opposite.

Whis tree is a native of South America, growing in Perth, Brazils, Terra Firma, and Mexico.

It is a large tree, the trunk of which is about two feet in diameter, dividing into numerous branches, covered with a greyish bark. Its wood is very hard, whitish externally, but becoming much darker towards the centre. Leaves alternate, composed of from seven to fifteen oval, entire leaflets, which are placed alternately on short green petioles. The flowers are numerous, and situated on pedicles longer than the leaves; the calyx is bell-shaped, pubescent, and divided into five segments: the corolla is white, papillionaceous, and composed of five petals, of which four are lance-shaped, and the other cordi-form and larger than the rest: the fllaments support yellow oblong anthers. 
The first botanical description given of this tree, was by Linnæus, Junior, who described it from a specimen sent by Mutis, from Terra Firma: previous to this we were ignorant from what tree the balsam was procured.

There are two kinds of balsam in commerce: the 1st and best is of a white colour; this is obtained by making incisions into the bark in Spring, from which this balsam flows; it is purer, possesses a fragrant odour like Benzoin, and is much more expensive than the other variety; this, sometimes is inspissated and hardened, constituting the dry Balsam of Peru. The other sort is of a brown colour, or nearly black, of a thicker consistence, and less agreeable odour : this is also obtained by making incisions into the tree, and at other times by boiling the twigs in water, when the balsam is extracted and floats on the surface.

The medicinal properties of each of these kinds are similar, but we rarely meet the first and purer sort in this country. The balsam commonly met with in our shops is of a dark brown colour, of the consistence of treacle, with an aromatic rather agreeable odour, and a pungent, disagreeable taste; it affords to boiling water a small quantity of Benzoic acid, which is deposited on cooling. Nearly the whole balsam is dissolved by rectified spirit; it may be mixed with water by the assistance of yolk of $\mathrm{egg}$, honey, \&c. By distillation with water it affords about onesixteenth of its weight of essential oil, which is of a reddish colour, having a fragrant odour and pungent taste. When thrown into the fire it inflames, giving out a fragrant smell. If heated in close vessels alone, we obtain an empyreumatic oil of a reddish colour with a 
small proportion of Benzoic acid, and a resinous matter remains in the retort. A mixture of resin, and some essential oil is sometimes mixed with the genuine balsam, a fraud not very readily detected, except by ascertaining the proportion of Benzoic acid. Sometimes the genuine balsam is diluted with some fixed oil.

The medical virtues of Peruvian Balsam are stimulant, expectorant, diaphoretic and aromatic. It acts as a general stimulus to the vascular system; and hence its utility in persons of a phlegmatic, indolent habit. In Gonorrhœa, after the inflammatory symptoms have subsided, chronic affections of the urinary organs, and in leucorrhæal discharges, it may prove an useful stimulus; also in chronic theumatism, asthmatic, and other chronic affections of the chest, where the expectoration is difficult, for want of a free secretion in the bronchiæ. In paralytic affections, particularly those following the use of lead; the Balsam of Peru may be given with the best effects, in doses of gtt. $x x x$. ter quaterve quotidie, if the stomach will retain it as often; this medicine seems in this disease to act upon the system generally, improving the health and appearance of the patient; and, as his strength returns, the disease commonly subsides. It was once employed as an external application in paralytic and rheumatic affections, but there are other applications much more efficacious. It was considered by former practitioners to check the morbid effects which commonly succeed punctures of nerves, tendons, \&c.; for this purpose it was dropt into the wounded part: it may sometimes be advantageously applied to foul and indolent ulcers-Dose from gtt. $\mathrm{x}$. to 3 ss. 
70. HAMATOXYLON CAMPECHIANUMLIGNUM CAMPECHENSE.

Campeachy Wood, or Logrwood.

Lignum.

Class X. Decandria.-Order I. Monogynia.

Natural Order. LomentaceE.

Generic Character. Calyx five-parted. Petals five. Capsule lanceolate, one-celled, two-valved; valves boat-shaped.

This tree is a native of $\Lambda$ merica, thriving best at Campeachy, in the Bay of Honduras; it has also been cultivated in Jamaica and St. Domingo, where it grows in tolerable abundance, though not equally luxuriant as in its native soil: it was once introduced into England, but is now nearly extinct in this country; it flowers in March and April.

The Hæmatoxylon-tree is crooked, about twenty feet in height, "and twenty inches thick, sending off very crooked branches; both the tree and branches are covered with a dark-coloured, rough bark; the smaller ramifications are numerous, close, prickly, and beset with strong, sharp spines. The leaves are abruptly pinnate, composed of four or fiye pair of leaflets, which are sessile, obcordate, and obliquely nerved. The flowers are in close, terminal spikes; the calyx is composed of five, oblong, obtuse 


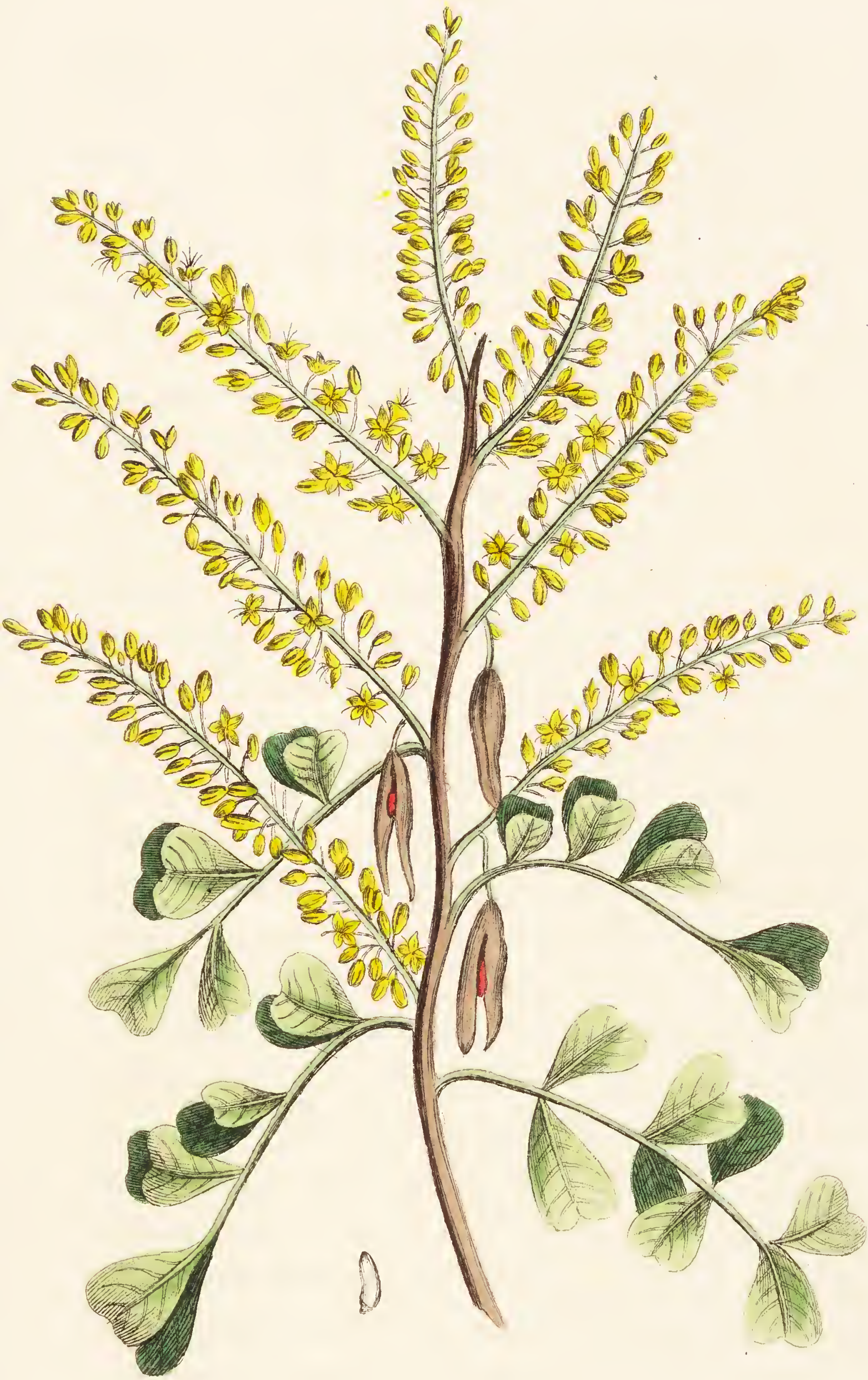

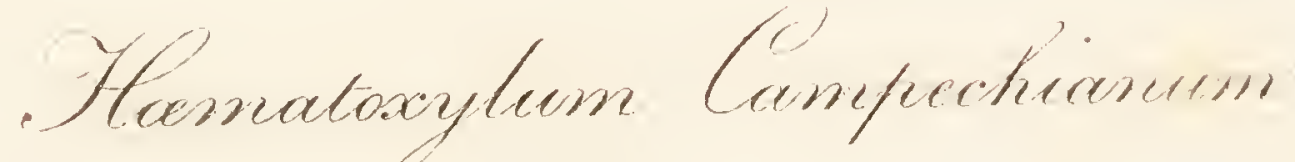





\section{3}

segments, of a brownish purple colour: the petals are spreading, obtusely lanceolate, and of a reddish yellow colour; the stamina are downy, tapering, shorter than the corolla, with small, oval anthers: the fruit is a double-valved pod, containing several flat, kidney-shaped seeds.

It is imported into this country in large, hard pieces, of a firm dense texture and deep red colour; it has a sweetish astringent taste, without any odour. It gives out its astringency and colour both to water and spirit: the latter is the most perfect menstruum; for water, by long boiling, although it becomes of a dark purplish red colour, leaves a considerable proportion of colouring matter in the wood. These decoctions or infusions are decomposed by several of the acids, and also by some metallic neutral salts. When administered internally, it is found to give a red colour to the stools, which may create considerable uneasiness in the minds of patients unless the cause of it be explained to them, for they may suspect that blood is coming from them.

Logwood is chiefly imported into this country as a dye, bat is sometimes medicinally employed as an astringent in diarrhoea, and in the chronic stage of dysentery, when the purging is kept up by the weakened and irritable state of the bowels; and, as its chief exhibition is confined to cases of this nature, the greater attention is necessary in the inspection of the evacuations. The Extract is the preparation most commonly taken; but the Decoction possesses similar properties. 


\section{QUASSIA SIMARUBA-SIMAROUBA.}

Simaruba Quassia, Mountain or Bitter Damson.

Cortex et Lignum.

Class X. Decandria.-Order I. Monogynia.

Natural Order. Gruinales.

Generic Character. Calyx five-leaved. Petals five: Nectary five-leaved. Drupes five, distant, bivalved, inserted into a fleshy receptacle.

Specific Character. Flowers monœcious, leaves abruptly pinnate, leaflets alternate, sub-petioled, petiole naked, flowers in pannicles.

THE Quassia is a native of South $\Lambda$ merica, Guiana, and other West India islands, flowering in April.

This tree is tall and of considerable thickness, sending off alternate, spreading branches, and covered with a smooth grey bark, which is marked with broad, yellow spots in several parts. The leaves are pinnate, alternate, each being composed of several pinnæ, which are elliptical, acute, and smooth, placed alternately on short footstalks, of a deep 


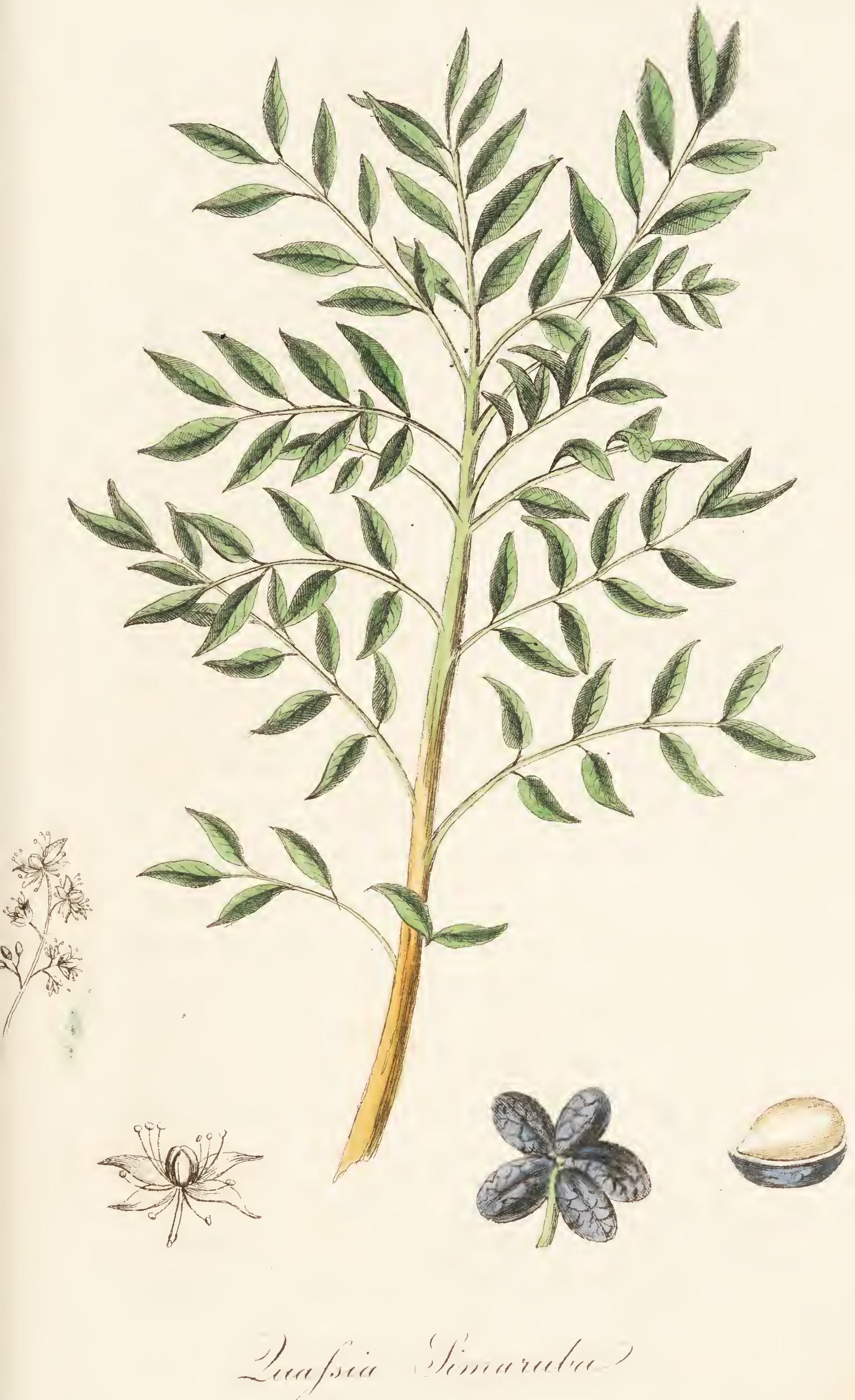



green colour above, and whitish beneath. The flowers are placed on axillary pannicles, male and female on the same tree, but sometimes on distinct trees; the calyx is divided into five erect segments: the petals lanceolate, longer than the calyx, into which they are inserted, and of a yellow colour; the nectary is composed of ten scales, which are inserted into the bases of the filaments; the filaments are slender, about the length of the corolla, and support long anthers; the germen is roundish and marked with ten furrows. The female flower is furnished with five connate germens, cylindrical erect styles and spreading stigmas.

The bark is the part of the tree chiefly used, although the Dublin College directs the wood to be employed: that bark which is procured from the roots is best and most esteemed. It is imported into this country in dried pieces, several feet in length, and three or four inches in width, generally folded up for the convenience of packing: it is light, of a fibrous texture, tough, and with the greatest difficulty powdered: it is rough, scaly, of a brown yellow colour externally, but internally paler and smoother: its taste is moderately bitter, but not disagreeable, without any particular odour. Both water and spirit become impregnated with its flavour by infusion, and cold water seems to effect this most completely. The bitterness of Simaruba is sometimes very inconsiderable; this may depend either on the age of the tree from which it was obtained, or from the bark being collected from the trunk of the tree instead of the branches or roots.

Simaruba is a tonic and astringent. It was first introduced into this country as a valuable remedy in dysentery, 


\section{6}

as correcting the tenesmus, and strengthening the tone of the system; also in diarrhœa, whether of a bilious nature, or a mere increased secretion from the villous coat of the intestines or a discharge of blood: the form of administering it is in Infusion, which should be taken freely during the day, and it will be found to aid the operation of other medicines, but cannot be relied upon alone for the cure of dysentery. In intermittent fevers and dyspepsia, it has been employed with advantage; but whilst we possess so many remedies of a more effectual and active nature, it is not likely that this will come into very general use. Dr. Cullen considers it merely as a simple bitter, not allowing it any particular properties. The dose of the powder is from $\partial_{\mathrm{j}}$. to $3 \mathrm{j}$.; but in this state it is very apt to nauseate the stomach, and this sometimes attends the exhibition of the Infusion in large doses: but this state of nausea may generally be corrected by combining it with a few drops of Tinct. Opii. Officinal Preparation Infus. Simarubæ. 



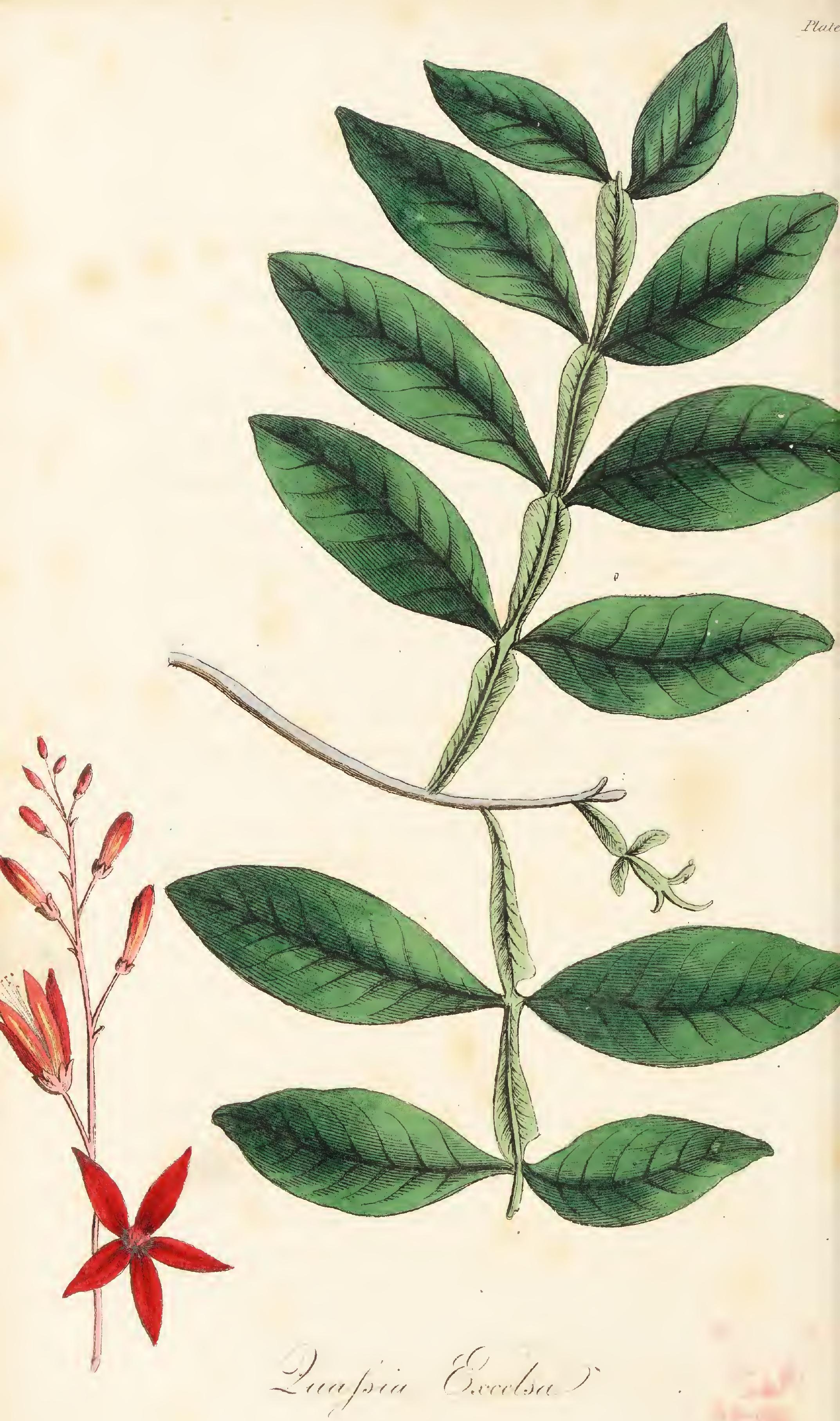


72. QUASSIA EXCELSA-QUASSIA AMARA.

\section{Quassia-Tree.}

Lignum.

\section{Class X. Decandia.-Order I. Monogynia.}

\section{Natural Order. HoLoraces.}

Generic Character. Calyx five-leaved. Pelals five. Nectary five-leaved. Drupes five, distant, bivalved, inserted into a fleshy receptacle.

Specific Character. Flowers hermaphrodite, leaves pinnate, terminating in an odd one; leaflets opposite, sessile; petiole articulated, winged; flowers in racemes.

Thus Tree is a native of Jamaica, Surinam, and the Caribean Islands, thriving best in moist, shady situations, and flowering in October and November.

The Quassia-tree rises many feet in height, having a smooth, tapering trunk, often eight or ten feet in circumference, and covered with a thin grey bark. The leaves are alternate, consisting of three or more pairs of opposite leaflets, with a single one at the end; these are elliptical, entire, veined, sessile, and of a deep green colour. The flowers are of a bright red, terminating the branches in clusters; the bractea are lance-shaped, and placed alternately on the peduncles: the calyx is small, persistent: the petals are equal and lance- 
shaped, having the nectary at their base; the filaments are slender, rather long than the corolla, and supporting simple anthers: the germen is ovate, with a slender style and tapering stigma.

The wood, root, and bark, of this tree possess similar properties, as well as other parts; but the former is the only officinal part, though probably the others are not inferior to it. Quassia is of a whitish colour, becoming yellow by exposure to the air, and the trunk is whiter than the root. It varies in thickness, from the size of the arm to that of a quill. It has no smell, but is very bitter, and the bitterness is very permanent; for it is with difficulty that we deprive the wood of the bitter principle; even by repeated boiling; it has no astringency nor nauseous taste; both water and spirit of wine extract its virtues. The Infusion is the best form for administering it. The Extract is so intensely bitter, that the smallest quantity cannot be applied to the tongue without exciting nausea. It is sometimes used as a substitute for hops in brewing porter, and it is thought that beverage owes its bitterness, in some instances, to the presence of this drug. It is one of the most simple bitters we possess, having no astringent or stimulating properties, and is therefore applicable to all those cases that require bitters, as in dyspepsia, intermittents, nervous irritability, \&c. Murray speaks of it as an antiputrescent, and attributes many virtues to it, which we do not find that it possesses. The dose of the powder is from grs. $x$. to $3 j$. Officinal Preparations Infus: Quassiæ, Tinct. Quassie, Ext. Quassiæ. 




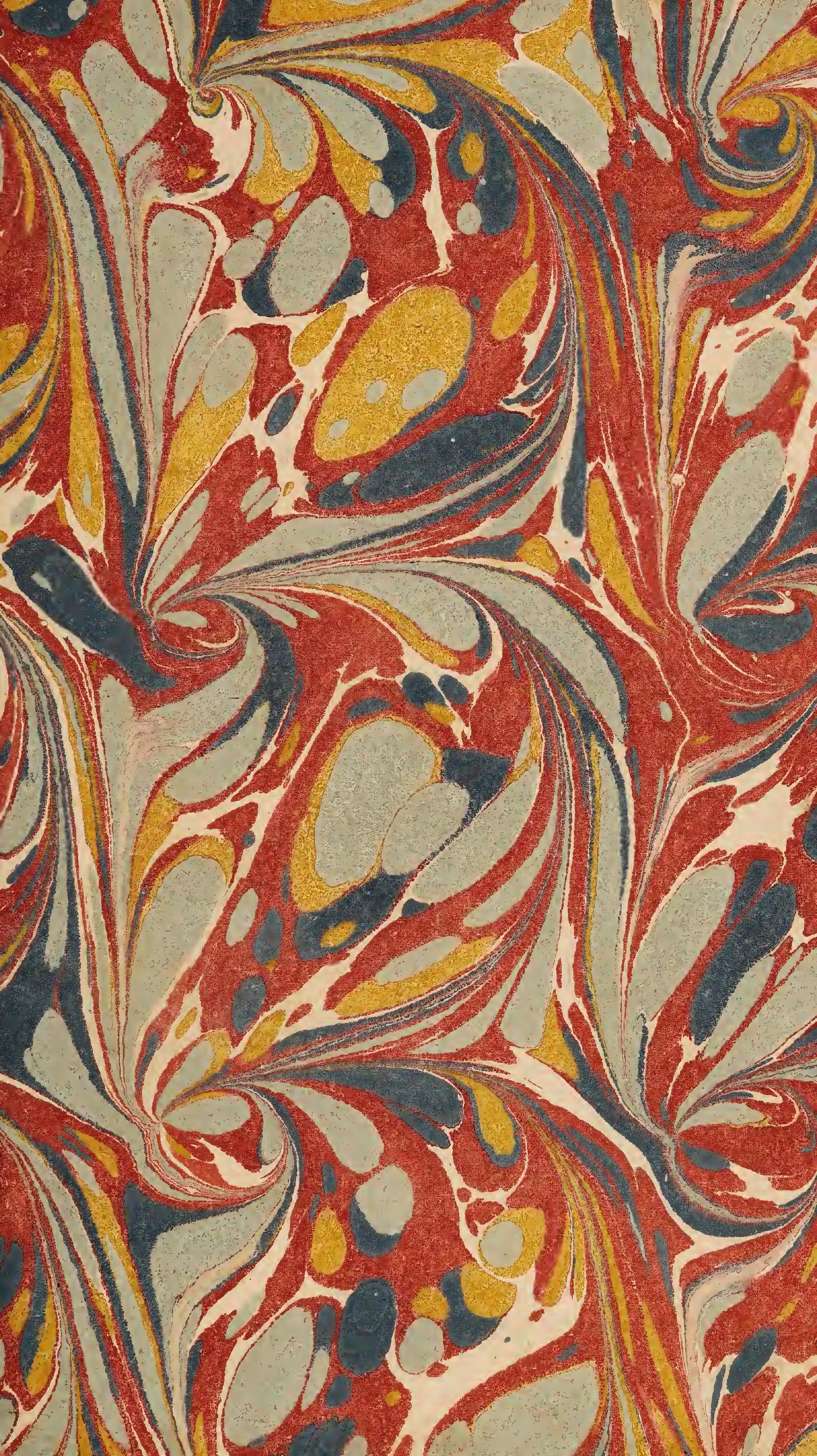


$\because+\cdots$ 